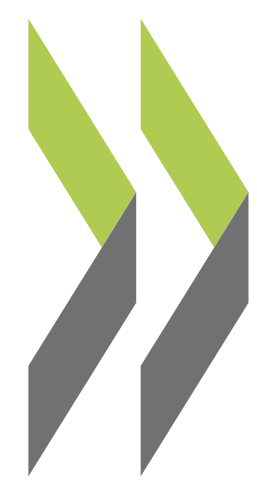

OECD Economics Department Working Papers No. 1088

How to Achieve Growthand Equity-friendly Fiscal Consolidation? A Proposed Methodology for Instrument Choice with an Illustrative Application to OECD Countries

\section{Boris Cournède,}

Antoine Goujard, Álvaro Pina 
Organisation de Coopération et de Développement Économiques

Organisation for Economic Co-operation and Development

01-Oct-2013

ECONOMICS DEPARTMENT

English - Or. English

Cancels \& replaces the same document of 24 September 2013

HOW TO ACHIEVE GROWTH- AND EQUITY-FRIENDLY FISCAL CONSOLIDATION? A PROPOSED METHODOLOGY FOR INSTRUMENT CHOICE WITH AN ILLUSTRATIVE APPLICATION TO OECD COUNTRIES

\section{ECONOMICS DEPARTMENT WORKING PAPER No. 1088}

By Boris Cournède, Antoine Goujard and Álvaro Pina

All Economics Department Working Papers are available through OECD's Internet website at www.oecd.org/eco/Workingpapers

JT03345306

Complete document available on OLIS in its original format

This document and any map included herein are without prejudice to the status of or sovereignty over any territory, to the delimitation of international frontiers and boundaries and to the name of any territory, city or area. 


\section{Abstract/Résumé \\ How to achieve growth- and equity-friendly fiscal consolidation? A proposed methodology for instrument choice with an illustrative application to OECD countries}

Despite sustained efforts made in recent years to rein in budget deficits, a majority of OECD countries still face substantial fiscal consolidation needs. The choices made about which spending areas to curtail and which taxes to hike will have implications for near-term activity and long-term growth as well as for equity and the current account. This paper proposes a method for choosing the instruments of consolidation so that they contribute to -- or minimise trade-offs with -- the goals of promoting near-term activity, longterm growth, equity, and global rebalancing. The proposed method is illustrated with detailed simulations for 31 OECD countries which are accompanied by an extensive range of alternative scenarios to confirm the robustness of the findings. The simulations highlight that half of OECD countries can reduce excess debt mainly through moderate adjustments to instruments (such as subsidies, pensions or property taxes) that have at most limited side-effects on other policy objectives. They also show that a smaller number of countries face more difficult choices, having to either make bigger adjustments in areas where spending cuts or tax hikes are least harmful or to rely significantly on consolidation instruments with substantial adverse side-effects. These trade-offs can to a large extent be alleviated through structural reforms in the delivery of public services and in taxation.

JEL classification codes: $\mathrm{H} 62, \mathrm{H} 63, \mathrm{H} 68$.

Key words: fiscal consolidation, growth, equity, global imbalances, income distribution, structural reforms.

$* * * * * * *$

\section{Comment concilier assainissement budgétaire, croissance et équité ? \\ Une méthode proposée pour choisir les instruments d'assainissement accompagnée d'un exemple d'application aux pays de l'OCDE}

Malgré les efforts importants qu'ils ont fournis au cours des dernières années pour réduire les deficits, une majorité des pays de l'OCDE continue de faire face à de larges besoins d'assainissement budgétaire. Les choix effectués s'agissant de la nature des dépenses à réduire et des impôts à augmenter auront des conséquences pour l'activité à court terme, pour la croissance à long terme aussi bien que pour l'équité et le compte courant. Ce document propose une méthode permettant de choisir les instruments de l'assainissement de telles sorte qu'ils soient aussi compatibles que possible avec les objectifs de promouvoir l'activité à court terme, la croissa nce à long terme, l'équité et le rééquilibrage économique équilibres mondial. La méthode proposée est illustrée par une série de simulations détaillées couvrant 31 pays de l'OCDE qui sont accompagnées d'une vaste gamme de scénarios alternatifs afin de vérifier la robustesse des résultats. Les simulations soulignent que la moitié des pays de l'OCDE peuvent réduire leur excès de dette principalement au moyen d'instruments (tels que les subventions, les pensions ou les taxes foncières) qui ont au plus des effets secondaires limités sur les autres objectifs de politique publique. Elles montrent aussi qu'un plus petit nombre de pays de l'OCDE sont confrontés à un choix plus difficile, ayant soit à fournir des efforts plus importants dans les domaines où la réduction des dépenses ou la hausse des taxes sont les moins dommageables, soit à s'appuyer fortement sur les instruments d'assainissement entraînant de notables effets secondaires. Ces arbitrages difficiles peuvent être atténués au moyen de réformes structurelles permettant d'améliorer l'efficacité de la dépense publique et du système fiscal.

JEL Classification: H62, H63, H68.

Mots-clés : assainissement budgétaire, croissance, équité, déséquilibres mondiaux, répartition des revenus, réformes structurelles. 


\section{TABLE OF CONTENTS}

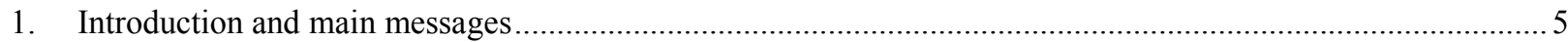

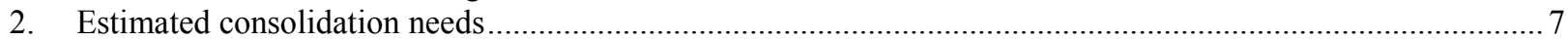

3. The effects of consolidation instruments on other policy objectives …............................................. 17

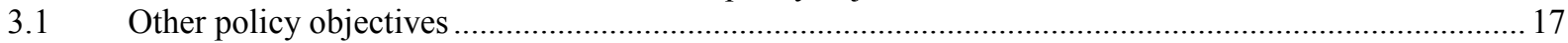

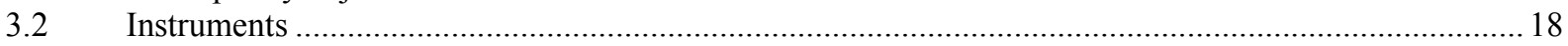

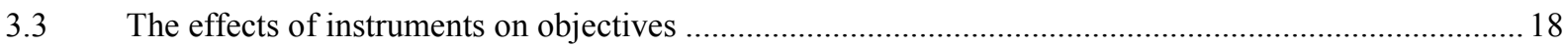

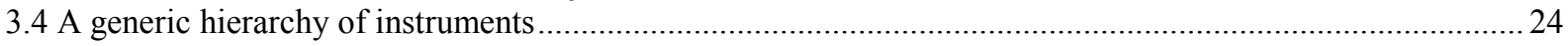

4. Adjusting instrument rankings for country circumstances over the short to medium term ...........................26

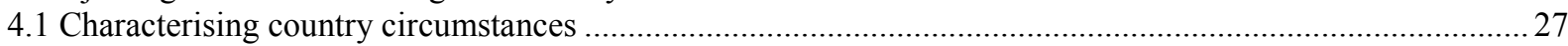

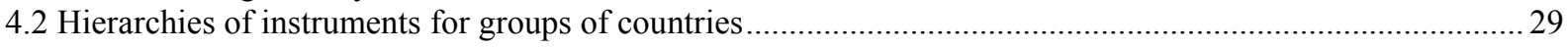

4.3 Robustness of country-specific rankings to the choice of a clustering technique ....................................... 31

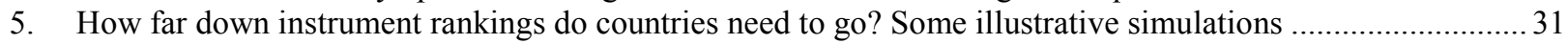

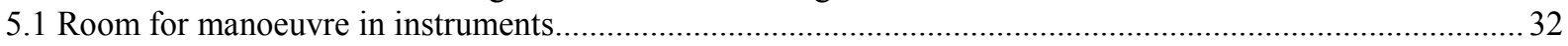

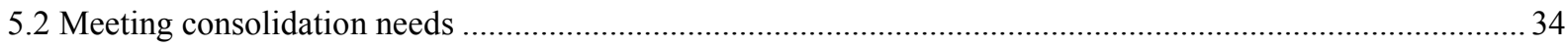

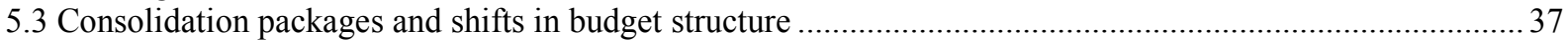

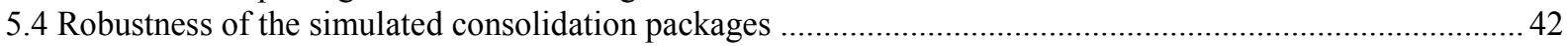

6. The case for combining structural reforms and fiscal adjustment .......................................................44

6.1 Improving trade-offs between consolidation and other policy objectives through structural reform ............. 44

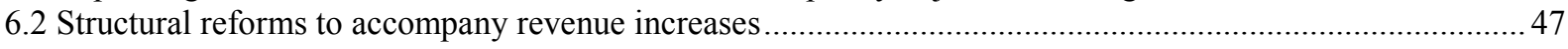

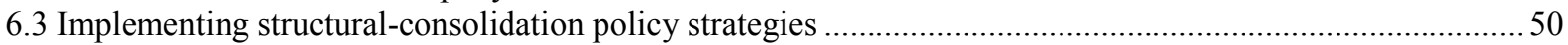

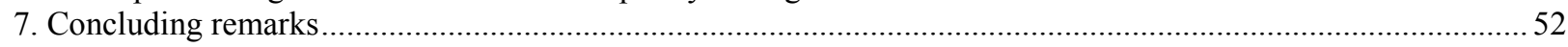

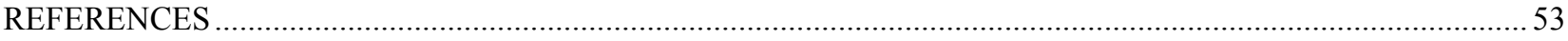

APPENDIX 1. DETAILED COMPOSITION OF CONSOLIDATION PACKAGES .............................................5

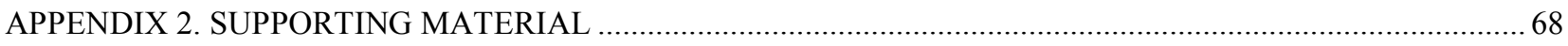

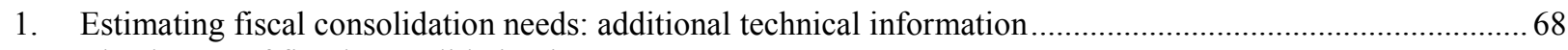

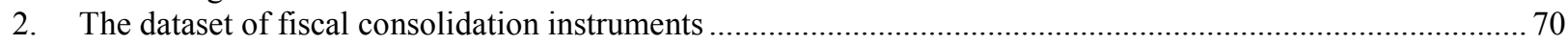

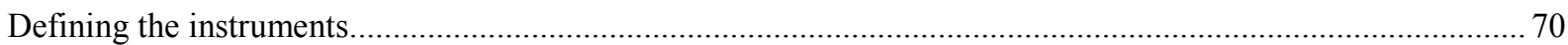

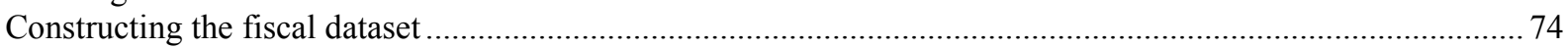

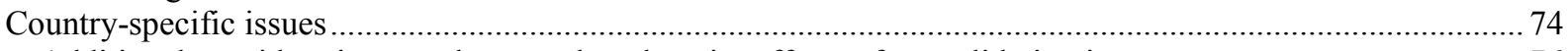

3. Additional considerations on the growth and equity effects of consolidation instruments ...........................76

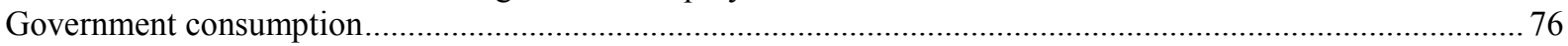

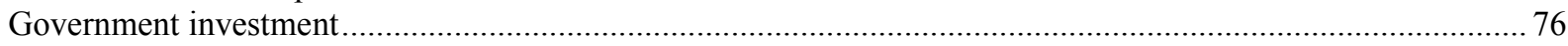

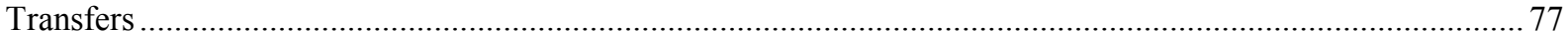

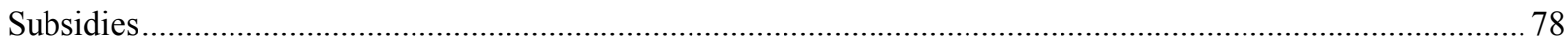

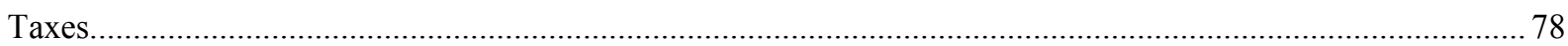

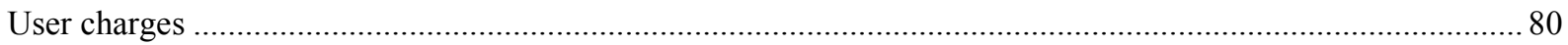

4. Methodological information on estimating debt behaviour during consolidation episodes........................... 80

5. Alternative simulations based on simple country groups instead of clustering ......................................... 80

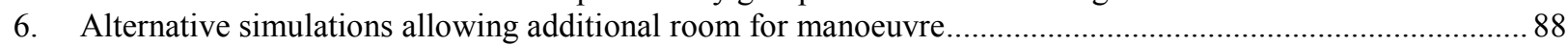

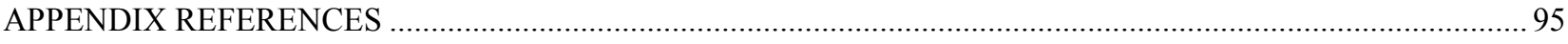

APPENDIX 3: SIMULATED FISCAL PATHS PER COUNTRY ….................................................................. 98 


\section{Tables}

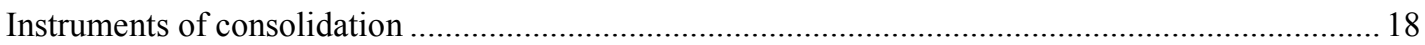

Summary assessment of growth and equity effects of fiscal consolidation instruments ................... 19

Weights put on the growth, equity and current account dimensions across groups of countries......... 30

Possible hierarchies of consolidation instruments for groups of countries................................... 31

Summary indicators about consolidation packages ................................................................ 39

Summary indicators about consolidation packages .............................................................. 40

Evolution of expenditure and revenue structures ............................................................. 41

Cross-country convergence in expenditure and revenue structures............................................. 42

Figures

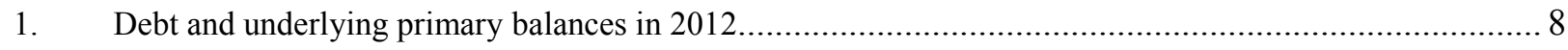

2. Defining short to medium-term and long-term consolidation needs ......................................... 9

3. Illustration of the budget consolidation profile compared with baseline in two countries....................... 11

4. Projected change in government pension expenditure on unchanged policies................................. 11

5. Projected percentage point increase in total public health and long-term care spending, 2010-2060 ........ 12

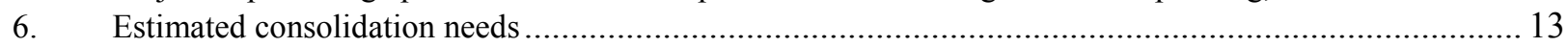

7. Long-term consolidation needs: estimates with and without pension reform .................................. 14

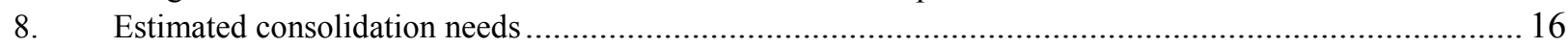

9. Large fiscal consolidation and the government debt-to-potential-GDP ratio.................................. 17

10. Estimates of short-term fiscal multipliers for different consolidation instruments ............................22

11. A possible generic hierarchy of consolidation instruments and its sensitivity to assumptions ................25

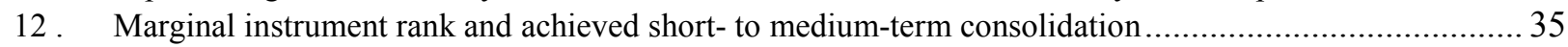

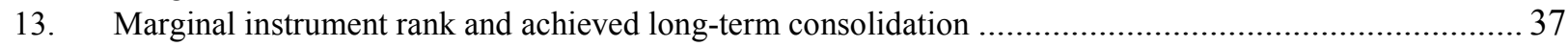

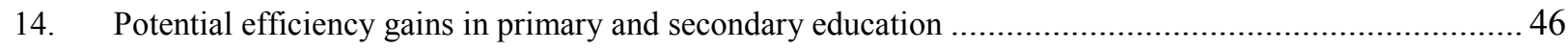

15. Potential gains in life expectancy from improved efficiency in health care .................................47

16. Tax expenditures in personal and corporate income taxes .....................................................48

17. VAT revenue ratio and illustrative potential efficiency gains in the VAT system .............................49

18. Use of performance budgeting at the central level of government .................................................51

19. Share of central government in subsidies paid and direct taxes received ..........................................52

20. Share of local and state governments in public spending on education, health and investment................52

\section{Boxes}

Box 1. Short- $v s$. long-term consolidation needs and average requirements ................................................ 8

Box 2. Main assumptions behind the OECD long-term growth projections ................................................ 10

Box 3. Forming country groups and deriving group-specific weights for objectives .....................................28

Box 4. Simulation design: details on instrument adjustment ................................................................... 33

Note: The statistical data for Israel are supplied by and under the responsibility of the relevant Israeli authorities. The use of such data by the OECD is without prejudice to the status of the Golan Heights, East Jerusalem and Israeli settlements in the West Bank under the terms of international law. 
ECO/WKP(2013)80

\title{
HOW TO ACHIEVE GROWTH- AND EQUITY-FRIENDLY FISCAL CONSOLIDATION? A PROPOSED METHODOLOGY FOR INSTRUMENT CHOICE WITH AN ILLUSTRATIVE APPLICATION TO OECD COUNTRIES
}

\author{
By Boris Cournède, Antoine Goujard and Álvaro Pina ${ }^{1}$
}

\section{Introduction and main messages}

1. Despite considerable progress in recent years, many OECD countries were still facing sizeable fiscal consolidation at the end of 2012 to bring back or keep public debt within manageable levels. Building on previous OECD and other work, the present study presents a structured approach to designing fiscal consolidation strategies that minimise adverse side-effects on growth and equity in the short and the long term as well as on external imbalances. The paper subsequently goes on to provide some illustrative applications of the approach.

2. The main messages can be summarised as follows:

- In most OECD countries, compared with what had been achieved by end 2012, additional consolidation is needed in the short to medium term to put government debt on a trajectory toward more prudent levels (defined for simplicity as gross debt at $60 \%$ of GDP). Seven countries, including Japan, the United Kingdom and the United States, appear in the simulations to need to improve their fiscal balances by more than 5\% of GDP over the medium term, compared with their end-2012 levels.

- Keeping debt stable in the very long run, i.e. in 2060 despite long-term spending pressures requires that consolidation should be sustained. In nine countries including Japan, the United Kingdom and the United States, the simulations suggest that the primary surplus should be steered to $5 \%$ of GDP above its baselineto keep debt stable in 2060 .

- Consolidation instruments (increases in particular taxes and cuts in specific spending areas) can be ranked according to their effects on short- and long-term growth, income distribution and current accounts, with the rankings taking into account country circumstances. Lowering production subsidies, reducing public pension spending and increasing property taxes come out as consolidation instruments that are most compatible with growth and equity objectives. At the opposite end, it appears particularly desirable to avoid increasing social security contributions or cutting back government expenditure on investment projects, health, childcare and education.

1. The authors are members of the OECD Economics Department. Álvaro Pina is also affiliated with ISEG (Lisboa School of Economics and Management) and UECE (Research Unit on Complexity and Economics, Lisboa). This paper is a revised version of a document prepared for a meeting of the Working Party No. 1 of the OECD Economic Policy Committee held in March 2013. Versions of the paper have also been presented at a Department of Economics seminar at ISEG, at the $9^{\text {th }}$ BMRC-QASS Conference on Macro and Financial Economics (both in May 2013) and at a special Lisbon Council event in July 2013. The authors would like to thank the meeting participants as well as Pier Carlo Padoan, Jørgen Elmeskov, Jean-Luc Schneider, Alain de Serres, Sebastian Barnes, Ray Barrell, Henrik Braconier, Orsetta Causa, Roger Farmer, Alberto Gonzalez Pandiella, Peter Hoeller, Isabell Koske, Stephen Matthews, Oliver Roehn and Eckhard Wurzel for valuable comments and suggestions, Caroline Abettan for excellent editorial support and Agnès Cavaciuti for expert statistical assistance. The views expressed in this paper are the authors' and are not necessarily shared by the OECD or its member countries. Corresponding author: boris.cournede@oecd.org. 
- Based on these rankings, illustrative consolidation packages to optimise the side-effects of consolidation on other policy objectives can be drawn up for each country.

- The packages are based on using instruments sequentially, and within reasonable limits, starting from the most desirable and moving down the ranking until consolidation needs are satisfied.

- Based on this approach, half of OECD countries (e.g. Australia, Canada, the Netherlands) appear to be in a position to fulfil their short- to medium-term consolidation needs entirely through instruments that are well ranked (that is to say ranked in the top half). This suggests that, in these countries, well-designed consolidation packages can avoid severe adverse side effects on growth, equity and current account imbalances.

- In the simulations, six (e.g. Finland, France, New Zealand) countries use some instruments with potentially adverse side-effects on growth and equity, such as cuts to public investment, but achieve more than half their short- to medium-term consolidation through well-ranked instruments.

- Finally, in the simulations, three countries (Japan, United Kingdom and the United States) implement more than $50 \%$ of their short-to-medium-term consolidation packages through instruments that have low rankings meaning that they are likely to involve substantial adverse sideeffects. Their simulated consolidation packages involve deep cuts to public spending on health expenditure, which can harm growth and equity unless coupled with substantial efficiency improvements.

- Despite the generally stronger consolidation requirements in the long term, twenty countries would manage to keep debt durably stable at $60 \%$ of GDP by relying only on well-ranked instruments.

- In the simulated very long-term packages, six countries (including Japan and the United Kingdom) use some poorly ranked instruments but can nonetheless achieve more than $50 \%$ of their adjustment with well-ranked instruments.

- Finally, three countries implement most of their simulated very long-term consolidation packages through poorly-ranked instruments, whichhave more adverse effects on long-term growth and equity objectives. For instance, in the long-term simulations, Australia and the United States increase their consumption taxes by $2.5 \%$ of GDP, and New Zealand reduces public investment by $1.1 \%$ of GDP.

- On average across countries, spending reductions would account for $41 \%$ of short- to mediumterm and $65 \%$ of long-term consolidation packages, the rest being achieved through tax hikes. The difference mostly reflects the greater concern for demand effects in the short term.

- The proposed illustrative consolidation packages lead to some, but not much, convergence in spending and revenue structure across countries over time. This result can be interpreted as meaning that the proposed approach is largely respectful of the diversity of national preferences over spending and revenue structure.

- Extensive sensitivity analysis indicates that all the above results are largely robust to uncertainty about the assessments of the effects of instruments except the spending-tax split in simulated shortterm consolidation plans. The simulation results are also very robust to changes to the method used to adapt instrument rankings to country circumstances. The assumptions made to define the maximum amount by which each consolidation instrument can be used have a direct influence on the degree to which countries with large adjustment needs have to rely on the most harmful categories of tax hikes or spending cuts. 
- In the many cases where countries have to use fiscal instruments that are detrimental for growth or equity on their own, they can ease the potential trade-off between consolidation and other policy objectives by exploiting the scope for efficiency gains through structural reforms.

3. In a preliminary step providing inputs for the subsequent analysis of ways to minimise the sideeffects of consolidation, the study first estimates fiscal consolidation needs in the short to medium term and the long term (Section 2). It then moves to its core subject and discusses the definition of growth, equity and current account objectives before presenting the list of potential consolidation instruments, evaluating their effects along these three dimensions and proposing a generic illustrative hierarchy of instruments (Section 3). On that basis, Section 4 proposes a method for developing country-specific hierarchies of instruments taking into account country specificities. A file available online allows readers to build their own rankings of consolidation instruments by keying in their preferred weights on growth, equity and current-account objectives. ${ }^{2}$ The study proceeds with an illustrative evaluation of how far down each country has to go on its list from more to less welcome instruments to meet its consolidation objectives without departing too much from its revealed preferences about government spending and revenue items and checks the robustness of the findings (Section 5). The results underscore the need for structural changes to be part of fiscal adjustment and for institutions to play a supportive role (Section 6). Section 7 makes a few concluding remarks.

4. Appendix 1 reports country details of the main simulations as well as summary statistics from alternative simulations based on random draws. Appendix 2 provides supporting material on: the methodology used to estimate consolidation needs, the dataset, the assessment of instrument impact, the analysis of debt behaviour during consolidation episodes, a variant without clustering analysis and another variant with increased room for manoeuvre. Appendix 3 plots the baseline and debt-control trajectories underpinning the estimates of consolidation needs. Further supporting empirical evidence is provided by Barbiero and Cournède (2013) and Goujard (2013).

\section{Estimated consolidation needs}

5. The legacy of the financial crisis and earlier fiscal imbalances has burdened many OECD governments with high debt levels often accompanied by still significant structural deficits (Figure 1) which call for large consolidation efforts to reduce debt to more prudent levels. As a preliminary step to permit a quantitative analysis of the composition of consolidation strategies, this section presents estimates of consolidation needs for both the short to medium term and the long term. The present calculations are based on a gradual consolidation effort, embodied in smooth time paths for theunderlying primary balance (See Appendix 1, section 1 for a detailed description of how the time paths are simulated). The underlying primary balance is the difference between government receipts and expenditure, both excluding interest flows, adjusted for the cycle and for one-offs. ${ }^{3}$ The objective of this adjustment is to look through the impact of cylical fluctuations on taxes and spending and also to adjust for that sometimes large stopgap measures that are implemented to reduce debt or more generally improve fiscal accounts (Koen and van den Noord, 2006). The simulated time paths ensure that the debt ratio is on a stable trajectory at the end of the consolidation horizon (2060). Second, in order to ensure that by 2060 the debt ratio not only stabilises but does so at the desired target level (60\% as in Johansson et al., 2013), the present work differentiates short- from long-term consolidation needs, as explained in greater detail below. As developed in Box 1, this approach differs in purpose and methodology from the consolidation requirements reported in the OECD Economic Outlook of May 2013 (OECD, 2013a).

2. It can be downloaded from: http://www.oecd.org/eco/public-finance/Simulation-ranking-web.xlsx.

3. See Joumard et al. (2008) for a presentation of the methodology used to correct for one-offs. 
Figure 1. Debt and underlying primary balances in 2012

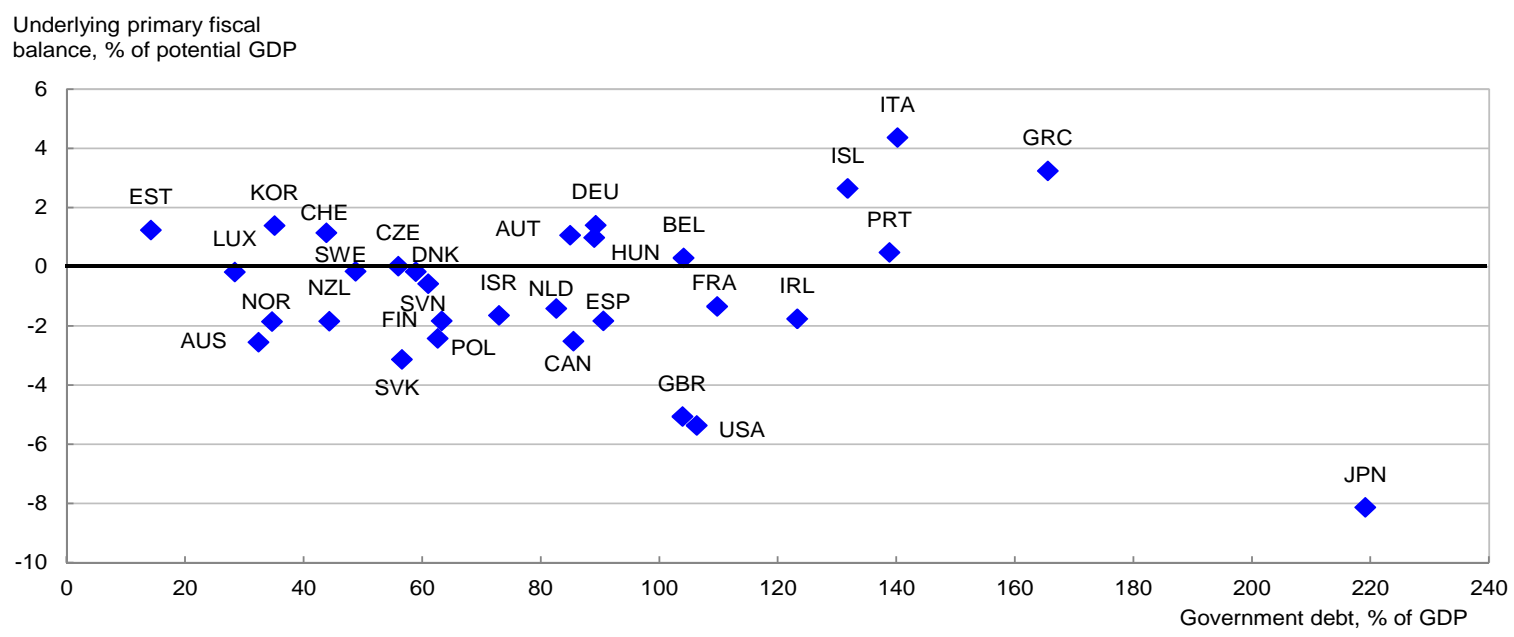

Source: OECD Economic Outlook of May 2013 database.

6. The short- to medium-term consolidation need is defined as the difference between a baseline and the peak of a trajectory for the underlying primary balance that brings gross general government debt to $60 \%$ of GDP by 2060 . Evidently, different consolidation paths can be taken to attain the $60 \%$ target, each leading to a different profile for the underlying primary balance (see Box 4.5 in OECD, 2013a). For the purpose of this exercise, and although some countries plan to adjust faster (see OECD, 2013a), the underlying primary balance is assumed to improve from its 2012 level at a rate of one per cent of potential GDP each year for as long as necessary to put debt on a trajectory toward the target. After that initial period of consolidation, which varies considerably in length across countries, the underlying primary balance is assumed to converge very gradually to the 2060 level which stabilises debt at $60 \%$ of GDP (see Figure 1 and Section 1 in Appendix 2). Initial improvement in the underlying primary balance at the fast annual pace of one per cent ( $1 \frac{1}{2}$ per cent in Japan) helps to ensure that debt is put on a downward path in a not too distant future. ${ }^{4}$ Interest rates and GDP growth, important drivers of debt dynamics, are assumed to follow the long-term baseline projections published OECD (2013a) of which the main assumptions are summarised in Box 2. The calculations are based on the effective interest rate paid by governments on the stock of debt, as projected in the OECD (2013a) long-term projections, so that the maturity structure of the debt stock is taken into account. Last historic point (2012) data for general government debt and underlying primary balances are also taken from the OECD (2013a). Figure 3 shows two concrete examples of baseline and debt-reducing trajectories (see Appendix 3 for charts depicting the simulated trajectories for all countries).

\section{Box 1. Short- vs. long-term consolidation needs and average requirements}

The estimated consolidation needs presented here differ from the average consolidation requirements reported in OECD (2013a) as they serve different purposes and therefore use different assumptions. The present set of consolidation needs forms a basis for the subsequent quantitative analysis of detailed consolidation packages that minimise side effects. The focus is firstly on how far these packages need to go in the short to medium term to bring debt under control and secondly on what has to be done to keep debt stable in the very long term, that is to say in

4. This initial improvement at a fast pace, which generates a peak in the trajectory for the underlying primary balance, is needed in most but not all countries. Countries with a better starting fiscal position do not need such a peak. Nevertheless, the time path for the underlying primary balance always exhibits a kink (often, but not always, a peak), which provides the point where short- to medium-term consolidation needs are calculated. 
2060 and beyond. This differs from the objective of the requirements reported in OECD (2013a) which was to show how much effort beyond that already built into the near-term projection is needed on average from 2015 to 2030 . From these different purposes and perspectives result different methodological choices with the main differences summarised as follows:

- The reference point for comparisons is 2012 in the current study, so that needed changes in individual areas of tax and spending can be compared to the latest historical point (or estimate). The reference point in OECD (2013a) is fiscal projections to 2014 to provide an idea of how much remains to be done in aggregate after the expected consolidation to 2014 .

- The present estimates refer to the peak effort needed in the short- to medium-term and in 2060 whereas the requirements reported in OECD (2013a) relate to the average effort over 2015-2030. The former is needed for the present exercise as the point to assess how far, at the peak, instruments have to be used, and whether these instruments have to be maintained or can be partly reversed afterwards. To assess the size of aggregate consolidation efforts in an extended medium-term perspective as is the case in OECD (2013a), however, the average offers a more robust measure given that many different paths with many different peaks can be imagined for moving to debt stabilisation.

- In order to allow more realistic estimates of consolidation needs in the very long run (2060), the present estimated needs are calculated over a baseline where government expenditure on health and long-term care increases gradually over time. The baseline for comparisons in OECD (2013a) does not incorporate such cost pressures which have a lesser impact when looking at average effort over 2015-30.

- For the sake of comparability of consolidation packages and in line with the long-term focus of the study, the present set of estimates assumes that all countries reach $60 \%$ gross debt-GDP ratios by 2060 . In OECD (2013a), in line with the extended medium-term focus, the time horizon is 2030 but, to avoid too abrupt changes, some countries are allowed to reach their $60 \%$ target after 2030 .

Despite the differences of purposes and method, the cross-country correlation between the present set of shortto medium-term consolidation needs and the requirements presented in OECD (2013a) is very strong with a coefficient of $96 \%$.

Source : OECD (2013a), OECD Economic Outlook of May 2013.

Figure 2. Defining short- to medium-term and long-term consolidation needs
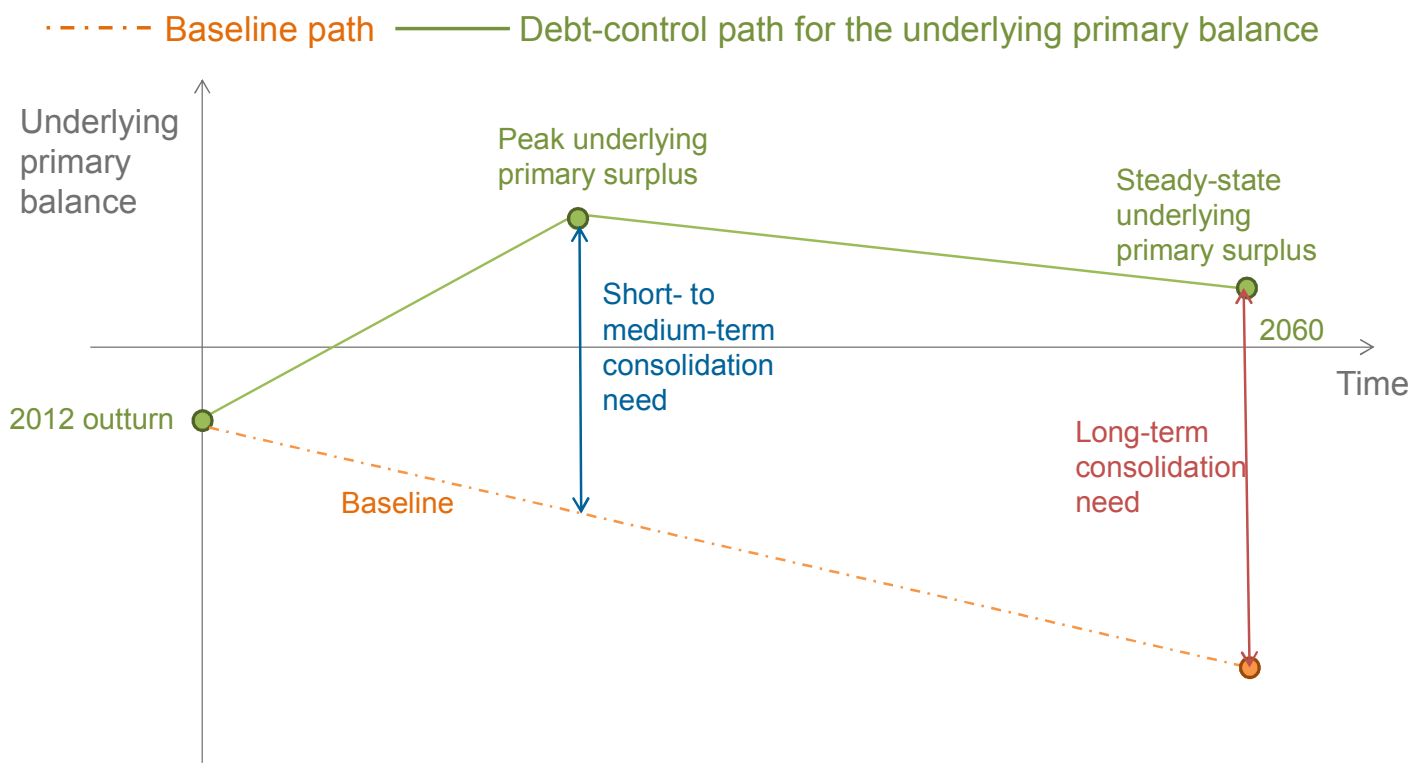


\section{Box 2. Main assumptions behind the OECD long-term growth projections}

Consolidation needs are calculated using the OECD long-term baseline growth projections to 2060 published in the OECD Economic Outlook of May 2013 (OECD, 2013a). The main features of this set of projections, which use the OECD long-term modelling framework presented in Johansson et al. (2013) are as follows:

- The backbone of these scenarios is a set of long-run projections for potential output based on physical and human capital and labour as production factors plus labour-augmenting technological progress. The latter is assumed to converge at a speed that depends on the starting point, with countries farther away from the technology frontier converging faster.

- The gap between actual and potential output is gradually eliminated from 2013 , for most countries within four to five years, depending on the initial size of the output gap.

- Inflation is assumed to converge gradually to its target rate ( $2 \%$ in most countries).

- Policy-controlled short-term interest rates increase gradually as output gaps close before converging to neutral short-term rates following potential GDP growth rates. Long-term interest rates are a forward convolution of short-term rates plus a fixed term premium, a fiscal risk premium reflecting debt levels and a global balancing premium. Effective interest rates are calculated as an average between short-term and long-term interest rates reflecting the maturity structure of government debt.

Source : Johansson et al. (2013)

7. The long-term consolidation need compares the "debt-control" underlying primary balance with the baseline at the end of the projection period. The baseline corresponds to a policy scenario where sufficient reforms are introduced for public pension spending to remain constant relative to potential GDP and for government expenditure on health and long-term care to grow at a contained pace. Other tax and expenditure components are assumed to be unchanged from their 2012 levels relative to GDP except for cyclical effects associated with the projected closure of output gaps.

8. The baseline scenario therefore incorporates significant reform in the areas of pensions and health.

- Many countries expect large increases in government pension expenditure relative to GDP on current policy settings (Figure 4). The baseline scenario assumes that, in these countries, substantial reforms are implemented, including adjustments of the effective retirement age, so as to keep stable the ratio of public pension spending to GDP.

- Similarly, the continuation of past trends in public spending on health and long-term care would appear to result in large further increases, as apparent in the projected "cost-pressure" scenario presented in de la Maisonneuve and Oliveira Martins (2013) and plotted on Figure 4. Hence, the baseline incorporates (unspecified) measures to contain cost pressures in health and long-term care, which could include a more frequent re-evaluation of drug prices, centralised bargaining for drug purchases, more user choice of health providers and incentives to enhance prevention inter alia. Nonetheless, even under the cost containment assumption, health spending is projected to rise as a share of GDP, which explains the trend decline in the primary balance in the baseline paths shown in Figures 2 and 3. 
Figure 3. Illustration of the budget consolidation profile compared with baseline in two countries

Simulated underlying primary balance, per cent of potential GDP

- Baseline path

Japan

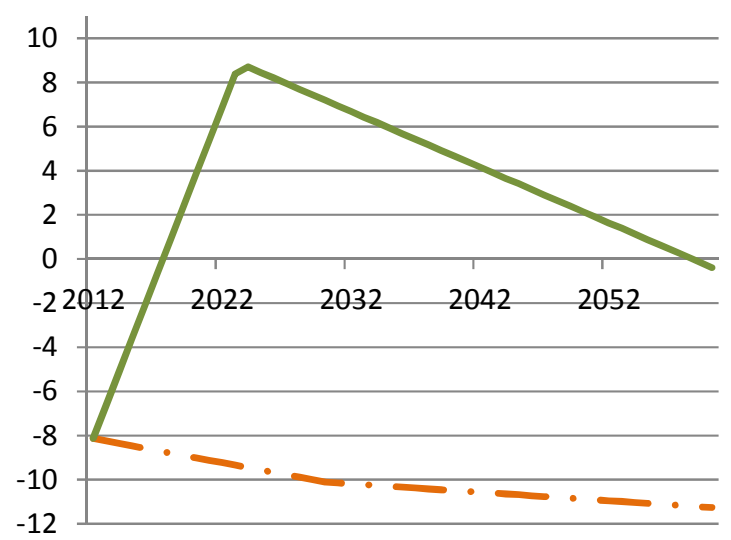

Debt-control path

Belgium

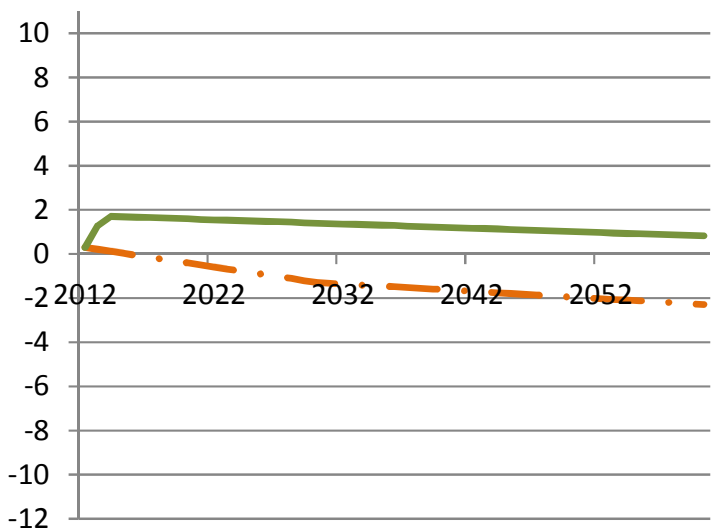

Source: OECD Economic Outlook of May 2013 database and OECD calculations.

Figure 4. Projected change in government pension expenditure on unchanged policies

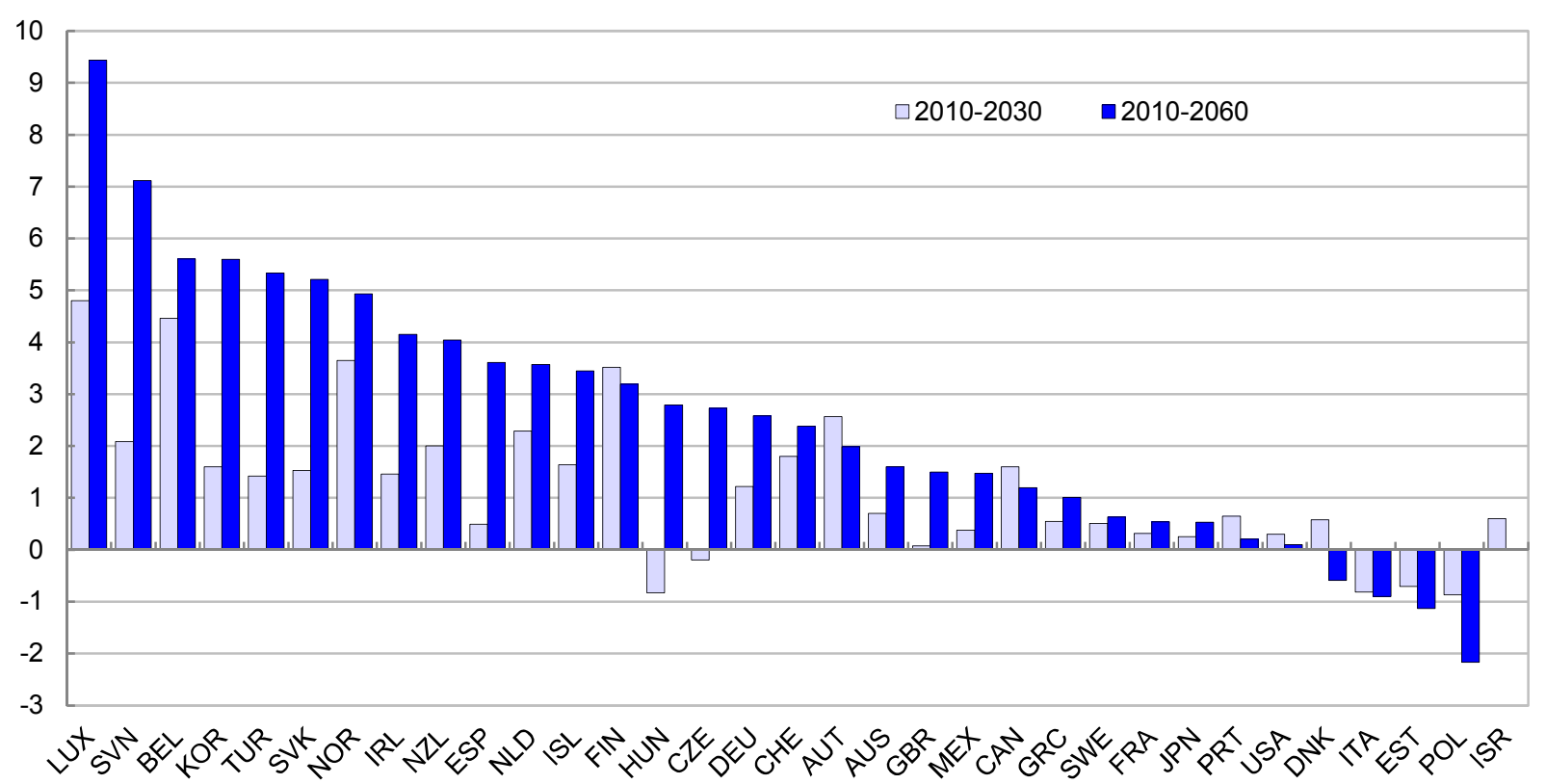

Source: EC (2012) for EU countries and Norway, OECD (2011a) for other countries except Japan where the estimate is taken from Merola and Sutherland (2012) and Israel where it has been estimated for 2030 based on projections to 2025 communicated by the Bank of Israel, 
Figure 5. Projected percentage point increase in total public health and long-term care spending, 2010-2060

Range of estimates across sensitivity analyses ${ }^{1}$

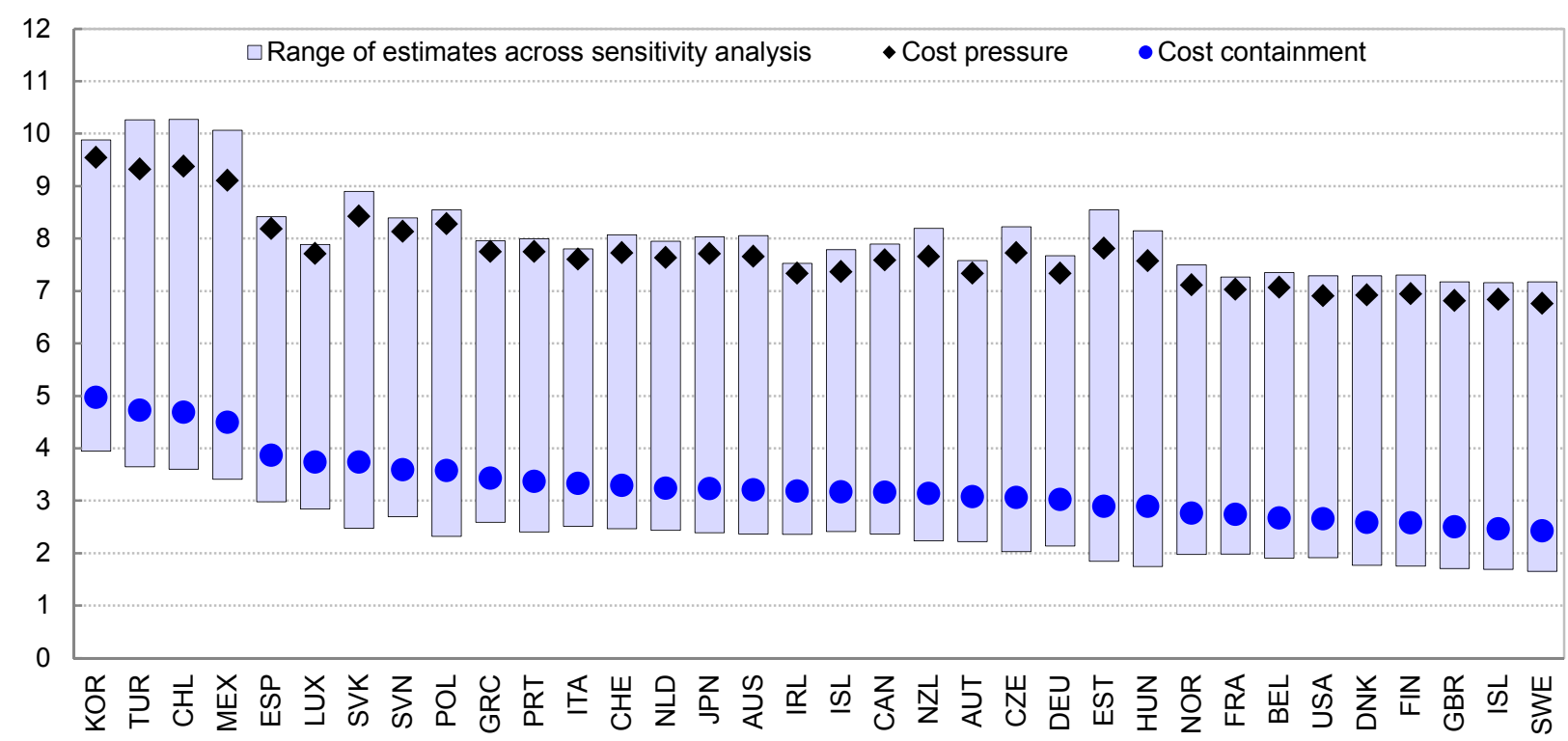

Note: Countries are ranked by the increase of expenditures between 2010 and 2060 in the cost-containment scenario. The vertical bars correspond to the range of the alternative scenarios, including sensitivity analysis.

Source: de la Maisonneuve and Oliveira Martins (2013).

9. Estimates based on the approach described above suggest that in Greece, Japan, Portugal, Spain, United Kingdom and the United States, a short- to medium-term consolidation in excess of 5\% of potential GDP is required to reduce debt to $60 \%$ of GDP by 2060 (Figure 6). This is the result of currently high debt levels (Greece, Ireland, Portugal and Spain) or their combination with large initial underlying primary deficits (Japan, United Kingdom and United States). To bring debt to the same level, another group needs short- to medium-term consolidation by more than 3\% of GDP — though less than 5\% — because of high debt levels (France, Iceland) or a significant underlying primary deficit (Finland, Poland, Slovak Republic). Other countries, including in particular Italy and Germany, face little or no short- to mediumterm structural consolidation needs, though high debt in the former makes this conclusion vulnerable to interest rate changes. When needed, consolidation is in most cases relatively brief in the simulations: three out of four countries that require short- to medium-term consolidation complete it in four years or less. Many countries have made consolidation plans that go a long way toward meeting these consolidation needs (OECD, 2013a). 
Figure 6. Estimated consolidation needs

Difference between debt-control and baseline underlying primary surplus, per cent of potential GDP

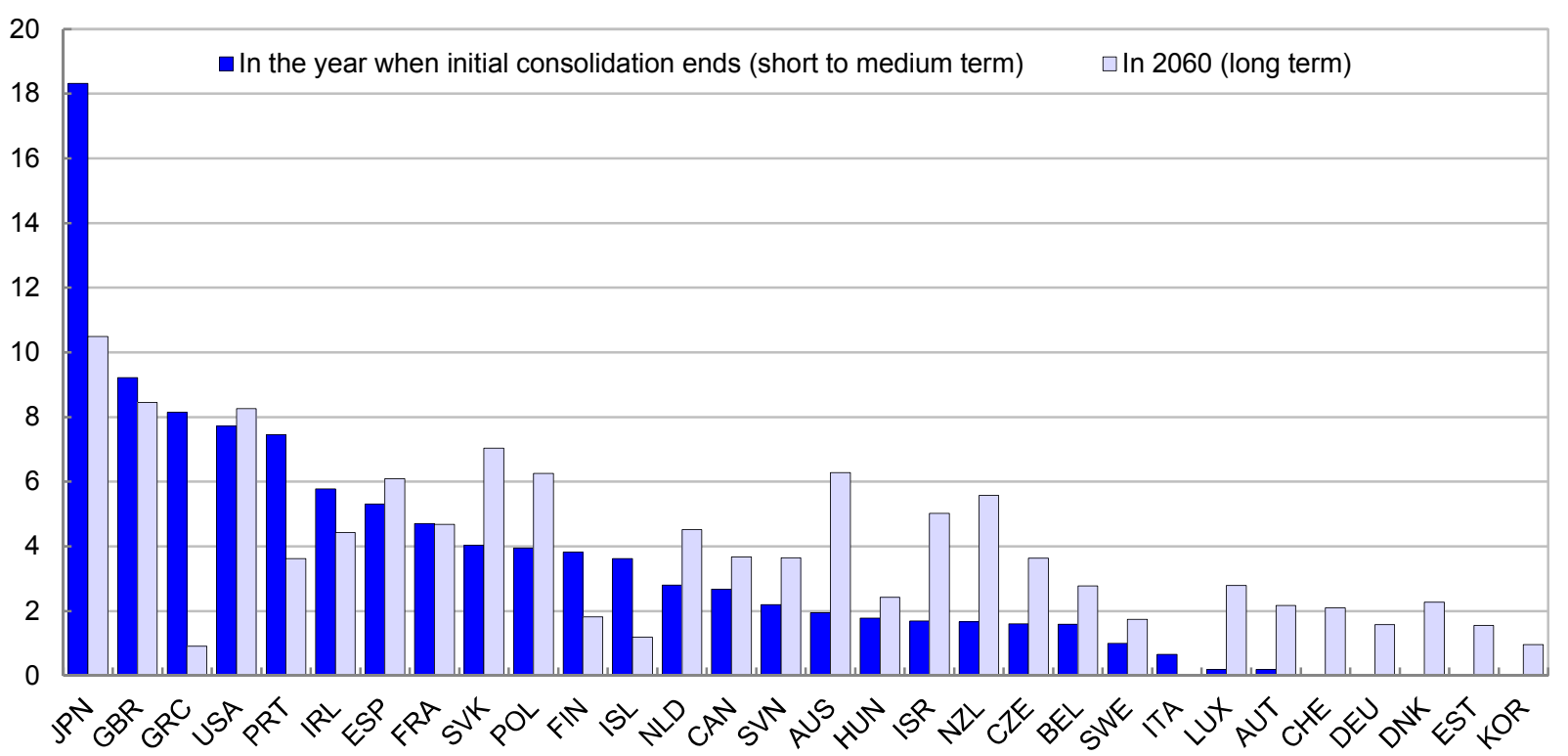

Source: OECD Economic Outlook of May 2013 long-term database and OECD calculations.

10. Consolidation needs are larger in the long than the short term for the majority of countries, with the difference particularly large in countries where short-term needs are limited thanks to low initial debt levels. The high estimated level of long-term consolidation needs reflects large expected spending increases on health and long-term care. That said, since the cross-country variation in projected increases in government health spending is limited, it does not account for much of the differences in estimated longterm consolidation needs. The latter are primarily due to the starting point for the underlying primary surplus in 2012. Another significant source of differences is that the OECD long-term growth scenarios project interest rates rising well above nominal GDP growth rates by 2060, which leaves governments holding large amounts of financial assets with substantial capital income to service their debt. This effect reduces the estimated long-term consolidation needs of Canada, Finland, Japan, Korea and Norway by $2 \frac{1}{2}$ per cent of GDP or more compared with a situation where these countries' governments had no financial assets.

11. If no pension reform was assumed in the baseline, that is to say if public pension expenditure was allowed to increase in line with unchanged-policy projections, estimated long-term consolidation needs would be considerably larger in many countries (Figure 7). These very large differences underscore the critical need for pension reform in countries that have not yet adjusted their systems to ensure that government pension spending remains contained in the face of ageing. In addition to being key to fiscal sustainability, successful pension reform also brings important benefits in terms of greater labour supply (Duval, 2003) and intergenerational equity (Gonand, 2010). 
Figure 7. Long-term consolidation needs: estimates with and without pension reform

Difference between debt-control and baseline underlying primary surplus in 2060, per cent of potential GDP

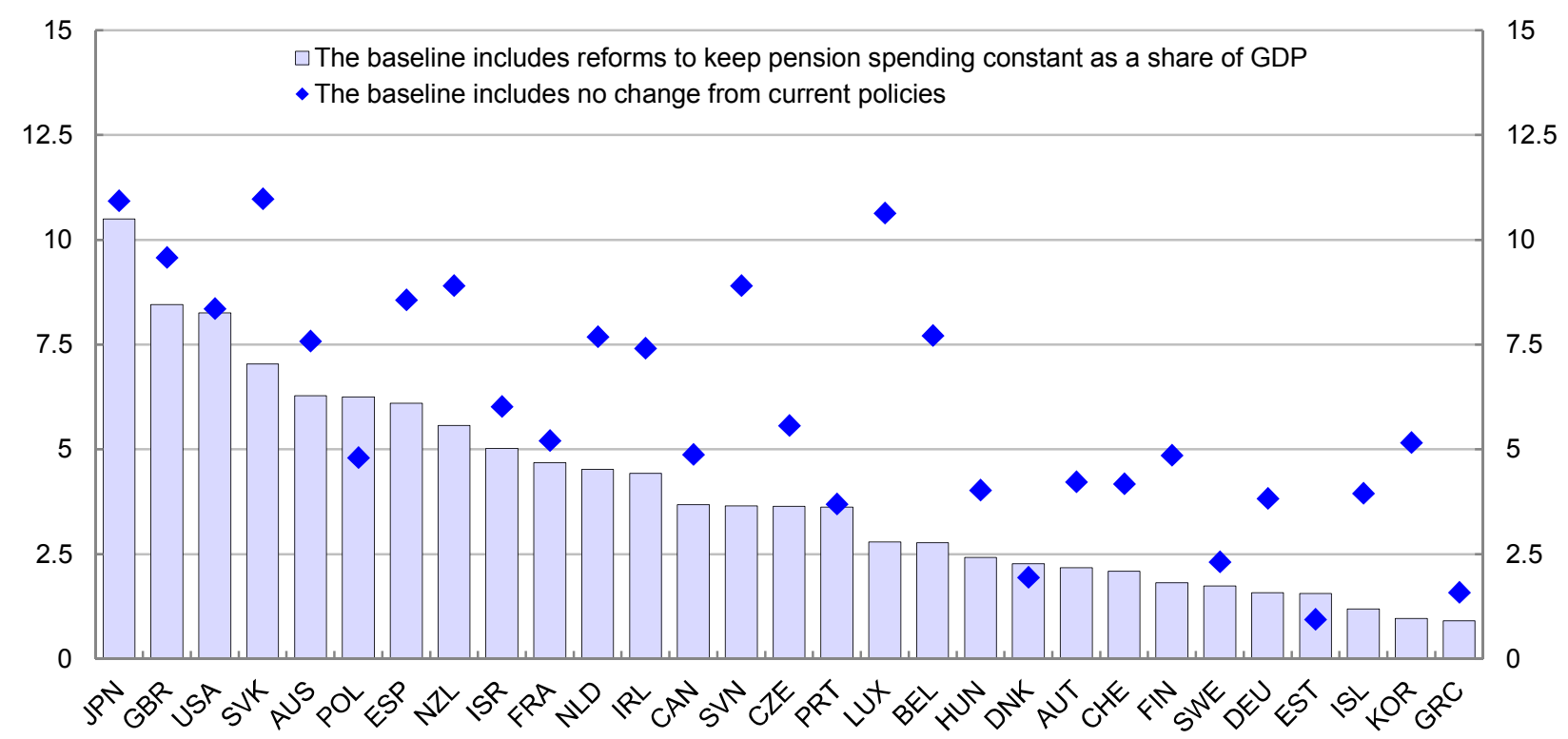

Source: OECD Economic Outlook of May 2013 and OECD calculations.

12. The choice of a gross debt target can exaggerate consolidation needs for governments that have large sellable financial assets or substantial implicit assets for instance in the form of deferred tax on pension savings. A limited group of OECD governments (Estonia, Finland, Korea, Luxembourg, Norway, Sweden) report net positive financial asset positions. A significant number of OECD governments hold financial assets that are valued at more than half of their country's GDP (Canada, Denmark, Finland, Greece, Iceland, Japan, Korea, Luxembourg, Norway, Slovenia, Sweden). ${ }^{5}$ Selling assets to meet consolidation needs, for instance by drawing them down to 50\% of GDP in countries that currently hold more, eliminates estimated short- to medium-term consolidation needs almost entirely in Denmark and fully in Sweden (Figure 8 Upper Panel). This draw-down hypothesis also reduces consolidation needs significantly in Japan, where they diminish by nearly 2 percentage points but remain nonetheless elevated at $16 \frac{1}{2}$ per cent of GDP. In the long term, however, this draw-down hypothesis results in larger consolidation needs (Figure 8 Lower Panel) because asset depletion reduces the amount of capital income on government assets compared with the assumption of keeping them constant as a share of GDP. In practice, the ease with which financial assets can be liquidated varies across countries depending on their nature, on the extent to which they are earmarked to prefund budgetary commitments and on whether they are owned by the central or other levels of government (Rawdanowicz et al., 2011).

13. The chosen level of the debt target also has implications for consolidation needs. While there is no obvious optimal maximum ratio of public debt to GDP, the $60 \%$ value has been retained as the main reference point for the simulations because of its widespread use as a policy target within the OECD membership. Aiming at a higher $100 \%$ target would reduce estimated short- to medium-term consolidation needs by about $2 \%$ of GDP in most OECD countries (Figure 8A). Allowing greater indebtedness however comes at the cost of larger interest payments to keep the debt ratio stable, pushing up estimated long-term

5. These assessments use end-2012 data or estimates for general government financial assets and liabilities on a national accounts basis as reported in the OECD Economic Outlook of May 2013 database. 
consolidation needs by about $1 \%$ of GDP in most OECD countries (Figure 8B). These considerations mean that the consolidation needs used in the rest of the paper, which correspond to the $60 \%$-of-GDP gross debt target without asset draw-down, should be seen as illustrative as the choice of a debt target and the level of the target ought to be country specific.

14. Feedbacks from consolidation to activity could also influence consolidation needs in ways that are not fully reflected in the present set of estimates. In many countries, deeper consolidation would through multiplier effects reduce growth and create more adverse debt dynamics than assumed in the present simulations in the short to medium term. These effects could be magnified by the fact that most countries consolidate, implying that each country faces additional headwinds from external demand in its consolidation effort. ${ }^{6}$ Afterwards, however, the return of output to potential would create more favourable growth and therefore debt dynamics than the one underpinning the present calculations. Simulations incorporating such effects by Rawdanowicz (2012) suggest that, even if multipliers are large, their effects on debt dynamics during and after the consolidation largely cancel out so that they have little effect on the estimated size of consolidation needs. One channel through which deep fiscal tightening can influence consolidation needs sizeably is if it generates hysteresis effects that depress potential output permanently, something which is assumed not to happen in the projections presented here. This consideration underscores the need to design consolidation strategies in ways that minimise the risk of generating hysteresis (see Section 4 below).

6. Empirical evidence suggests that, when trading partners consolidate, growth is reduced, even after controlling for growth in trading-partner countries (Goujard, 2013). This finding that consolidation has cross-border effects over and above direct growth spillovers is consistent with the view that consolidation tends to rebalance production toward servicing external demand (IMF, 2010). 
Figure 8. Estimated consolidation needs

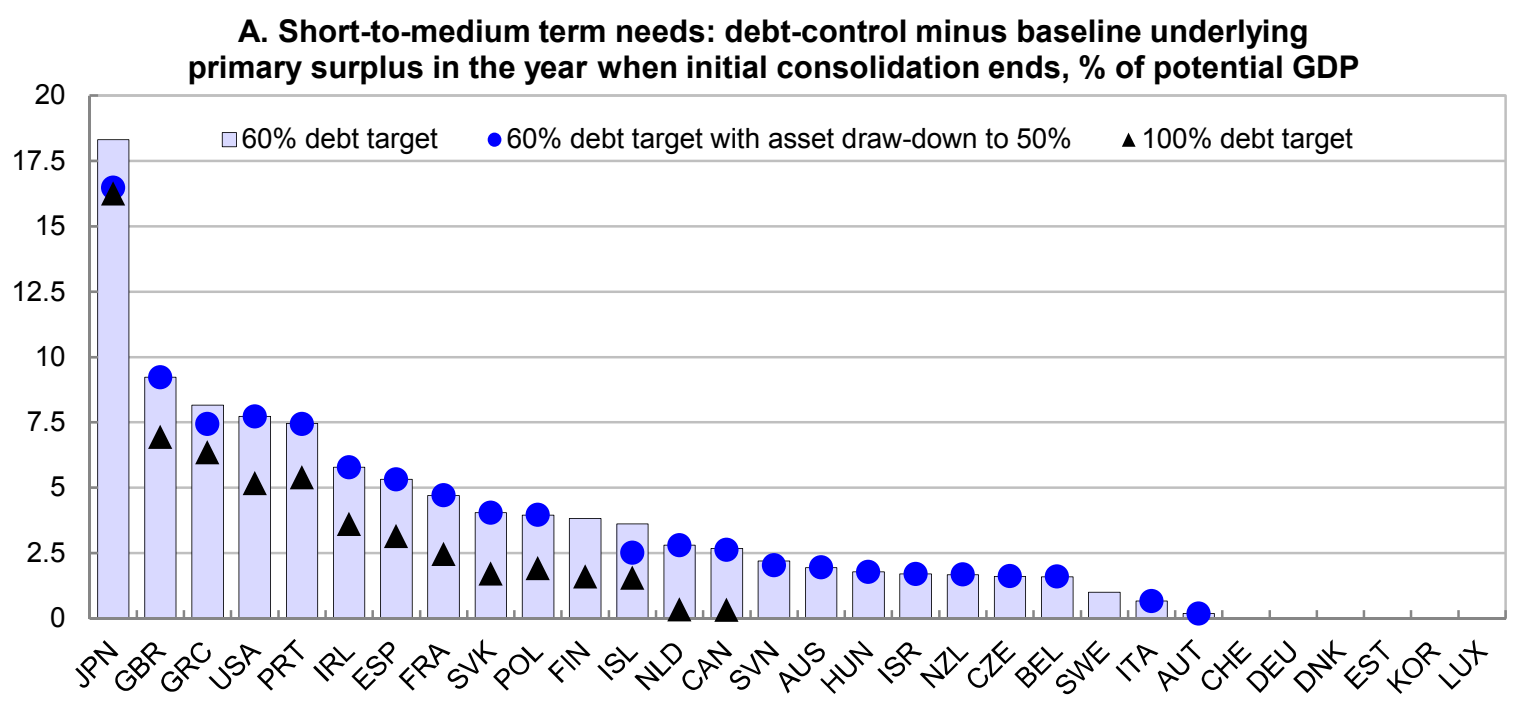

B. Long-term needs: debt-control minus baseline underlying primary surplus in $2060, \%$ of potential GDP

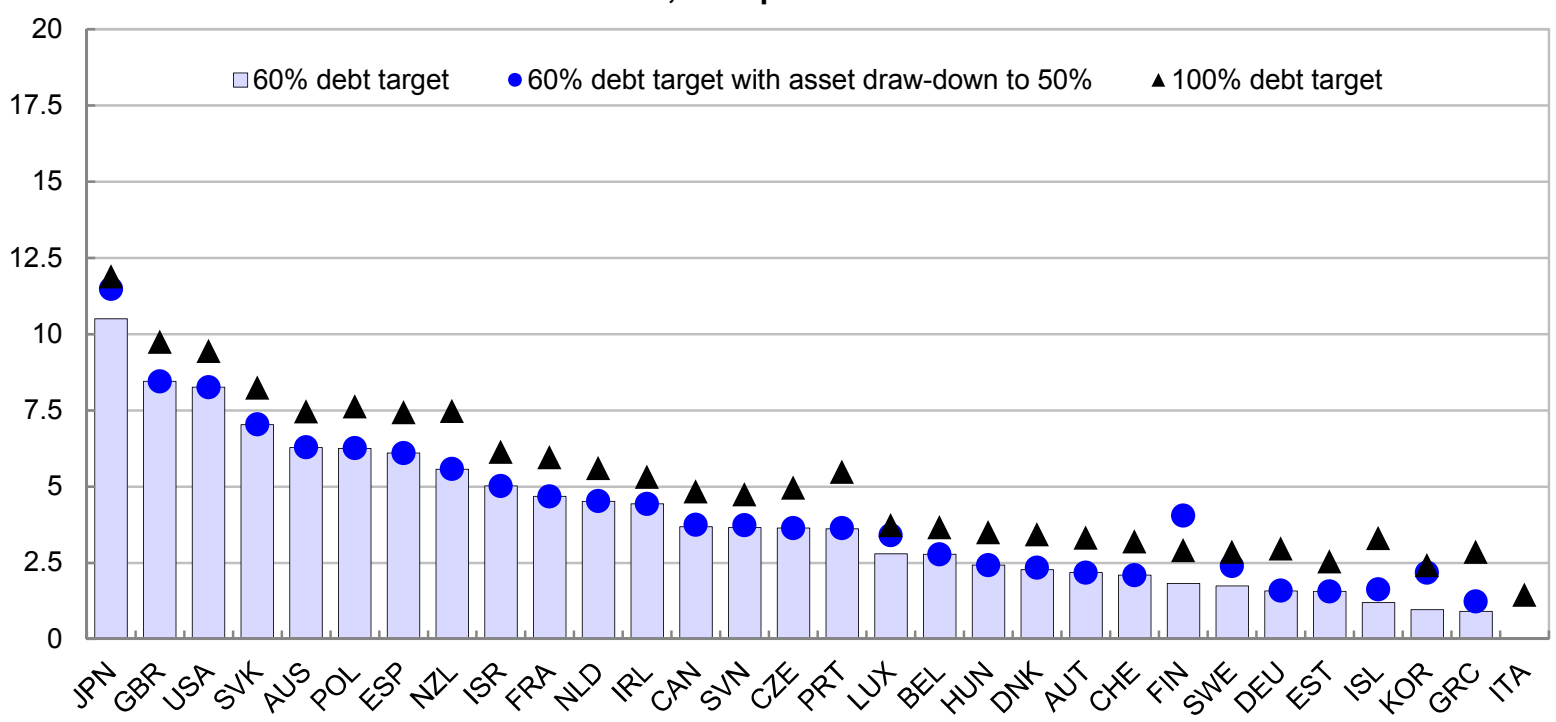

Source: OECD Economic Outlook of May 2013 long-term database and OECD calculations.

15. Feedbacks from consolidation to real interest rates could reduce consolidation needs. Consolidation strategies that are credibly seen as bringing back debt firmly within manageable levels are likely to lower real interest rates (Turner and Spinelli, 2012). The historical experience is that large fiscal consolidation generally puts debt on a falling trend relative to potential GDP three to four years after its start (see Figure 9 and Blöchliger et al., 2012). Lower real interest rates improve debt dynamics directly, by fuelling demand, and also by boosting potential output. These effects can be particularly strong in crisis countries where credible consolidation can carry them from a situation of high and rising indebtedness, elevated risk premia and low growth to a "good equilibrium" characterised by falling debt, lower risk premia and higher growth (Padoan et al., 2012). 
Figure 9. Large fiscal consolidation and the government debt-to-potential-GDP ratio

Deviation from cross-country and time-period averages, per cent

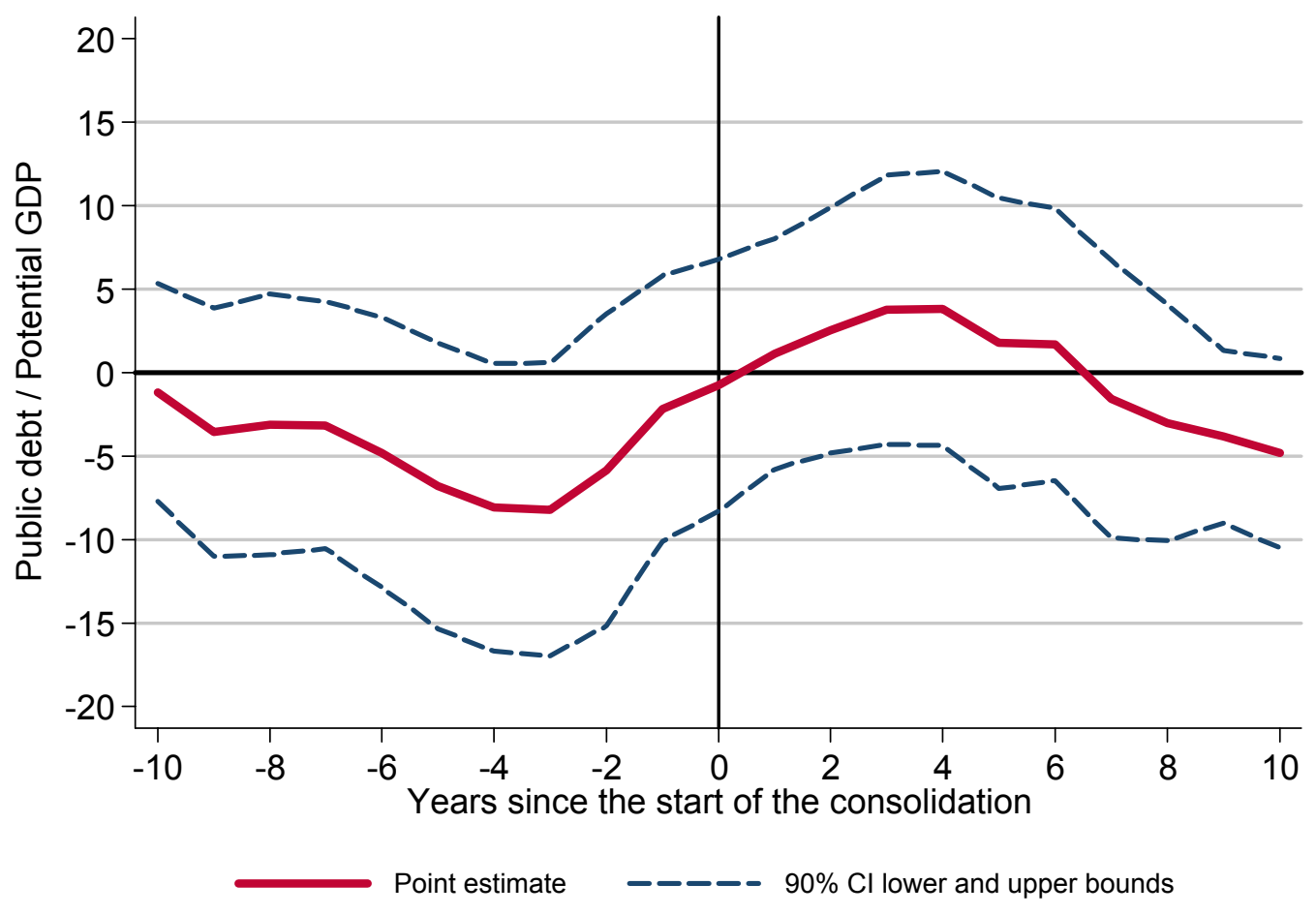

Note: The solid lines show the association between fiscal consolidation and the public debt to GDP ratio. Consolidations are defined as a $1.5 \%$ of GDP action-based consolidation effort: countries and period episodes are taken from Devries et al. (2011). Consecutive years of consolidation are dropped as in Alesina and Ardagna (2010). Driscoll-Kraay (1998) standard errors robust to heteroskedasticity, arbitrary spatial correlation and autocorrelation up to 5 years. Government debt and GDP data are taken from the OECD Economic Outlook No.92 database. See Appendix 2, Section 4 for more details on the methodology.

\section{The effects of consolidation instruments on other policy objectives}

\subsection{Other policy objectives}

16. While the point of fiscal consolidation is to reduce debt, it cannot ignore other policy objectives. The present study looks at the extent to which fiscal consolidation can proceed while minimising adverse effects on short-term growth, preserving long-term prosperity, avoiding exacerbating income inequality in the short and long term and contributing to global rebalancing. In addition to being an objective in its own right, equity may influence the sustainability of fiscal adjustment programmes. Consolidation strategies perceived as inequitable are more likely to be reversed and to fail to reduce debt.

17. The distinction made here between short- and long-term effects does not relate to specific time spans but to adjustment processes. Short-term effects correspond to the direct impact of measures as they are implemented. Long-term effects describe their consequences when cyclical adjustment has run its course and behaviour has responded fully to the measures (meaning in particular that any generalequilibrium impacts have materialised). 


\subsection{Instruments}

18. The instruments considered are policies that permanently affect government underlying primary spending and revenues. Government underlying primary spending is broken into ten categories, including four consumption items, three transfer items, subsidies, public investment (Table 1) and a residual item which is not considered as an instrument of consolidation. The expenditure breakdown broadly follows national accounts classifications with the difference that user charges are not netted out from government consumption. Instead, user charges are included among the eight consolidation instruments considered on the revenue side. Cutting tax expenditures, a potentially large and attractive source of revenue, is nevertheless not included as an instrument because of the lack of sufficiently reliable and internationally comparable data across countries. Section 6 however discusses how reductions in tax expenditures can contribute to policy strategies that combine fiscal consolidation with structural reform. Appendix 2 Section 2 provides details on the definition of the categories, on the sources used and on the methods employed to gather data from different sources in a way that adds up to government primary spending as recorded in national accounts.

Table 1. Instruments of consolidation

\begin{tabular}{ll}
\hline \multicolumn{1}{c}{ Expenditure cuts } & \multicolumn{1}{c}{ Revenue increases } \\
\hline Public consumption: education & Personal income taxes \\
\hline Public consumption: health & Social security contributions \\
\hline Public consumption: other (except family) & Corporate income taxes \\
\hline Cash transfers: pensions & Environmental taxes \\
Cash transfers: unemployment benefits & Consumption taxes (non-environmental) \\
Cash transfers: sickness and disability & Recurrent taxes on immovable property \\
Public consumption and cash transfers: family & Other property taxes \\
\hline Subsidies & Sales of goods and services \\
\hline Public investment & \\
\hline
\end{tabular}

Source: see Appendix 2.

\subsection{The effects of instruments on objectives}

19. An attempt is made at evaluating the effect of revenue increases and expenditure cuts on growth, equity and global rebalancing objectives. The effects of instruments on the current account are also evaluated because consolidation strategies should take into account coordinated efforts in multilateral settings such as the G20 to achieve balanced growth at the global level. For the purpose of this exercise, the instruments are assessed on their own without considering how their side-effects on long-term growth and equity could be minimised through structural reforms in the tax or spending area under consideration, other structural reforms or redistributive policies. The distinction between purely fiscal changes and structural reform is obviously not so clear cut in practice. ${ }^{7}$ Still, it is useful insofar as it allows for an assessment of the side-effects that some consolidation instruments can imply for other policy objectives

7. On the spending side, for instance, cuts in education spending achieved through reduced service provision can be described as pure budgetary measures whereas efficiency gains that can maintain a similar level of service for lower costs represents structural reform. On the revenue side, one example where the distinction is clear is indirect taxation where an increase in the standard VAT rate can be seen as a pure fiscal change while measures such as reducing the reliance on reduced rates and exemptions are part of structural tax reform. One example where the distinction is difficult to make is unemployment insurance where almost any form of reduction in benefits will amount to a change in structural policy settings. 
(this section) before discussing the benefits of joint policy strategies that combine consolidation with structural reform (Section 6).

20. The present assessment builds on previous work by the OECD and the wider literature complemented by new estimates presented in Barbiero and Cournède (2013). Table 2 summarises this assessment which is based on the main points discussed immediately below while additional Appendix 2, Section 3, provides additional supporting material on the growth and equity effects of consolidation instruments. Besides showing the estimated direction of the effect, some crude indications of the relative strength are also provided, based on empirical evidence.

Table 2. Summary assessment of growth and equity effects of fiscal consolidation instruments

\begin{tabular}{|c|c|c|c|c|c|}
\hline & \multicolumn{2}{|c|}{ Growth } & \multicolumn{2}{|c|}{ Equity } & \multirow{2}{*}{\begin{tabular}{l}
\multicolumn{1}{c}{$\begin{array}{c}\text { Current } \\
\text { account }^{(a)}\end{array}$} \\
Short- to \\
medium-term
\end{tabular}} \\
\hline & $\begin{array}{l}\text { Short- } \\
\text { term }\end{array}$ & $\begin{array}{l}\text { Long- } \\
\text { term }\end{array}$ & $\begin{array}{l}\text { Short- } \\
\text { term }\end{array}$ & $\begin{array}{l}\text { Long- } \\
\text { term }\end{array}$ & \\
\hline \multicolumn{6}{|l|}{ Spending cuts } \\
\hline Education & -- & -- & - & -- & + \\
\hline Health services provided in kind & -- & - & - & - & ++ \\
\hline $\begin{array}{l}\text { Other government consumption (excluding } \\
\text { family policy) }\end{array}$ & -- & + & - & & + \\
\hline Pensions & & ++ & & & ++ \\
\hline Sickness and disability payments & - & + & -- & - & ++ \\
\hline Unemployment benefits & - & + & - & & ++ \\
\hline Family & - & - & -- & -- & + \\
\hline Subsidies & - & ++ & + & + & + \\
\hline Public investment & -- & -- & & & ++ \\
\hline \multicolumn{6}{|l|}{ Revenue increases } \\
\hline Personal income taxes & - & -- & + & + & + \\
\hline Social security contributions & - & -- & - & - & \\
\hline Corporate income taxes & - & -- & + & + & ++ \\
\hline Environmental taxes & - & $+^{(\mathrm{b})}$ & - & & + \\
\hline $\begin{array}{l}\text { Consumption taxes (other than } \\
\text { environmental) }\end{array}$ & - & - & - & & ++ \\
\hline Recurrent taxes on immovable property & - & & & & + \\
\hline Other property taxes & - & & ++ & + & + \\
\hline Sales of goods and services & - & + & - & - & + \\
\hline
\end{tabular}

Note: (a) Current-account effects refer to a deficit country, and would switch sign in the case of a surplus country.

(b) This + sign reflects positive welfare effects as the long-term impact on output narrowly defined as GDP may be ambiguous.

Source: see main text and Section 3 of Appendix 2.

\section{Long-term growth effects}

21. A number of fiscal consolidation instruments can enhance the long-term level of output. Evidence suggests that, in advanced economies, reducing the size of government increases long-term output although there is clearly no consensus on what constitutes the optimal size of the public sector even from a strict efficiency point of view (OECD, 2003; Cournède and Gonand, 2006; Barbiero and Cournède, 
2013). This output-enhancing effect of reducing government spending is likely to be stronger in areas such as subsidies ${ }^{8}$ where public expenditure frequently distorts the allocation of resources in the economy. Similarly, cuts in public spending that can prompt a positive response of labour utilisation, such as in pensions, are likely to have a particularly favourable effect on the long-term level of output per capita. Reductions in public spending on unemployment benefits can also boost employment and output per capita insofar as they do not bring unemployment benefits down to a level prompting inefficient employee-job matches that could curb productivity. Cuts in disability payments can boost labour utilisation (Hagemann, 2012) although this effect will arise only insofar as workers with significant residual capacity are receiving disability assistance.

22. Some revenue measures can also contribute positively to long-term output when they promote more efficient use or allocation of services or resources that were previously inadequately priced. To the extent that their current levels correspond to under-pricing, higher user charges reduce the waste of economic resources, thereby boosting productivity and output. Better pricing the use of environmental services through taxation can lead to welfare gains through improved environmental amenities that are not measured in GDP. While, as other forms of taxation, environmental taxes reduce labour supply and the accumulation of human-made capital, they also have long-term effects that go in the direction of boosting output compared with a baseline of wasteful use of environmental capital (de Serres et al., 2010). For instance, if no action is taken, climate change can involve large losses of physical and human capital as well as reduced productivity through more frequent and intense storms, rising sea levels, additional deaths from specific diseases (e.g. malaria) and deteriorating air quality (de Serres et al, 2010). Whether the net long-term output effect is positive is ambiguous conceptually and difficult to estimate empirically especially because of the very long lags involved.

23. In contrast, other consolidation instruments can reduce the productive potential of economies. At a general level, raising the tax burden tends to reduce factor supply and long-term output (OECD, 2003; Bouis et al., 2011). Evidence on the impact of the tax structure (Johansson et al., 2008; Bouis et al., 2011) indicates that taxes on mobile or adjustable production factors affect aggregate supply with particular severity. In the present classification of instruments, personal income taxes, social security contributions and corporate income taxes fall into this category. Other taxes such as value-added or consumption taxes have proven to exert still meaningful but less strong distortionary effects (Johansson et al., 2008).

24. Spending reductions can entail potentially large long-term losses in output when they cut into areas where governments provide particularly valuable public goods or growth-enhancing services that are insufficiently produced by market forces. Empirical evidence (OECD, 2003; Sutherland and Price, 2007) suggests that cuts in public investment or government spending on education broadly fall into this category. As developed in Section 6, cuts in government investment or education that respectively focus on low-externality projects or are accompanied by education reform can have more limited, or even favourable, growth effects. However, as mentioned earlier, the simple assessment summarised in Table 2 is concerned only with plain fiscal changes without structural reform, implying a lower provision of public goods and services. Cuts in health care can also reduce output per capita by reducing labour supply and productivity. When controlling for taxes, public health spending appears to have a positive, albeit moderate, effect on output per capita (Barbiero and Cournède, 2013). ${ }^{9}$ Through its contribution to well-

8. Some categories of subsidies, however, can work in the direction of growth potential. In particular, government subsidies can encourage business research and development activities where the social rate of return exceeds the private rate of return because of cross-company spillovers (Jaumotte and Pain, 2005).

9. Although part of the empirical literature finds a negative effect of public health spending on GDP per capita, this appears to be related to the output cost of the associated taxes which the present study considers separately (see for instance Box 6.1 in OECD, 2011c). 
being, health spending is most likely to have additional positive welfare effects that are not measured in GDP.

25. Cuts in childcare can reduce output per capita primarily by depressing labour force participation (OECD, 2007). Reductions in family benefits have a more ambiguous effect on output per capita through three channels that work in opposite directions. Firstly, they can prompt greater labour market participation, boosting output per capita. Secondly, such cuts can increase child poverty (Whiteford and Adema, 2007), hampering the formation of human capital and resulting in lower long-term output per capita. Thirdly, cuts in family benefits are likely to have a negative, albeit small, effect on fertility rates (OECD, 2011b) ${ }^{10}$ Overall, the net effect of cuts in the aggregate of childcare and family benefits on longterm output per capita is most likely to be negative. Some consolidation instruments are likely to have neutral or very weak long-run effects on output. Such is the case of taxes with relatively low distortive effects, such as property taxes (Johansson et al., 2008).

\section{Short-term growth effects}

26. Most fiscal consolidation instruments are harmful for growth in the short run, but there are differences among them and a few exceptions. ${ }^{11}$ Although the vast literature on fiscal multipliers has not achieved consensus, international experience largely suggests that they are highest for public investment and government consumption and substantial but smaller for transfers and taxes (Figure 10; OECD, 2009a; Barrell et al, 2012). The main reason behind this difference is that changes in government investment and consumption affect activity directly while the effects of changes in taxes and transfers transit through the accounts of households and firms, offering greater possibilities for offset from saving behaviour. Consistent with this ranking, empirical evidence indicates that private-sector offsets from changes in government balances depend on their composition and are strongest for revenues, intermediate for spending and weakest for investment (Röhn, 2010).

10. While for about two decades a reduction in the fertility rate works in the direction of lowering the dependency ratio and boosting output per capita, in the following five to six decades it contributes to an increase in the dependency ratio with negative implications for output per capita.

11. In theory, fiscal policy changes could, under specific conditions, be expected to have no major impact on aggregate demand if households anticipate the future tax benefits from debt reduction and adjust their saving in a way that just offset the rise in public savings. In practice, given that such a Ricardian equivalence effect depends on many conditions, including the access to complete financial markets, which typically fail to hold, a significant short-term impact from consolidation on aggregate spending is generally observed (Sutherland et al., 2010) 
Figure 10. Estimates of short-term fiscal multipliers for different consolidation instruments GDP contraction from a permanent 1 percentage-point increase in the underlying primary balance, per cent

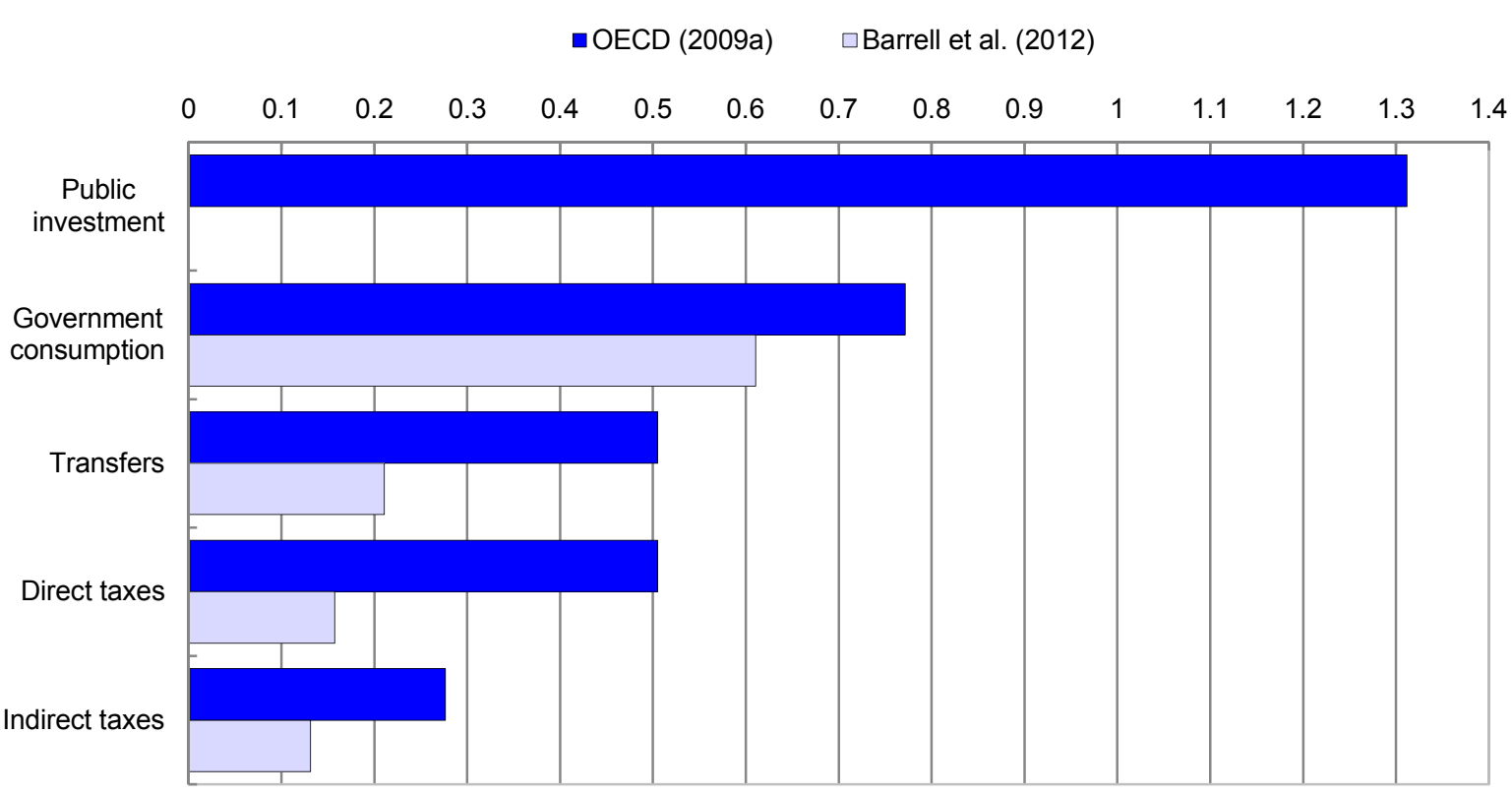

Note: the effects plotted in the chart are unweighted averages of country estimates reported in the quoted documents. The effect is averaged over the first and second years of consolidation for OECD(2009a) estimates and refers to the first year for Barrell et al.'s (2012) estimates. The simulations underlying Barrell et al.'s (2012) multipliers assume unchanged monetary policy in the year of the fiscal shock, but they incorporate the positive output effect of a fall in long-term interest rates resulting from the anticipation of a more accommodative monetary-policy path in the years following the shock. No multiplier estimate is available for public investment in Barrell et al. (2012).

27. The short-term output effects of instruments will depend on their design. In most cases, this design dependence does not preclude a broad assessment of their effect, but as far as cuts in pension spending are concerned, even the direction of the impact can change depending on how they are implemented. If cuts fall on current pensioners, they correspond to a reduction in transfers and are likely to affect output with a similar multiplier. In contrast, if pension spending is cut by raising the retirement age including for workers close to this age when the change is implemented, some positive demand effects are possible (Kerdrain et al., 2010) at the same time as supply expands, with an ambiguous net effect on the degree of economic slack.

28. In countries that are experiencing confidence crises because of their fiscal positions, the estimated multipliers reported above, which are calculated as historical averages, may not apply to their current circumstances. In fiscal-crisis countries, the absence of consolidation could translate into a massive loss of confidence triggering economic collapse. If it helps avoiding such extreme counterfactual scenarios, consolidation may be highly expansionary. There is also a possibility that, in such circumstances, different instruments may have different expansionary effects, notably by signalling the degree of determination of public authorities and thereby the likelihood that consolidation may be maintained. In particular, cuts in spending areas that raise serious political-economy challenges, such as subsidies, has been found to increase the probability of large consolidations to be successful (Molnar, 2012). There is however no consensus on the existence of these potential expansionary effects of consolidation, on their strength, on measuring when they may apply and how they may differ across instruments at a disaggregated level. For these reasons, these potential expansionary effects are not integrated in the assessment but should be seen as caveats regarding the extent to which the summary assessment presented in Table 2 applies to actual or potential crisis countries. 


\section{Effects on equity ${ }^{12}$}

29. Many consolidation instruments work in the direction of aggravating income inequality (Table 2). Transfers in particular have strong redistributive power so that cuts in benefits are generally regressive, , perhaps with the exception of public pensions where the equity effect is likely to be muted in countries where they are based on earned income and close to actuarial neutrality. Reducing the provision of public services likewise contributes to increasing inequality in effective consumption (OECD, 2011d). ${ }^{13}$ Also, a number of taxes fall more heavily on lower-income households, with the implication that increasing them would raise disposable income inequality.

30. Some fiscal consolidation instruments, on the other hand, can reduce income or wealth inequality. Such is particularly the case of hikes in inheritance and capital gains taxes, which the classification used in the present study includes among "other property taxes". ${ }^{14}$ Increasing taxes that are typically designed to be progressive, such as personal income taxes, or concentrated on capital income, such as corporate income taxes, also goes in the direction of reducing disposable income inequality. . The same holds for hikes in revenue instruments that are concentrated on capital income such as corporate income taxes (although some of their burden also falls on labour).

31. The equity implications of fiscal consolidation instruments can also evolve as behaviour responds to fiscal changes. Cuts in unemployment insurance payments, disability benefits or other social assistance programmes that are partly used as a way of withdrawing from the labour market can over time foster greater labour force participation. Since labour income tends to be greater than benefit payments, the supply response will work over time to reduce the regressive impact of cuts. On the tax side, environmental taxes, although they tend to be regressive in the short term, provide benefits that accrue in priority to lowincome groups as those are more exposed to environmental degradation (Serret and Johnstone, 2006). Some of these effects, such as better health allowing greater labour supply, are reflected in higher measured income. Other often lagged effects such as improved well-being from better environmental conditions are not reflected in income distribution data. Consumption taxes, which are regressive in the short term because low-income households save a smaller share of their income than better-off ones, are neutral in a lifetime perspective taking into account the period when former savers spend what they previously accumulated. Finally, the redistributive benefits of some consolidation measures can wane over time as individuals put in place effective avoidance strategies as appears to be the case for inheritance taxes (Kopczuk, 2007).

12. The assessment of the effect of instruments on income inequality draws largely on OECD (2012) and Rawdanowicz et al. (2013).

13. The study however incorporates no assessment of the impact of public investment on inequality. At a conceptual level, the effect is ambiguous. By providing the basis for public capital services that are consumed without relation to income, public investment should promote equality in effective consumption. On the other hand, inasmuch as public capital is complementary to private capital and boosts returns on capital, it could work in the direction of exacerbating income inequality because of the concentration of control over private capital. While there is evidence in favour of net equality-enhancing effects of public investment in developing countries, there are no comparable findings for OECD countries.

14. No positive or negative assessment is included for real estate taxes because of a lack of clear evidence. In most OECD countries, lower-income households pay a higher share of their income in recurring property taxes than higher income taxes, so that on this count recurring property taxes might be described as regressive. However, this situation largely reflects larger home ownership among retirees, implying that recurring property taxation is not necessarily regressive in a dynamic perspective, and may even be progressive if adjusting income fully for the market value of owner-occupied housing services. 


\section{Short- to medium-term effects on the current account}

32. At a broad level fiscal consolidation works to push the current account towards a surplus over the short to medium term, but different instruments can have different effects depending on how they shape private saving and investment decisions. The impacts of individual consolidation instruments over and above the general macro-economic effect are assessed based on the results reported in Kerdrain et al. (2010). Reductions in health care spending and in unemployment or disability benefits are likely to strengthen the current account through increased precautionary saving, whereas cutting pension benefits should lead to higher saving by the working-age population to smooth consumption over the life cycle. An increase in corporate taxation could improve the current account through lower investment (Schwellnus and Arnold, 2008; Vartia, 2008). Higher consumption taxes tend to penalise imports relative to exports, and thus may temporarily strengthen the current account, while the opposite holds for social security contributions.

\subsection{A generic hierarchy of instruments}

33. Based on the estimated impacts reported above, a generic hierarchy of consolidation instruments can be established (Figure 11). This is done simply by putting the same weight on each objective, assigning numerical values to the pluses and minuses and using the resulting scores to rank the instruments. The generic hierarchy puts no weight on the current-account because the pursuit of global rebalancing operates in opposite ways depending on the sign of the imbalance and not at all in countries that have broadly balanced positions. Instead, current-account effects enter at a more country-specific level (see further below).

34. A long-term variant of the generic hierarchy can also be established for the purposes of looking solely at very long-term consolidation strategies by considering only to long-term growth and equity effects, with equal weights. In this long-term variant, the instruments follow this ranking: 1) Subsidies, 2) Pensions, 3) Other government consumption, Unemployment benefits, Environmental taxes and Other property taxes, 7) Sickness and disability payments, Recurrent taxes on immovable property and Sales of goods and services; 10) Consumption, Personal income and Corporate income taxes; 13) Public Investment, Health services; 15) Family policy and Social security contributions; 17) Education.

35. Figure 10 also illustrates the sensitivity of instrument ranking to different weighting schemes and to uncertainty about the assessment of effects. When changing the weights attributed to objectives, a certain degree of sensitivity is indeed observed as instruments score differently across objectives, but the ranking of most instruments remains broadly stable in particular at both ends of the spectrum (Figure 11A). Similar robustness is observed when modifying the assessment of effects, even though the changes applied are strong, being equivalent to adding or withdrawing one plus or one minus sign in a full column of Table 2 (Figure 11B). Even combining these two sources of uncertainty leaves the ranking broadly stable, especially at both ends of the hierarchy (Figure 11C). Reductions in subsidies and in pension spending as well as increases in other property taxes come out robustly as preferred consolidation instruments. At the lower end, spending cuts in the areas of education, health care and family policy, as well as hikes in social security contributions, appear as particularly unfavourable in terms of generating adverse side effects for growth and equity. In contrast, the middle part of the ranking is more fluid. 
ECO/WKP(2013)80

Figure 11. A possible generic hierarchy of consolidation instruments and its sensitivity to assumptions

A. Sensitivity to uncertainty about the weights given to objectives

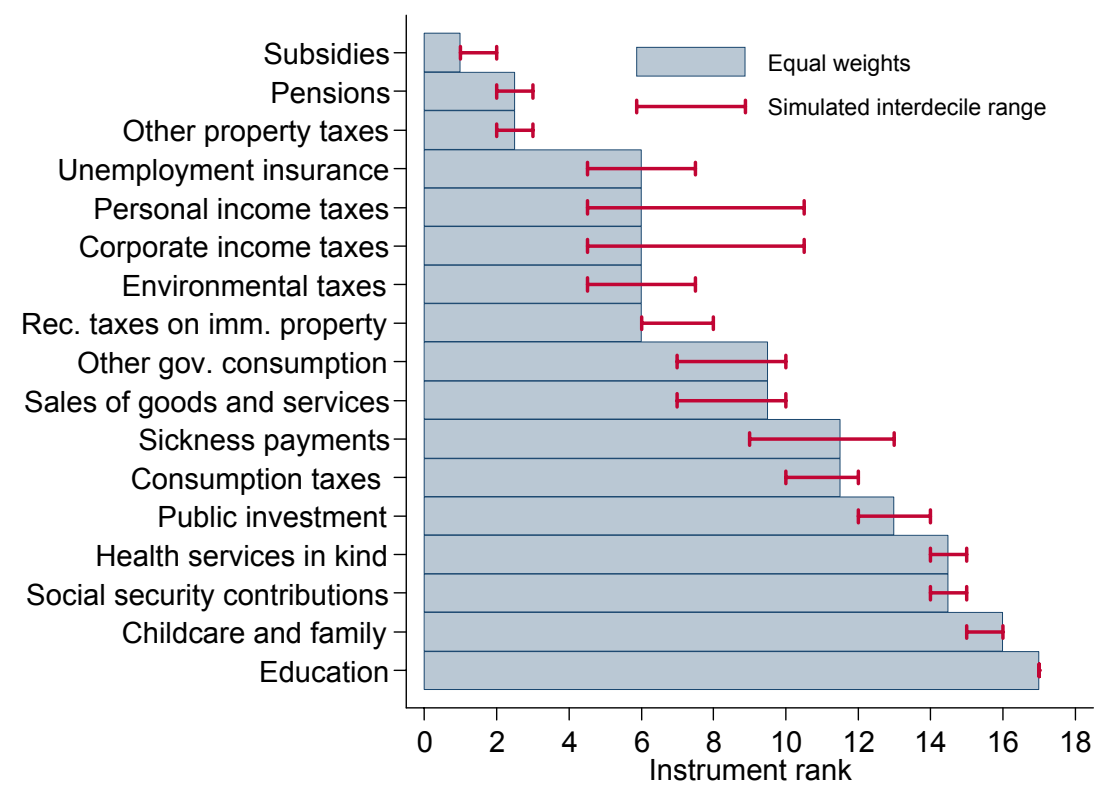

Note: The rankings are based on the assessment in Table 2 . Scores of +1 and -1 are given to each + and- signs respectively, each objective (except the current account) is given a weight, and the resulting indicator is used to rank instruments. Weights ranging each from 0.15 to 0.55 and summing to unity have been given to each objective in 10,000 random draws. Weights have been restricted to no smaller than 0.15 because each objective is considered important.

B. Sensitivity to uncertainty about the assessment of instruments (pluses and minuses) in Table 2

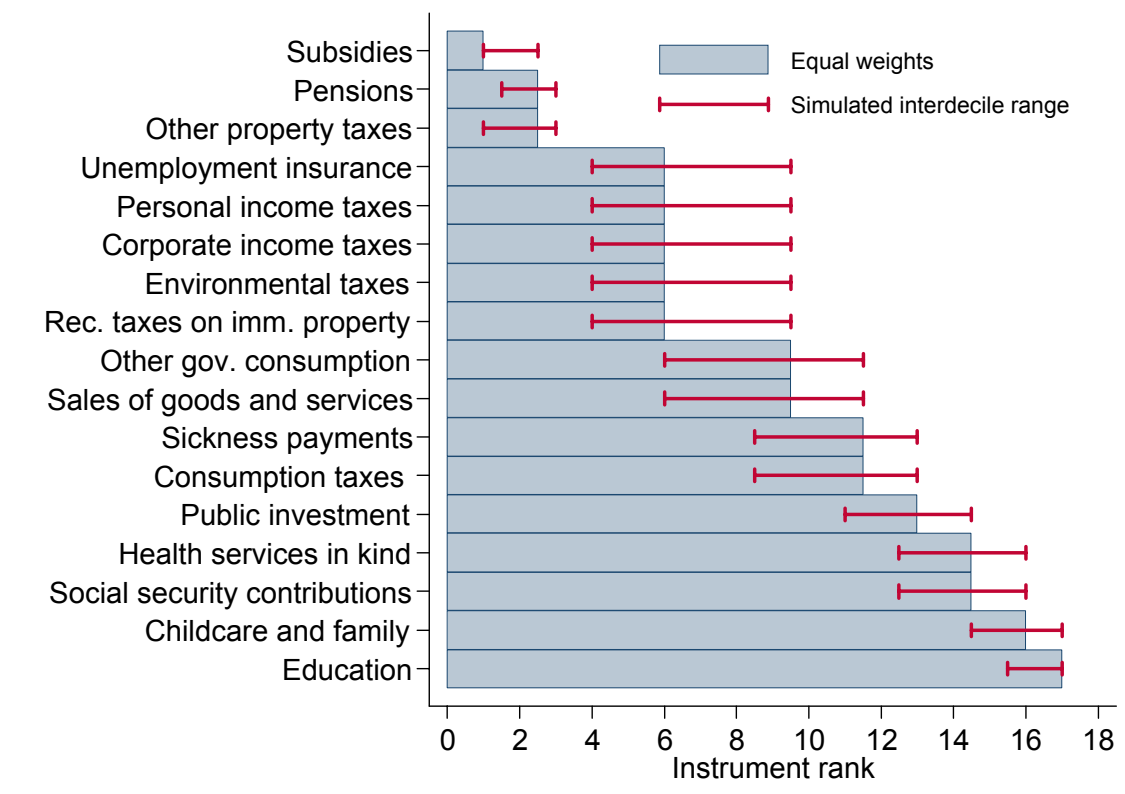

Note: The rankings are based on Table 2. Scores of +1 and -1 are given to each + and- signs respectively, each objective (except the current account) is given a weight of one quarter, and the resulting indicator is used to rank instruments. Each individual instrument score along each objective shown in Table 2 is kept with a probability of $3 / 4$ or increased by +1 with a probability of $1 / 8$ or reduced by -1 with a probability of $1 / 8$ using in 10,000 random draws. 
Figure 11. A possible generic hierarchy of consolidation instruments and its sensitivity to assumption (continued)

C. Sensitivity to joint uncertainty about weights and assessments

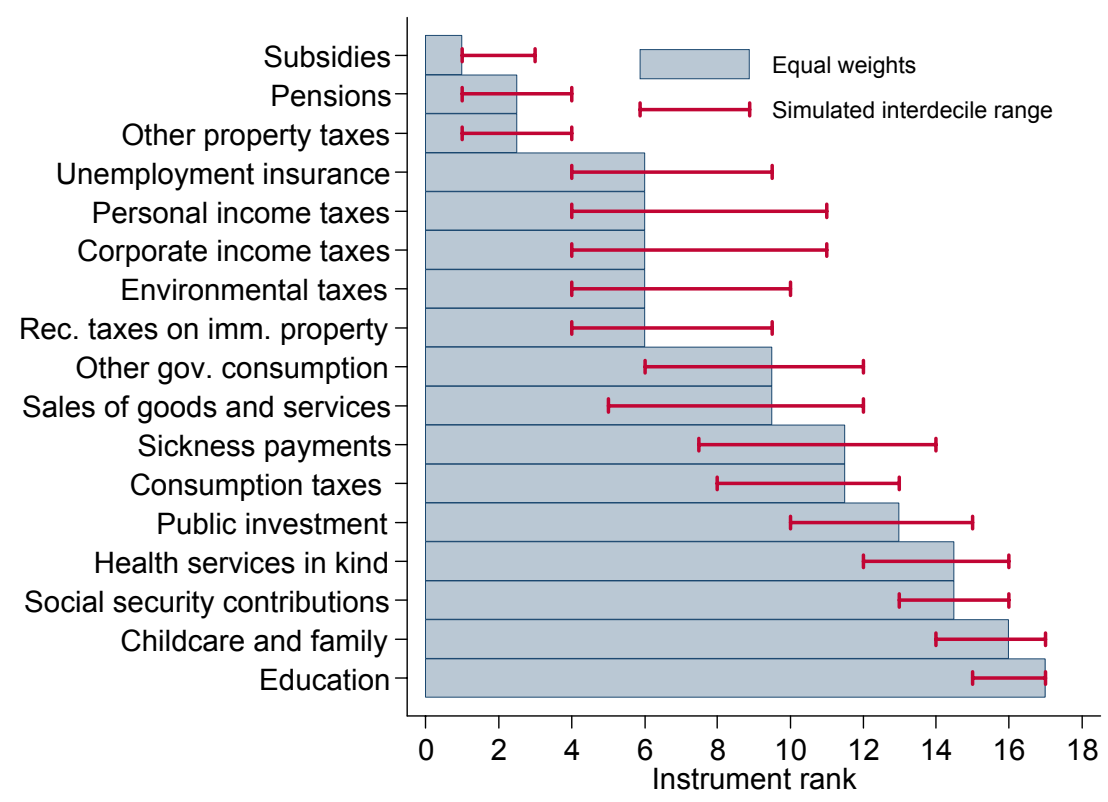

Note: The rankings are based on the assessment in Table 2 . Scores of +1 and -1 are given to each + and- signs respectively, each objective is given a weight, and the resulting indicator is used to rank instruments. Each individual instrument score based on the assessment in Table 2 is kept with a probability of $3 / 4$ or increased by +1 with a probability of $1 / 8$ or reduced by -1 with a probability of $1 / 8$. Weights ranging each from 0.15 to 0.55 and summing to unity have been given to each objective. Weights have been restricted to no smaller than 0.15 because each objective is considered important. A total of 40,000 random draws have been made.

36. In addition to the arbitrary nature of the scoring and weighting scheme, considerable caveats surround the rankings above. They are based on an assessment of equity and growth effects of consolidation instruments which is drawn primarily from studies that estimate average effects in historical experience across countries. In practice, however, the growth and equity effects of instruments vary across countries: for instance, cutting investment in new roads in a country where highway density is already high should be less harmful to long-term growth than in a country with severe infrastructure gaps. Taking this cross-country variation into account is beyond the scope of this study, but it nonetheless goes beyond a pure one-size-fits-all approach. More specifically, the economic and social situation of countries in need of consolidation is taken into account by changing the weight of the different objectives, as is developed below. Also, the way in which the room for manoeuvre is evaluated for each instrument takes into account whether or not the level of taxation or spending in this area is particularly high in the country under consideration.

\section{Adjusting instrument rankings for country circumstances over the short to medium term}

37. The generic hierarchy is adapted to country-specific circumstances by adjusting the weights put on growth, equity and global rebalancing objectives. Summary indicators are defined for each of the growth, equity and current account dimensions, and then used to compare country situations and form country groups. This makes it possible to derive a set of weights for each group and therefore a hierarchy of instruments for each group. While technically feasible, a country-specific ranking of instruments would give a false impression of accuracy with respect to country-specific instrument impacts and risk obscuring the substantial uncertainties and error margins of the exercise. 
38. The group-specific rankings derived here will guide the choice of instruments for short- to medium-term consolidation efforts in the illustrative simulations. In the long run, however, a single hierarchy of instruments (presented in Section 3) is assumed to apply. As further addressed below, this is because some of the dimensions taken on board to form country groups lose relevance as the time horizon expands (e.g. short-run growth and current account imbalances), while a solid basis is absent for giving differentiated weights to long-run growth impacts.

\subsection{Characterising country circumstances}

\section{Short-run growth}

39. This study attaches different weights to the short-run growth impacts of fiscal retrenchment depending on the degree of cyclical weakness faced by countries and their vulnerability to hysteresis. ${ }^{15} \mathrm{~A}$ deeper negative output gap makes any short-run output losses from consolidation more painful, especially if fiscal multipliers of the Keynesian kind have become larger under such circumstances. Indeed, some recent studies find multipliers to be larger in recessions than expansions (Auerbach and Gorodnichenko, 2012; Baum et al., 2012), particularly in a context of financial crisis with monetary policy constrained by the zero nominal interest rate bound (IMF, 2010; Christiano et al., 2011; Corsetti et al., 2012). In turn, hysteresis effects could translate short-run slack into permanently lower levels of potential output through channels such as higher structural unemployment and a smaller capital stock (Bouis et al., 2012).

40. The degree of openness also has an influence on the magnitude of multipliers. The well-known inverse relationship between trade openness and multiplier size (OECD, 2009) could be invoked to give a lower weight to short-run growth impacts in more open economies. However, this would ignore the stronger negative spillover effects on partners' output that fiscal consolidation in those economies will tend to exert (Goujard, 2013). Consistent with ruling out a beggar-thy-neighbour approach to fiscal consolidation, the impact of openness on fiscal multipliers is therefore not taken into account.

41. The average of two variables, the output gap in 2012 and the 2007-2012 percentage point change in the long-term unemployment rate, is used as a synthetic indicator of how different countries fare on the counts above. Long-term unemployment is used as proxy of vulnerability to hysteresis, since it is a key variable in the transmission of short-run labour market slack to structural unemployment (Guichard and Rusticelli, 2010). It is taken in changes (and not levels) so as to capture impacts from the current crisis rather than pre-existing structural characteristics, which are better addressed through structural reforms in labour markets, as well as in product markets and tax and welfare systems.

\section{Long-term growth}

42. Assessing for which countries fiscal policy needs to be more supportive of long-run growth, with a concomitantly larger weight given to this objective, would be a hazardous task. Using weaker growth prospects as an argument for a larger weight runs into the difficulty that long-term growth projections are inevitably fraught with uncertainty and depend to a significant degree on policy assumptions in a wide range of areas, such as education, retirement age or product market and trade regulations (Johansson et al., 2013). The long-term growth impacts of fiscal consolidation instruments are therefore deemed equally important for all countries.

15. Besides affecting the choice of fiscal instruments, short-run growth impacts also have important implications for the optimal pace and timing of consolidation, an issue from which this paper largely abstracts and for which the reader is referred for instance to Rawdanowicz (2012). 


\section{Income distribution}

43. The impacts of fiscal instruments on income distribution arguably gain increased prominence in more unequal countries. The links between inequality, growth and welfare are admittedly complex, and, to some extent, inequality differences across countries are rooted in social preferences, so that strong opposition to regressive changes might arise at comparatively low levels of inequality in strongly egalitarian societies. Still, beyond certain levels, inequality, and particularly poverty, may be bad for growth. Channels of transmission of inequality's detrimental effects include hampered investment in human capital, an area where inequalities can be self-perpetuating (Causa and Johansson, 2009; Hoeller et al., 2012). The Gini coefficient and the poverty rate (defined as income below $60 \%$ of the median) are combined into one indicator to summarise where countries stand as regards inequality. While the Gini coefficient encapsulates the whole income distribution, the poverty rate focuses on the lower tail. These two variables are computed after taxes and cash transfers, thus reflecting both the direct (on disposable incomes) and indirect (on market incomes) impacts of those fiscal tools on income distribution, though not the direct impact (on effective consumption) of in-kind transfers.

\section{Current account balance}

44. Addressing significant external imbalances is also a widely shared objective of economic policy (G20, 2009), which calls for taking account of the current account impacts of different budget items when designing consolidation strategies. Imbalances carry risks for the individual countries concerned (the prospect of a hard landing for debtors, or growing credit risk for surplus countries), all the more so when they are particularly large, but also for the global economy (OECD, 2012). National positions are characterised on the basis of estimates of cyclically-adjusted current account balances, which correct headline balances for the difference in output gaps between countries (Ollivaud and Schwellnus, 2013): a country facing a deeper downturn than its trading partners will temporarily tend to post a headline current account stronger than the adjusted one, as imports become more depressed than exports. The summary indicator used is the average of two variables: adjusted current account balances in 2012 as percentages of both national and OECD GDP. The ratio of the cyclically adjusted current-account balance to OECD GDP, which captures the absolute size of imbalances, serves a proxy for their global implications which countries are assumed to internalise as part of the global rebalancing agenda.

\section{Box 3. Forming country groups and deriving group-specific weights for objectives}

Country groups capturing similarities along three dimensions (short-term growth, equity and the current account) are derived from a hierarchical cluster analysis based on the three summary indicators discussed in the text, with squared Euclidean distance to measure differences between groups, and a k-means algorithm used in a second stage to minimise the distance of each country to its cluster centre. The several variables used to characterise country circumstances as well as the ensuing summary indicators (repeated below for ease of reference) have all been normalised (i.e., set to zero mean and unit standard deviation) so that scale differences do not affect results:

- $\quad$ Short-term growth concerns have been summarised by the average of the output gap in 2012 and the 20072012 percentage point change in the long-term unemployment rate;

- Equity concerns by the average of the Gini coefficient and the $60 \%$-threshold poverty rate (both applied to measures of household income after taxes and transfers) at the end of the 2000s;

- And current account disequilibria by the average of cyclically-adjusted current account balances in 2012 as a percentage of, respectively, national GDP and of OECD GDP.

The three coordinates of each cluster centre (one for each of the three summary indicators) have then been used to derive cluster-specific weights for short-term growth, equity (where the derived weight is applied to both the short 
and the long term) and the current account (as explained in the main text, the weight of the long-term growth objective is preset at a uniform 0.25 for all country groups).

These weights are derived in two steps. First, since weights cannot be negative, the cluster centre coordinates are transformed into values in the $[0,1]$ interval while preserving their ordering (from smallest to largest). This is done for each summary indicator by fitting a logistic cumulative distribution function $(F)$ to the coordinates $(x)$ of the several cluster centres. The current account summary indicator has been handled differently, both to treat in a symmetric way deficits and surpluses, and to focus on large rather than small imbalances: $F$ has been fitted to the log of the indicator's absolute value, and the smaller ensuing $F(x)$ values have been reset to zero (in clusters comprising up to half of the total number of countries under analysis).

Second, the three $F(x)$ values obtained for each cluster have been renormalised, so that weights for each cluster add up to one. More precisely, for cluster $c$, the weights of the four dimensions, $d=1, \ldots, 4$ (counting short-term and long-term equity separately) are derived from the $F\left(x_{c d}\right)$ values (again, using twice the $F(x)$ value for equity) so as to sum to 0.75 (one minus the weight of long-term growth):

$$
w_{c d}=\frac{3}{4} \times \frac{F\left(x_{c d}\right)}{\sum_{i=1}^{4} F\left(x_{c i}\right)}
$$

The ensuing weights $(w)$ are displayed in Table 3. It should be borne in mind that weights compare the relative importance of the several dimensions considered within a cluster, but not across clusters. It is therefore possible that a cluster with pressing concerns on several fronts (like clusters no. 2 and 3) will display smaller weights for some objectives than a cluster where those same objectives, though less problematic in a cross-cluster comparison, are the sole concern which stands out (such as short-term growth in cluster no. 4).

\subsection{Hierarchies of instruments for groups of countries}

45. A cluster analysis has been performed to identify groups of countries that share similar characteristics regarding short-term growth, equity and external imbalances (Box 3). Based on the summary indicators discussed above, five clusters have been identified:

1. The first cluster is formed by eleven geographically dispersed countries (Australia, Canada, Estonia, Israel, Italy, Japan, Korea, New Zealand, Poland, Portugal and the United Kingdom), which mainly have in common above-average levels of inequality. Short-term growth risks are generally moderate (Italy and Portugal being exceptions) and current account positions, though with considerable heterogeneity, do not include cases of extreme imbalances and are on average fairly close to balance.

2. The United States finds itself alone in the second cluster, as the sheer absolute size of its current account deficit places it at a considerable distance even from other deficit countries. Inequality is high and cyclical developments carry potentially substantial hysteresis risks although the materialisation of these risks would run counter to historical experience.

3. The third cluster comprises three euro area members from the geographical periphery (Greece, Ireland and Spain) sharing very high cyclical slack and hysteresis risks. Greece and Spain (but not Ireland) also display above-average inequality and large underlying external deficits.

4. A fourth cluster is formed by eleven European countries: Austria, Belgium, the Czech Republic, Denmark, Finland, France, Hungary, Iceland, Norway, Slovakia and Slovenia. It is the most egalitarian cluster. As in the first group of countries, current account imbalances are on average 
small, though with significant intra-group heterogeneity ${ }^{16}$, and short-term growth risks are generally moderate.

5. The fifth and final cluster comprises five countries, Germany, Luxembourg, the Netherlands, Sweden and Switzerland, all with large current account surpluses. Inequality levels are belowaverage and short-term growth vulnerability risks are among the lowest in the OECD.

46. For each of these clusters, specific weights are calculated for the short-term growth, equity and current-account objectives (Table 3). The weights depend on the degree to which each objective is relevant for the cluster as a whole in comparison with the other objectives (but do not compare the importance of each objective across different clusters of countries). For instance, short-run growth will attract a strong weight in groups of countries where cyclical weakness and hysteresis risks -- whether very high in themselves (cluster 3) or only moderate (cluster 4) -- are clearly a more important concern than equity or current account issues. Similarly, the high weight attached to the current account objective in cluster 5 stems from the contrast between large surpluses and mostly benign short-term growth and equity outlooks. As mentioned above, the same weight $(25 \%)$ is given to long-term growth in all clusters. These clusterspecific weights are used to aggregate the pluses and minuses reported in Table 2 after converting them into numerical values, give scores to instruments and rank them.

Table 3. Weights put on the growth, equity and current account dimensions across groups of countries

\begin{tabular}{|c|c|c|c|c|c|c|}
\hline \multirow{2}{*}{ Cluster } & \multirow{2}{*}{ Countries } & \multicolumn{2}{|c|}{ Growth } & \multicolumn{2}{|c|}{ Equity } & \multirow{2}{*}{$\begin{array}{c}\begin{array}{c}\text { Current } \\
\text { account }\end{array} \\
\text { short-term } \\
\end{array}$} \\
\hline & & short-term & long-term & short-term & long-term & \\
\hline 1 & $\begin{array}{l}\text { Australia, Canada, Estonia, Israel, Italy, } \\
\text { Japan, Korea, New Zealand, Poland, } \\
\text { Portugal, United Kingdom }\end{array}$ & 0.13 & 0.25 & 0.30 & 0.30 & 0.01 \\
\hline 2 & United States & 0.13 & 0.25 & 0.21 & 0.21 & 0.20 \\
\hline 3 & Greece, Ireland, Spain & 0.29 & 0.25 & 0.18 & 0.18 & 0.10 \\
\hline 4 & $\begin{array}{l}\text { Austria, Belgium, Czech Republic, } \\
\text { Denmark, Finland, France, Hungary, } \\
\text { Iceland, Norway, Slovak Republic, } \\
\text { Slovenia }\end{array}$ & 0.47 & 0.25 & 0.14 & 0.14 & 0.00 \\
\hline 5 & $\begin{array}{l}\text { Germany, Luxembourg, Netherlands, } \\
\text { Sweden, Switzerland }\end{array}$ & 0.12 & 0.25 & 0.15 & 0.15 & 0.33 \\
\hline
\end{tabular}

47. Table 4 displays the ensuing cluster-specific instrument rankings. Rank variation across country groups is smallest for those instruments that have similar impacts on virtually all objectives, such as education, subsidies or property taxes, and widest for instruments with the sharpest trade-offs between growth, equity and the current account. For instance, personal and corporate income taxes come out as good candidate instruments for cluster 1 , where equity objectives carry a high weight, but much less so for countries such as those forming clusters 4 and 5 where relatively equal income distribution is assumed to lead to less emphasis on outcomes in this area. In the cluster 5, the ranking of corporate income tax hikes is brought down further by their likely detrimental effects on investment which complicate external surplus

16. As is well known, Norway has a huge current account surplus (17.4\% of 2012 GDP in cyclically-adjusted terms). However, unlike other surplus countries, this is largely due to the exploitation of finite natural resources (fossil fuels). As the Norwegian external position reflects exceptional circumstances, it has not been taken into account when forming clusters, and Norway has been treated as if it had a balanced current account. 
reduction. In contrast, increases in social contributions move up a few ranks due to their effect that goes in the direction of reducing current account surpluses via labour costs. Short-term growth impacts do not vary considerably across instruments (as there are no positive effects) and are therefore a less powerful determinant of rank variation. Their influence is nonetheless visible, for instance in the lower position of other government consumption in clusters 3 and 4 where short-term contractionary effects carry more weight.

Table 4. Possible hierarchies of consolidation instruments for groups of countries

\begin{tabular}{|c|c|c|c|c|c|c|c|}
\hline \multirow{2}{*}{ Instruments } & \multirow{2}{*}{$\begin{array}{l}\text { Generic } \\
\text { ranking }\end{array}$} & \multicolumn{5}{|c|}{ Cluster-specific ranking } & \multirow{2}{*}{$\begin{array}{l}\text { Long-term } \\
\text { ranking }\end{array}$} \\
\hline & & 1 & 2 & 3 & 4 & 5 & \\
\hline Subsidies & 1 & 1 & 1 & 2 & 2 & 1 & 1 \\
\hline Pensions & $2-3$ & 3 & 2 & 1 & 1 & 3 & 2 \\
\hline Other property taxes & $2-3$ & 2 & 3 & 3 & 3 & 2 & $3-6$ \\
\hline Unemployment benefits & $4-8$ & 7 & 4 & 4 & 4 & 9 & $3-6$ \\
\hline Personal income taxes & $4-8$ & 5 & 8 & 9 & $9-10$ & 8 & $10-12$ \\
\hline Corporate income taxes & $4-8$ & 4 & 5 & 7 & $9-10$ & 12 & $10-12$ \\
\hline Environmental taxes & $4-8$ & 8 & 6 & 5 & 4 & 4 & $3-6$ \\
\hline Recurrent taxes on immovable property & $4-8$ & 6 & 7 & 6 & 6 & 5 & $7-9$ \\
\hline Other government in kind consumption & $9-10$ & 9 & 9 & 11 & 11 & 6 & 3-6 \\
\hline Sales of goods and services & $9-10$ & 10 & 10 & 8 & 7 & 7 & $7-9$ \\
\hline Sickness and disability payments & $11-12$ & 13 & 11 & 10 & 8 & 11 & $7-9$ \\
\hline Consumption taxes (other than environmental) & $11-12$ & 11 & 12 & 12 & 12 & 13 & $10-12$ \\
\hline Public investment & 13 & 12 & 13 & 13 & 15 & 15 & $13-14$ \\
\hline Health services provided in kind & $14-15$ & 14 & 14 & 14 & 16 & 16 & $13-14$ \\
\hline Social security contributions & $14-15$ & 15 & 16 & 15 & 13 & 10 & $15-16$ \\
\hline Family & 16 & 16 & 15 & 16 & 14 & 14 & $15-16$ \\
\hline Education & 17 & 17 & 17 & 17 & 17 & 17 & 17 \\
\hline
\end{tabular}

Note: The rankings are based on the assessments in Table 2 with scores of +1 and -1 given to each + and - signs, respectively, and weights taken from Table 3 . The current account scores of Table 2 switch sign for surplus clusters. The long-term ranking in the final column is based on equal weights given to impacts on long-term growth and equity. Cluster 1 regroups Australia, Canada, Estonia, Israel, Italy, Japan, Korea, New Zealand, Poland, Portugal and the United Kingdom. Cluster 2 includes only the United States. Cluster 3 comprises Greece, Ireland and Spain. Cluster 4 is formed by Austria, Belgium, the Czech Republic, Denmark, Finland, France, Hungary, Iceland, Norway, Slovakia and Slovenia. Cluster 5 is made up by Germany, Luxembourg, the Netherlands, Sweden and Switzerland.

\subsection{Robustness of country-specific rankings to the choice of a clustering technique}

48. While there is something intrinsically mechanical to the derivation of weights from a mathematical clustering technique, the ensuing instrument hierarchies are reasonably robust to shocks to weights as suggested by the relative stability of the ranking plotted in Panel B of Figure 11. This robustness has been checked further in a variant exposed in Section 5 of Appendix 2: countries have been divided in three groups solely on the basis of their current account positions and equal weights have been given to each objective within each group. The instrument hierarchies that result from this alternative weighting scheme are very highly correlated with the clustering-based ones plotted in Table 4: the rank correlations between alternative and clustering-based hierarchies are greater than $93 \%$ in all clusters except Cluster 4 where it is $89 \%$.

\section{How far down instrument rankings do countries need to go? Some illustrative simulations}

49. In this section simulations are performed to investigate how far down instrument rankings countries may need to go in order to meet their consolidation needs. Countries are assumed to implement budget tightening according to the relevant instrument ranking, i.e., to start by adjusting the most beneficial 
(or least detrimental) instrument and only proceed down the list after exhausting the estimated room for manoeuvre available in the preceding instrument. In practice, implementing this approach would raise political-economy challenges: the top ranking instruments tend to be either streams of spending accruing to politically powerful constituencies, such as subsidies or pensions, or forms of taxation where planned increases often meet with strong resistance, such as property taxes. Nevertheless, it may still provide a useful benchmark for considering a consolidation strategy.

50. The analysis is conducted separately for the short to medium term and for the long term, and requires three building blocks, themselves differentiated according to the respective time dimension: i) estimated consolidation needs for both horizons, as presented in section 2; ii) a hierarchy of instruments, which is common to all countries in the long run simulation (as presented in section 3 ) but varies across clusters in the short to medium term (Table 4 and Section 4); iii) estimates of the available margin for adjustment in each instrument, which is discussed next.

\subsection{Room for manoeuvre in instruments}

51. Although it is an important building block when drawing up an illustrative consolidation plan, estimating the room for manoeuvre for each policy instrument - or, put differently, the margin of feasible adjustment - is necessarily judgemental. As such, it can only be done in an indicative and approximate way that is to some degree arbitrary. In a cross-country setting, it is impossible to fully account for the economic circumstances, social preferences and institutions which, in each country, shape the relative size of budget items. At one extreme, it could be assumed that the current structure of budgets already equalises the marginal costs and benefits of adjusting the different instruments (whose growth and equity impacts vary across countries, as acknowledged above), and is therefore optimal. If so, consolidation should be pursued, at least at the beginning, through a proportional adjustment of budget items. At another extreme, the budget structure status quo, hard to change as it may be, could be viewed as the suboptimal outcome of political and institutional distortions, the correction of which would require sweeping changes. For instance, it could be the case that property taxes should be increased further even in countries where they are already high by international comparison.

52. This exercise attempts to strike a balance between the above considerations by assuming that there is some margin, albeit limited, to scale back expenditure items that are large relative to a significant number of other OECD countries and similarly to increase revenue streams that are relatively low. One reason for not pushing adjustment along each individual item too far is that the positive and negative assessments underpinning the rankings can be expected to be most reliable in relatively standard situations. The effects may change if adjustment along one item takes a country to a more extreme situation. For instance, up to a point reducing spending on unemployment benefits improves incentives to take up a new job and boosts long-term output through higher employment, but if cuts are pushed too far they can impair the quality of labour market matches and harm output through lower productivity while also resulting in insufficient macroeconomic stabilisation. On the tax side, marginal rate increases from a high starting point are more distortive than from a low-rate baseline. At the same time, social preference and political feasibility considerations call for putting an upper bound on the amount of change to any spending cuts (tax hikes) in a given item, no matter how high (low) the departure point is.

53. In operational terms, simulations assume that room for manoeuvre exists in a revenue instrument if a country is below the 66th percentile in the cross-country distribution of cyclically adjusted receipts from this instrument as a share of potential GDP. In other terms, there is room to increase a given tax if one third of OECD countries raise more income, relative to potential GDP, with this tax. Similarly, room for manoeuvre on the spending side exists if a country is above the $33^{\text {rd }}$ percentile in the cross-country distribution of cyclically-adjusted spending on this instrument as a share of potential GDP. The room for manoeuvre is given in the general case by $i$ ) the gap between the value in the country under consideration 
and the $66^{\text {th }}$ or $33^{\text {rd }}$ percentile or by ii) the standard deviation of the cross-country distribution of the instrument at hand, whichever is smallest (Box 5). It turns out that this simulation design imposes only a moderate degree of convergence in budget structures across countries (Section 5.3).

54. A few additional adjustments have been made to improve comparability and minimise the mechanical nature of the simulations (Box 5):

- Spending on pensions, education and unemployment benefits as a share of potential GDP has been corrected for the number of potential beneficiaries, defined in terms of age cohorts or labour market status. For instance, this acknowledges that, all else equal, a higher rate of structural unemployment implies a smaller room for manoeuvre in reducing the unemployment benefits bill.

- Further to the above correction, a special adjustment is made to reduce the available room for cuts in pension spending to acknowledge that the baseline already incorporates significant effort. More specifically, the room for manoeuvre is set at the standard deviation of the cross-country distribution minus the projected increase until 2060 in government pension expenditure on unchanged policies (Figure 4). This increase is taken as an estimate of the implicit effort in keeping baseline pension spending constant as a share of potential GDP. In the short to medium term, the room for manoeuvre is set at a quarter of its long-run value, as the budget savings yielded by most measures (e.g. raising the retirement age, or lowering the replacement rate for new retirees) will only accrue gradually over time.

- Leeway for raising personal income tax and social security contributions is assessed on the basis of the cross-country distribution of their sum, taking account of the wide heterogeneity across countries in the balance between those two revenue items which are often largely substitutes. For instance, a country that raises very low amounts of social contributions may nevertheless have little room for manoeuvre along this instrument if it has very high personal income taxation, as is the case in Denmark.

\section{Box 4. Simulation design: details on instrument adjustment}

This box sets out in more detail the rules governing the use of fiscal instruments in simulations. It is assumed that country $i$ has some room for manoeuvre $(R M)$ in revenue item $T$ when its value $T_{i}$ (adjusted for the cycle and one-offs and taken as a percentage of potential GDP) stands below the cross-country $66^{\text {th }}$ percentile for that item $\left(T^{P 66}\right)$. Room for manoeuvre is then given by the minimum of the cross-country standard deviation $\left(\sigma_{T}\right)$ and the gap to the $66^{\text {th }}$ percentile $\left(T^{P 66}-T_{i}\right)$, except if the latter falls below a certain threshold, in which case a minimum scope for adjustment (set at a quarter of the standard deviation) is admitted. This tries to avoid cases of either implausibly large or pointlessly small instrument adjustment. Formally:

$$
R M_{i}(T)=\left\{\begin{array}{c}
\min \left[\sigma_{T}, \max \left(T^{P 66}-T_{i}, \sigma_{T} / 4\right)\right], T_{i}<T^{P 66} \\
0, T_{i} \geq T^{P 66}
\end{array}\right.
$$

On the spending side, room for manoeuvre exists when the country value $\left(G_{i}\right)$ exceeds the $33^{\text {rd }}$ percentile $\left(G^{P 33}\right)$ and is defined along similar lines:

$$
R M_{i}(G)=\left\{\begin{array}{c}
\min \left[\sigma_{G}, \max \left(G_{i}-G^{P 33}, \sigma_{G} / 4\right)\right], G_{i}>G^{P 33} \\
0, G_{i} \leq G^{P 33}
\end{array}\right.
$$

Cross-country distributions refer to 2012 for the short- to medium-term simulations (see Appendix 1 for a presentation of the dataset) and to 2060 for the long-term simulations. Because in the baseline most fiscal variables 
are assumed to remain constant as a percentage of (potential) GDP, their cross-country distributions will be identical in both years, and so will countries' room for manoeuvre. The only exception is health care, where long-term pressures are taken into account as described in section 2, giving rise to larger spending relative to GDP in 2060 than in 2012.

Room for manoeuvre in a total of five fiscal instruments, three on the spending side and two among revenues, is the object of additional adjustments, thus departing somewhat from the above formulas. To take account of country differences in demographic and labour market circumstances, expenditure on pensions, education and unemployment benefits is adjusted for the number of potential beneficiaries, defined respectively as individuals aged 65 and over, aged 25 and below, and those unemployed when the economy is operating at potential. In each of the three cases, a scaled variable $G_{i} / R_{G i}$ is constructed, where $R_{G i}$ is the ratio of potential beneficiaries to total population; this scaled variable corresponds to spending per potential beneficiary relative to GDP per capita, and therefore, as regards pensions and unemployment benefits, bears some resemblance to a replacement rate. The cross-country distribution of $G / R_{G}$ yields estimates of room for manoeuvre $-R M_{i}\left(G / R_{G}\right)$ - by application of the formula above in the case of education and unemployment benefits, whereas for pensions, in addition, a smaller upper bound on long-run spending reductions is set ( $\sigma$ minus the 2012-2060 change - when positive - in government pension spending on unchanged policies, also scaled by $R_{G i}$ ). Room for manoeuvre scaled back to percentage points of potential GDP is then given by:

$$
R M_{i}(G)=R_{G i} \cdot R M_{i}\left(G / R_{G}\right)
$$

As regards education and unemployment benefits, these adjustments are performed separately for 2012 and 2060 and therefore introduce some differentiation in cross-country distributions (and ensuing room for manoeuvre) between the two simulation horisons. In the area of pensions, the room for manoeuvre in the short to medium run is assumed to be four times smaller than in the long run, the latter being computed as described above. Long-run population projections are taken from Eurostat and United Nations sources as in Johansson et al. (2013) while projected NAIRU and trend labour force come from the OECD Economic Outlook of May 2013 long-term database.

The room for manoeuvre in personal income tax (PIT) and social security contributions (SSC) is assessed on the basis of the cross-country distribution of their sum according to the general formula above. The individual distributions of PIT and SSC are nonetheless taken into account and impose additional constraints on increases in these items, which cannot exceed one standard deviation of the respective individual instrument nor take place if that instrument already exceeds the $66^{\text {th }}$ percentile of its cross-country distribution.

When instruments are tied in rankings (which is rare in the short- to medium-term simulations, but relatively common in the long run), spending items are used before revenue items, as spending-based fiscal adjustments are often found to be more durable (Alesina and Ardagna, 2012; Molnar, 2012). In case of ties between two spending instruments (or two revenue ones) both are used in proportion to the respective room for manoeuvre.

Besides the 17 instruments considered, property income and residual items (on both revenue and expenditure sides) also stem from the budget decomposition performed (Section 3.2 and Appendix 2). Residual items are not regarded as instruments, since their heterogeneous character makes it hard to assess their growth and equity impacts. However, they are assumed to take part in the overall consolidation effort by keeping a (broadly) constant share in total receipts and disbursements. More precisely, if after a given revenue (spending) instrument has been used the consolidation needs of the country at hand have not been fully met yet, before moving to the next instrument the residual revenue (spending) item is increased (decreased) so as to restore it to its baseline share in total underlying primary revenue (expenditure).

\subsection{Meeting consolidation needs}

\section{Short- to medium-term consolidation needs}

55. Under the simulation design outlined above, almost all countries have the scope to meet their short- to medium-term consolidation needs within the constraints put on instrument use. The only exception is Japan where the constraints imposed by the chosen simulation design limit consolidation to $15 \%$ of GDP against an estimated need of $18 \frac{1}{2}$ per cent of GDP. This discrepancy implies that, in practice, the constraints imposed on instrument use would have to be eased.

56. However, even when fully meeting consolidation needs, several countries are forced to resort to a significant degree to instruments which lie towards the bottom of their respective instrument 
hierarchies (Table 4), and thus generally have an overall detrimental impact on objectives. On the basis of the marginal (i.e. worst) instrument used (Figure 12) as well as the full consolidation packages pursued (Tables A1.1 to A1.5 in Appendix 1), three groups of countries can be identified:

- Sixteen countries (Australia, Austria, Belgium, Canada, Czech Republic, Hungary, Israel, Italy, Luxembourg, Netherlands, Poland, Portugal, Slovak Republic, Slovenia, Spain and Sweden) only need to use instruments featuring in the top half (first nine places) of their respective clusterspecific rankings. All these countries have short- to medium-term consolidation needs which do not exceed 3 percentage points of potential GDP. Though the simulated adjustment is not without economic costs, these will be mainly of a Keynesian nature, while negative impacts on equity or on long-term growth will be absent or, at worst, limited.

- Six countries (Finland, France, Greece, Iceland, Ireland and New Zealand) use marginal instruments placed in the lower half of the respective cluster-specific hierarchies (ranked $10^{\text {th }}$ or worse), but manage to implement consolidation packages where more than $50 \%$ of the adjustment comes from instruments in the upper half. While the use of detrimental instruments remains moderate, fiscal tightening will entail costs which go beyond short-run aggregate demand, raising concerns about impacts on equity and long-term growth.

- Three countries (Japan, United Kingdom and the United States) have to resort to marginal instruments ranked $14^{\text {th }}$ or worst, with more than $50 \%$ of pursued consolidation packages consisting in the use of instruments placed in the lower half of rankings. Short- to medium-term consolidation therefore presents considerable challenges for these countries as it appears difficult to avoid potentially strong detrimental effects on both growth and equity.

Among the countries covered in this study, six do not need any short- to medium-term fiscal tightening (Denmark, Estonia, Germany, Korea, Norway and Switzerland) so that no packages have been simulated for them.

Figure 12. Marginal instrument rank and achieved short- to medium-term consolidation

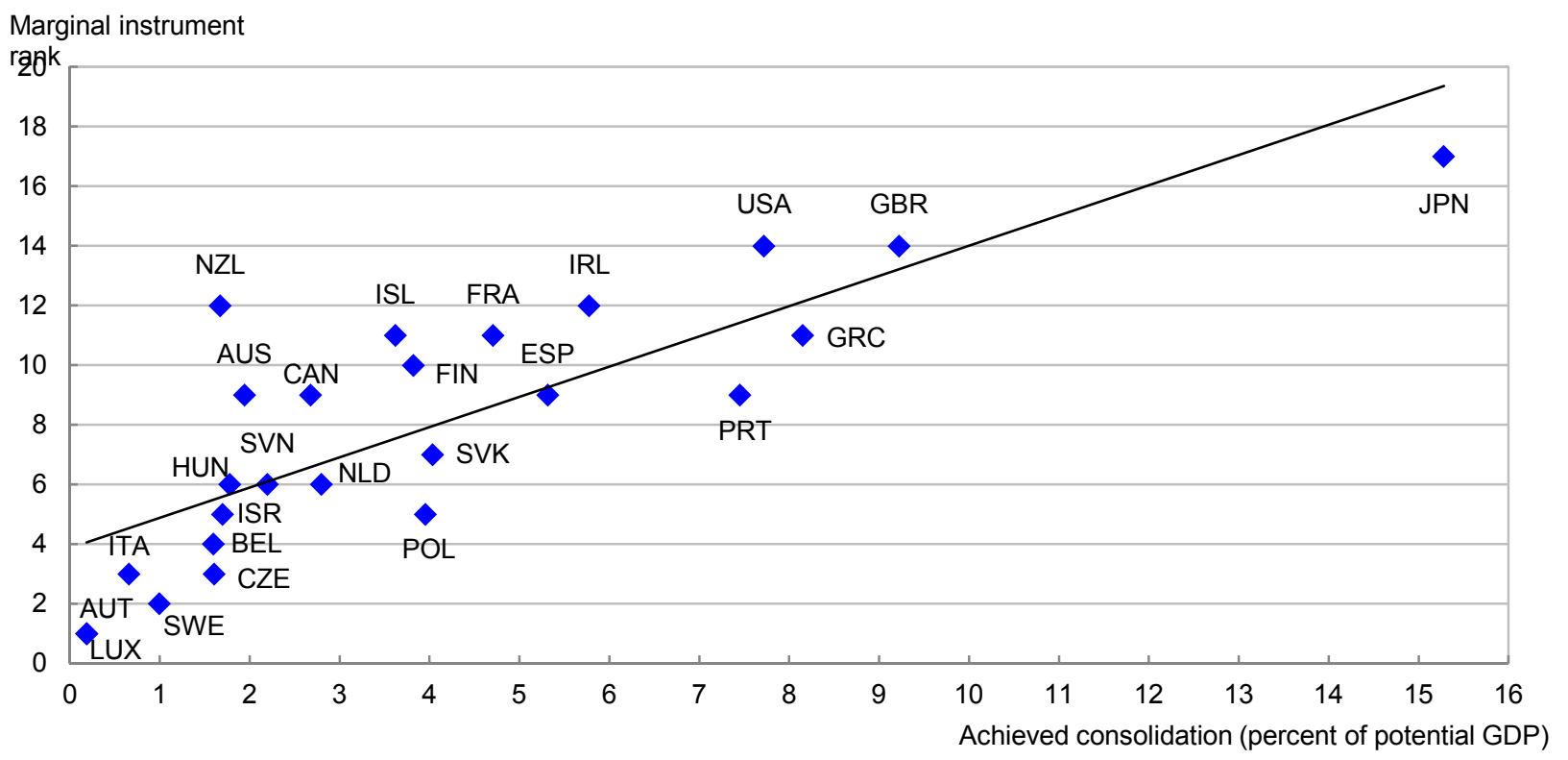




\section{Long-term needs}

Despite generally larger consolidation needs in the long run, all countries can meet them fully while complying with the constraints imposed by the simulation design. However, as with short- to medium-term consolidation packages, there is a risk of significant negative impacts on equity and long-term growth for some countries. As above, one can identify three groups of countries according to their marginal instrument (Figure 12) and full consolidation packages (Appendix Table A1.6):

- Twenty countries (Austria, Belgium, Canada, Czech Republic, Denmark, Estonia, Finland, France, Germany, Greece, Hungary, Iceland, Korea, Luxembourg, Netherlands, Poland, Portugal, Slovenia, Sweden and Switzerland) with low or moderate consolidation needs enjoy the favourable position of only having to use instruments in the upper half (top nine places) of the uniform long-run hierarchy, of which the overall impact on long-run growth and equity can be deemed mostly beneficial or fairly neutral. ${ }^{17}$

- Six countries (Ireland, Israel, Japan, Slovak Republic, Spain and the United Kingdom) resort to marginal instruments in the lower half of the ranking $\left(10^{\text {th }}\right.$ to $17^{\text {th }}$ places $)$, which may entail more detrimental consequences for growth and equity objectives. However, these countries have consolidation packages where more than half (and in some cases virtually all) of the adjustment comes from better instruments (those in the upper half of the hierarchy).

- Three countries (Australia, New Zealand and the United States) with large long-term consolidation needs face the unpleasant prospect of both employing low-quality marginal instruments and letting poor instruments (those in the lower half of the ranking) account for more than half of the total fiscal adjustment. Therefore this group faces a substantial risk of overall negative impacts of consolidation on growth and equity.

With the assumptions outlined above, Italy and Norway have no estimated long-term consolidation needs and therefore no simulated packages at that horizon.

57. Despite estimated consolidation needs being generally larger in the long than the short run, more countries rely fully on well ranked instruments in their simulated long-term packages than in the short- to medium term ones. One reason is that other government consumption, an area with substantial consolidation potential in many countries, is much better ranked in the long term when demand effects are no longer taken into account. Another reason is that the simulations are designed to offer more room for adjustment in public pension spending in the long than the short term, reflecting that expenditure savings in general accrue gradually in this area. Finally, more countries are estimated to face positive consolidation needs in the long than the short term.

58. At either simulation horizon, countries facing the unpleasant prospect of having to resort on a large scale to low-ranking instruments have two non-mutually exclusive options. The first, further discussed in section 6, is to supplement the use of such instruments by structural changes that make them

17. The top nine instruments have either $(i)$ beneficial impacts on both long-term growth and long-term equity (Table 2), as is the case of subsidy reduction, (ii) impacts which are beneficial on one objective and fairly neutral on the other, as it happens with reductions in other government consumption, or (iii) opposite impacts on long-term growth and long-term equity which can somehow be regarded as compensating each other, reductions in sickness and disability payments being an example. Implicit in this "compensation" argument is the use of +1 and -1 scores for each + and - sign in Table 2, which is admittedly a simplifying assumption, rather than an attempt to calibrate a social welfare function. 
more growth- or equity-friendly. The second option is to use the best instruments more intensively than implied by the somewhat arbitrary constraints. The simulation design implies that countries such as Australia, New Zealand and the United States which start out with an above-average use of the least detrimental forms of taxation or below-average spending in the least effective areas tend to lack room for manoeuvre in the best budget instruments. If the constraint that adjustment cannot take a country into the group of the ten OECD countries that tax most or spend least in the area of under consideration is relaxed by moving from ten- to five-country reference groups, then New Zealand and the United States achieve close to half of their simulated long-term consolidation with well ranked instruments. With this relaxation of the constraint, Australia carries out three quarters of its simulated long-term adjustment with well ranked instruments.

Figure 13. Marginal instrument rank and achieved long-term consolidation

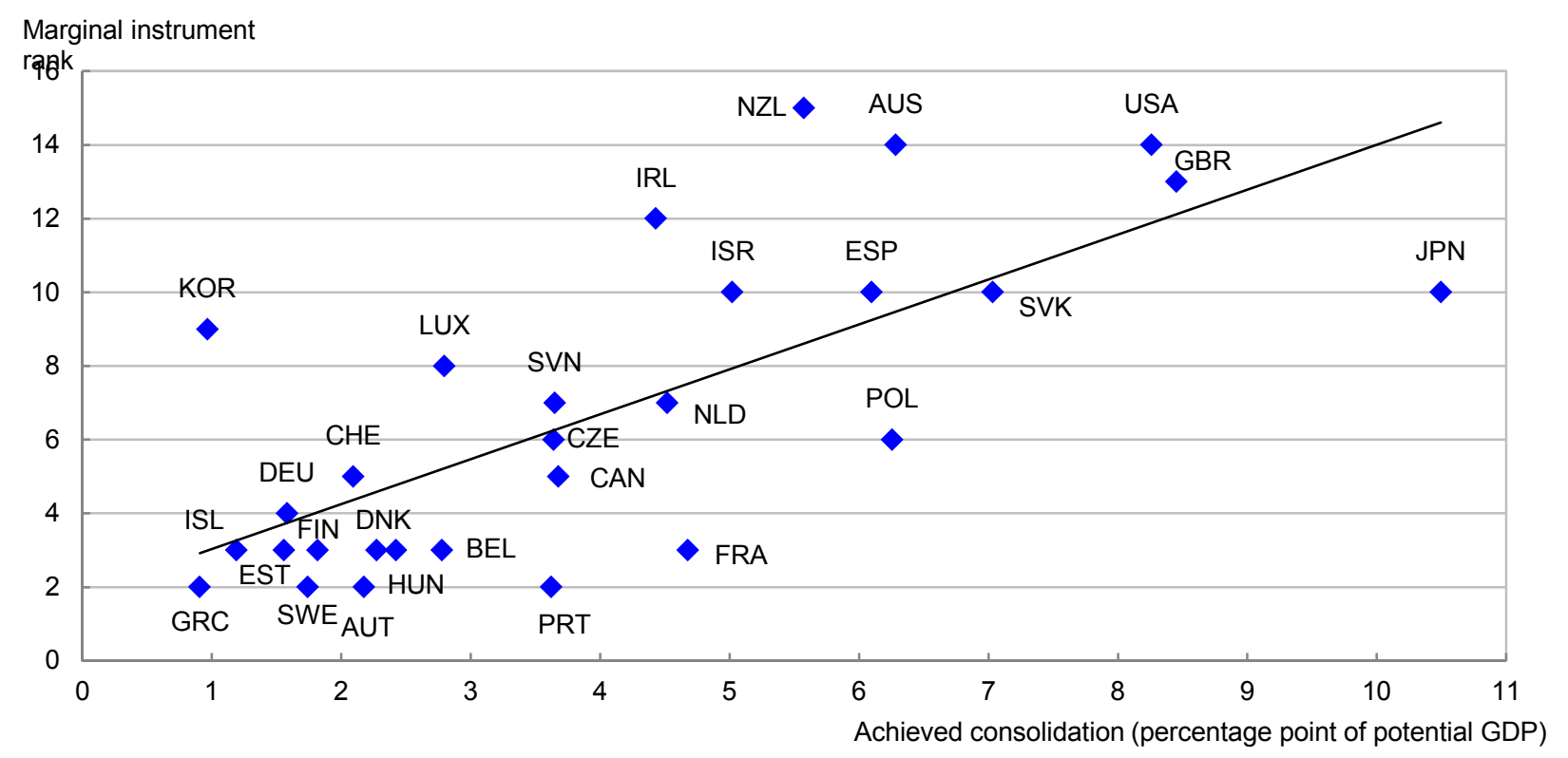

\subsection{Consolidation packages and shifts in budget structure}

59. The sequential nature of instrument use in the simulations, based on hierarchies which have strong resemblances across groups of countries (in the short to medium term) or are even common to all countries (in the long run), results in some instruments featuring much more often than others in consolidation packages. As a consequence, revenue and expenditure structures evolve and undergo some convergence across countries. While this subsection discusses general trends across countries, Tables A1-6 in Appendix 1 provide detailed information by country about the illustrative consolidation packages.

60. In the short to medium term, subsidies and other property taxes are the most widely used instrument, and together account on average across countries for about a third of consolidation packages (Table 5). This large figure, however, should be kept in perspective, as it is heavily influenced by the fact that some countries with small short-term consolidation needs, such as Austria, Italy and Sweden, use subsidy reductions as the prime or even the sole adjustment tool. Spending reductions on unemployment benefits and pensions as well as increases in environmental taxes, corporate and personal income taxes, and recurring property taxes come next in frequency of use. Cuts in the areas of health, education and family policy are very rare in simulated packages, as are increases in social security 
contributions, reflecting their negative side-effects across the growth and equity dimensions. This finding is very robust to uncertainty about the effects of instruments and their ranking (Table 5).

61. The simulated long-term consolidation packages exhibit some differences from their short- to medium-term counterparts for two main reasons:

- Firstly, instruments resulting in cuts to public expenditure move up the ranking in the long term as their larger Keynesian demand effects are no longer taken into account. Cuts in other government consumption as a result play a much more important role in long- than in short-term simulated packages.

- Secondly more room for manoeuvre is assumed to be available in the area of pensions (over and above the effort implicit in the baseline) in a 2060 perspective than over the medium term. Consequently, pensions are used more intensively to meet consolidation needs in the long than the short term.

These two factors result in a number of policy reversals, that is to say cases where a given country makes a larger use of a given instrument in the short to medium term than in the long term. Such policy reversals mainly concern taxes, and in particular property and corporate income taxes (Table 5), which generally fall from the upper to the lower half of instrument hierarchies as the time horizon expands.

62. As a result from this shift in the use of consolidation tools, the average share of spending reductions across national consolidation packages rises from $41 \%$ in the short to medium term to $65 \%$ in the long term. At both simulation horizons, the share of spending is particularly high among countries with modest consolidation needs, which to a large extent can be fulfilled with instruments like subsidies or pensions, which occupy top places in most rankings. In contrast, countries with substantial consolidation gaps often need to use large tax items as well, leading to a more balanced revenue-expenditure split or even to revenue-side adjustment becoming predominant.

63. Revenue and expenditure structures undergo some change from 2012 (the starting year) to 2020 (the medium term) and 2060 (the long term), reflecting both baseline developments (in the form of health spending pressures) and consolidation patterns. On the expenditure side, the share of health care in total spending rises at the expense of virtually all other instruments (Table 6). In the long run, this increase prevents overall primary spending from falling relative to GDP. In line with the different intensities of instrument use, pensions and other government consumption fall the most relative to GDP (mainly after 2020), while family and education spending remains broadly unchanged. Revenue items broadly follow a hump-shaped profile where they rise relative to GDP to meet short- to medium-term needs before falling back to on average one percentage point above their 2012 ratios to GDP in the very long term. 
Table 5. Summary indicators about consolidation packages

\begin{tabular}{|c|c|c|c|c|c|c|}
\hline \multirow[b]{3}{*}{ Description } & \multicolumn{4}{|c|}{ Memorandum items } & \multirow{2}{*}{\multicolumn{2}{|c|}{$\begin{array}{l}\text { Number of countries } \\
\text { resorting to instrument }\end{array}$}} \\
\hline & \multicolumn{2}{|c|}{$\begin{array}{l}\text { Baseline average } \\
\text { (\% of potential GDP) }\end{array}$} & \multicolumn{2}{|c|}{$\begin{array}{c}\text { Baseline standard } \\
\text { deviation } \\
\text { (pp potential GDP) }\end{array}$} & & \\
\hline & $\begin{array}{c}\text { short- } \\
\text { term }\end{array}$ & $\begin{array}{l}\text { long- } \\
\text { term }\end{array}$ & $\begin{array}{l}\text { short- } \\
\text { term }\end{array}$ & long-term & $\begin{array}{l}\text { short- } \\
\text { term }\end{array}$ & long-term \\
\hline Subsidies & 1.2 & 1.2 & 0.8 & 0.8 & $\begin{array}{c}14 \\
(13-15)\end{array}$ & $\begin{array}{c}15 \\
(14-15)\end{array}$ \\
\hline Pensions & 8.1 & 8.1 & 3.3 & 3.3 & $\begin{array}{c}11 \\
(9-12)\end{array}$ & $\begin{array}{c}12 \\
(12-12)\end{array}$ \\
\hline Other property taxes & 0.7 & 0.7 & 0.6 & 0.6 & $\begin{array}{c}16 \\
(12-16)\end{array}$ & $\begin{array}{c}11 \\
(8-14)\end{array}$ \\
\hline Unemployment benefits & 1.1 & 1.1 & 0.9 & 0.9 & $\begin{array}{c}11 \\
(6-12)\end{array}$ & $\begin{array}{c}13 \\
(7-15)\end{array}$ \\
\hline Personal income taxes & 8.6 & 8.6 & 3.3 & 3.3 & $\begin{array}{c}9 \\
(5-12)\end{array}$ & $\begin{array}{c}7 \\
(0-8)\end{array}$ \\
\hline Corporate income taxes & 2.9 & 2.9 & 0.9 & 0.9 & $\begin{array}{c}11 \\
(4-14)\end{array}$ & $\begin{array}{c}5 \\
(1-6)\end{array}$ \\
\hline Environmental taxes & 2.3 & 2.3 & 0.7 & 0.7 & $\begin{array}{c}13 \\
(7-15)\end{array}$ & $\begin{array}{c}11 \\
(10-14)\end{array}$ \\
\hline Recurrent taxes on immovable property & 1.3 & 1.3 & 1 & 1 & $\begin{array}{c}9 \\
(3-12)\end{array}$ & $\begin{array}{c}4 \\
(3-8)\end{array}$ \\
\hline $\begin{array}{l}\text { Other government in kind consumption } \\
\text { (excluding family policy) }\end{array}$ & 8.4 & 8.4 & 2.4 & 2.4 & $\begin{array}{c}8 \\
(4-12)\end{array}$ & $\begin{array}{c}14 \\
(11-17)\end{array}$ \\
\hline Sales of goods and services & 2.8 & 2.8 & 1 & 1 & $\begin{array}{c}7 \\
(3-11)\end{array}$ & $\begin{array}{c}7 \\
(6-9)\end{array}$ \\
\hline Sickness and disability payments & 2 & 2 & 0.6 & 0.6 & $\begin{array}{c}4 \\
(1-9)\end{array}$ & $\begin{array}{c}7 \\
(5-12)\end{array}$ \\
\hline $\begin{array}{l}\text { Consumption taxes } \\
\text { (other than environmental) }\end{array}$ & 9 & 9 & 2.4 & 2.4 & $\begin{array}{c}4 \\
(3-10)\end{array}$ & $\begin{array}{c}8 \\
(3-9)\end{array}$ \\
\hline Public investment & 2.6 & 2.6 & 1 & 1 & $\begin{array}{c}4 \\
(1-6)\end{array}$ & $\begin{array}{c}4 \\
(2-6)\end{array}$ \\
\hline Health services provided in kind & 6.5 & 9.6 & 1.4 & 1.3 & $\begin{array}{c}3 \\
(2-4)\end{array}$ & $\begin{array}{c}4 \\
(3-7)\end{array}$ \\
\hline Social security contributions & 11.2 & 11.2 & 5.4 & 5.4 & $\begin{array}{c}1 \\
(1-3)\end{array}$ & $\begin{array}{c}0 \\
(0-3)\end{array}$ \\
\hline Family & 2.4 & 2.4 & 1.1 & 1.1 & $\begin{array}{c}0 \\
(0-2)\end{array}$ & $\begin{array}{c}1 \\
(0-3)\end{array}$ \\
\hline Education & 5.3 & 5.3 & 1.1 & 1.1 & $\begin{array}{c}1 \\
(1-2)\end{array}$ & $\begin{array}{c}0 \\
(0-1)\end{array}$ \\
\hline
\end{tabular}

Note: Instruments are ranked as in Figure 11. ST and LT denote respectively short to medium term and long term. All figures in the table refer to the 24 countries common to both simulation horizons. Average shares of instruments are computed across national consolidation packages (Tables A1.1 to 6 in Appendix 1). Policy reversals (cases of stronger instrument use in ST than in LT) exclude cases solely due to a smaller room for manoeuvre (i.e. in both ST and LT instrument use exhausts the available room for manoeuvre, which is smaller in LT than in ST). Simulated interdecile intervals shown between brackets are computed using 200 random draws. Each individual assessment (i.e. each cell) in Table 2 is increased by one, decreased by one or retained with probabilities $1 / 8,1 / 8$ and $3 / 4$ respectively. 
Table 5. (Cont.) Summary indicators about consolidation packages

\begin{tabular}{|c|c|c|c|c|c|c|}
\hline \multirow[b]{3}{*}{ Description } & \multirow{2}{*}{\multicolumn{2}{|c|}{$\begin{array}{c}\text { Average use among } \\
\text { countries resorting to } \\
\text { instrument } \\
(\% \text { of potential GDP) }\end{array}$}} & \multirow{2}{*}{\multicolumn{2}{|c|}{$\begin{array}{l}\text { Average share of } \\
\text { instrument in total } \\
\text { consolidation }(\%)\end{array}$}} & \multicolumn{2}{|c|}{ Policy reversals } \\
\hline & & & & & \multirow{2}{*}{$\begin{array}{c}\begin{array}{c}\text { Number } \\
\text { of cases }\end{array} \\
\text { short- } \\
\text { term }\end{array}$} & \multirow{2}{*}{$\begin{array}{c}\begin{array}{c}\text { Average reversal } \\
\text { (pp of potential } \\
\text { GDP) }\end{array} \\
\text { long-term }\end{array}$} \\
\hline & $\begin{array}{c}\text { short- } \\
\text { term }\end{array}$ & $\begin{array}{l}\text { long- } \\
\text { term }\end{array}$ & $\begin{array}{c}\text { short- } \\
\text { term }\end{array}$ & long-term & & \\
\hline \multirow[t]{2}{*}{ Subsidies } & 0.6 & 0.6 & 19.8 & 15.3 & 0 & 0 \\
\hline & $(0.6-0.6)$ & $(0.6-0.6)$ & $(15.6-23.9)$ & $(13.4-15.3)$ & $(0-2)$ & $(0.0-0.3)$ \\
\hline \multirow[t]{2}{*}{ Pensions } & 0.5 & 1.7 & 8.2 & 22.1 & 0 & 0 \\
\hline & $(0.4-0.5)$ & $(1.5-1.8)$ & $(3.4-9.5)$ & $(16.0-23.5)$ & $(0-1)$ & $(0.0-0.2)$ \\
\hline \multirow[t]{2}{*}{ Other property taxes } & 0.4 & 0.4 & 10.1 & 3.6 & 8 & 0.3 \\
\hline & $(0.4-0.5)$ & $(0.4-0.5)$ & $(6.4-12.4)$ & $(2.0-6.7)$ & (3-9) & $(0.2-0.4)$ \\
\hline \multirow[t]{2}{*}{ Unemployment benefits } & 0.6 & 0.5 & 7.7 & 6.3 & 3 & 0.4 \\
\hline & $(0.5-0.7)$ & $(0.4-0.6)$ & $(2.8-9.3)$ & $(3.3-10.5)$ & $(0-3)$ & $(0.0-0.7)$ \\
\hline \multirow[t]{2}{*}{ Personal income taxes } & 1.9 & 1 & 11 & 3.5 & 6 & 2 \\
\hline & $(1.8-2.3)$ & $(0.0-1.5)$ & $(5.5-19.2)$ & $(0.0-7.0)$ & $(5-9)$ & $(1.6-2.3)$ \\
\hline \multirow[t]{2}{*}{ Corporate income taxes } & 0.5 & 0.2 & 4.2 & 0.8 & 10 & 0.4 \\
\hline & $(0.3-0.5)$ & $(0.0-0.5)$ & $(1.0-7.6)$ & $(0.0-1.9)$ & $(3-11)$ & $(0.3-0.5)$ \\
\hline \multirow[t]{2}{*}{ Environmental taxes } & 0.6 & 0.5 & 8.1 & 4 & 6 & 0.3 \\
\hline & $(0.4-0.6)$ & $(0.5-0.6)$ & $(2.6-10.4)$ & $(3.0-6.9)$ & $(2-7)$ & $(0.1-0.5)$ \\
\hline \multirow[t]{2}{*}{ Recurrent taxes on immovable property } & 0.8 & 0.7 & 7.6 & 2.5 & 6 & 0.8 \\
\hline & $(0.6-0.8)$ & $(0.4-0.8)$ & $(1.2-11.1)$ & $(0.8-4.7)$ & $(2-9)$ & $(0.5-0.8)$ \\
\hline \multirow{2}{*}{$\begin{array}{l}\text { Other government in kind consumption } \\
\text { (excluding family policy) }\end{array}$} & 1 & 1.4 & 7.2 & 20.5 & 4 & 0.6 \\
\hline & $(1.0-1.5)$ & $(1.3-1.5)$ & $(3.6-18.8)$ & $(13.2-27.3)$ & $(1-5)$ & $(0.7-1.3)$ \\
\hline \multirow[t]{2}{*}{ Sales of goods and services } & 0.6 & 0.7 & 3 & 3.5 & 2 & 0.3 \\
\hline & $(0.5-0.7)$ & $(0.4-0.8)$ & $(0.7-6.5)$ & $(1.2-4.6)$ & $(1-6)$ & $(0.1-0.4)$ \\
\hline \multirow[t]{2}{*}{ Sickness and disability payments } & 0.4 & 0.5 & 1.4 & 2.8 & 2 & 0.4 \\
\hline & $(0.1-0.5)$ & $(0.4-0.6)$ & $(0.1-4.7)$ & $(1.5-4.5)$ & $(0-4)$ & $(0.0-0.4)$ \\
\hline Consumption taxes & 1.9 & 1.3 & 3.7 & 5.9 & 2 & 0.7 \\
\hline (other than environmental) & $(1.4-2.1)$ & $(1.0-1.8)$ & $(3.0-11.6)$ & $(2.2-10.2)$ & $(2-6)$ & $(0.5-1.6)$ \\
\hline \multirow[t]{2}{*}{ Public investment } & 0.5 & 0.5 & 1 & 1.4 & 3 & 0.5 \\
\hline & $(0.5-1.1)$ & $(0.4-0.7)$ & $(0.3-3.5)$ & $(0.5-2.4)$ & $(1-3)$ & $(0.1-1.1)$ \\
\hline \multirow[t]{2}{*}{ Health services provided in kind } & 1.4 & 0.6 & 1.8 & 1.5 & 0 & 0 \\
\hline & $(1.2-1.5)$ & $(0.4-1.0)$ & $(1.1-2.3)$ & $(0.7-3.9)$ & $(0-0)$ & $(0.0-0.0)$ \\
\hline \multirow[t]{2}{*}{ Social security contributions } & 0.9 & 0 & 0.2 & 0 & 1 & 0.9 \\
\hline & $(0.8-1.6)$ & $(0.0-0.7)$ & $(0.2-2.6)$ & $(0.0-1.8)$ & $(1-3)$ & $(0.8-1.7)$ \\
\hline \multirow[t]{2}{*}{ Family } & 0 & 0.5 & 0 & 0.4 & 0 & 0 \\
\hline & $(0.0-1.0)$ & $(0.0-0.7)$ & $(0.0-1.2)$ & $(0.0-1.6)$ & $(0-2)$ & $(0.0-0.8)$ \\
\hline \multirow[t]{2}{*}{ Education } & 0.3 & 0 & 0.1 & 0 & 0 & 0 \\
\hline & $(0.3-0.3)$ & $(0.0-0.3)$ & $(0.1-0.2)$ & $(0.0-0.2)$ & $(0-0)$ & $(0.0-0.0)$ \\
\hline
\end{tabular}


Table 6. Evolution of expenditure and revenue structures

Averages across countries

\begin{tabular}{|c|c|c|c|c|c|c|}
\hline \multirow[b]{2}{*}{ Expenditure } & \multicolumn{2}{|c|}{2012} & \multicolumn{2}{|c|}{2020} & \multicolumn{2}{|c|}{2060} \\
\hline & $\begin{array}{c}\% \text { of } \\
\text { potential } \\
\text { GDP } \\
\end{array}$ & $\begin{array}{c}\text { Share of } \\
\text { spending or } \\
\text { revenue (\%) }\end{array}$ & $\begin{array}{c}\% \text { of } \\
\text { potential } \\
\text { GDP } \\
\end{array}$ & $\begin{array}{c}\text { Share of } \\
\text { spending or } \\
\text { revenue (\%) }\end{array}$ & $\begin{array}{c}\% \text { of } \\
\text { potential } \\
\text { GDP } \\
\end{array}$ & $\begin{array}{c}\text { Share of } \\
\text { spending or } \\
\text { revenue }(\%)\end{array}$ \\
\hline Public investment & 2.6 & 6.2 & $\begin{array}{c}2.5 \\
(2.5-2.6)\end{array}$ & $\begin{array}{c}6.3 \\
(6.1-6.4)\end{array}$ & $\begin{array}{c}2.5 \\
(2.4-2.6)\end{array}$ & $\begin{array}{c}6 \\
(5.8-6.1)\end{array}$ \\
\hline Education & 5.3 & 12.5 & $\begin{array}{c}5.2 \\
(5.2-5.2)\end{array}$ & $\begin{array}{c}12.9 \\
(12.9-13.0)\end{array}$ & $\begin{array}{c}5.3 \\
(5.2-5.3)\end{array}$ & $\begin{array}{c}12.4 \\
(12.4-12.5)\end{array}$ \\
\hline Health services provided in kind & 6.5 & 15.5 & $\begin{array}{c}6.4 \\
(6.4-6.4)\end{array}$ & $\begin{array}{c}15.7 \\
(15.6-15.9)\end{array}$ & $\begin{array}{c}9.5 \\
(9.3-9.5)\end{array}$ & $\begin{array}{c}22.4 \\
(22.0-22.5)\end{array}$ \\
\hline $\begin{array}{l}\text { Other in kind consumption } \\
\text { (excluding family policy) }\end{array}$ & 8.4 & 19.9 & $\begin{array}{c}8.1 \\
(7.7-8.2)\end{array}$ & $\begin{array}{c}19.9 \\
(19.2-20.2)\end{array}$ & $\begin{array}{c}7.6 \\
(7.5-7.8)\end{array}$ & $\begin{array}{c}18 \\
(17.7-18.4)\end{array}$ \\
\hline Pensions & 8.1 & 19.1 & $\begin{array}{c}7.9 \\
(7.8-7.9)\end{array}$ & $\begin{array}{c}19.4 \\
(19.3-19.5)\end{array}$ & $\begin{array}{c}7.2 \\
(7.2-7.3)\end{array}$ & $\begin{array}{c}17.1 \\
(17.0-17.4)\end{array}$ \\
\hline Sickness and disability payments & 2 & 4.7 & $\begin{array}{c}1.9 \\
(1.8-2.0)\end{array}$ & $\begin{array}{c}4.7 \\
(4.5-4.8)\end{array}$ & $\begin{array}{c}1.8 \\
(1.8-1.9)\end{array}$ & $\begin{array}{c}4.3 \\
(4.2-4.4)\end{array}$ \\
\hline Unemployment benefits & 1.1 & 2.6 & $\begin{array}{c}0.8 \\
(0.8-1.0)\end{array}$ & $\begin{array}{c}2 \\
(2.0-2.4)\end{array}$ & $\begin{array}{c}0.9 \\
(0.8-1.0)\end{array}$ & $\begin{array}{c}2 \\
(1.8-2.2)\end{array}$ \\
\hline Family & 2.4 & 5.6 & $\begin{array}{c}2.4 \\
(2.3-2.4)\end{array}$ & $\begin{array}{c}5.8 \\
(5.7-5.8)\end{array}$ & $\begin{array}{c}2.3 \\
(2.3-2.4)\end{array}$ & $\begin{array}{c}5.5 \\
(5.3-5.6)\end{array}$ \\
\hline Subsidies & 1.2 & 2.8 & $\begin{array}{c}0.8 \\
(0.8-0.9)\end{array}$ & $\begin{array}{c}2 \\
(2.0-2.1)\end{array}$ & $\begin{array}{c}0.8 \\
(0.8-0.8)\end{array}$ & $\begin{array}{c}1.8 \\
(1.8-1.9)\end{array}$ \\
\hline Residual spending items & 4.7 & 11.1 & 4.5 & 11.2 & 4.5 & 10.5 \\
\hline Total of spending instruments & 42.2 & 100 & $\begin{array}{c}40.5 \\
(40.3-40.7)\end{array}$ & 100 & $\begin{array}{c}42.3 \\
(42.1-42.5)\end{array}$ & 100 \\
\hline \multicolumn{7}{|l|}{ Revenue } \\
\hline Personal income taxes & 8.6 & 21.3 & $\begin{array}{c}9.3 \\
(9.1-9.5)\end{array}$ & $\begin{array}{c}21.7 \\
(21.4-22.4)\end{array}$ & $\begin{array}{c}8.8 \\
(8.6-9.1)\end{array}$ & $\begin{array}{c}21.2 \\
(20.6-21.7)\end{array}$ \\
\hline Social security contributions & 11.2 & 27.8 & $\begin{array}{c}11.2 \\
(11.2-11.4)\end{array}$ & $\begin{array}{c}26.3 \\
(26.2-26.7)\end{array}$ & $\begin{array}{c}11.2 \\
(11.2-11.3)\end{array}$ & $\begin{array}{c}26.7 \\
(26.7-27.0)\end{array}$ \\
\hline Corporate income taxes & 2.9 & 7.1 & $\begin{array}{c}3.1 \\
(2.9-3.2)\end{array}$ & $\begin{array}{c}7.2 \\
(6.9-7.4)\end{array}$ & $\begin{array}{c}2.9 \\
(2.9-3.0)\end{array}$ & $\begin{array}{c}7 \\
(6.9-7.1)\end{array}$ \\
\hline Environmental taxes & 2.3 & 5.8 & $\begin{array}{c}2.6 \\
(2.5-2.7)\end{array}$ & $\begin{array}{c}6.2 \\
(5.8-6.3)\end{array}$ & $\begin{array}{c}2.6 \\
(2.5-2.7)\end{array}$ & $\begin{array}{c}6.2 \\
(6.1-6.4)\end{array}$ \\
\hline $\begin{array}{l}\text { Consumption taxes } \\
\text { (other than environmental) }\end{array}$ & 9 & 22.4 & $\begin{array}{c}9.3 \\
(9.2-9.6)\end{array}$ & $\begin{array}{c}21.9 \\
(21.8-22.5)\end{array}$ & $\begin{array}{c}9.4 \\
(9.1-9.7)\end{array}$ & $\begin{array}{c}22.5 \\
(21.9-23.1)\end{array}$ \\
\hline $\begin{array}{l}\text { Recurring taxes on immovable } \\
\text { property }\end{array}$ & 1.3 & 3.1 & $\begin{array}{c}1.5 \\
(1.3-1.6)\end{array}$ & $\begin{array}{c}3.6 \\
(3.2-3.8)\end{array}$ & $\begin{array}{c}1.4 \\
(1.3-1.5)\end{array}$ & $\begin{array}{c}3.3 \\
(3.1-3.5)\end{array}$ \\
\hline Other property taxes & 0.7 & 1.7 & $\begin{array}{c}1 \\
(0.9-1.0)\end{array}$ & $\begin{array}{c}2.3 \\
(2.1-2.4)\end{array}$ & $\begin{array}{c}0.9 \\
(0.8-1.0)\end{array}$ & $\begin{array}{c}2.1 \\
(2.0-2.3)\end{array}$ \\
\hline Sales of goods and services & 2.8 & 7 & $\begin{array}{c}3 \\
(2.9-3.0)\end{array}$ & $\begin{array}{c}7 \\
(6.8-7.2)\end{array}$ & $\begin{array}{c}3 \\
(2.9-3.1)\end{array}$ & $\begin{array}{c}7.2 \\
(6.9-7.3)\end{array}$ \\
\hline Residual revenue items & 1.5 & 3.8 & 1.6 & 3.8 & 1.6 & 3.8 \\
\hline Total of revenue instruments & 40.2 & 100 & $\begin{array}{c}42.6 \\
(42.3-42.8)\end{array}$ & 100 & $\begin{array}{c}41.7 \\
(41.5-41.9)\end{array}$ & 100 \\
\hline
\end{tabular}

Note: The table reports the size of the 17 fiscal instruments in p.p. of potential GDP, averaged across the 24 countries common to both simulation horizons, in 2012, 2020 and 2060. Figures for 2020 and 2060 reflect baseline developments in health spending as well as the consolidation packages implemented by each country in the short to medium term and in the long term, respectively. For simplicity, the year 2020 is taken as the medium-term consolidation horizon, though the latter varies somewhat across countries. Simulated interdecile intervals shown between brackets are computed using 200 random draws. Each individual assessment (i.e. each cell) in Table 2 is increased by one, decreased by one or retained with probabilities $1 / 8,1 / 8$ and $3 / 4$ respectively. Residual spending and revenue items are not reported, as their share in the respective total remains broadly constant by simulation design (Box 4). 
64. Budget structures also display some convergence across countries, as a consequence of broadly similar instrument orderings, but not much primarily because of the constraints imposed on instrument use (Table 7). On both revenue and expenditure sides, the cross-country dispersion of the size of budget items displays a general downward trend, which, unsurprisingly, tends to be more marked in the case of widely used instruments, such as subsidies, other government consumption, environmental levies and consumption taxes. Even in these cases, however, dispersion is only reduced by a third in the long term, and by much less in most other instruments.

Table 7. Cross-country convergence in expenditure and revenue structures

\begin{tabular}{|c|c|c|c|}
\hline \multirow[b]{2}{*}{ Expenditure } & \multicolumn{3}{|c|}{$\begin{array}{c}\text { Standard deviation } \\
\text { (percentage point of pot. GDP) }\end{array}$} \\
\hline & 2012 & 2020 & 2060 \\
\hline Public investment & 1 & 0.9 & 0.9 \\
\hline Education & 1.1 & 1.1 & 1.1 \\
\hline Health services provided in kind & 1.4 & 1.3 & 1.2 \\
\hline Other government in kind consumption & 2.4 & 2.3 & 1.9 \\
\hline Pensions & 3.3 & 3.1 & 2.8 \\
\hline Sickness and disability payments & 0.6 & 0.6 & 0.5 \\
\hline Unemployment benefits & 0.9 & 0.6 & 0.6 \\
\hline Family policy & 1.1 & 1.1 & 1 \\
\hline Subsidies & 0.8 & 0.6 & 0.5 \\
\hline \multicolumn{4}{|l|}{ Revenue } \\
\hline Personal income taxes & 3.3 & 3 & 3.1 \\
\hline Social security contributions & 5.4 & 5.4 & 5.4 \\
\hline Corporate income taxes & 0.9 & 0.9 & 0.9 \\
\hline Environmental taxes & 0.7 & 0.5 & 0.5 \\
\hline Consumption taxes & 2.4 & 2 & 1.9 \\
\hline Recurrent taxes on immovable property & 1 & 0.9 & 1 \\
\hline Other property taxes & 0.6 & 0.5 & 0.5 \\
\hline Sales of goods and services & 1 & 0.9 & 0.9 \\
\hline
\end{tabular}

Note: The table reports variability indicators computed across the 24 countries common to both simulation horizons, in 2012,2020 and 2060. Figures for 2020 and 2060 reflect baseline developments in health spending as well as the consolidation packages implemented by each country in the short to medium term and in the long term, respectively. The year 2020 is taken as a proxy for the medium-term consolidation horizon although the latter varies across countries (Appendix 2, Section 1).

\subsection{Robustness of the simulated consolidation packages}

\section{Sensitivity to uncertainty about the assessment of instrument impacts}

65. Numerous checks have been performed to test the robustness of the findings to uncertainty about the assessments of the side-effects of consolidation instruments. A large number (200) of alternative scenarios have been simulated: in each of these, one in every four assessments in Table 2, which is equivalent of a full column, is chosen randomly and modified by adding a plus or minus sign. For each random draw, cluster-specific and long-term rankings corresponding to the new assessment of impacts are calculated. Then, for each random draw, full consolidation packages are simulated for the short to medium term as well as the long term. The values between brackets in Tables 5-6 and A1.1-A1.6 show the $10^{\text {th }}$ and $90^{\text {th }}$ percentiles of the values spanned by the results in the simulations associated with the randow draws.

66. The conclusions from these 200 randomly generated simulations can be summarised as follows: 
- The degree to which countries have to use poorly ranked instruments, or can avoid doing so, is robust to uncertainty about impact assessments, especially in countries with large consolidation needs (Tables A1.1-A1.6). In particular, in the alternative scenarios, there are very few shifts from being able to achieve most of the consolidation with well ranked instruments to being forced to rely heavily on badly ranked instruments, neither is there much movement in the opposite direction.

- The average use of each instrument is quite stable across alternative scenarios for both very well and very poorly ranked instruments (Table 5). There is more variation for middle-ranked instruments.

- The finding that short- as well as long-term simulated consolidation packages very seldom involve cuts in the areas of health, education and family policy holds very strongly in the robustness checks (Table 5).

- While the split between spending and tax adjustment shows sensitivity to uncertainty, especially at the country level (Tables A1.1-A1.5), the findings that long-term packages rely more on spending reductions than tax increases and that short-term adjustment give a larger role to tax increases are very robust (Table A1.6)

- Policy reversals show some sensitivity to uncertainty (Table 5). The reason is that policy reversals occur mostly for instruments that feature in the middle of the generic ranking, which is the most unstable part of the ranking.

- The finding that the simulated packages largely respect the diversity of revealed preferences about tax-and-spending structures by prompting only very limited cross-country convergence is very robust in the random simulations (Table 6).

\section{Sensitivity to the chosen clustering technique}

67. A variant of the framework for simulating short- to medium-term consolidation packages has been prepared to check the sensitivity of the results to the weights put on objectives as a result of the clustering techniques. In this alternative framework, the clustering technique is replaced by splitting covered OECD countries into three equal-sized groups depending on the sign and size of the current account: strongly positive, strongly negative and close-to-balance. Instead of deriving the weighting scheme from clustering analysis, in the variant framework all objectives receive the same weight. Section 5 of Appendix 2 describes the methodology used to prepare this variant in greater detail and reports the results in Tables A2.4 to A2.8.

68. In summary, the results are relatively close to the main set of short- to medium-term simulations and corroborate its main findings although they take country circumstances less well into account. In addition, 200 random simulations have been conducted around this variant to assess its sensitivity to uncertainty about the assessment of the effects of instruments. The results are the same for the variant as for the main framework: most results are quite robust to uncertainty about instrument assessment (Tables A2.4 to A2.8). The only notable exception is the tax-spending split especially in countries with small consolidation needs.

\section{Sensitivity to the assumptions made on the available room for manoeuvre for each instrument}

69. Variants of the short- to medium-term and long-term simulations have been conducted to explore the influence of the constraints on instrument use. The constraint that a given tax can be raised until the country reaches the $66^{\text {th }}$ percentile of the covered OECD countries (and a spending item cut until the $33^{\text {rd }}$ percentile) has been relaxed by allowing instrument use until the $80^{\text {th }}$ and $20^{\text {th }}$ percentiles for tax and 
spending items respectively. The constraint that each instrument cannot be used for an amount greater than one standard deviation of the cross-country distribution has been retained.

70. In the short- to medium-term as well as the long-term simulations, relaxing the constraint on instrument use in this manner makes it possible for countries to make much more of their adjustment with well ranked instruments (see Tables A2.9 to A2.14 for detailed results). The difference is particularly apparent for countries that make most of their adjustment through poorly ranked instruments in the main simulations. In the long-term packages, as mentioned above, Australia, New Zealand and the United States find themselves in this situation. When the constraint on instrument use is relaxed as presented here, almost three quarters of the adjustment is achieved with well ranked instruments in Australia, and about half in New Zealand and the United States.

71. At the other extreme, another possibility would be to constrain the room for manoeuvre at the median of OECD countries. In other words, for a tax instrument, the adjustment would be allowed only as long as a country does not raise more revenue with it, as a share of GDP, than half the OECD countries covered in the study. For a spending instrument, the limit on the room for manoeuvre would be to spend no less in this area than half the covered OECD countries. The asterisks appearing in Appendix tables A2.1A2.6 indicate all cases where the adjustment along one instrument crosses the median. The large number of asterisks in these tables illustrate that crossing the median is common in the simulations. Consequently, constraining the adjustment to stop at the median would result in greater use of poorly ranked instruments.

\section{The case for combining structural reforms and fiscal adjustment}

72. This section looks at the scope for potential efficiency gains in selected spending or tax areas where estimates are available. It then discusses the role of budgetary institutions in implementing strategies that combine reform and consolidation.

\subsection{Improving trade-offs between consolidation and other policy objectives through structural reform}

73. The illustrative consolidation packages identified in the previous section were designed without consideration for achieving efficiency gains. Cuts in expenditures were assumed to entail corresponding reductions in the provisions of public services (or benefits in the case of transfers) and increases in revenues were assumed to come through higher tax rates.Structural reforms, while desirable in their own right, can also ease the trade-offs between consolidation, equity and long-term growth objectives. Compared with pure budgetary changes, structural reforms in the area where taxes are raised or spending reduced can alleviate negative side-effects. In the most favourable cases, structural reform can even eliminate trade-offs and bring fiscal improvements as well as progress along growth or equity goals. Consistent with this view, some studies find that structural reforms makes fiscal consolidation more likely to succeed (Alesina and Ardagna, 2012; Mauro, 2011).

74. Structural reforms can also contribute to long run fiscal consolidation directly, even when they entail upfront budgetary costs. Measures that sustainably boost private-sector employment are likely to improve the budget balance permanently (OECD, 2013b) through tax base extension and lower spending on unemployment benefits. Structural reforms that improve productivity in general cannot be expected to result in permanently improved budget balances as public-sector wages and transfers catch up with higher private-sector wages over time. Nevertheless, by providing a boost to the level or growth rate of GDP, productivity-enhancing structural reforms have the potential to improve public debt dynamics and thereby reduce consolidation needs.

75. At a general level, structural reforms that improve efficiency in the delivery of public services can reduce the adverse growth impact of spending cuts in productive areas of government spending. 
Similarly, the negative equity impact of spending cuts can be headed off by structural reforms that ensure a better targeting of public services and transfers and stimulate labour supply. On the tax side, the growth impact of hikes can be reduced through the closing of loopholes and base broadening (including by curbing fraud and evasion) rather than via rate increases.

76. Despite their large potential payoffs, implementing structural reforms is fraught with difficulties. Even abstracting from political economy considerations, some reforms entail trade-offs themselves - for example, eliminating reduced VAT rates for basic necessities will bring revenue and efficiency gains but at the cost of hurting the poor. While trade-offs can often be alleviated by accompanying measures (like voucher programmes or targeted transfers, to pursue the same example), these sometimes reduce fiscal savings and involve other budget items, requiring an integrated rather than piecemeal approach. Such an approach is also essential in welfare reforms to avoid that beneficiaries switch between benefit types (Hagemann, 2012). Furthermore, reforms can in general do little to ease trade-offs between consolidation and short-term growth. More generally, one broad caveat attached to the estimates of potential efficiency gains reported in this section is that some of these margins have been used already, not least as a response to the crisis (OECD, 2013).

\section{Structural reforms to accompany reductions in selected individual spending areas}

77. In education, structural reforms can bring benefits along all fiscal, growth and equity dimensions. For instance, introducing tuition fees in higher education coupled with means-tested grants or loan guarantees can improve public finances, possibly spur growth by encouraging tertiary schooling completion and educational investment in areas with greater economic potential and help to correct the regressive impact of public spending on tertiary education (Hagemann, 2012). This regressive impact can also be tackled by reforms to make student performance at primary and secondary levels, and therefore access to tertiary education, less dependent on socio-economic background (Causa and Chapuis, 2009).

78. In primary and secondary education, a recent update of the analysis conducted by Sutherland et al. (2007) points to potentially sizeable efficiency gains in many OECD countries (Figure 14). ${ }^{18}$ In tertiary education, European OECD countries can potentially obtain savings from efficiency gains worth around $0.4 \%$ of GDP on average (St. Aubyn et al., 2009). Earlier and more recent OECD work has suggested that more performance monitoring, more school autonomy and greater user choice is associated with greater efficiency in the public provision of primary and secondary schooling (Sutherland and Price, 2007, Frederiksen, 2013). As it turns out, countries with the greatest potential for efficiency gains are generally not the ones with the largest consolidation needs, with the exception of the United States. However, in the United States, the need to address widening skill gaps identified in particular in the 2012 OECD Economic Survey points to a case for allocating efficiency gains to providing more and better education rather than cutting expenditure (OECD, 2012b).

18. This study uses data-envelopment analysis (DEA), a technique that relates outcomes with inputs and draws up an efficiency frontier based on the situation of the best performers. With a number of assumptions, countries can then be compared to this efficiency frontier to provide a rough indication of the extent to which they might achieve the same results with lower inputs. See Sutherland et al. (2007) for more details. 
Figure 14. Potential efficiency gains in primary and secondary education

Per cent of GDP, 2007

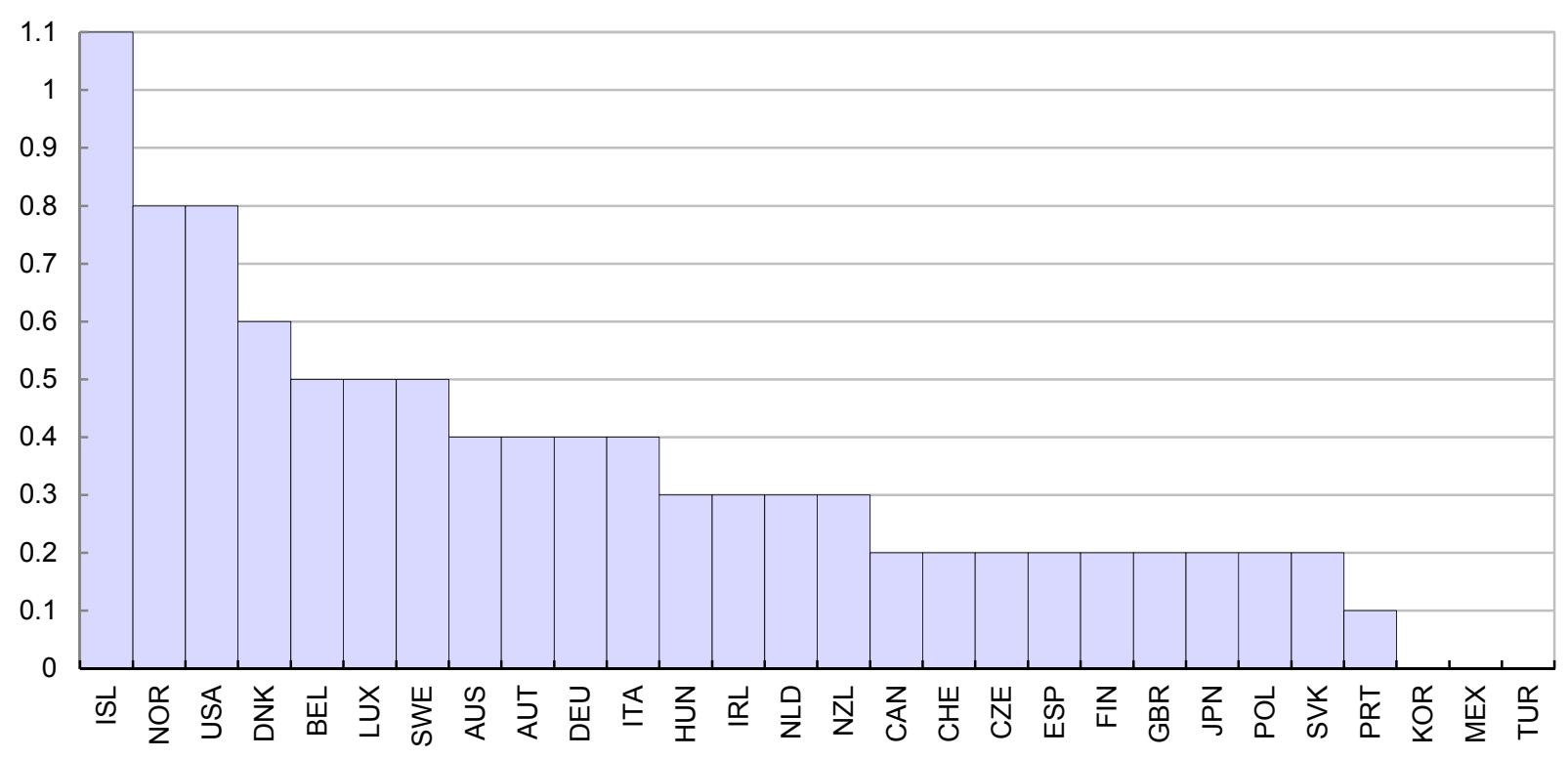

Note:. Data-envelopment analysis (DEA) has been performed to estimate by how much, given students' socio-economic background, spending could be reduced while maintaining the same average level and dispersion of PISA scores. See Sutherland et al. (2007) for more details.

Source: Update of Sutherland et al. (2007) reported in Hagemann (2012).

79. In health care, efficiency gains could also permit to improve or maintain service provision while containing cost to the public purse, therefore mitigating adverse growth and equity impacts (Hagemann, 2012). Although they are subject to considerable uncertainty, quantitative estimates suggest that the scope for efficiency gains in the health sector can potentially be very large (Figure 15). Previous OECD work emphasised that, while structural reforms to realise potential efficiency gains vary depending on the structure of health systems, some apply to most countries. In particular, better priority setting, improved consistency in responsibility assignment across levels of government, and better user information on the quality and price of services would be reform options to consider in many OECD countries (Joumard et al, 2010). 
Figure 15. Potential gains in life expectancy from improved efficiency in health care

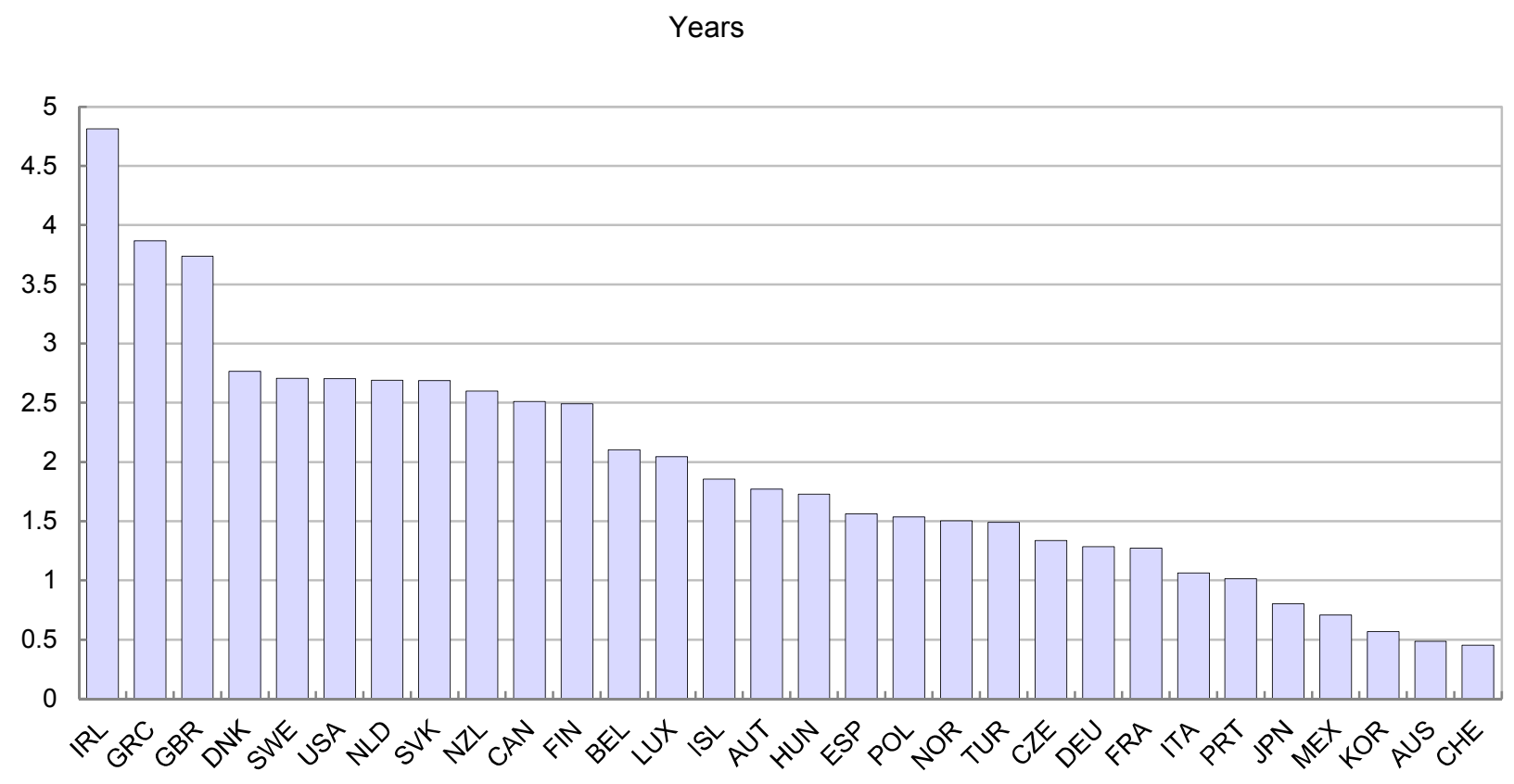

Note: Potential gains in life expectancy represent the number of years that could be gained by achieving the same efficiency in health-service provision as the frontier estimated through data envelopment analysis (DEA) in Joumard et al. (2010) with the same level of inputs. The results refer to the entire health sector as the estimation technique does not readily allow separating the public from the private sector because the boundary between public and private provision varies considerably across countries.

Source: Joumard et al. (2010).

\subsection{Structural reforms to accompany revenue increases}

80. On the tax side, the growth impact of hikes can be reduced through the closing of loopholes and base broadening (including by curbing tax avoidance and evasion) rather than via rate increases. Hence, an important way of improving the trade-off between raising more revenue and preserving growth-friendly incentives is to cut back tax expenditures. As regards personal and corporate income taxes, tax expenditures often distort resource allocation and hamper productivity growth: some examples are the preferential tax treatment of owner-occupied housing or the dispersion of effective corporate tax rates. Figure 16 gives estimates from two different studies for corporate and personal income taxes. Despite the large margins of uncertainty surrounding the reported figures, in countries like Canada, Spain, United Kingdom or the United States even the smallest of the two estimates is very large, amounting to about one third to one half of short- to medium-term consolidation needs. Structural reforms in personal and corporate income taxes that curb tax expenditures will also in general lead to a more equal income distribution. 
Figure 16. Tax expenditures in personal and corporate income taxes

Different years between 2004 and 2008, per cent of GDP

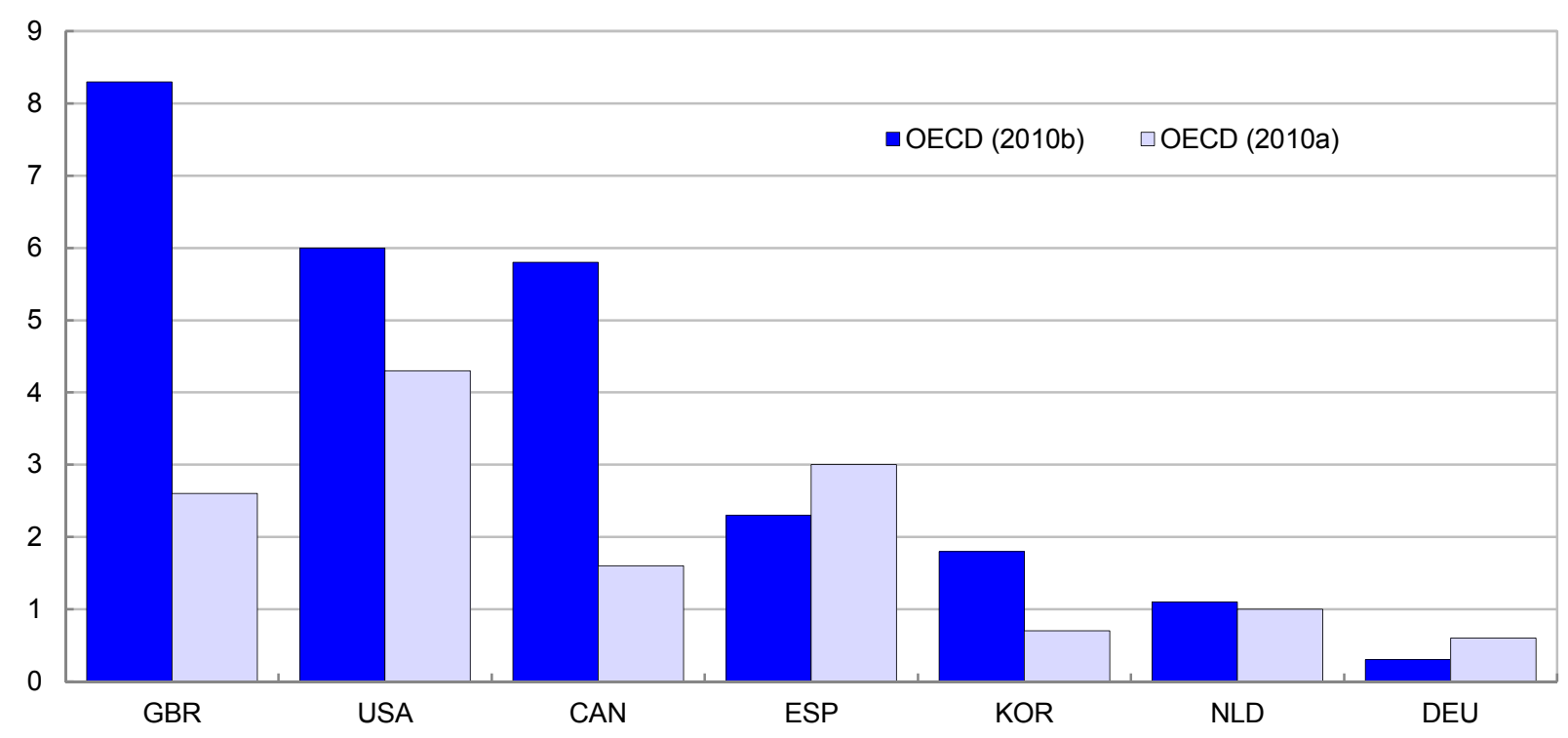

Note: international comparisons are subject to important limitations, as countries use different definitions of tax expenditures. For a given country, comparisons across studies are also hampered by factors like different years and inconsistencies in filling the questionnaires used to collect information (e.g. in OECD (2010a) some countries reported only the 20 largest items, and others only those at central government level).

81. However, the recommendation of structural tax reform to eliminate tax breaks cannot be made across the board as some measures work to preserve productive potential or to alleviate poverty or both. Such is the case of tax credits for low-income earners, which tackle poverty traps created by other parts of the tax and transfer system. Another important example are well-designed corporate income tax credits for research and development activities, which can provide remuneration for the growth-enhancing externalities from R\&D (Jaumotte and Pain, 2005; Johansson et al., 2008, Westmore, 2013).

82. In the area of consumption taxes, base-broadening reforms can bring in additional proceeds and reduce distortions detrimental to growth. If accompanied by targeted measures towards poorer households (for instance voucher programmes), abolishing reduced value-added or consumption tax rates can improve public finances without negative consequences for equity, at very low cost for growth (although targeted transfers involve a risk of contributing to poverty traps). Although crude and subject to important caveats (see note to Figure 17), the so-called VAT revenue ratio is the most readily available indicator to provide illustrative estimates, on a cross-country basis, of the scope for base-broadening. The ratio compares actual VAT revenue to the standard VAT rate multiplied by final consumption expenditure. The very high estimates shown in Figure 16 are uncertain and difficult to achieve in full including because the tax base would shrink in response to higher rates. Nevertheless, their sheer size suggests that, even after factoring in the costs of accompanying distributional measures, base broadening can yield substantial additional revenues while reducing cross-sector distortions. 
Figure 17. VAT revenue ratio and illustrative potential efficiency gains in the VAT system

Per cent of GDP

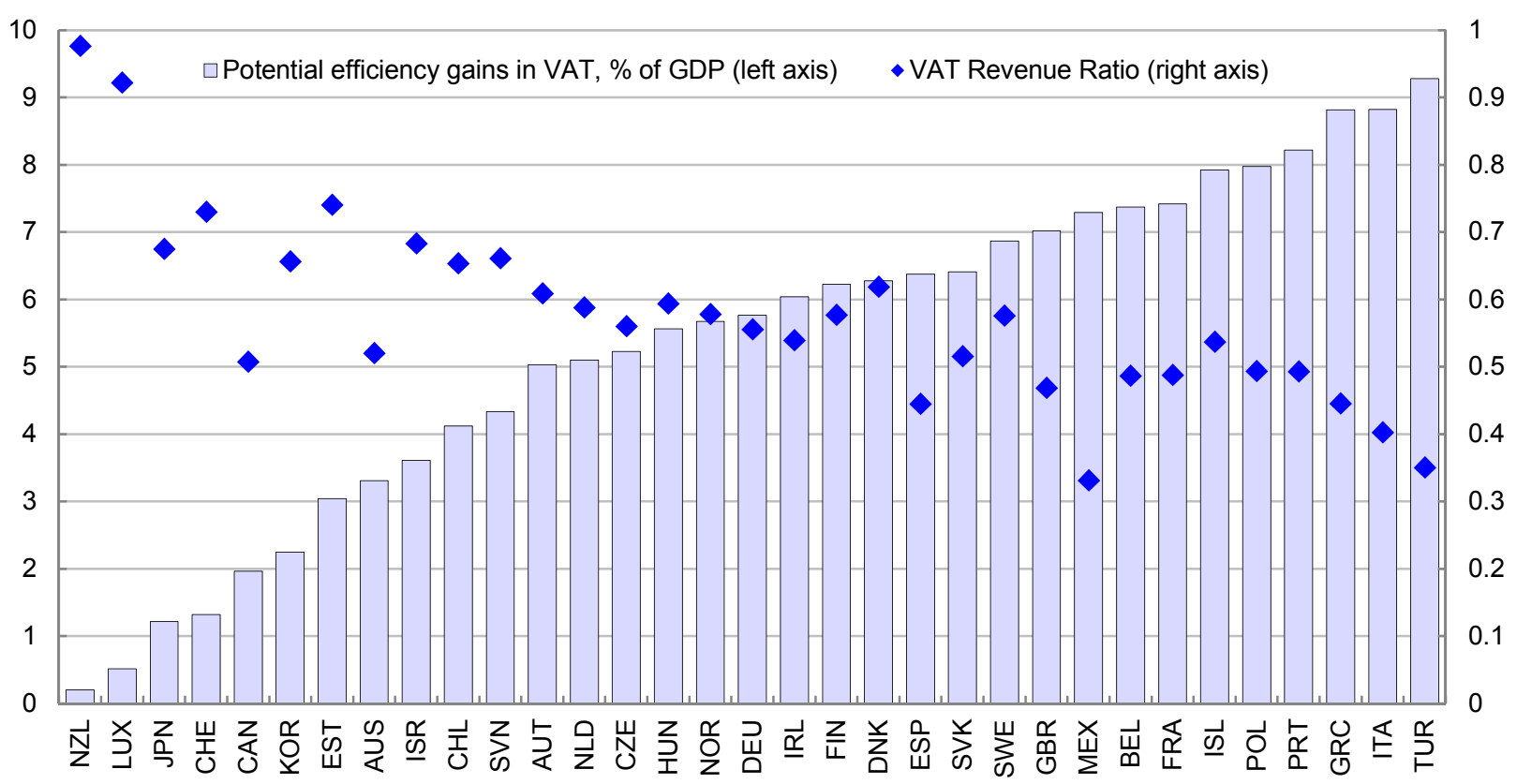

Note: The VAT revenue ratio (VRR) is calculated as total VAT receipts from OECD revenue statistics divided by an estimate of potential VAT revenues. This estimate is equal to the standard VAT rate multiplied by final consumption expenditure in national accounts (excluding VAT receipts). The estimates of potential efficiency gains shown in the chart are calculated strictly for illustrative purposes by assuming that the VRR can be raised to one. This simple calculation neglects that final consumption as calculated for national accounts purposes differs from the VAT tax base. For instance, imputed rents on owner-occupied housing and government services provided free of charge are included in final consumption but not the VAT tax base. In particular, making the government pay VAT to itself on the services it provides without charge would produce no net budget gain. On the other hand, final consumption does not include housing construction, which is subject to VAT in many countries.

Source: OECD (2012) Consumption Tax Trends and OECD calculations.

83. As regards property taxes, broadening bases by regularly bringing real estate taxable values in line with market valuations could yield equity gains in addition to bringing in additional revenues and reducing distortions. In many countries cadastral values have become outdated, often by a large margin (by way of example Austria, Belgium and France last carried out a housing valuation exercise three or four decades ago). Though the redistributive impact of updating is complex, being felt across individuals, generations and territorial units, it will tend to be progressive at least if account is taken of the distribution of wealth, and not merely of current income. Even on the basis of the latter, equity gains will ensue if those residing in buildings with more outdated values (often older buildings in city centres) tend to enjoy aboveaverage income. Admittedly, updating cadastral values will raise difficulties for old people living on low pensions in large old houses, but this issue could be addressed by offering those taxpayers the option of paying this part of taxes in a deferred manner on their estate after their death. More generally, making the property tax structure more progressive would be an option to help offset harmful equity effects from other consolidation measures. 


\subsection{Implementing structural-consolidation policy strategies}

\section{Designing and implementing fiscal consolidation and structural reform jointly}

84. Policy strategies are desirable to take full advantage of the complementarities between fiscal consolidation and structural reform that have been outlined in the previous section. ${ }^{19}$ Even though consolidation, especially if it is large, necessarily involves deep changes in parameters of taxation and spending, these changes do not in themselves amount to effective structural reform. International experience suggests that in fast-paced consolidation episodes the need for quick spending reductions or tax increases means that the changes in tax and spending parameters introduced for consolidation purposes often tend to be at odds with efficiency objectives (OECD, 2009b). In particular, when the main objective is to achieve fiscal results quickly, it appears very difficult to introduce effective structural reforms in areas such as pension and health care where long lead times are required (Larch and Turrini, 2008). Furthermore, case studies presented in OECD (2009b) point out that changes in tax and spending items that are presented to the public as needed essentially for fiscal adjustment can meet strong, sometimes successful, pressure to reverse them once consolidation is achieved. These lessons from experience indicate that effective structural reform does not necessarily ensue from fiscal consolidation efforts, highlighting the benefits of putting in place policy strategies that explicitly combine fiscal and structural efforts in a common framework.

\section{Improving efficiency through better public sector governance}

85. Reforms to deliver public services more efficiently have an important role to play in structuralconsolidation strategies in particular since, as discussed above, they can ease the trade-offs between spending-side consolidation instruments and growth and equity objectives. Performance-based budgeting, which gauges performance against specified output measures, provides a way of encouraging efficiency gains (Curristine, Lonti and Joumard, 2007; OECD, 2007b). Econometric comparisons across US states suggest that the introduction of performance-based budgeting tends to reduce aggregate public spending (Crain and O'Roark, 2004). The wide variation in the use of performance-budgeting across OECD countries at the central government level (Figure 18) suggests that many OECD governments have significant scope for reform in this direction.

19. Those structural reforms that might have contractionary effects in the short run could be seen as substitutes for fiscal consolidation since both ease the burden on future generations (through higher output or lower legacy debt respectively) at a cost to the current ones (Teulings, 2012). However, the track record of structural reforms in OECD countries suggests that there is at most weak empirical evidence that a very limited number of structural reforms may reduce aggregate output in the short term (Bouis et al., 2012). 
Figure 18. Use of performance budgeting at the central level of government Index varying from 0 (no use of performance budgeting) to 1 (high use), 2007

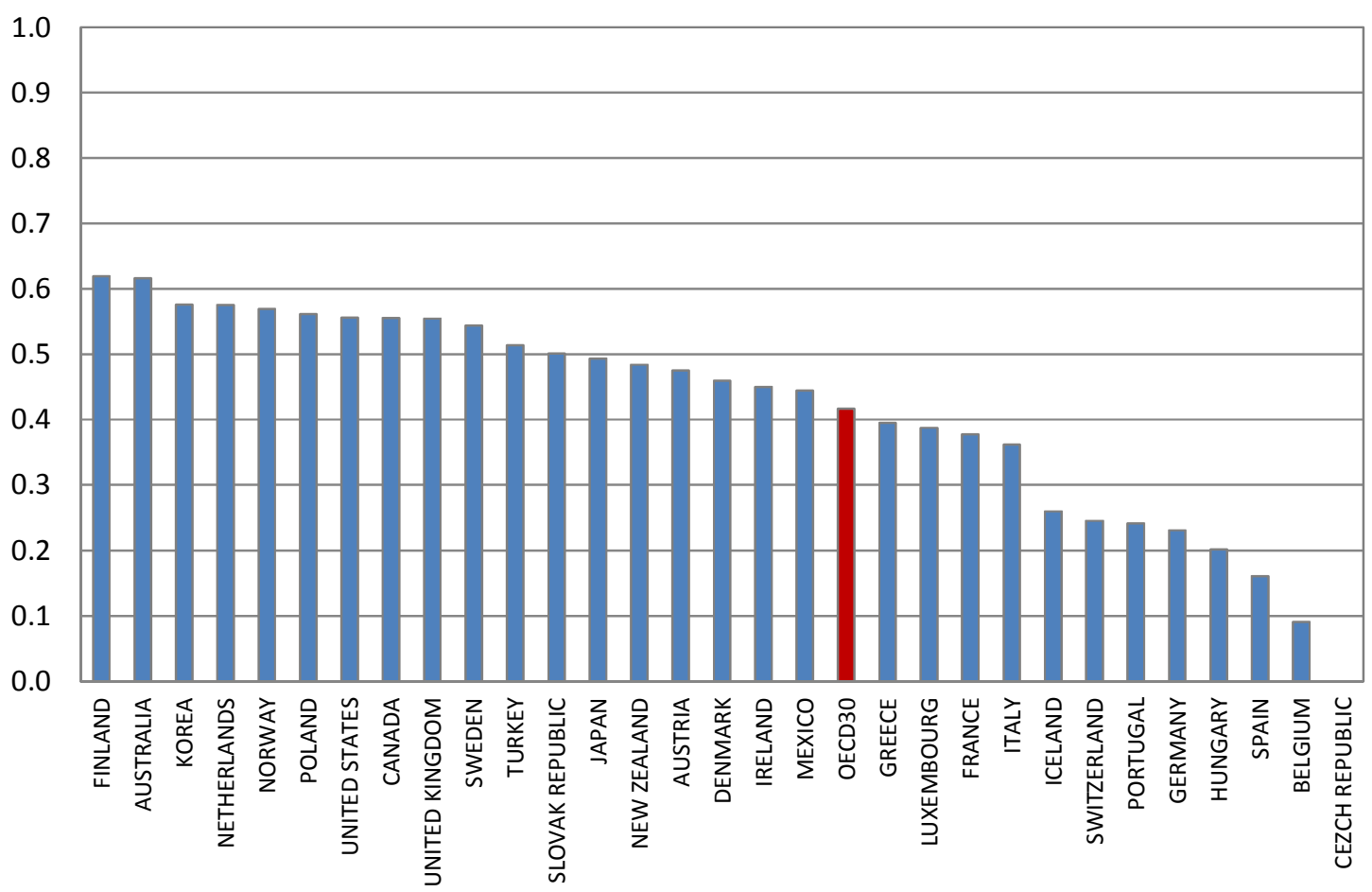

Source: OECD (2009c)

\section{Mobilising all levels of government}

86. The distribution of tax and spending powers across levels of government can influence its efficiency. Although this distribution is often at least partly rooted in constitutional arrangements, it can evolve during consolidation episodes. Fiscal consolidation often involves cuts in intergovernmental grants to sub-central levels of government (Vammalle and Hulbert, 2013), and the evidence is that such cuts make consolidation efforts more likely to prove successful (Blöchliger, 2012) Insofar as reductions in intergovernmental transfers lead sub-central levels of government to rely more on their own tax revenues, this could be favourable to economic growth. Recent evidence suggests that the aggregate growth benefits of decentralisation derive primarily from the decentralisation of revenue raising (Blöchliger, 2013; Blöchliger and Égert, 2013).

87. Some countries may face the challenge that consolidation measures are unevenly distributed across government levels. In particular, the consolidation instruments in the top third of the illustrative short- to medium-term generic ranking (subsidies, pensions, other property taxes, unemployment benefits and personal and corporate income taxes) in many countries fall predominantly within the accounts of the central government (Figure 19). The bottom third of the illustrative generic ranking of instruments includes large spending items (education, health and public investment) which are paid largely by local governments in many countries (Figure 20). In countries where this discrepancy could result in consolidation being undertaken with most measures concentrated at the central level on unchanged institutional arrangements, it may call for adjusting fiscal relations across government levels. 
Figure 19. Share of central government in subsidies paid and direct taxes received Per cent, 2009

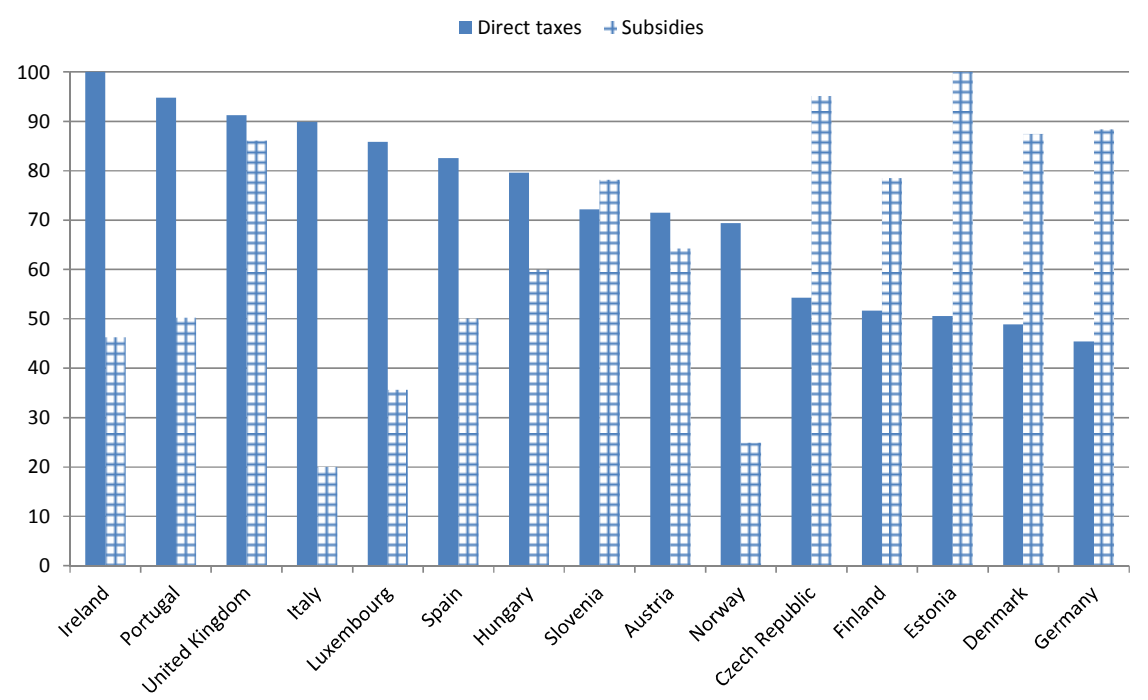

Note: Direct taxes include personal and corporate income taxes as well as property taxes.

Source: OECD National Accounts

Figure 20. Share of local and state governments in public spending on education, health and investment

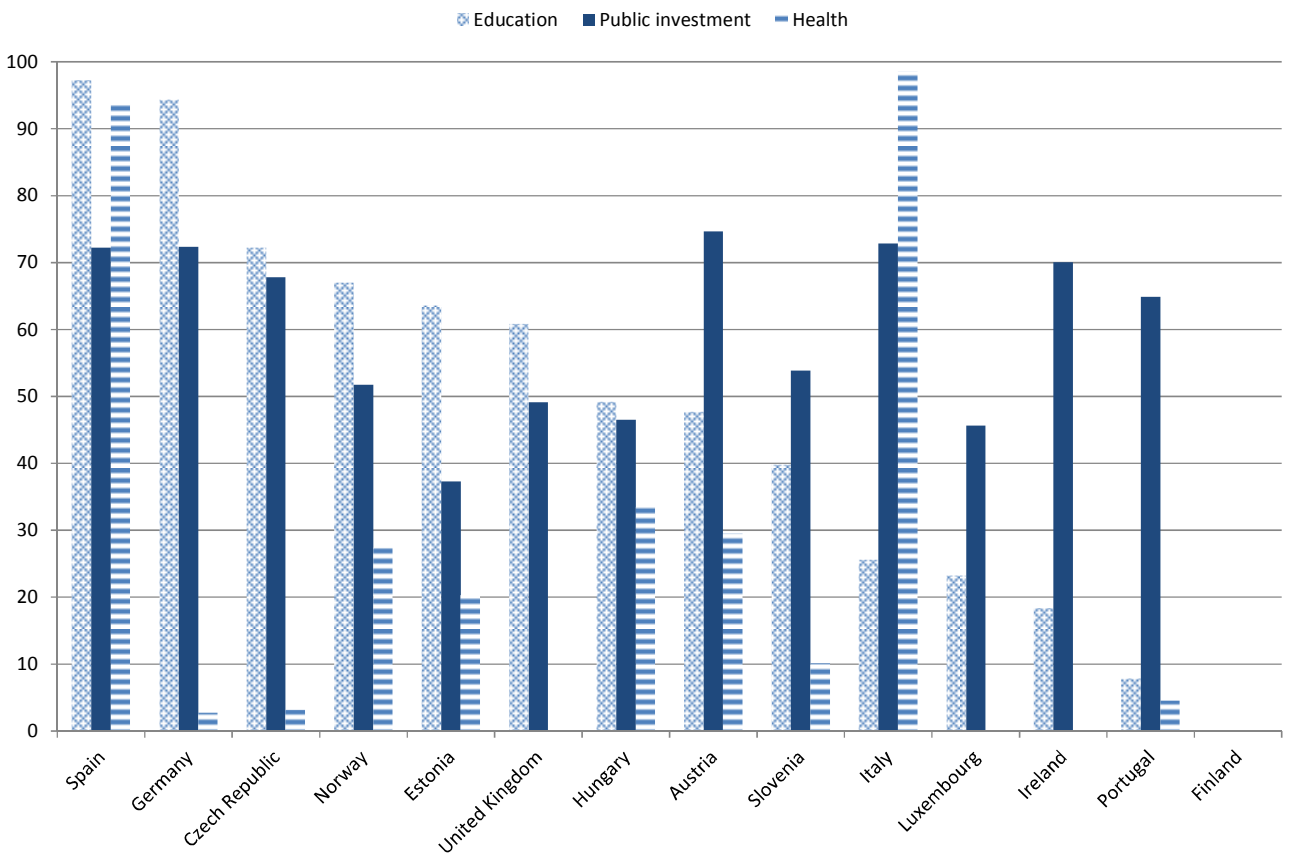

Source: OECD National Accounts

\section{Concluding remarks}

88. The present study proposed a structured way of looking at consolidation instruments in the light of their consequences on other economic objectives, namely short-term demand effects, long-term growth effects, short- and long-term effects on equity and medium-term effects on the current account. While different consolidation strategies can minimise adverse impacts on growth, equity and the current account, quantitative simulations have been provided to illustrate how deep adjustments in better instruments would 
have to go in order to avoid relying too much on more harmful instruments. In the design of actual consolidation strategies, these illustrative simulations cannot substitute for the necessary analysis of how country circumstances shape the effect of a package of spending reductions, tax increases and structural reforms.

89. Despite their limitations, the simulations, which are found to be broadly robust to uncertainty about the effects of consolidation instruments on other policy objectives, support three main conclusions. Firstly, instrument prioritisation offers most countries real possibilities to adjust fiscal balances without much harm to other economic objectives. Secondly, some OECD countries find themselves in a more challenging situation where it may be appropriate to use better instruments more aggressively than assumed in the main simulations. Thirdly, coupling fiscal adjustment with structural reform is a way of making fiscal consolidation more compatible with other policy objectives and more likely to be successful.

\section{REFERENCES}

Alesina, A. and S. Ardagna (2010), "Large Changes in Fiscal Policy: Taxes vs. Spending”, in Tax Policy and the Economy, Vol. 24, The University of Chicago Press.

Alesina, R. and S. Ardagna (2012), "The Design of Fiscal Adjustments", NBER Working Paper Series, No. 18423.

Auerbach, A. J. and Y. Gorodnichenko (2012), Measuring the Output Responses to Fiscal Policy, American Economic Journal: Economic Policy 2012, 4(2): 1-27.

Barbiero, O. and B. Cournède (2013), "New Econometric Estimates of Long-Term Growth Effects of Different Areas of Public Spending", OECD Economics Department Working Papers, forthcoming.

Baum, A., M. Poplawski-Ribeiro and A. Weber (2012), "Fiscal Multipliers and the State of the Economy", IMF Working Paper, No. 12/286, IMF, Washington DC.

Barrell, R., D. Holland and I. Hurst (2012), "Fiscal Consolidation Part 2: Fiscal Multipliers and Fiscal Consolidation", OECD Economics Department Working Papers, No. 933, OECD.

Blöchliger, H. (2012), "Fiscal Consolidation Across Government Levels", paper presented to the joint IMF-OECD Fiscal Workshop on Instruments of Fiscal Consolidation, Paris, 11-12 November, available at http://www.oecd.org/eco/public-finance/jointimf-oecdfiscalworkshop.htm

Blöchliger, H., D.-H. Song and D. Sutherland (2012), "Fiscal Consolidation Part 4: Case Studies of Large Fiscal Consolidation Episodes," OECD Economics Department Working Papers, No. 935.

Blöchliger, H.J. (2013), "Decentralisation and Growth Part 1: Decentralisation, Economic Activity and Educational Performance", OECD Economics Department Working Papers, forthcoming. 
Blöchliger, H.J. and B. Égert (2013), "Decentralisation and Growth Part 2: Decentralisation and its Impact on Economic Activity, Productivity and Investment", OECD Economics Department Working Papers, forthcoming.

Bouis, R., B. Cournède and A. K. Christensen (2012), "Implications of Output Gap Uncertainty in Times of Crisis", OECD Economics Department Working Papers, No. 977, OECD, Paris.

Bouis, R., R. Duval and F. Murtin (2011), “The Policy and Institutional Drivers of Economic Growth Across OECD and Non- OECD Economies", OECD Economic Department Working Papers, No. 843.

Bouis, R., O. Causa, L. Demmou, R. Duval and A. Zdzienicka (2012), "The Short-Term Effects of Structural Reforms: An Empirical Analysis", OECD Economics Department Working Papers, No. 949, OECD, Paris.

Causa, O. and C. Chapuis (2009), "Equity in Student Achievement Across OECD Countries: An Investigation of the Role of Policies", OECD Economics Department Working Papers, No. 708, OECD Publishing.

Causa, O. and Å. Johansson (2009), "Intergenerational Social Mobility”, OECD Economics Department Working Papers, No. 707, OECD, Paris.

Christiano, L., M. Eichenbaum, and S. Rebelo (2011), When Is the Government Spending Multiplier Large?, Journal of Political Economy, Vol. 119, No. 1 (February 2011), pp. 78-121.

Corsetti, G., A. Meier and G. J. Müller (2012), What Determines Government Spending Multipliers?, Economic Policy, October 2012, pp. 521-565.

Cournède, B. and F. Gonand (2006). "Restoring Fiscal Sustainability in the Euro Area: Raise Taxes or Curb Spending?," OECD Economics Department Working Papers, No. 520, OECD.

Crain, W. M. and J. B. O'Roark (2004), “The Impact of Performance-Based Budgeting on State Fiscal Performance", Economics of Governance, Vol. 5.

Curristine, T., Z. Lonti and I. Joumard (2007), "Improving Public Sector Efficiency: Challenges and Opportunities," OECD Journal on Budgeting, Vol. 7 No. 1, OECD, Paris.

DeLong, J. B. and Summers, L. H. (2012), Fiscal Policy in a Depressed Economy, Brookings Papers on Economic Activity: Spring 2012

Devries, P., J. Guajardo, D. Leigh and A. Pescatori (2011), "A New Action-Based Dataset on Fiscal Consolidation," IMF Working Paper, No. 11/128, Washington DC.

European Commission (2012), “Fiscal Sustainability Report 2012”, European Economy, Vol. 8/2012.

Fredriksen, K. (2013), "Decentralisation and Growth Part 3: Decentralisation, Public Investment and Educational Performance," OECD Economics Department Working Papers, forthcoming.

Goujard, A. (2013), "Cross-country spillovers from fiscal consolidation", OECD Economics Department Working Papers, forthcoming. 
Guichard, S. and E. Rusticelli, (2010), "Assessing the Impact of the Financial Crisis on Structural Unemployment in OECD Countries", OECD Economics Department Working Papers, No. 767, OECD, Paris.

Hagemann, R. (2012), "Fiscal Consolidation: Part 6. What Are the Best Policy Instruments for Fiscal Consolidation?”, OECD Economics Department Working Papers, No. 937, OECD, Paris.

Hoeller, P. et al. (2012), "Less Income Inequality and More Growth - Are They Compatible? Part 1. Mapping Income Inequality Across the OECD", OECD Economics Department Working Papers, No. 924, OECD Publishing.

IMF (2010), "Will it Hurt? Macroeconomic Effects of Fiscal Consolidation", IMF World Economic Outlook, Chapter 3, October, Washington DC.

Jaumotte, F. and N. Pain (2005), "Innovation in the Business Sector," OECD Economics Department Working Papers, No. 459, OECD, Paris.

Johansson, Å, C. Heady, J. Arnold, B. Brys and L. Vartia (2008), "Taxation and Economic Growth", OECD Economics Department Working Papers, No. 620, OECD, Paris.

Johansson, A., D. Turner, Y. Guillemette, F. Murtin, C. de la Maisonneuve, P. Bagnoli, G. Bousquet and F. Spinelli (2013), "Long-term Growth Scenarios," OECD Economics Department Working Papers No. 1000, OECD, Paris.

Joumard, I., M. Minegishi, C. André, C. Nicq and R. Price (2008), “Accounting for one-off operations when assessing underlying fiscal positions," OECD Economics Department Working Papers, No. 642.

Joumard, I., P. Hoeller, C. André and C. Nicq (2010), "Health Care Systems: Efficiency and Policy Settings", OECD, Paris.

Kerdrain, C., I. Koske and I. Wanner (2010), “The Impact of Structural Policies on Saving, Investment and Current Accounts”, OECD Economics Department Working Papers, No. 815, OECD Publishing.

Koen, V. and P. van den Noord (2006), "Fiscal gimmickry in Europe: one-off measures and creative accounting," in Wierts, P., S. Deroose, E. Flores and A. Turrini (eds), Fiscal Policy Surveillance in Europe, Palgrave Macmillan.

Kopczuk, W. (2007), "Bequest and Tax Planning: Evidence from Estate Tax Retuns”, Quarterly Journal of Economics, MIT Press, Vol. 122.

Larch, M. and A. Turini (2008), "Received Wisdom and Beyond: Lessons from Fiscal Consolidations in the EU", European Economy.

de la Maisonneuve, C. and J. Oliveira Martins (2013), "Public Spending on Health and Long-Term Care : A New Set of Projections", OECD Economics Department Working Paper, forthcoming.

Mauro, P. (ed.) (2011), Chipping Away at Public Debt, Wiley.

Molnar, M. (2012), "Fiscal Consolidation Part 5: What Factors Determine the Success of Consolidation Efforts?”, OECD Economics Department Working Papers, No. 936. 
ECO/WKP(2013)80

OECD (2009), "The Effectiveness and Scope of Fiscal Stimulus," OECD Economic Outlook: Interim Report, March, OECD, Paris.

OECD (2003), The Sources of Growth in OECD Countries, OECD, Paris.

OECD (2007a), Babies and Bosses: Reconciling Work and Family Life, OECD, Paris.

OECD (2007b), Performance Budgeting in OECD Countries, OECD, Paris.

OECD (2009a), Interim OECD Economic Outlook, OECD, Paris.

OECD (2009b), The Political Economy of Reform: Lessons from Pensions, Product Markets and Labour Markets in Ten OECD Countries, OECD, Paris.

OECD (2009c), Government at a Glance 2009, OECD, Paris.

OECD (2010a), Choosing a Broad Base-Low Rate Approach to Taxation, OECD, Paris.

OECD (2010b), OECD Economic Outlook No.88, November, OECD, Paris.

OECD (2010c), Tax Expenditures in OECD Countries, OECD, Paris.

OECD (2011a), Pensions At a Glance: Retirement Income Systems in OECD and G20 Countries, OECD, Paris.

OECD (2011b), Doing Better for Families, OECD, Paris.

OECD (2011c), Going for Growth: Economic Policy Reforms, OECD, Paris.

OECD (2011d), Divided We Stand: Why Inequality Keeps Rising, OECD, Paris.

OECD (2012a), "Financial Contagion in the Era of Globalised Banking?", OECD Economics Department Policy Notes, No. 14, June.

OECD (2012b), OECD Economic Surveys: United States, OECD, Paris.

OECD (2013a), OECD Economic Outlook, No. 93, May, OECD, Paris..

OECD (2013b), Economic Policy Reforms 2013: Going for Growth, OECD, Paris.

Ollivaud, P. and C. Schwellnus (2013), "International Imbalances: Recent Developments and MediumTerm Outlook", OECD Economics Department Working Papers, forthcoming.

Padoan, P.C., U. Sila and P. van den Noord (2012), “Avoiding Debt Traps: Fiscal Consolidation, Financial Backstops and Structural Reforms”, OECD Journal: Economic Studies, OECD.

Rawdanowicz, L. E. Wurzel, and P. Ollivaud (2011), "Current Issues in Managing Government Debt and Assets”, OECD Economics Department Working Papers, No. 923.

Rawdanowicz, L. (2012), "Choosing the Pace of Fiscal Consolidation," OECD Economics Department Working Papers, No. 992, OECD, Paris. 
Rawdanowicz, L., E. Wurzel and A. K. Christensen (2013), “The Equity Implications of Fiscal Consolidation”, OECD Economics Department Working Papers, No. 1013, OECD, Paris.

Röhn, O. (2010), "New Evidence on the Private Saving Offset and Ricardian Equivalence", OECD Economics Department Working Papers No. 762.Schwellnus, C. and J.M. Arnold (2008), "Do Corporate Taxes Reduce Productivity and Investment at the Firm Level? Cross-Country Evidence From the Amadeus Dataset", OECD Economics Department Working Papers No. 641.

de Serres, A., F. Murtin and G. Nicoletti (2010), "A Framework for Assessing Green Growth Policies", OECD Economics Department Working Papers, No. 774, OECD;

Serret, Y. and N. Johnstone (2006), Ed., The Distributional Effects of Environmental Policy, OECD.

St. Aubyn, M., A. Pina, F. Garcia and J. Pais (2009), Study On The Efficiency and Effectiveness of Public Spending on Tertiary Education, Economic Papers, No. 390, European Commission, DirectorateGeneral for Economic and Financial Affairs.

Sutherland, D. and R. Price (2007), "Linkages Between Performance and Institutions in the Primary and Secondary Education Sector”, OECD Economics Department Working Papers, No. 558.

Sutherland, D. , P. Hoeller, B. Égert and O. Roehn (2010), "Counter-Cyclical Economic Policy”, OECD Economics Department Working Papers, No. 760, OECD.

Sutherland, D., P. Hoeller and R. Merola (2012), "Fiscal Consolidation: Part1. How Much is Needed to Reduce Debt to a Prudent Level?", OECD Economics Department Working Papers, No. 932.

Turner, D. and F. Spinelli (2012) "Explaining the Interest-Rate-Growth Differential Underlying Government Debt Dynamics", OECD Economics Department Working Papers, No. 919.

Vammalle, C. and C. Hulbert (2013), "Sub-National Finances and Fiscal Consolidation: Walking on Thin Ice”, OECD Regional Development Working Papers, No. 2013/02, OECD, Paris.

Vartia, L. (2008), "How do Taxes Affect Investment and Productivity? An industry-level analysis of OECD countries", OECD Economics Department Working Papers No. 656.

Westmore, B (2013), "R\&D, Patenting and Productivity: The Role of Public Policy", OECD Economics Department Working Paper (forthcoming), OECD, Paris.

Whiteford, P. and W. Adema (2007), "What Works Best in Reducing Child Poverty: A Benefit or Work Strategy?", OECD Social, Employment and Migration Working Papers, No. 51, OECD, Paris. 


\section{APPENDIX 1. DETAILED COMPOSITION OF CONSOLIDATION PACKAGES}

90. The present section provides detailed quantitative information about the illustrative consolidation packages presented in Section 5 of the main text. Tables A1.1 to A1.5 provide results about the illustrative short- to medium-term consolidation packages of countries with one table per cluster. Table A1.6 details the illustrative long-term consolidation packages for all covered countries. The instruments used are as described in Section 2 of Appendix 1. The categories "used spending residual" and "used revenue residual" refer to the part of the adjustment that is achieved through residual items of primary expenditure and receipts which are not considered as instruments of consolidation as they have no direct economic interpretation. However, there is no reason to assume that they remain constant as a share of potential GDP when other budgetary items adjust, so the assumption is made that they remain fixed as shares of total primary spending or revenues (whichever is relevant). 
ECO/WKP(2013)80

Table A1.1. Instrument use and achieved short- to medium-term consolidation vs. needs in Cluster No. 1 Percentages of potential GDP except otherwise mentioned

\begin{tabular}{|c|c|c|c|c|c|c|c|c|c|}
\hline description & AUS & CAN & GBR & ISR & ITA & JPN & NZL & POL & PRT \\
\hline \multirow[t]{2}{*}{ Subsidies } & $0.6^{*}$ & 0.3 & 0 & 0 & 0.3 & 0 & 0 & 0 & 0 \\
\hline & $(0.6-0.6)$ & $(0.3-0.3)$ & $(0.0-0.0)$ & $(0.0-0.0)$ & $(0.0-0.3)$ & $(0.0-0.0)$ & $(0.0-0.0)$ & $(0.0-0.0)$ & $(0.0-0.0)$ \\
\hline \multirow[t]{2}{*}{ Other property taxes } & 0 & $0.5 *$ & 0.2 & 0.2 & 0 & $0.4^{*}$ & $0.7 *$ & $0.7^{*}$ & $0.4^{*}$ \\
\hline & $(0.0-0.0)$ & $(0.5-0.5)$ & $(0.2-0.2)$ & $(0.2-0.2)$ & $(0.0-0.0)$ & $(0.4-0.4)$ & $(0.7-0.7)$ & $(0.7-0.7)$ & $(0.3-0.3)$ \\
\hline \multirow[t]{2}{*}{ Pensions } & 0 & 0 & 0.3 & 0.2 & 0.3 & 0.8 & 0 & 0.9 & 0.9 \\
\hline & $(0.0-0.0)$ & $(0.0-0.0)$ & $(0.3-0.3)$ & $(0.0-0.2)$ & $(0.0-0.7)$ & $(0.8-0.8)$ & $(0.0-0.0)$ & $(0.0-0.9)$ & $(0.9-0.9)$ \\
\hline \multirow[t]{2}{*}{ Corporate income taxes } & 0 & 0.2 & $0.4 *$ & 0 & 0 & 0 & 0 & $0.9^{*}$ & 0.2 \\
\hline & $(0.0-0.0)$ & $(0.0-0.2)$ & $(0.4-0.4)$ & $(0.0-0.0)$ & $(0.0-0.3)$ & $(0.0-0.0)$ & $(0.0-0.0)$ & $(0.0-0.9)$ & $(0.0-0.2)$ \\
\hline \multirow[t]{2}{*}{ Personal income taxes } & 0 & 0 & 0.5 & 1.3 & 0 & $4.6^{*}$ & 0 & 1.3 & $4.1^{*}$ \\
\hline & $(0.0-0.0)$ & $(0.0-0.0)$ & $(0.5-0.5)$ & $(0.0-1.5)$ & $(0.0-0.0)$ & $(4.6-4.6)$ & $(0.0-0.0)$ & $(0.0-2.7)$ & $(3.9-4.1)$ \\
\hline Recurrent taxes on & 0 & 0 & 0 & 0 & 0 & 0 & 0 & 0 & $0.8^{*}$ \\
\hline immovable property & $(0.0-0.0)$ & $(0.0-0.0)$ & $(0.0-0.0)$ & $(0.0-0.0)$ & $(0.0-0.0)$ & $(0.0-0.0)$ & $(0.0-0.0)$ & $(0.0-0.3)$ & $(0.0-0.8)$ \\
\hline \multirow[t]{2}{*}{ Unemployment benefits } & 0 & $0.2 *$ & 0 & 0 & 0 & 0.3 & 0 & 0 & 0.3 \\
\hline & $(0.0-0.0)$ & $(0.0-0.2)$ & $(0.0-0.0)$ & $(0.0-0.0)$ & $(0.0-0.0)$ & $(0.3-0.3)$ & $(0.0-0.0)$ & $(0.0-0.0)$ & $(0.0-0.3)$ \\
\hline \multirow[t]{2}{*}{ Environmental taxes } & $0.7^{*}$ & 0.7 & $0.2 *$ & 0 & 0 & 0.7 & 0.7 & 0 & 0.2 \\
\hline & $(0.0-0.7)$ & $(0.0-0.7)$ & $(0.2-0.2)$ & $(0.0-0.0)$ & $(0.0-0.0)$ & $(0.7-0.7)$ & $(0.0-0.7)$ & $(0.0-0.7)$ & $(0.0-0.2)$ \\
\hline \multirow{2}{*}{$\begin{array}{l}\text { Other gov. in kind } \\
\text { consumption }\end{array}$} & 0.6 & 0.6 & $2.2 *$ & 0 & 0 & 0 & 0 & 0 & 0.2 \\
\hline & $(0.0-1.0)$ & $(0.0-1.8)$ & $(2.2-2.2)$ & $(0.0-1.3)$ & $(0.0-0.0)$ & $(0.0-0.0)$ & $(0.0-0.0)$ & $(0.0-1.1)$ & $(0.0-0.6)$ \\
\hline \multirow{2}{*}{$\begin{array}{l}\text { Sales of goods and } \\
\text { services }\end{array}$} & 0 & 0 & $0.7^{*}$ & 0 & 0 & $1.0^{*}$ & 0 & 0 & 0 \\
\hline & $(0.0-0.0)$ & $(0.0-0.0)$ & $(0.7-0.7)$ & $(0.0-0.0)$ & $(0.0-0.0)$ & $(1.0-1.0)$ & $(0.0-0.0)$ & $(0.0-0.0)$ & $(0.0-0.3)$ \\
\hline \multirow{2}{*}{$\begin{array}{l}\text { Consumption taxes (other } \\
\text { than environmental) }\end{array}$} & 0 & 0 & $1.4 *$ & 0 & 0 & 2.5 & 0 & 0 & 0 \\
\hline & $(0.0-0.6)$ & $(0.0-0.8)$ & $(0.0-1.4)$ & $(0.0-0.0)$ & $(0.0-0.0)$ & $(2.5-2.5)$ & $(0.0-0.0)$ & $(0.0-0.0)$ & $(0.0-0.6)$ \\
\hline \multirow[t]{2}{*}{ Public investment } & 0 & 0 & 0.3 & 0 & 0 & 1.1 & 0.2 & 0 & 0 \\
\hline & $(0.0-0.6)$ & $(0.0-0.6)$ & $(0.0-0.3)$ & $(0.0-0.0)$ & $(0.0-0.0)$ & $(1.1-1.1)$ & $(0.0-0.9)$ & $(0.0-0.0)$ & $(0.0-0.0)$ \\
\hline \multirow{2}{*}{$\begin{array}{l}\text { Sickness and disability } \\
\text { payments }\end{array}$} & 0 & 0 & $0.7^{*}$ & 0 & 0 & 0 & 0 & 0 & 0 \\
\hline & $(0.0-0.0)$ & $(0.0-0.0)$ & $(0.0-0.7)$ & $(0.0-0.0)$ & $(0.0-0.0)$ & $(0.0-0.0)$ & $(0.0-0.4)$ & $(0.0-0.0)$ & $(0.0-0.2)$ \\
\hline \multirow{2}{*}{$\begin{array}{l}\text { Health services provided } \\
\text { in kind }\end{array}$} & 0 & 0 & $1.5^{*}$ & 0 & 0 & $1.5^{*}$ & 0 & 0 & 0 \\
\hline & $(0.0-0.0)$ & $(0.0-0.0)$ & $(0.0-1.5)$ & $(0.0-0.0)$ & $(0.0-0.0)$ & $(1.5-1.5)$ & $(0.0-0.2)$ & $(0.0-0.0)$ & $(0.0-0.0)$ \\
\hline \multirow{2}{*}{$\begin{array}{l}\text { Social security } \\
\text { contributions }\end{array}$} & 0 & 0 & 0 & 0 & 0 & $0.9^{*}$ & 0 & 0 & 0 \\
\hline & $(0.0-0.0)$ & $(0.0-0.0)$ & $(0.0-3.0)$ & $(0.0-0.0)$ & $(0.0-0.0)$ & $(0.9-0.9)$ & $(0.0-0.0)$ & $(0.0-0.0)$ & $(0.0-0.0)$ \\
\hline \multirow[t]{2}{*}{ Family } & 0 & 0 & 0 & 0 & 0 & 0 & 0 & 0 & 0 \\
\hline & $(0.0-0.0)$ & $(0.0-0.0)$ & $(0.0-0.4)$ & $(0.0-0.0)$ & $(0.0-0.0)$ & $(0.0-0.0)$ & $(0.0-0.0)$ & $(0.0-0.0)$ & $(0.0-0.0)$ \\
\hline \multirow[t]{2}{*}{ Education } & 0 & 0 & 0 & 0 & 0 & 0.3 & 0 & 0 & 0 \\
\hline & $(0.0-0.0)$ & $(0.0-0.0)$ & $(0.0-0.2)$ & $(0.0-0.0)$ & $(0.0-0.0)$ & $(0.3-0.3)$ & $(0.0-0.0)$ & $(0.0-0.0)$ & $(0.0-0.0)$ \\
\hline \multirow{4}{*}{$\begin{array}{l}\text { Used spending residual } \\
\text { Used revenue residual } \\
\text { Share spending efforts }\end{array}$} & 0.1 & 0.1 & 0.9 & 0 & 0 & 0.6 & 0 & 0.1 & 0.1 \\
\hline & 0 & 0 & 0.2 & 0 & 0 & 0.5 & 0.1 & 0.1 & 0.4 \\
\hline & 65 & 45 & 62 & 14 & 100 & 30 & 9 & 25 & 20 \\
\hline & $(35-97)$ & $(23-81)$ & $(35-64)$ & $(0-89)$ & $(53-100)$ & $(30-31)$ & $(9-56)$ & $(0-53)$ & $(17-25)$ \\
\hline \multirow{4}{*}{$\begin{array}{l}\text { Achieved consolidation } \\
\text { Consolidation needs } \\
\text { Share top } 9 \text { instruments }\end{array}$} & 1.9 & 2.7 & 9.2 & 1.7 & 0.7 & 15.3 & 1.7 & 4 & 7.5 \\
\hline & 1.9 & 2.7 & 9.2 & 1.7 & 0.7 & 18.3 & 1.7 & 4 & 7.5 \\
\hline & 100 & 100 & 45 & 100 & 100 & 48 & 90 & 100 & 100 \\
\hline & $(70-100)$ & $(78-100)$ & $(27-61)$ & $(100-100)$ & $(100-100)$ & $(47-66)$ & $(88-100)$ & $(100-100)$ & $(96-100)$ \\
\hline \multirow{2}{*}{$\begin{array}{l}\text { Instruments } \\
\text { crossing the median }\end{array}$} & 2 & 2 & 7 & 0 & 0 & 5 & 1 & 2 & 3 \\
\hline & $(1-2)$ & $(1-3)$ & $(5-7)$ & $(0-1)$ & $(0-1)$ & $(5-5)$ & $(1-2)$ & $(1-2)$ & $(3-4)$ \\
\hline
\end{tabular}




\section{ECO/WKP(2013)80}

Table A1.2. Instrument use and achieved short- to medium-term consolidation vs. needs in Cluster No. 2

Percentages of potential GDP except otherwise mentioned

\begin{tabular}{|c|c|}
\hline description & USA \\
\hline Subsidies & $\begin{array}{c}0 \\
(0.0-0.0)\end{array}$ \\
\hline Pensions & $\begin{array}{c}0.5 \\
(0.5-0.5)\end{array}$ \\
\hline Other property taxes & $\begin{array}{c}0.7^{*} \\
(0.7-0.7)\end{array}$ \\
\hline Unemployment benefits & $\begin{array}{c}0.2 \\
(0.2-0.2)\end{array}$ \\
\hline Corporate income taxes & $\begin{array}{c}0.2 \\
(0.2-0.2)\end{array}$ \\
\hline Environmental taxes & $\begin{array}{c}0.7 \\
(0.7-0.7)\end{array}$ \\
\hline Recurrent taxes on immovable property & $\begin{array}{c}0 \\
(0.0-0.0)\end{array}$ \\
\hline Personal income taxes & $\begin{array}{c}1 \\
(1.0-1.0)\end{array}$ \\
\hline $\begin{array}{l}\text { Other government in kind consumption } \\
\text { (excluding family policy) }\end{array}$ & $\begin{array}{c}0 \\
(0.0-0.0)\end{array}$ \\
\hline Sales of goods and services & $\begin{array}{c}0 \\
(0.0-0.0)\end{array}$ \\
\hline Sickness and disability payments & $\begin{array}{c}0 \\
(0.0-0.0)\end{array}$ \\
\hline Consumption taxes (other than environmental) & $\begin{array}{c}2.5 \\
(2.5-2.5)\end{array}$ \\
\hline Public investment & $\begin{array}{c}0.3 \\
(0.0-0.3)\end{array}$ \\
\hline Health services provided in kind & $\begin{array}{c}1.3^{*} \\
(1.3-1.5)\end{array}$ \\
\hline Family & $\begin{array}{c}0 \\
(0.0-0.0)\end{array}$ \\
\hline Social security contributions & $\begin{array}{c}0 \\
(0.0-0.6)\end{array}$ \\
\hline Education & $\begin{array}{c}0 \\
(0.0-0.0) \\
\end{array}$ \\
\hline Used spending residual & 0.2 \\
\hline Used revenue residual & 0.2 \\
\hline Share spending efforts & $\begin{array}{c}31 \\
(31-37)\end{array}$ \\
\hline Achieved consolidation & 7.7 \\
\hline Consolidation needs & 7.7 \\
\hline Share top 9 instruments & $\begin{array}{c}45 \\
(31-74)\end{array}$ \\
\hline Instruments crossing the median & $\begin{array}{c}2 \\
(2-2)\end{array}$ \\
\hline
\end{tabular}

Note: see note to Table A1.1. 
Table A1.3. Instrument use and achieved short- to medium-term consolidation vs. needs in Cluster No. 3

Percentages of potential GDP except otherwise mentioned

\begin{tabular}{|c|c|c|c|}
\hline description & ESP & GRC & IRL \\
\hline \multirow[t]{2}{*}{ Pensions } & 0 & 0.6 & 0 \\
\hline & $(0.0-0.0)$ & $(0.6-0.6)$ & $(0.0-0.0)$ \\
\hline \multirow[t]{2}{*}{ Subsidies } & 0.2 & 0 & 0 \\
\hline & $(0.2-0.2)$ & $(0.0-0.0)$ & $(0.0-0.0)$ \\
\hline \multirow[t]{2}{*}{ Other property taxes } & 0 & 0 & 0 \\
\hline & $(0.0-0.0)$ & $(0.0-0.0)$ & $(0.0-0.0)$ \\
\hline \multirow[t]{2}{*}{ Unemployment benefits } & 1.6 & 0 & 1.1 \\
\hline & $(0.2-1.6)$ & $(0.0-0.0)$ & $(1.1-1.1)$ \\
\hline \multirow[t]{2}{*}{ Environmental taxes } & 0.7 & 0.2 & $0.3^{*}$ \\
\hline & $(0.0-0.7)$ & $(0.0-0.2)$ & $(0.3-0.3)$ \\
\hline \multirow[t]{2}{*}{ Recurrent taxes on immovable property } & 0.4 & $1.0^{*}$ & $1.0^{*}$ \\
\hline & $(0.0-0.4)$ & $(0.7-1.0)$ & $(0.5-1.0)$ \\
\hline \multirow[t]{2}{*}{ Corporate income taxes } & $0.9^{*}$ & 0.2 & $0.8^{*}$ \\
\hline & $(0.0-0.9)$ & $(0.0-0.2)$ & $(0.0-0.8)$ \\
\hline \multirow[t]{2}{*}{ Sales of goods and services } & 1 & 0.3 & $0.3^{*}$ \\
\hline & $(0.0-1.0)$ & $(0.0-0.3)$ & $(0.0-0.3)$ \\
\hline \multirow[t]{2}{*}{ Personal income taxes } & 0.3 & $3.4^{*}$ & 0.3 \\
\hline & $(0.0-2.5)$ & $(2.3-3.4)$ & $(0.0-0.3)$ \\
\hline \multirow[t]{2}{*}{ Sickness and disability payments } & 0 & 0 & $0.3^{*}$ \\
\hline & $(0.0-0.7)$ & $(0.0-0.0)$ & $(0.0-0.3)$ \\
\hline Other government in kind consumption & 0 & $1.9^{*}$ & 0 \\
\hline (excluding family policy) & $(0.0-0.6)$ & $(1.1-2.3)$ & $(0.0-0.0)$ \\
\hline Consumption taxes & 0 & 0 & 1.4 \\
\hline (other than environmental) & $(0.0-2.5)$ & $(0.0-0.7)$ & $(1.4-2.5)$ \\
\hline \multirow[t]{2}{*}{ Public investment } & 0 & 0 & 0 \\
\hline & $(0.0-0.0)$ & $(0.0-0.0)$ & $(0.0-0.0)$ \\
\hline \multirow[t]{2}{*}{ Health services provided in kind } & 0 & 0 & 0 \\
\hline & $(0.0-0.0)$ & $(0.0-0.0)$ & $(0.0-0.0)$ \\
\hline \multirow[t]{2}{*}{ Social security contributions } & 0 & 0 & 0 \\
\hline & $(0.0-0.0)$ & $(0.0-0.0)$ & $(0.0-0.0)$ \\
\hline \multirow[t]{2}{*}{ Family } & 0 & 0 & 0 \\
\hline & $(0.0-0.0)$ & $(0.0-0.0)$ & $(0.0-0.0)$ \\
\hline \multirow[t]{2}{*}{ Education } & 0 & 0 & 0 \\
\hline & $(0.0-0.0)$ & $(0.0-0.0)$ & $(0.0-0.0)$ \\
\hline Used spending residual & 0.1 & 0.1 & 0.2 \\
\hline Used revenue residual & 0.1 & 0.4 & 0.2 \\
\hline \multirow[t]{2}{*}{ Share spending efforts } & 36 & 33 & 27 \\
\hline & $(18-58)$ & $(23-41)$ & $(22-27)$ \\
\hline Achieved consolidation & 5.3 & 8.2 & 5.8 \\
\hline Consolidation needs & 5.3 & 8.2 & 5.8 \\
\hline \multirow[t]{2}{*}{ Share top 9 instruments } & 100 & 75 & 69 \\
\hline & $(100-100)$ & $(36-100)$ & $(52-100)$ \\
\hline Instruments & 1 & 3 & 5 \\
\hline crossing the median & $(1-2)$ & $(2-3)$ & $(4-5)$ \\
\hline
\end{tabular}

Note: see note to Table A1.1 


\section{ECO/WKP(2013)80}

Table A1.4. Instrument use and achieved short- to medium-term consolidation vs. needs in Cluster No. 4 Percentages of potential GDP except otherwise mentioned

\begin{tabular}{|c|c|c|c|c|c|c|c|c|c|}
\hline description & AUT & BEL & CZE & FIN & FRA & HUN & ISL & SVK & SVN \\
\hline \multirow[t]{2}{*}{ Pensions } & 0.2 & 0 & 0.1 & 0 & 0.6 & 0.2 & 0 & 0 & 0 \\
\hline & $(0.0-0.2)$ & $(0.0-0.0)$ & $(0.1-0.1)$ & $(0.0-0.0)$ & $(0.6-0.6)$ & $(0.2-0.2)$ & $(0.0-0.0)$ & $(0.0-0.0)$ & $(0.0-0.0)$ \\
\hline \multirow[t]{2}{*}{ Subsidies } & 0 & 0.8 & 0.8 & $0.7^{*}$ & $0.7^{*}$ & $0.7 *$ & $0.8^{*}$ & $0.5^{*}$ & $0.5^{*}$ \\
\hline & $(0.0-0.2)$ & $(0.8-0.8)$ & $(0.7-0.8)$ & $(0.7-0.7)$ & $(0.7-0.7)$ & $(0.7-0.7)$ & $(0.8-0.8)$ & $(0.5-0.5)$ & $(0.5-0.5)$ \\
\hline \multirow[t]{2}{*}{ Other property taxes } & 0 & 0 & $0.6^{*}$ & $0.4^{*}$ & 0 & 0.2 & 0.3 & $0.7^{*}$ & $0.7^{*}$ \\
\hline & $(0.0-0.0)$ & $(0.0-0.0)$ & $(0.0-0.6)$ & $(0.4-0.4)$ & $(0.0-0.0)$ & $(0.0-0.2)$ & $(0.3-0.3)$ & $(0.6-0.7)$ & $(0.2-0.7)$ \\
\hline \multirow[t]{2}{*}{ Unemployment benefits } & 0 & 0.7 & 0 & 0.9 & $0.8^{*}$ & 0.2 & 0.6 & 0 & 0 \\
\hline & $(0.0-0.0)$ & $(0.0-0.7)$ & $(0.0-0.5)$ & $(0.0-0.9)$ & $(0.6-0.8)$ & $(0.0-0.2)$ & $(0.0-0.6)$ & $(0.0-0.0)$ & $(0.0-0.0)$ \\
\hline \multirow[t]{2}{*}{ Environmental taxes } & 0 & 0 & 0 & 0 & $0.7^{*}$ & 0 & $0.5^{*}$ & 0.7 & 0 \\
\hline & $(0.0-0.0)$ & $(0.0-0.6)$ & $(0.0-0.0)$ & $(0.0-0.0)$ & $(0.4-0.7)$ & $(0.0-0.0)$ & $(0.0-0.5)$ & $(0.0-0.7)$ & $(0.0-0.0)$ \\
\hline \multirow[t]{2}{*}{$\begin{array}{l}\text { Recurrent taxes on immovable } \\
\text { property }\end{array}$} & 0 & 0 & 0 & $0.8 *$ & 0 & $0.4^{*}$ & 0 & $1.0^{*}$ & $0.9^{*}$ \\
\hline & $(0.0-0.0)$ & $(0.0-0.3)$ & $(0.0-0.6)$ & $(0.0-0.8)$ & $(0.0-0.0)$ & $(0.0-0.9)$ & $(0.0-0.0)$ & $(0.0-1.0)$ & $(0.0-0.9)$ \\
\hline \multirow[t]{2}{*}{ Sales of goods and services } & 0 & 0 & 0 & 0 & 0 & 0 & 0.3 & 1 & 0 \\
\hline & $(0.0-0.0)$ & $(0.0-0.7)$ & $(0.0-0.2)$ & $(0.0-0.0)$ & $(0.0-0.0)$ & $(0.0-0.3)$ & $(0.0-0.3)$ & $(0.0-1.0)$ & $(0.0-0.0)$ \\
\hline \multirow[t]{2}{*}{$\begin{array}{l}\text { Sickness and disability } \\
\text { payments }\end{array}$} & 0 & 0 & 0 & 0.7 & 0 & 0 & 0.2 & 0 & 0 \\
\hline & $(0.0-0.0)$ & $(0.0-0.3)$ & $(0.0-0.0)$ & $(0.0-0.7)$ & $(0.0-0.0)$ & $(0.0-0.4)$ & $(0.0-0.2)$ & $(0.0-0.0)$ & $(0.0-0.2)$ \\
\hline \multirow[t]{2}{*}{ Personal income taxes } & 0 & 0 & 0 & 0 & 0 & 0 & 0 & 0 & 0 \\
\hline & $(0.0-0.0)$ & $(0.0-0.0)$ & $(0.0-0.0)$ & $(0.0-0.0)$ & $(0.0-0.0)$ & $(0.0-0.4)$ & $(0.0-0.0)$ & $(0.0-2.0)$ & $(0.0-0.9)$ \\
\hline \multirow[t]{2}{*}{ Corporate income taxes } & 0 & 0 & 0 & 0.1 & $0.5^{*}$ & 0 & $0.5^{*}$ & 0 & 0 \\
\hline & $(0.0-0.0)$ & $(0.0-0.0)$ & $(0.0-0.0)$ & $(0.0-0.9)$ & $(0.0-0.5)$ & $(0.0-0.4)$ & $(0.0-0.5)$ & $(0.0-0.4)$ & $(0.0-0.9)$ \\
\hline $\begin{array}{l}\text { Other government in kind } \\
\text { consumption }\end{array}$ & 0 & 0 & 0 & 0 & $1.2 *$ & 0 & 0.2 & 0 & 0 \\
\hline (excluding family policy) & $(0.0-0.0)$ & $(0.0-0.0)$ & $(0.0-0.0)$ & $(0.0-1.7)$ & $(0.0-1.8)$ & $(0.0-0.0)$ & $(0.0-1.6)$ & $(0.0-0.0)$ & $(0.0-0.3)$ \\
\hline Consumption taxes & 0 & 0 & 0 & 0 & 0 & 0 & 0 & 0 & 0 \\
\hline (other than environmental) & $(0.0-0.0)$ & $(0.0-0.0)$ & $(0.0-0.0)$ & $(0.0-0.0)$ & $(0.0-0.0)$ & $(0.0-0.0)$ & $(0.0-0.0)$ & $(0.0-2.0)$ & $(0.0-0.0)$ \\
\hline \multirow[t]{2}{*}{ Social security contributions } & 0 & 0 & 0 & 0 & 0 & 0 & 0 & 0 & 0 \\
\hline & $(0.0-0.0)$ & $(0.0-0.0)$ & $(0.0-0.0)$ & $(0.0-0.0)$ & $(0.0-0.0)$ & $(0.0-0.0)$ & $(0.0-0.3)$ & $(0.0-0.0)$ & $(0.0-0.0)$ \\
\hline \multirow[t]{2}{*}{ Family } & 0 & 0 & 0 & 0 & 0 & 0 & 0 & 0 & 0 \\
\hline & $(0.0-0.0)$ & $(0.0-0.0)$ & $(0.0-0.0)$ & $(0.0-0.0)$ & $(0.0-1.1)$ & $(0.0-0.0)$ & $(0.0-0.2)$ & $(0.0-0.0)$ & $(0.0-0.0)$ \\
\hline \multirow[t]{2}{*}{ Public investment } & 0 & 0 & 0 & 0 & 0 & 0 & 0 & 0 & 0 \\
\hline & $(0.0-0.0)$ & $(0.0-0.0)$ & $(0.0-0.0)$ & $(0.0-0.0)$ & $(0.0-0.0)$ & $(0.0-0.0)$ & $(0.0-0.0)$ & $(0.0-0.0)$ & $(0.0-0.0)$ \\
\hline \multirow[t]{2}{*}{$\begin{array}{l}\text { Health services provided in } \\
\text { kind }\end{array}$} & 0 & 0 & 0 & 0 & 0 & 0 & 0 & 0 & 0 \\
\hline & $(0.0-0.0)$ & $(0.0-0.0)$ & $(0.0-0.0)$ & $(0.0-0.0)$ & $(0.0-0.0)$ & $(0.0-0.0)$ & $(0.0-0.0)$ & $(0.0-0.0)$ & $(0.0-0.0)$ \\
\hline \multirow[t]{2}{*}{ Education } & 0 & 0 & 0 & 0 & 0 & 0 & 0 & 0 & 0 \\
\hline & $(0.0-0.0)$ & $(0.0-0.0)$ & $(0.0-0.0)$ & $(0.0-0.0)$ & $(0.0-0.0)$ & $(0.0-0.0)$ & $(0.0-0.0)$ & $(0.0-0.0)$ & $(0.0-0.0)$ \\
\hline Used spending residual & 0 & 0.1 & 0.1 & 0.2 & 0.2 & 0.1 & 0.2 & 0.1 & 0.1 \\
\hline Used revenue residual & 0 & 0 & 0 & 0 & 0 & 0 & 0 & 0.1 & 0.1 \\
\hline \multirow[t]{2}{*}{ Share spending efforts } & 100 & 100 & 64 & 65 & 73 & 67 & 56 & 13 & 23 \\
\hline & $(100-100)$ & $(56-100)$ & $(60-100)$ & $(45-88)$ & $(73-89)$ & $(51-90)$ & $(50-83)$ & $(13-13)$ & $(23-55)$ \\
\hline Achieved consolidation & 0.2 & 1.6 & 1.6 & 3.8 & 4.7 & 1.8 & 3.6 & 4 & 2.2 \\
\hline Consolidation needs & 0.2 & 1.6 & 1.6 & 3.8 & 4.7 & 1.8 & 3.6 & 4 & 2.2 \\
\hline \multirow[t]{2}{*}{ Share top 9 instruments } & 100 & 100 & 100 & 97 & 63 & 100 & 79 & 100 & 100 \\
\hline & $(100-100)$ & $(100-100)$ & $(100-100)$ & $(79-100)$ & $(63-100)$ & $(100-100)$ & $(78-100)$ & $(100-100)$ & $(100-100)$ \\
\hline \multirow[t]{2}{*}{$\begin{array}{l}\text { Instruments crossing the } \\
\text { median }\end{array}$} & 0 & 0 & 1 & 3 & 5 & 2 & 3 & 3 & 3 \\
\hline & $(0-0)$ & $(0-1)$ & $(1-2)$ & $(2-4)$ & $(3-5)$ & $(1-2)$ & $(2-3)$ & $(2-4)$ & $(2-3)$ \\
\hline
\end{tabular}

Note: see note to Table A1.1. 
Table A1.5. Instrument use and achieved short- to medium-term consolidation vs. needs in Cluster No. 5

Percentages of potential GDP except otherwise mentioned

\begin{tabular}{|c|c|c|c|}
\hline description & LUX & NLD & SWE \\
\hline \multirow[t]{2}{*}{ Subsidies } & 0.2 & $0.6^{*}$ & $0.7 *$ \\
\hline & $(0.2-0.2)$ & $(0.6-0.6)$ & $(0.3-0.8)$ \\
\hline \multirow[t]{2}{*}{ Other property taxes } & 0 & 0.2 & 0.2 \\
\hline & $(0.0-0.0)$ & $(0.0-0.2)$ & $(0.0-0.7)$ \\
\hline \multirow[t]{2}{*}{ Pensions } & 0 & 0 & 0 \\
\hline & $(0.0-0.0)$ & $(0.0-0.0)$ & $(0.0-0.3)$ \\
\hline \multirow[t]{2}{*}{ Environmental taxes } & 0 & 0 & 0 \\
\hline & $(0.0-0.0)$ & $(0.0-0.0)$ & $(0.0-0.0)$ \\
\hline \multirow[t]{2}{*}{ Recurrent taxes on immovable property } & 0 & $0.8^{*}$ & 0 \\
\hline & $(0.0-0.0)$ & $(0.0-0.8)$ & $(0.0-0.0)$ \\
\hline Other government in kind consumption & 0 & 1.1 & 0 \\
\hline (excluding family policy) & $(0.0-0.0)$ & $(0.0-1.9)$ & $(0.0-0.0)$ \\
\hline \multirow[t]{2}{*}{ Sales of goods and services } & 0 & 0 & 0 \\
\hline & $(0.0-0.0)$ & $(0.0-0.0)$ & $(0.0-0.0)$ \\
\hline \multirow[t]{2}{*}{ Personal income taxes } & 0 & 0 & 0 \\
\hline & $(0.0-0.0)$ & $(0.0-0.0)$ & $(0.0-0.0)$ \\
\hline \multirow[t]{2}{*}{ Unemployment benefits } & 0 & 0 & 0 \\
\hline & $(0.0-0.0)$ & $(0.0-0.4)$ & $(0.0-0.0)$ \\
\hline \multirow[t]{2}{*}{ Social security contributions } & 0 & 0 & 0 \\
\hline & $(0.0-0.0)$ & $(0.0-0.0)$ & $(0.0-0.0)$ \\
\hline \multirow[t]{2}{*}{ Corporate income taxes } & 0 & 0 & 0 \\
\hline & $(0.0-0.0)$ & $(0.0-0.0)$ & $(0.0-0.0)$ \\
\hline \multirow[t]{2}{*}{ Sickness and disability payments } & 0 & 0 & 0 \\
\hline & $(0.0-0.0)$ & $(0.0-0.0)$ & $(0.0-0.0)$ \\
\hline \multirow[t]{2}{*}{ Consumption taxes (other than environmental) } & 0 & 0 & 0 \\
\hline & $(0.0-0.0)$ & $(0.0-0.0)$ & $(0.0-0.0)$ \\
\hline \multirow[t]{2}{*}{ Family } & 0 & 0 & 0 \\
\hline & $(0.0-0.0)$ & $(0.0-0.0)$ & $(0.0-0.0)$ \\
\hline \multirow[t]{2}{*}{ Public investment } & 0 & 0 & 0 \\
\hline & $(0.0-0.0)$ & $(0.0-0.0)$ & $(0.0-0.0)$ \\
\hline \multirow[t]{2}{*}{ Health services provided in kind } & 0 & 0 & 0 \\
\hline & $(0.0-0.0)$ & $(0.0-0.0)$ & $(0.0-0.0)$ \\
\hline \multirow[t]{2}{*}{ Education } & 0 & 0 & 0 \\
\hline & $(0.0-0.0)$ & $(0.0-0.0)$ & $(0.0-0.0)$ \\
\hline Used spending residual & 0 & 0.1 & 0.1 \\
\hline Used revenue residual & 0 & 0 & 0 \\
\hline \multirow[t]{2}{*}{ Share spending efforts } & 100 & 65 & 85 \\
\hline & $(100-100)$ & $(65-92)$ & $(30-100)$ \\
\hline Achieved consolidation & 0.2 & 2.8 & 1 \\
\hline Consolidation needs & 0.2 & 2.8 & 1 \\
\hline \multirow[t]{2}{*}{ Share top 9 instruments } & 100 & 100 & 100 \\
\hline & $(100-100)$ & $(100-100)$ & $(100-100)$ \\
\hline \multirow[t]{2}{*}{ Instruments crossing the median } & 0 & 2 & 1 \\
\hline & $(0-0)$ & $(1-2)$ & $(1-2)$ \\
\hline
\end{tabular}

Note: see note to Table A1.1. 
Table A1.6. Instrument use and achieved long-term consolidation vs. needs

Percentages of potential GDP except otherwise mentioned

\begin{tabular}{|c|c|c|c|c|c|c|c|c|}
\hline description & JPN & GBR & USA & SVK & AUS & POL & ESP & NZL \\
\hline Subsidies & $\begin{array}{c}0 \\
(0.0-0.0)\end{array}$ & $\begin{array}{c}0 \\
(0.0-0.0)\end{array}$ & $\begin{array}{c}0 \\
(0.0-0.0)\end{array}$ & $\begin{array}{c}0.5^{*} \\
(0.5-0.5)\end{array}$ & $\begin{array}{c}0.6^{*} \\
(0.6-0.6)\end{array}$ & $\begin{array}{c}0 \\
(0.0-0.0)\end{array}$ & $\begin{array}{c}0.2 \\
(0.2-0.2)\end{array}$ & $\begin{array}{c}0 \\
(0.0-0.0)\end{array}$ \\
\hline Pensions & $\begin{array}{c}3.2 \\
(3.2-3.2)\end{array}$ & $\begin{array}{c}1 \\
(1.0-1.0)\end{array}$ & $\begin{array}{c}1.9 \\
(1.9-1.9)\end{array}$ & $\begin{array}{c}0 \\
(0.0-0.0)\end{array}$ & $\begin{array}{c}0 \\
(0.0-0.0)\end{array}$ & $\begin{array}{c}3.7 \\
(3.7-3.7)\end{array}$ & $\begin{array}{c}0 \\
(0.0-0.0)\end{array}$ & $\begin{array}{c}3.2 \\
(3.2-3.2)\end{array}$ \\
\hline $\begin{array}{l}\text { Other in kind consumption } \\
\text { (excluding family policy) }\end{array}$ & $\begin{array}{c}0 \\
(0.0-0.0)\end{array}$ & $\begin{array}{c}2.2^{*} \\
(2.2-2.2)\end{array}$ & $\begin{array}{c}0 \\
(0.0-0.0)\end{array}$ & $\begin{array}{c}0 \\
(0.0-0.0)\end{array}$ & $\begin{array}{c}1 \\
(1.0-1.0)\end{array}$ & $\begin{array}{c}1.1 \\
(0.6-1.1)\end{array}$ & $\begin{array}{c}0.6 \\
(0.6-0.6)\end{array}$ & $\begin{array}{c}0 \\
(0.0-0.0)\end{array}$ \\
\hline Unemployment benefits & $\begin{array}{c}0.3 \\
(0.3-0.3)\end{array}$ & $\begin{array}{c}0 \\
(0.0-0.0)\end{array}$ & $\begin{array}{c}0.2 \\
(0.2-0.2)\end{array}$ & $\begin{array}{c}0 \\
(0.0-0.0)\end{array}$ & $\begin{array}{c}0 \\
(0.0-0.0)\end{array}$ & $\begin{array}{c}0 \\
(0.0-0.0)\end{array}$ & $\begin{array}{c}1.4 \\
(1.4-1.4)\end{array}$ & $\begin{array}{c}0.3 \\
(0.3-0.3)\end{array}$ \\
\hline Environmental taxes & $\begin{array}{c}0.7 \\
(0.7-0.7)\end{array}$ & $\begin{array}{c}0.2^{*} \\
(0.2-0.2)\end{array}$ & $\begin{array}{c}0.7 \\
(0.7-0.7)\end{array}$ & $\begin{array}{c}0.7 \\
(0.7-0.7)\end{array}$ & $\begin{array}{c}0.7^{*} \\
(0.7-0.7)\end{array}$ & $\begin{array}{c}0.6 \\
(0.0-0.7)\end{array}$ & $\begin{array}{c}0.7 \\
(0.7-0.7)\end{array}$ & $\begin{array}{c}0.7 \\
(0.7-0.7)\end{array}$ \\
\hline Other property taxes & $\begin{array}{c}0.4 * \\
(0.4-0.4)\end{array}$ & $\begin{array}{c}0.2 \\
(0.2-0.2)\end{array}$ & $\begin{array}{c}0.7 * \\
(0.7-0.7)\end{array}$ & $\begin{array}{c}0.7^{*} \\
(0.7-0.7)\end{array}$ & $\begin{array}{c}0 \\
(0.0-0.0)\end{array}$ & $\begin{array}{c}0.6^{*} \\
(0.0-0.7)\end{array}$ & $\begin{array}{c}0 \\
(0.0-0.0)\end{array}$ & $\begin{array}{c}0.4^{*} \\
(0.4-0.4)\end{array}$ \\
\hline $\begin{array}{l}\text { Sickness and disability } \\
\text { payments }\end{array}$ & $\begin{array}{c}0 \\
(0.0-0.0)\end{array}$ & $\begin{array}{c}0.7 * \\
(0.7-0.7)\end{array}$ & $\begin{array}{c}0 \\
(0.0-0.0)\end{array}$ & $\begin{array}{c}0 \\
(0.0-0.0)\end{array}$ & $\begin{array}{c}0 \\
(0.0-0.0)\end{array}$ & $\begin{array}{c}0 \\
(0.0-0.4)\end{array}$ & $\begin{array}{c}0.7^{*} \\
(0.4-0.7)\end{array}$ & $\begin{array}{c}0 \\
(0.0-0.0)\end{array}$ \\
\hline $\begin{array}{l}\text { Recurrent taxes on } \\
\text { immovable property }\end{array}$ & $\begin{array}{c}0 \\
(0.0-0.0)\end{array}$ & $\begin{array}{c}0 \\
(0.0-0.0)\end{array}$ & $\begin{array}{c}0 \\
(0.0-0.0)\end{array}$ & $\begin{array}{c}1.0^{*} \\
(0.4-1.0)\end{array}$ & $\begin{array}{c}0 \\
(0.0-0.0)\end{array}$ & $\begin{array}{c}0 \\
(0.0-0.1)\end{array}$ & $\begin{array}{c}0.4 \\
(0.0-0.4)\end{array}$ & $\begin{array}{c}0 \\
(0.0-0.0)\end{array}$ \\
\hline Sales of goods and services & $\begin{array}{c}1.0^{*} \\
(0.6-1.0)\end{array}$ & $\begin{array}{c}0.7^{*} \\
(0.7-0.7)\end{array}$ & $\begin{array}{c}0 \\
(0.0-0.0)\end{array}$ & $\begin{array}{c}1 \\
(0.5-1.0)\end{array}$ & $\begin{array}{c}0 \\
(0.0-0.0)\end{array}$ & $\begin{array}{c}0 \\
(0.0-0.5)\end{array}$ & $\begin{array}{c}1 \\
(0.2-1.0)\end{array}$ & $\begin{array}{c}1.0^{*} \\
(0.6-1.0)\end{array}$ \\
\hline Personal income taxes & $\begin{array}{c}2.8 \\
(0.0-4.4)\end{array}$ & $\begin{array}{c}0.5 \\
(0.0-0.5)\end{array}$ & $\begin{array}{c}1 \\
(0.0-1.0)\end{array}$ & $\begin{array}{c}1.8 \\
(0.0-3.3)\end{array}$ & $\begin{array}{c}0 \\
(0.0-0.0)\end{array}$ & $\begin{array}{c}0 \\
(0.0-0.0)\end{array}$ & $\begin{array}{c}0.4 \\
(0.0-1.5)\end{array}$ & $\begin{array}{c}2.8 \\
(0.0-4.4)\end{array}$ \\
\hline Corporate income taxes & $\begin{array}{c}0 \\
(0.0-0.0)\end{array}$ & $\begin{array}{c}0.4^{*} \\
(0.0-0.4)\end{array}$ & $\begin{array}{c}0.2 \\
(0.0-0.2)\end{array}$ & $\begin{array}{c}0.2^{*} \\
(0.0-0.4)\end{array}$ & $\begin{array}{c}0 \\
(0.0-0.0)\end{array}$ & $\begin{array}{c}0 \\
(0.0-0.0)\end{array}$ & $\begin{array}{c}0.1 \\
(0.0-0.9)\end{array}$ & $\begin{array}{c}0 \\
(0.0-0.0)\end{array}$ \\
\hline $\begin{array}{l}\text { Consumption taxes (other } \\
\text { than environmental) }\end{array}$ & $\begin{array}{c}1.5 \\
(0.0-2.5)\end{array}$ & $\begin{array}{c}1.4^{*} \\
(0.0-1.4)\end{array}$ & $\begin{array}{c}2.5 \\
(1.1-2.5)\end{array}$ & $\begin{array}{c}0.9 \\
(0.0-2.3)\end{array}$ & $\begin{array}{c}2.5 \\
(2.0-2.5)\end{array}$ & $\begin{array}{c}0 \\
(0.0-0.0)\end{array}$ & $\begin{array}{c}0.4 \\
(0.0-1.6)\end{array}$ & $\begin{array}{c}1.5 \\
(0.0-2.5)\end{array}$ \\
\hline Public investment & $\begin{array}{c}0 \\
(0.0-1.1)\end{array}$ & $\begin{array}{c}0.1 \\
(0.0-0.3)\end{array}$ & $\begin{array}{c}0.1 \\
(0.0-0.3)\end{array}$ & $\begin{array}{c}0 \\
(0.0-0.3)\end{array}$ & $\begin{array}{c}0.8 \\
(0.0-1.1)\end{array}$ & $\begin{array}{c}0 \\
(0.0-0.0)\end{array}$ & $\begin{array}{c}0 \\
(0.0-0.0)\end{array}$ & $\begin{array}{c}0 \\
(0.0-1.1)\end{array}$ \\
\hline $\begin{array}{l}\text { Health services } \\
\text { provided in kind }\end{array}$ & $\begin{array}{c}0 \\
(0.0-1.3)\end{array}$ & $\begin{array}{c}0.2 \\
(0.0-1.2)\end{array}$ & $\begin{array}{c}0.3 \\
(0.0-1.3)\end{array}$ & $\begin{array}{c}0 \\
(0.0-0.3)\end{array}$ & $\begin{array}{c}0.4 \\
(0.0-0.5)\end{array}$ & $\begin{array}{c}0 \\
(0.0-0.0)\end{array}$ & $\begin{array}{c}0 \\
(0.0-0.9)\end{array}$ & $\begin{array}{c}0 \\
(0.0-1.3)\end{array}$ \\
\hline Family & $\begin{array}{c}0 \\
(0.0-0.0)\end{array}$ & $\begin{array}{c}0 \\
(0.0-0.3)\end{array}$ & $\begin{array}{c}0 \\
(0.0-0.0)\end{array}$ & $\begin{array}{c}0 \\
(0.0-0.0)\end{array}$ & $\begin{array}{c}0 \\
(0.0-0.8)\end{array}$ & $\begin{array}{c}0 \\
(0.0-0.0)\end{array}$ & $\begin{array}{c}0 \\
(0.0-0.0)\end{array}$ & $\begin{array}{c}0 \\
(0.0-0.0)\end{array}$ \\
\hline Social security contributions & $\begin{array}{c}0 \\
(0.0-0.0)\end{array}$ & $\begin{array}{c}0 \\
(0.0-0.0)\end{array}$ & $\begin{array}{c}0 \\
(0.0-0.1)\end{array}$ & $\begin{array}{c}0 \\
(0.0-0.0)\end{array}$ & $\begin{array}{c}0 \\
(0.0-0.1)\end{array}$ & $\begin{array}{c}0 \\
(0.0-0.0)\end{array}$ & $\begin{array}{c}0 \\
(0.0-0.0)\end{array}$ & $\begin{array}{c}0 \\
(0.0-0.0)\end{array}$ \\
\hline Education & $\begin{array}{c}0 \\
(0.0-0.0)\end{array}$ & $\begin{array}{c}0 \\
(0.0-0.0)\end{array}$ & $\begin{array}{c}0 \\
(0.0-0.0)\end{array}$ & $\begin{array}{c}0 \\
(0.0-0.0)\end{array}$ & $\begin{array}{c}0 \\
(0.0-0.0)\end{array}$ & $\begin{array}{c}0 \\
(0.0-0.0)\end{array}$ & $\begin{array}{c}0 \\
(0.0-0.0)\end{array}$ & $\begin{array}{c}0 \\
(0.0-0.0)\end{array}$ \\
\hline Used spending residual & $(0.4-0.7)$ & $(0.8-1.1)$ & $(0.5-0.8)$ & $(0.1-0.2)$ & $(0.2-0.3)$ & $(0.2-0.3)$ & $(0.1-0.1)$ & $(0.4-0.7)$ \\
\hline Used revenue residual & $(0.1-0.3)$ & $(0.1-0.2)$ & $(0.1-0.3)$ & $(0.2-0.4)$ & $(0.0-0.0)$ & $(0.0-0.1)$ & $(0.0-0.1)$ & $(0.1-0.3)$ \\
\hline Share spending efforts & $\begin{array}{c}37 \\
(37-54)\end{array}$ & $\begin{array}{c}59 \\
(59-76)\end{array}$ & $\begin{array}{c}36 \\
(35-54)\end{array}$ & $\begin{array}{c}8 \\
(7-13)\end{array}$ & $\begin{array}{c}49 \\
(49-56)\end{array}$ & $\begin{array}{c}80 \\
(76-88)\end{array}$ & $\begin{array}{c}49 \\
(40-64)\end{array}$ & $\begin{array}{c}37 \\
(37-54)\end{array}$ \\
\hline Achieved consolidation & 10.5 & 8.5 & 8.3 & 7 & 6.3 & 6.3 & 6.1 & 10.5 \\
\hline Consolidation needs & 10.5 & 8.5 & 8.3 & 7 & 6.3 & 6.3 & 6.1 & 10.5 \\
\hline Share top 9 instruments & $\begin{array}{c}57 \\
(48-94)\end{array}$ & $\begin{array}{c}66 \\
(63-82)\end{array}$ & $\begin{array}{c}46 \\
(46-79)\end{array}$ & $\begin{array}{c}58 \\
(49-94)\end{array}$ & $\begin{array}{c}39 \\
(39-80)\end{array}$ & $\begin{array}{c}100 \\
(100-100)\end{array}$ & $\begin{array}{c}85 \\
(82-100)\end{array}$ & $\begin{array}{c}57 \\
(48-94)\end{array}$ \\
\hline $\begin{array}{l}\text { Instruments crossing the } \\
\text { median }\end{array}$ & $\begin{array}{c}2 \\
(1-3)\end{array}$ & $\begin{array}{c}6 \\
(6-7)\end{array}$ & $\begin{array}{c}1 \\
(1-2)\end{array}$ & $\begin{array}{c}4 \\
(3-5)\end{array}$ & $\begin{array}{c}2 \\
(2-3)\end{array}$ & $\begin{array}{c}1 \\
(0-2)\end{array}$ & $\begin{array}{c}1 \\
(1-2)\end{array}$ & $\begin{array}{c}2 \\
(1-3)\end{array}$ \\
\hline
\end{tabular}


Table A1.6 (cont.) Instrument use and achieved long-term consolidation vs. needs

Percentage of potential GDP except otherwise mentioned

\begin{tabular}{|c|c|c|c|c|c|c|c|c|}
\hline description & ISR & FRA & NLD & IRL & CAN & SVN & CZE & PRT \\
\hline \multirow[t]{2}{*}{ Subsidies } & 0 & $0.7^{*}$ & $0.6^{*}$ & 0 & 0.3 & $0.5^{*}$ & 0.8 & 0 \\
\hline & $(0.0-0.0)$ & $(0.7-0.7)$ & $(0.6-0.6)$ & $(0.0-0.0)$ & $(0.3-0.3)$ & $(0.5-0.5)$ & $(0.8-0.8)$ & $(0.0-0.0)$ \\
\hline \multirow[t]{2}{*}{ Pensions } & 0.8 & 2.2 & 0 & 0 & 0 & 0 & 0.4 & 3.4 \\
\hline & $(0.8-0.8)$ & $(1.8-2.3)$ & $(0.0-0.0)$ & $(0.0-0.0)$ & $(0.0-0.0)$ & $(0.0-0.0)$ & $(0.4-0.4)$ & $(2.8-3.4)$ \\
\hline Other in kind consumption & 2.3 & $1.1 *$ & 2.3 & 0 & $2.3 *$ & $2.0 *$ & $1.4 *$ & 0 \\
\hline (excluding family policy) & $(2.3-2.3)$ & $(0.0-1.7)$ & $(2.3-2.3)$ & $(0.0-0.0)$ & $(1.8-2.3)$ & $(2.0-2.0)$ & $(0.9-1.4)$ & $(0.0-0.5)$ \\
\hline \multirow[t]{2}{*}{ Unemployment benefits } & 0 & 0.4 & 0.5 & 0.9 & $0.2 *$ & 0 & $0.4^{*}$ & 0 \\
\hline & $(0.0-0.0)$ & $(0.0-0.7)$ & $(0.5-0.5)$ & $(0.9-0.9)$ & $(0.0-0.2)$ & $(0.0-0.0)$ & $(0.1-0.4)$ & $(0.0-0.3)$ \\
\hline \multirow[t]{2}{*}{ Environmental taxes } & 0 & 0 & 0 & $0.3 *$ & 0.3 & 0 & 0 & 0 \\
\hline & $(0.0-0.0)$ & $(0.0-0.7)$ & $(0.0-0.0)$ & $(0.3-0.3)$ & $(0.0-0.7)$ & $(0.0-0.0)$ & $(0.0-0.0)$ & $(0.0-0.0)$ \\
\hline \multirow[t]{2}{*}{ Other property taxes } & 0.2 & 0 & 0.2 & 0 & $0.2 *$ & $0.7^{*}$ & $0.3 *$ & 0 \\
\hline & $(0.2-0.2)$ & $(0.0-0.0)$ & $(0.0-0.2)$ & $(0.0-0.0)$ & $(0.0-0.5)$ & $(0.2-0.7)$ & $(0.0-0.6)$ & $(0.0-0.0)$ \\
\hline \multirow{2}{*}{$\begin{array}{l}\text { Sickness and disability } \\
\text { payments }\end{array}$} & $0.5^{*}$ & 0 & 0.6 & $0.3 *$ & 0 & $0.2^{*}$ & 0 & 0 \\
\hline & $(0.1-0.5)$ & $(0.0-0.0)$ & $(0.0-0.7)$ & $(0.3-0.3)$ & $(0.0-0.0)$ & $(0.0-0.2)$ & $(0.0-0.3)$ & $(0.0-0.0)$ \\
\hline \multirow{2}{*}{$\begin{array}{l}\text { Recurrent taxes on } \\
\text { immovable property }\end{array}$} & 0 & 0 & 0 & $1.0 *$ & 0 & 0 & 0 & 0 \\
\hline & $(0.0-0.0)$ & $(0.0-0.0)$ & $(0.0-0.6)$ & $(0.5-1.0)$ & $(0.0-0.0)$ & $(0.0-0.5)$ & $(0.0-0.2)$ & $(0.0-0.0)$ \\
\hline \multirow[t]{2}{*}{ Sales of goods and services } & $0.5^{*}$ & 0 & 0 & $0.3 *$ & 0 & 0 & 0 & 0 \\
\hline & $(0.1-0.5)$ & $(0.0-0.0)$ & $(0.0-0.0)$ & $(0.1-0.3)$ & $(0.0-0.0)$ & $(0.0-0.0)$ & $(0.0-0.1)$ & $(0.0-0.0)$ \\
\hline \multirow[t]{2}{*}{ Personal income taxes } & 0.2 & 0 & 0 & 0.1 & 0 & 0 & 0 & 0 \\
\hline & $(0.0-0.8)$ & $(0.0-0.0)$ & $(0.0-0.0)$ & $(0.0-0.3)$ & $(0.0-0.0)$ & $(0.0-0.0)$ & $(0.0-0.0)$ & $(0.0-0.0)$ \\
\hline \multirow[t]{2}{*}{ Corporate income taxes } & 0 & 0 & 0 & 0.3 & 0 & 0 & 0 & 0 \\
\hline & $(0.0-0.0)$ & $(0.0-0.0)$ & $(0.0-0.0)$ & $(0.0-0.8)$ & $(0.0-0.0)$ & $(0.0-0.0)$ & $(0.0-0.0)$ & $(0.0-0.0)$ \\
\hline \multirow{2}{*}{$\begin{array}{l}\text { Consumption taxes (other } \\
\text { than environmental) }\end{array}$} & 0.1 & 0 & 0 & 1 & 0 & 0 & 0 & 0 \\
\hline & $(0.0-0.7)$ & $(0.0-0.0)$ & $(0.0-0.1)$ & $(0.3-2.0)$ & $(0.0-0.0)$ & $(0.0-0.0)$ & $(0.0-0.0)$ & $(0.0-0.0)$ \\
\hline \multirow[t]{2}{*}{ Public investment } & 0 & 0 & 0 & 0 & 0 & 0 & 0 & 0 \\
\hline & $(0.0-0.0)$ & $(0.0-0.0)$ & $(0.0-0.0)$ & $(0.0-0.0)$ & $(0.0-0.0)$ & $(0.0-0.0)$ & $(0.0-0.0)$ & $(0.0-0.0)$ \\
\hline \multirow{2}{*}{$\begin{array}{l}\text { Health services } \\
\text { provided in kind }\end{array}$} & 0 & 0 & 0 & 0 & 0 & 0 & 0 & 0 \\
\hline & $(0.0-0.0)$ & $(0.0-0.0)$ & $(0.0-0.0)$ & $(0.0-0.0)$ & $(0.0-0.0)$ & $(0.0-0.0)$ & $(0.0-0.0)$ & $(0.0-0.0)$ \\
\hline \multirow[t]{2}{*}{ Family } & 0 & 0 & 0 & 0 & 0 & 0 & 0 & 0 \\
\hline & $(0.0-0.0)$ & $(0.0-0.0)$ & $(0.0-0.0)$ & $(0.0-0.0)$ & $(0.0-0.0)$ & $(0.0-0.0)$ & $(0.0-0.0)$ & $(0.0-0.0)$ \\
\hline \multirow[t]{2}{*}{ Social security contributions } & 0 & 0 & 0 & 0 & 0 & 0 & 0 & 0 \\
\hline & $(0.0-0.0)$ & $(0.0-0.0)$ & $(0.0-0.0)$ & $(0.0-0.0)$ & $(0.0-0.0)$ & $(0.0-0.0)$ & $(0.0-0.0)$ & $(0.0-0.0)$ \\
\hline \multirow[t]{2}{*}{ Education } & 0 & 0 & 0 & 0 & 0 & 0 & 0 & 0 \\
\hline & $(0.0-0.0)$ & $(0.0-0.0)$ & $(0.0-0.0)$ & $(0.0-0.0)$ & $(0.0-0.0)$ & $(0.0-0.0)$ & $(0.0-0.0)$ & $(0.0-0.0)$ \\
\hline Used spending residual & $(0.3-0.4)$ & $(0.2-0.4)$ & $(0.3-0.3)$ & $(0.1-0.1)$ & $(0.1-0.3)$ & $(0.3-0.3)$ & $(0.2-0.3)$ & $(0.0-0.2)$ \\
\hline Used revenue residual & $(0.0-0.1)$ & $(0.0-0.0)$ & $(0.0-0.0)$ & $(0.1-0.2)$ & $(0.0-0.0)$ & $(0.0-0.1)$ & $(0.0-0.0)$ & $(0.0-0.0)$ \\
\hline \multirow[t]{2}{*}{ Share spending efforts } & 80 & 100 & 95 & 29 & 87 & 80 & 92 & 100 \\
\hline & $(69-80)$ & $(84-100)$ & $(81-97)$ & $(29-29)$ & $(66-87)$ & $(74-83)$ & $(82-100)$ & $(100-100)$ \\
\hline Achieved consolidation & 5 & 4.7 & 4.5 & 4.4 & 3.7 & 3.6 & 3.6 & 3.6 \\
\hline Consolidation needs & 5 & 4.7 & 4.5 & 4.4 & 3.7 & 3.6 & 3.6 & 3.6 \\
\hline \multirow[t]{2}{*}{ Share top 9 instruments } & 93 & 100 & 100 & 65 & 100 & 100 & 100 & 100 \\
\hline & $(83-100)$ & $(100-100)$ & $(100-100)$ & $(50-98)$ & $(100-100)$ & $(100-100)$ & $(100-100)$ & $(100-100)$ \\
\hline \multirow{2}{*}{$\begin{array}{l}\text { Instruments crossing the } \\
\text { median }\end{array}$} & 2 & 2 & 1 & 4 & 3 & 4 & 3 & 0 \\
\hline & $(1-2)$ & $(2-3)$ & $(1-2)$ & $(3-5)$ & $(2-3)$ & $(3-4)$ & $(2-4)$ & $(0-0)$ \\
\hline
\end{tabular}

Note: see note to Table A1.1. 
Table A1.6 (cont.) Instrument use and achieved long-term consolidation vs. needs

Percentage of potential GDP except otherwise mentioned

\begin{tabular}{|c|c|c|c|c|c|c|c|c|}
\hline description & LUX & BEL & HUN & DNK & AUT & CHE & FIN & SWE \\
\hline \multirow[t]{2}{*}{ Subsidies } & $0.8^{*}$ & 0.8 & $0.7^{*}$ & 0.8 & 0.8 & 0.8 & $0.7 *$ & $0.7 *$ \\
\hline & $(0.8-0.8)$ & $(0.8-0.8)$ & $(0.7-0.7)$ & $(0.8-0.8)$ & $(0.8-0.8)$ & $(0.8-0.8)$ & $(0.7-0.7)$ & $(0.0-0.8)$ \\
\hline \multirow[t]{2}{*}{ Pensions } & 0 & 0 & 0.6 & 0.7 & 1.2 & 0 & 0 & $0.9 *$ \\
\hline & $(0.0-0.0)$ & $(0.0-0.0)$ & $(0.3-0.6)$ & $(0.2-0.7)$ & $(0.8-1.3)$ & $(0.0-0.0)$ & $(0.0-0.0)$ & $(0.3-1.5)$ \\
\hline Other in kind consumption & 0 & $1.3 *$ & 0.9 & 0.4 & 0 & 0.6 & 0.8 & 0 \\
\hline (excluding family policy) & $(0.0-0.0)$ & $(0.3-1.9)$ & $(0.4-1.3)$ & $(0.0-1.0)$ & $(0.0-0.0)$ & $(0.1-0.6)$ & $(0.0-1.1)$ & $(0.0-0.5)$ \\
\hline \multirow[t]{2}{*}{ Unemployment benefits } & $0.5^{*}$ & 0.6 & 0.1 & 0.1 & 0 & 0.2 & 0.3 & 0 \\
\hline & $(0.5-0.5)$ & $(0.0-0.9)$ & $(0.0-0.2)$ & $(0.0-0.6)$ & $(0.0-0.3)$ & $(0.0-0.2)$ & $(0.0-0.9)$ & $(0.0-0.0)$ \\
\hline \multirow[t]{2}{*}{ Environmental taxes } & 0.2 & 0 & 0 & 0 & 0 & 0.3 & 0 & 0 \\
\hline & $(0.1-0.2)$ & $(0.0-0.6)$ & $(0.0-0.0)$ & $(0.0-0.0)$ & $(0.0-0.0)$ & $(0.0-0.7)$ & $(0.0-0.0)$ & $(0.0-0.0)$ \\
\hline \multirow[t]{2}{*}{ Other property taxes } & 0 & 0 & 0 & 0 & 0 & 0 & 0 & 0 \\
\hline & $(0.0-0.0)$ & $(0.0-0.0)$ & $(0.0-0.2)$ & $(0.0-0.4)$ & $(0.0-0.0)$ & $(0.0-0.0)$ & $(0.0-0.4)$ & $(0.0-0.0)$ \\
\hline \multirow{2}{*}{$\begin{array}{l}\text { Sickness and disability } \\
\text { payments }\end{array}$} & 0 & 0 & 0 & 0 & 0 & 0 & 0 & 0 \\
\hline & $(0.0-0.0)$ & $(0.0-0.2)$ & $(0.0-0.1)$ & $(0.0-0.1)$ & $(0.0-0.0)$ & $(0.0-0.3)$ & $(0.0-0.2)$ & $(0.0-0.0)$ \\
\hline \multirow{2}{*}{$\begin{array}{l}\text { Recurrent taxes on } \\
\text { immovable property }\end{array}$} & 0.5 & 0 & 0 & 0 & 0 & 0 & 0 & 0 \\
\hline & $(0.0-1.0)$ & $(0.0-0.0)$ & $(0.0-0.0)$ & $(0.0-0.0)$ & $(0.0-0.0)$ & $(0.0-0.2)$ & $(0.0-0.0)$ & $(0.0-0.0)$ \\
\hline \multirow[t]{2}{*}{ Sales of goods and services } & 0.5 & 0 & 0 & 0 & 0 & 0 & 0 & 0 \\
\hline & $(0.0-1.0)$ & $(0.0-0.0)$ & $(0.0-0.0)$ & $(0.0-0.0)$ & $(0.0-0.0)$ & $(0.0-0.0)$ & $(0.0-0.0)$ & $(0.0-0.0)$ \\
\hline \multirow[t]{2}{*}{ Personal income taxes } & 0 & 0 & 0 & 0 & 0 & 0 & 0 & 0 \\
\hline & $(0.0-0.4)$ & $(0.0-0.0)$ & $(0.0-0.0)$ & $(0.0-0.0)$ & $(0.0-0.0)$ & $(0.0-0.0)$ & $(0.0-0.0)$ & $(0.0-0.0)$ \\
\hline \multirow[t]{2}{*}{ Corporate income taxes } & 0 & 0 & 0 & 0 & 0 & 0 & 0 & 0 \\
\hline & $(0.0-0.0)$ & $(0.0-0.0)$ & $(0.0-0.0)$ & $(0.0-0.0)$ & $(0.0-0.0)$ & $(0.0-0.0)$ & $(0.0-0.0)$ & $(0.0-0.0)$ \\
\hline \multirow{2}{*}{$\begin{array}{l}\text { Consumption taxes (other } \\
\text { than environmental) }\end{array}$} & 0 & 0 & 0 & 0 & 0 & 0 & 0 & 0 \\
\hline & $(0.0-0.5)$ & $(0.0-0.0)$ & $(0.0-0.0)$ & $(0.0-0.0)$ & $(0.0-0.0)$ & $(0.0-0.0)$ & $(0.0-0.0)$ & $(0.0-0.0)$ \\
\hline \multirow[t]{2}{*}{ Public investment } & 0 & 0 & 0 & 0 & 0 & 0 & 0 & 0 \\
\hline & $(0.0-0.0)$ & $(0.0-0.0)$ & $(0.0-0.0)$ & $(0.0-0.0)$ & $(0.0-0.0)$ & $(0.0-0.0)$ & $(0.0-0.0)$ & $(0.0-0.0)$ \\
\hline \multirow{2}{*}{$\begin{array}{l}\text { Health services } \\
\text { provided in kind }\end{array}$} & 0 & 0 & 0 & 0 & 0 & 0 & 0 & 0 \\
\hline & $(0.0-0.0)$ & $(0.0-0.0)$ & $(0.0-0.0)$ & $(0.0-0.0)$ & $(0.0-0.0)$ & $(0.0-0.0)$ & $(0.0-0.0)$ & $(0.0-0.0)$ \\
\hline \multirow[t]{2}{*}{ Family } & 0 & 0 & 0 & 0 & 0 & 0 & 0 & 0 \\
\hline & $(0.0-0.0)$ & $(0.0-0.0)$ & $(0.0-0.0)$ & $(0.0-0.0)$ & $(0.0-0.0)$ & $(0.0-0.0)$ & $(0.0-0.0)$ & $(0.0-0.0)$ \\
\hline \multirow[t]{2}{*}{ Social security contributions } & 0 & 0 & 0 & 0 & 0 & 0 & 0 & 0 \\
\hline & $(0.0-0.0)$ & $(0.0-0.0)$ & $(0.0-0.0)$ & $(0.0-0.0)$ & $(0.0-0.0)$ & $(0.0-0.0)$ & $(0.0-0.0)$ & $(0.0-0.0)$ \\
\hline \multirow[t]{2}{*}{ Education } & 0 & 0 & 0 & 0 & 0 & 0 & 0 & 0 \\
\hline & $(0.0-0.0)$ & $(0.0-0.0)$ & $(0.0-0.0)$ & $(0.0-0.0)$ & $(0.0-0.0)$ & $(0.0-0.0)$ & $(0.0-0.0)$ & $(0.0-0.0)$ \\
\hline Used spending residual & $(0.2-0.3)$ & $(0.1-0.1)$ & $(0.1-0.2)$ & $(0.1-0.2)$ & $(0.1-0.1)$ & $(0.1-0.2)$ & $(0.1-0.1)$ & $(0.0-0.1)$ \\
\hline Used revenue residual & $(0.0-0.0)$ & $(0.0-0.0)$ & $(0.0-0.0)$ & $(0.0-0.0)$ & $(0.0-0.0)$ & $(0.0-0.0)$ & $(0.0-0.0)$ & $(0.0-0.0)$ \\
\hline \multirow[t]{2}{*}{ Share spending efforts } & 58 & 100 & 100 & 100 & 100 & 86 & 100 & 100 \\
\hline & $(57-59)$ & $(78-100)$ & $(92-100)$ & $(83-100)$ & $(100-100)$ & $(65-100)$ & $(75-100)$ & $(100-100)$ \\
\hline Achieved consolidation & 2.8 & 2.8 & 2.4 & 2.3 & 2.2 & 2.1 & 1.8 & 1.7 \\
\hline Consolidation needs & 2.8 & 2.8 & 2.4 & 2.3 & 2.2 & 2.1 & 1.8 & 1.7 \\
\hline \multirow[t]{2}{*}{ Share top 9 instruments } & 100 & 100 & 100 & 100 & 100 & 100 & 100 & 100 \\
\hline & $(89-100)$ & $(100-100)$ & $(100-100)$ & $(100-100)$ & $(100-100)$ & $(100-100)$ & $(100-100)$ & $(100-100)$ \\
\hline \multirow{2}{*}{$\begin{array}{l}\text { Instruments crossing the } \\
\text { median }\end{array}$} & 2 & 1 & 1 & 0 & 0 & 0 & 1 & 2 \\
\hline & $(2-3)$ & $(1-2)$ & $(1-2)$ & $(0-1)$ & $(0-1)$ & $(0-1)$ & $(1-2)$ & $(1-2)$ \\
\hline
\end{tabular}

Note: see note to Table A1.1. 
Table A1.6 (cont.) Instrument use and achieved long-term consolidation vs. needs

Percentage of potential GDP except otherwise mentioned

\begin{tabular}{|c|c|c|c|c|c|}
\hline description & DEU & EST & ISL & KOR & GRC \\
\hline \multirow[t]{2}{*}{ Subsidies } & 0.3 & 0.3 & $0.8^{*}$ & 0 & 0 \\
\hline & $(0.3-0.3)$ & $(0.3-0.3)$ & $(0.7-0.8)$ & $(0.0-0.0)$ & $(0.0-0.0)$ \\
\hline \multirow[t]{2}{*}{ Pensions } & 0.8 & 0 & 0 & 0 & 0.9 \\
\hline & $(0.6-0.8)$ & $(0.0-0.0)$ & $(0.0-0.0)$ & $(0.0-0.0)$ & $(0.5-0.9)$ \\
\hline Other in kind consumption & 0 & $1.3 *$ & 0.2 & 0 & 0 \\
\hline (excluding family policy) & $(0.0-0.0)$ & $(0.4-1.3)$ & $(0.0-0.3)$ & $(0.0-0.0)$ & $(0.0-0.4)$ \\
\hline \multirow[t]{2}{*}{ Unemployment benefits } & 0.4 & 0 & 0.1 & 0.1 & 0 \\
\hline & $(0.0-0.6)$ & $(0.0-0.0)$ & $(0.0-0.3)$ & $(0.1-0.1)$ & $(0.0-0.0)$ \\
\hline \multirow[t]{2}{*}{ Environmental taxes } & 0 & 0 & 0 & 0 & 0 \\
\hline & $(0.0-0.4)$ & $(0.0-0.0)$ & $(0.0-0.2)$ & $(0.0-0.0)$ & $(0.0-0.0)$ \\
\hline \multirow[t]{2}{*}{ Other property taxes } & 0 & 0 & 0 & 0 & 0 \\
\hline & $(0.0-0.4)$ & $(0.0-0.7)$ & $(0.0-0.3)$ & $(0.0-0.0)$ & $(0.0-0.0)$ \\
\hline Sickness and disability & 0 & 0 & 0 & 0 & 0 \\
\hline payments & $(0.0-0.0)$ & $(0.0-0.1)$ & $(0.0-0.0)$ & $(0.0-0.0)$ & $(0.0-0.0)$ \\
\hline Recurrent taxes on & 0 & 0 & 0 & 0.3 & 0 \\
\hline immovable property & $(0.0-0.0)$ & $(0.0-0.0)$ & $(0.0-0.0)$ & $(0.0-0.6)$ & $(0.0-0.0)$ \\
\hline \multirow[t]{2}{*}{ Sales of goods and services } & 0 & 0 & 0 & 0.5 & 0 \\
\hline & $(0.0-0.0)$ & $(0.0-0.0)$ & $(0.0-0.0)$ & $(0.0-0.9)$ & $(0.0-0.0)$ \\
\hline \multirow[t]{2}{*}{ Personal income taxes } & 0 & 0 & 0 & 0 & 0 \\
\hline & $(0.0-0.0)$ & $(0.0-0.0)$ & $(0.0-0.0)$ & $(0.0-0.6)$ & $(0.0-0.0)$ \\
\hline \multirow[t]{2}{*}{ Corporate income taxes } & 0 & 0 & 0 & 0 & 0 \\
\hline & $(0.0-0.0)$ & $(0.0-0.0)$ & $(0.0-0.0)$ & $(0.0-0.0)$ & $(0.0-0.0)$ \\
\hline Consumption taxes (other & 0 & 0 & 0 & 0 & 0 \\
\hline than environmental) & $(0.0-0.0)$ & $(0.0-0.0)$ & $(0.0-0.0)$ & $(0.0-0.5)$ & $(0.0-0.0)$ \\
\hline \multirow[t]{2}{*}{ Public investment } & 0 & 0 & 0 & 0 & 0 \\
\hline & $(0.0-0.0)$ & $(0.0-0.0)$ & $(0.0-0.0)$ & $(0.0-0.0)$ & $(0.0-0.0)$ \\
\hline Health services & 0 & 0 & 0 & 0 & 0 \\
\hline provided in kind & $(0.0-0.0)$ & $(0.0-0.0)$ & $(0.0-0.0)$ & $(0.0-0.0)$ & $(0.0-0.0)$ \\
\hline \multirow[t]{2}{*}{ Family } & 0 & 0 & 0 & 0 & 0 \\
\hline & $(0.0-0.0)$ & $(0.0-0.0)$ & $(0.0-0.0)$ & $(0.0-0.0)$ & $(0.0-0.0)$ \\
\hline \multirow[t]{2}{*}{ Social security contributions } & 0 & 0 & 0 & 0 & 0 \\
\hline & $(0.0-0.0)$ & $(0.0-0.0)$ & $(0.0-0.0)$ & $(0.0-0.0)$ & $(0.0-0.0)$ \\
\hline \multirow[t]{2}{*}{ Education } & 0 & 0 & 0 & 0 & 0 \\
\hline & $(0.0-0.0)$ & $(0.0-0.0)$ & $(0.0-0.0)$ & $(0.0-0.0)$ & $(0.0-0.0)$ \\
\hline Used spending residual & $(0.1-0.1)$ & $(0.0-0.0)$ & $(0.0-0.1)$ & $(0.0-0.0)$ & $(0.0-0.0)$ \\
\hline Used revenue residual & $(0.0-0.0)$ & $(0.0-0.0)$ & $(0.0-0.0)$ & $(0.0-0.0)$ & $(0.0-0.0)$ \\
\hline \multirow[t]{2}{*}{ Share spending efforts } & 100 & 100 & 100 & 12 & 100 \\
\hline & $(76-100)$ & $(53-100)$ & $(76-100)$ & $(12-12)$ & $(100-100)$ \\
\hline Achieved consolidation & 1.6 & 1.6 & 1.2 & 1 & 0.9 \\
\hline Consolidation needs & 1.6 & 1.6 & 1.2 & 1 & 0.9 \\
\hline \multirow[t]{2}{*}{ Share top 9 instruments } & 100 & 100 & 100 & 100 & 100 \\
\hline & $(100-100)$ & $(100-100)$ & $(100-100)$ & $(74-100)$ & $(100-100)$ \\
\hline Instruments crossing the & 0 & 1 & 1 & 0 & 0 \\
\hline median & $(0-1)$ & $(1-1)$ & $(1-1)$ & $(0-0)$ & $(0-0)$ \\
\hline
\end{tabular}

Note: see note to Table A1.1. 


\section{APPENDIX 2. SUPPORTING MATERIAL}

\section{Estimating fiscal consolidation needs: additional technical information}

91. The present section provides additional background information on the calculation of fiscal consolidation needs that are presented in Section 2 of the main text. The present set of consolidation needs estimates is aimed at indicating a way in which the fiscal balance can evolve so as to reduce (or contain) public debt to a manageable level (set at $60 \%$ of GDP) and keep it there at the end of the projection period (2060). A target of $60 \%$ for gross general government debt relative to GDP has been chosen for reasons of consistency with the OECD long-term growth scenarios (OECD, 2012; Johansson et al., 2013; OECD, 2013). In addition to reaching this $60 \%$ target, a second objective of the consolidation path is to keep debt stable at this $60 \%$ of ratio of GDP by 2060 . The debt target is specified in gross terms, while government financial assets are assumed to remain constant as a ratio to GDP.

92. The debt-to-GDP ratio $d_{i}^{t}$ in country $i$ at the end of year $t$ results primarily from the past debt ratio $d_{i}^{t-1}$, the real interest rate $r_{i}^{t}$ paid on government debt, the real growth rate $g_{i}^{t}$, and the primary balance (as a share of GDP) $p_{i}^{t}$. Another driver of the debt ratio is the income generated by government financial assets (at the real rate $\tilde{r}_{i}^{t}$ ) net of the reinvestment needed to keep the asset-GDP ratio $a_{i}$ constant. Consequently, the debt-ratio evolves according to the following accumulation equation:

$$
d_{i}^{t}=d_{i}^{t-1}\left(1+r_{i}^{t}-g_{i}^{t}\right)-p_{i}^{t}+a_{i}\left(\tilde{r}_{i}^{t}-g_{i}^{t}\right) \quad(\mathrm{E} 1) .
$$

The primary balance ratio to GDP can itself be written as a function of the underlying primary balance as a ratio to potential GDP $p_{i}^{t}$, the output gap as a ratio to potential GDP $o_{i}^{t}$, a semi-elasticity $\varepsilon_{i}$ and the amount of one-off factors $f_{i}^{t}$ :

$$
p_{i}^{t}=\underline{p}_{i}^{t}+\varepsilon_{i} o_{i}^{t}+f_{i}^{t}(\mathrm{E} 2)
$$

93. In the present study, the fiscal consolidation path is defined as a trajectory for $\underline{p}_{i}^{t}$ that starts from the 2012 estimate in the OECD Economic Outlook of May 2013 and then takes projected values from 2013 to 2060. Using equation (E2), the fiscal consolidation path $\underline{p}_{i}^{t}$ is combined with the projections for $\varepsilon_{i} o_{i}^{t}+f_{i}^{t}$ in the OECD Economic Outlook of May 2013 long-term database to obtain projections of the primary deficit ratio $p_{i}^{t}$ from 2013 to 2060 . This path for the primary deficit ratio $p_{i}^{t}$ is then fed into equation (E1) to calculate the debt trajectory starting from the 2012 estimate of $d_{i}^{t}$ and the long-term projections for $r_{i}^{t}-g_{i}^{t}$ in in the OECD Economic Outlook of May 2013. The rates $r_{i}^{t}$ and $\tilde{r}_{i}^{t}$ are the effective interest rates paid and received by the government on its liabilities and assets, respectively, as projected in the OECD Economic Outlook of May 2013 long-term database, deflated by the rate of change of the GDP deflator taken from the same source. ${ }^{20}$ The effective interest rate $r_{i}^{t}$ takes into account the maturity structure of the stock of government debt.

20. One exception is Norway where such projections are not available. A rough projection of Norwegian real interest rates to 2060 has been built by adding a premium to the projection for the real growth rate in the the OECD Economic Outlook of May 2013 long-term baseline. This premium is calculated each year between 2015 and 2060 as a weighted average between two growth-interest rate differentials: the last (2014) projected one for Norway and the OECD average in the year under consideration, with the weight on the former gradually decreasing to zero over the period. The income return on Norway's financial assets 
94. The consolidation path $\left(\underline{p}_{i}^{t}\right)_{t=2013}^{2060}$ must satisfy the desired objectives of debt reaching $60 \%$ of GDP by 2060 (O1) and being stable (O2):

$$
\begin{aligned}
& d_{i}^{2060}=60 \% \\
& \left.\frac{\partial}{\partial t} d_{i}^{t}\right|_{t=2060}=0 \quad(\mathrm{O} 1),
\end{aligned}
$$

Using Equation (E1) and then (O2), and observing that cyclical effects and one-offs have vanished by 2060, it follows that the stability objective (O2) is satisfied if and only if:

$$
\underline{p}_{i}^{2060}=p_{i}^{2060}=d_{i}^{2060}\left(r_{i}^{2060}-g_{i}^{2060}\right)+a_{i}\left(\tilde{r}_{i}^{t}-g_{i}^{t}\right) \quad(\mathrm{E} 3) .
$$

The stability condition (O2) therefore pins down the end point for the consolidation path. Nevertheless, there are an infinite number of consolidation paths $\left(\underline{p}_{i}^{t}\right)_{t=2013}^{2060}$ that satisfy the first objective (O1) of a $60 \%$ debt-to-GDP ratio by 2060 .

95. The present study chooses a particular functional form for the consolidation path. It assumes that the underlying primary balance moves by one per cent of GDP each year until it reaches a certain value $\underline{p}_{i}^{*}$ and from then on evolves in equal yearly steps until its end value. In symbols instead of words, this functional form is defined as follows: $f\left(\underline{p}_{i}^{*}, \underline{p}_{i}^{2060}, t\right)$

$$
\begin{aligned}
& =\underline{p}_{i}^{2012}+(t-2012) \operatorname{sign}\left(\underline{p}_{i}^{*}-\underline{p}_{i}^{2012}\right) \quad \text { if } t \leq t_{i}^{*} \text { where } t_{i}^{*}=2012+\text { abs }\left|\underline{p}_{i}^{*}-\underline{p}_{i}^{2012}\right| \\
& =\underline{p}_{i}^{*}+\frac{\left(t-t_{i}^{*}\right)}{\left(2060-t_{i}^{*}\right)}\left(\underline{p}_{i}^{2060}-\underline{p}_{i}^{*}\right) \text { if } t>t_{i}^{*} \quad \text { (D2). }
\end{aligned}
$$

With this choice of functional form, ${ }^{21}$ the problem reduces to finding the value for $\underline{p}_{i}^{*}$ such that, with $\underline{p}_{i}^{t}=f\left(\underline{p}_{i}^{*}, \underline{p}_{i}^{2060}, t\right)$, the debt accumulation equation (E1) yields $d_{i}^{2060}=60 \%$.

96. The study covers all the OECD membership except Chile, Mexico and Turkey where the necessary national accounts data and projections for the general government sector are not available. As mentioned above, all the data and projections for the variables mentioned in this section are taken from the OECD long-term baseline published in the OECD Economic Outlook of May 2013.

97. Appendix A2 plots the consolidation paths for all covered countries. Most countries follow the hump shape depicted in Figures 1 and 2 of the main text $\left(\underline{p}_{i}^{*}>\underline{p}_{i}^{2060}>\underline{p}_{i}^{2012}\right)$ : they first have to increase their primary balance to get rid of legacy debt before they can allow it to diminish to reach the lower level that is consistent with debt being stable as a ratio to GDP at 60\%. A number of countries (Australia, Czech Republic, Finland, New Zealand, Poland, Slovak Republic, Slovenia) however do not exhibit this pattern

is projected to 2060 by starting from its average over the last five years of data and making it gradually converge to the average rate of return OECD governments receive on their financial assets in the $O E C D$ Economic Outlook of May 2013 long-term projections.

21. Formula (D1) is adjusted in the special case of Japan where consolidation is assumed to proceed at a faster pace of $1 \frac{1}{2}$ per cent of potential GDP per year to avoid an overly long consolidation period 
as they start from low debt so that the short- to medium-term level of the surplus required to make sure that debt remains below $60 \%$ until 2060 is lower than the surplus required in 2060 to keep the debt ratio stable $\left(p_{i}^{2012}<p_{i}^{*}<p_{i}^{2060}\right)$. Finally, in a group of countries (Denmark, Estonia, Korea, Luxembourg, Norway, Sweden, Switzerland), however, the uniform objective of a $60 \%$ debt-to-GDP ratio results mechanically in a profile of fiscal relaxation to reach the target from the bottom. Such a profile does not appear advisable in practice as the $60 \%$ target is set relatively high, leaving little room for shock absorption, and because fiscal relaxation often proves very difficult to reverse in practice. These countries are considered as having no short- to medium-term consolidation need, and the corresponding discussion does not apply to them.

98. Consolidation needs are estimated by comparing these "debt-control" trajectories for the underlying primary surplus that stabilise debt at $60 \%$ by 2060 with a baseline $\underline{\underline{p}}_{i}^{t}$. As described in the main text, the baseline for the underlying primary surplus starts from the 2012 estimated value in the $O E C D$ Economic Outlook of May 2013: $\quad \underline{p}_{i}^{2012}=\underline{p}_{i}^{2012}$. The baseline incorporates the assumption that pension reforms, including adjustments to the retirement age in line with longevity, keep public pension spending stable as a share of potential GDP. The baseline also incorporates some reform of health and long-term care so that public spending in this area increases in line with the projections $h_{i}^{t}$ in the "costcontainment" scenario presented in de la Maisonneuve and Oliveira Martins (2013). In other areas, fiscal policy parameters are assumed to be unchanged in the sense that corresponding spending and revenue items stay constant as a proportion of potential GDP. As a result, the baseline underlying primary balance evolves as: $\underline{p}_{i}^{t}=\underline{p}_{i}^{2012}-\left(h_{i}^{t}-h_{i}^{2012}\right)$.

99. The short- to medium-term consolidation need $c_{i}^{s m}$ is defined as the difference between the underlying primary surplus in the year $t_{i}^{*}$ when the value $\underline{p}_{i}^{*}$ is reached and the baseline in the same year:

$c_{i}^{s m}=p_{i}^{*}-\check{p}_{i}^{t_{i}^{*}}$. Given the choice of increasing the underlying primary balance by one per cent of potential GDP per year, there is a very direct link between the duration and size of consolidation. The short- to medium-term part of the simulated consolidation is completed by 2017 in the vast majority of covered countries, the exceptions being Greece, Ireland, Japan, Portugal, the United Kingdom and the United States.

100. The long-term consolidation need $c_{i}^{l}$ is defined as the difference between the underlying primary surplus that stabilises a 60\% debt-GDP ratio and its baseline level in 2060:

$c_{i}^{l}=\underline{p}_{i}^{2060}-\underline{p}_{i}^{2060}$. With a common target debt-ratio, differences in the long-term objective for the primary surplus only reflect differences in assumptions about real growth and interest rates by 2060 in the OECD long-term scenarios, which are small. The variation in estimated long-term consolidation needs (Figure 6 of the main text) therefore primary reflect differences in the baseline. The cross-country variation in projected increases in public health and long-term care spending is relatively limited in the costcontainment scenario. As a result, the main source of variation in estimated long-term consolidation needs comes from the starting point for the underlying primary surplus.

\section{The dataset of fiscal consolidation instruments}

\section{Defining the instruments}

101. The revenue and expenditure sides of budgets are decomposed into sets of variables which may potentially be the object of consolidation measures, and are hence referred to as the instruments of consolidation. Their definition balances concerns of economic interpretability, parsimony and data 
availability, while ensuring a consistent accounting framework where no budget items are missed or overlap, and hence the various categories of spending and revenue sum to total spending and revenue. A total of 17 consolidation instruments are identified, plus residual and property income items (Tables A2.1 and A2.2). Revenue instruments span the main categories of taxes plus a non-tax item, sales of goods and services (mainly user charges). Spending instruments articulate the economic and functional classifications of expenditure, where the former focuses on the economic nature of transactions (such as wages, cash transfers or public investment) and the latter on their purpose (like education, health or defence). Residual spending and revenue categories are heterogeneous and hence hard to characterise: though they are not taken as instruments, they are assumed to take part in the overall consolidation effort by keeping a constant share to underlying primary disbursements and receipts. Property income (paid or received) follows from the trajectories of interest rates and asset stocks.

102. Consolidation instruments are hence defined in a quantitative, internationally-comparable way, and their use to achieve budget targets does not map into specific policy measures. For instance, resorting to an increase in personal income taxes could be done either through higher marginal rates or by curbing tax expenditures. Likewise, spending on health care could be brought down either by reducing the levels of service provision or by achieving efficiency gains. Structural reforms of taxation and public spending, of which tackling tax expenditures and spending inefficiencies are prime examples, are strongly advocated, especially when large consolidation requirements force governments to use instruments with growth- or equity-damaging impacts. However, severe data limitations, as well as the need to preserve a consistent accounting framework, preclude the identification of tax expenditures and efficiency gains in specific areas as autonomous instruments. Though the scope for base broadening can be quantified for some taxes, such as VAT (through the VAT revenue ratio), efforts at international comparisons of tax expenditures across various tax bases have been subject to important limitations and covered only a subset of OECD members (OECD, 2010a). Potential savings from efficiency gains have been estimated in only a limited number of areas (e.g. Sutherland et al., 2007, for primary and secondary education; OECD, 2010b, for health care) and are also subject to important qualifications. For these reasons, the study considers the quantitative changes in the instruments of fiscal consolidation (spending cuts and revenue increases) separately from the structural measures that can accompany or contribute to them. 


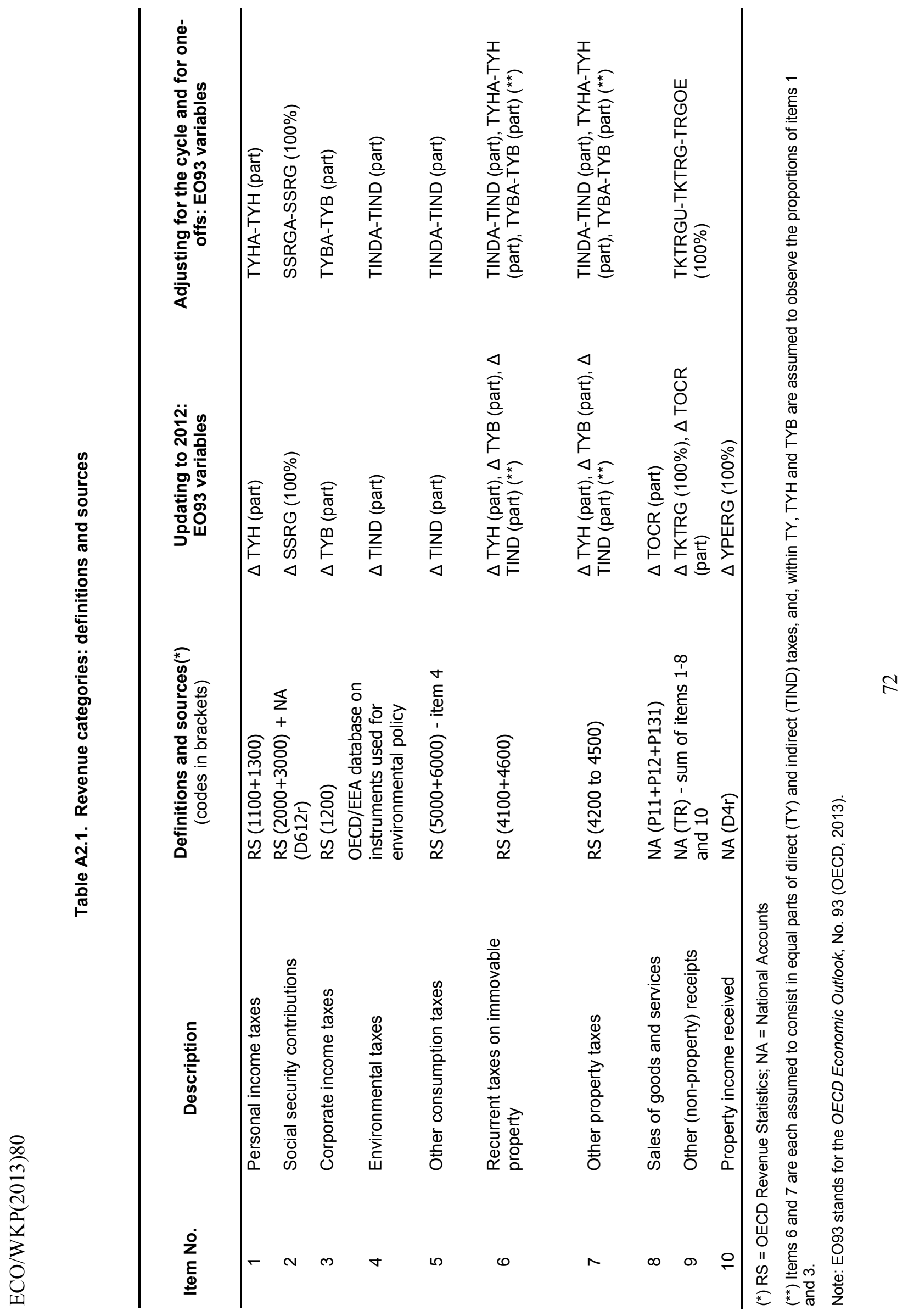




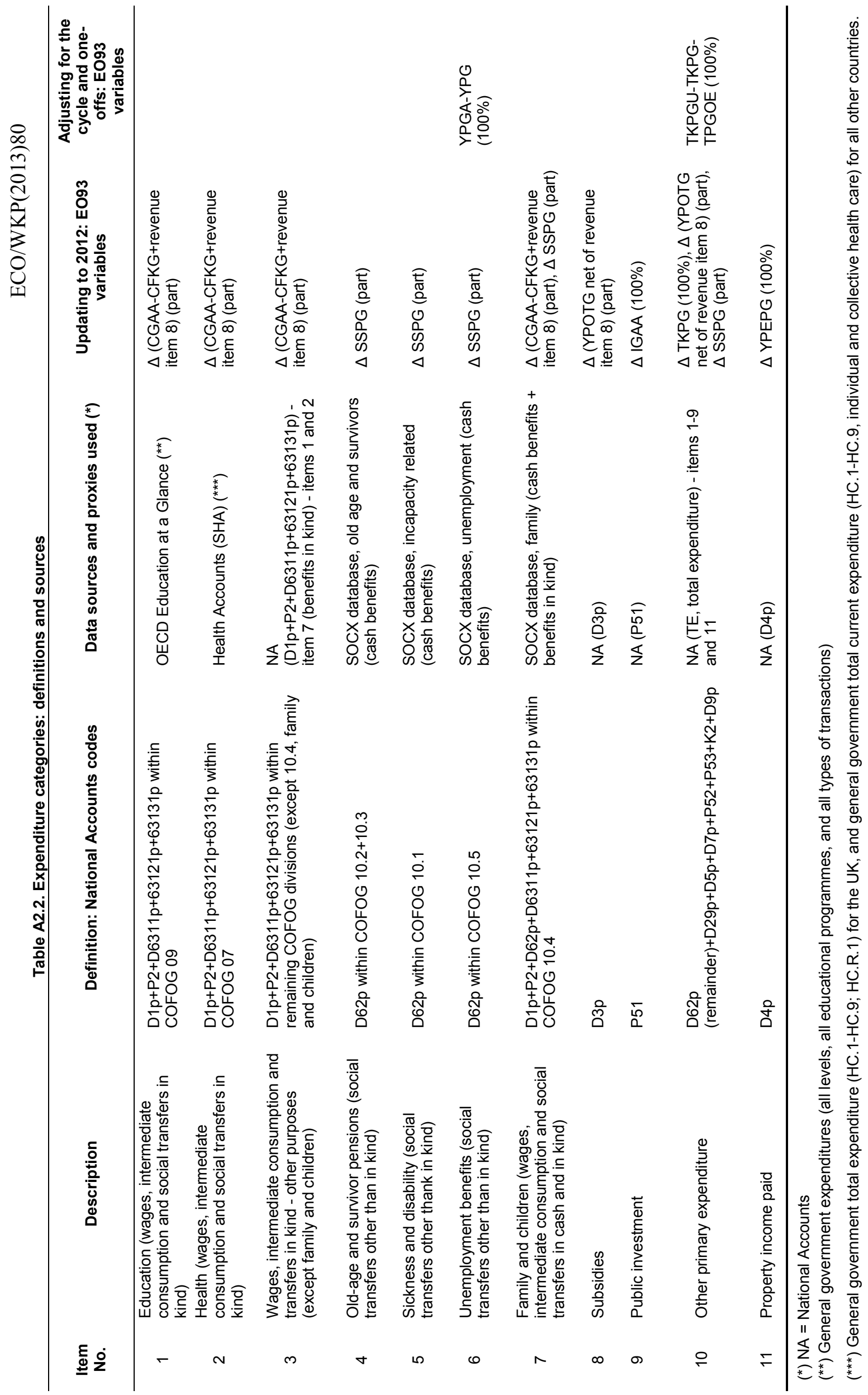


103. A dataset containing estimates in 2012 of all consolidation instruments in 31 OECD countries has been constructed, as described in more detail below (severe data limitations have prevented the inclusion of Chile, Mexico and Turkey). Using values in 2012 ensures consistency with the estimates of consolidation requirements and incorporates the effects of the various consolidation measures already implemented by member countries. ${ }^{22}$ Further, instruments are defined in underlying terms (i.e. net of cyclical effects and of one-offs), as a percentage of potential GDP. This avoids distortions in the crosscountry comparison of fiscal variables. For instance, the use of nominal values as a percentage of actual GDP could have resulted in overestimating the structural importance of spending items in countries with big negative output gaps.

\section{Constructing the fiscal dataset}

104. Underlying instrument values in 2012 have been estimated in three main steps. First, actual values in the most recent year available have been collected. Second, values have been updated to 2012 on the basis of the projections in the OECD Economic Outlook of May 2013 (OECD, 2013). Third, instruments have been adjusted for the cycle and for one-offs, also in a way consistent with OECD (2013).

105. In the first step, data is collected or estimated for the most recent year available in both the main statistical sources, national accounts and the OECD Revenue Statistics. This year (call it year Y) varies across countries, though it is often 2010 or 2011 (Table 3). However, on the spending side, though these sources give the totals for wages, intermediate consumption and transfers in kind and for social transfers other than in kind, they do not provide the functional breakdown defining the first seven instruments, as COFOG data is insufficiently disaggregated or simply not available. Alternative sources are then used (Tables 1, 2 and 3) and, when they refer to a year before year Y, values are extrapolated by assuming a constant share of the instrument in question in the respective national accounts total. For instance, Education at a Glance data for 2009 is extrapolated to 2010 (assuming this is year Y) by preserving the 2009 share of education spending relative to total wages, intermediate consumption and transfers in kind.

106. In the second step, the change from year $\mathrm{Y}$ to 2012 in the fiscal variables forecast in OECD (2013) is allocated to the several instruments of consolidation (plus residual and property income items), ensuring that total revenue and total expenditure in the dataset of instruments equal those totals in OECD (2013). Tables 1 and 2 set the correspondence used. Since the dataset of instruments is more disaggregated than the OECD (2013) fiscal block, it is often assumed that instruments keep a constant share relative to certain variables. For instance, while the change in the OECD (2013) variable TKTRG is fully allocated to the expenditure residual item, the change in TOCR is split between sales of goods and services and the residual item by assuming that the year Y ratio between sales and the residual (net of TKTRG) is maintained. On the spending side, it is worth underlining that unemployment benefits are assumed to remain a constant proportion of cash transfers in cyclically-adjusted rather than nominal terms.

107. In the third step, instruments are adjusted for the cycle and for one-offs, drawing again on OECD (2013) fiscal variables (Tables A2.1 and A2.2) and, as above, often making an assumption of constant proportions. Adjusted instruments are in all cases taken as a percentage of potential, rather than actual, GDP.

\section{Country-specific issues}

108. For each country, Table A2.3 documents the date of the latest available information from the several sources. Further, Swiss institutional features have given rise to a number of adjustments. In

22. In the wake of the previous paragraph, one should note that obtaining 2012 estimates of tax expenditures or potential efficiency gains would be virtually impossible. 
Switzerland, most health expenditure recorded as public in the health accounts is not classified as general government expenditure in national accounts, since the system is largely managed by private non-profit organizations (OECD, 2011). This would imply an artificially low value for other government consumption (item 3 in Table A2.2), since the latter is obtained by difference. To correct this problem, the difference in public spending on health between health accounts and national accounts is added to other government consumption. On the revenue side, a similar adjustment is made for social contributions to ensure budget balance neutrality and improve international comparability.

Table A2.3. Country data sources

\begin{tabular}{|c|c|c|c|c|c|c|}
\hline Country & $\begin{array}{l}\text { National } \\
\text { accounts }\end{array}$ & $\begin{array}{l}\text { Revenue } \\
\text { statistics }\end{array}$ & $\begin{array}{l}\text { Health } \\
\text { accounts }\end{array}$ & $\begin{array}{c}\text { Social } \\
\text { Expenditure } \\
\text { Database }\end{array}$ & $\begin{array}{l}\text { Education at } \\
\text { a Glance }\end{array}$ & $\begin{array}{c}\text { Environmental } \\
\text { taxes }\end{array}$ \\
\hline Australia & 2009 & 2009 & 2009 & 2009 & 2009 & 2009 \\
\hline Austria & 2011 & 2011 & 2010 & 2009 & 2009 & 2011 \\
\hline Belgium & 2011 & 2011 & 2010 & 2009 & 2009 & 2011 \\
\hline Canada & 2010 & 2010 & 2010 & 2009 & 2009 & 2010 \\
\hline Czech Republic & 2011 & 2011 & 2010 & 2009 & 2009 & 2011 \\
\hline Denmark & 2011 & 2011 & 2010 & 2009 & 2009 & 2011 \\
\hline Estonia & 2011 & 2011 & 2010 & 2009 & 2009 & 2011 \\
\hline Finland & 2011 & 2011 & 2010 & 2009 & 2009 & 2011 \\
\hline France & 2011 & 2011 & 2010 & 2009 & 2009 & 2011 \\
\hline Germany & 2011 & 2011 & 2010 & 2009 & 2009 & 2011 \\
\hline Greece & 2010 & 2010 & 2007 & 2009 & 2005 & 2010 \\
\hline Hungary & 2011 & 2011 & 2010 & 2009 & 2009 & 2011 \\
\hline Iceland & 2011 & 2011 & 2010 & 2009 & 2009 & 2011 \\
\hline Ireland & 2011 & 2011 & 2010 & 2009 & 2009 & 2011 \\
\hline Israel & 2011 & 2011 & 2009 & 2009 & 2009 & 2010 \\
\hline Italy & 2011 & 2011 & 2011 & 2009 & 2009 & 2011 \\
\hline Japan & 2010 & 2010 & 2009 & 2009 & 2009 & 2010 \\
\hline Korea & 2010 & 2010 & 2010 & 2009 & 2009 & 2010 \\
\hline Luxembourg & 2011 & 2011 & 2009 & 2009 & 2002 & 2011 \\
\hline Netherlands & 2010 & 2010 & 2010 & 2009 & 2009 & 2010 \\
\hline New Zealand & 2010 & 2010 & 2010 & 2009 & 2009 & 2010 \\
\hline Norway & 2011 & 2011 & 2011 & 2009 & 2009 & 2011 \\
\hline Poland & 2010 & 2010 & 2010 & 2009 & 2009 & 2010 \\
\hline Portugal & 2010 & 2010 & 2010 & 2009 & 2009 & 2010 \\
\hline Slovak Republic & 2011 & 2011 & 2010 & 2009 & 2009 & 2011 \\
\hline Slovenia & 2011 & 2011 & 2010 & 2009 & 2009 & 2010 \\
\hline Spain & 2011 & 2011 & 2010 & 2009 & 2009 & 2011 \\
\hline Sweden & 2011 & 2011 & 2010 & 2009 & 2009 & 2011 \\
\hline Switzerland & 2011 & 2011 & 2010 & 2008 & 2009 & 2011 \\
\hline United Kingdom & 2011 & 2011 & 2010 & 2009 & 2009 & 2011 \\
\hline United States & 2011 & 2011 & 2010 & 2009 & 2009 & 2010 \\
\hline Median & 2011 & 2011 & 2010 & 2009 & 2009 & 2011 \\
\hline Min & 2009 & 2009 & 2007 & 2008 & 2002 & 2009 \\
\hline Max & 2011 & 2011 & 2011 & 2009 & 2009 & 2011 \\
\hline
\end{tabular}

Source: OECD national accounts and revenue statistics, OECD health accounts, OECD Social Expenditure database, OECD Education at a Glance, and the OECD/European Environment Agency database on instruments used for environmental policy and natural resources management. 


\section{Additional considerations on the growth and equity effects of consolidation instruments}

109. This section gives detail additional to the main text on the underpinning of the assessment summarised by the pluses and minuses signs in Table A2.2 of the main text. The assessment proposed in Table A2.2 of the main text focuses on the effects of consolidation instruments themselves and does not incorporate the possible response of joint reform of structural or redistributive policies. In principle, all the long-term-growth-damaging instruments listed below can be accompanied by structural reforms that could mitigate, offset, or even more than offset, their harmful growth implications. Similarly, all regressive instruments can be supplemented by redistributive provisions tailored to preserve, or equalise, the income distribution. For many instruments the same behavioural responses to their implementation shape longterm effects along both the growth and equity dimensions which are therefore discussed together in the present section.

\section{Government consumption}

\section{Health care}

110. Government spending on health care reduces inequality in effective consumption (Hoeller et al., 2012). The favourable welfare effects of providing health services to people who cannot afford them otherwise are likely to be particularly large.

111. With good health contributing to human capital preservation, health spending can be expected to contribute positively to the productive potential of an economy (Joumard et al., 2010). Investment in health has indeed been found to boost economic output in OECD countries (Gyimah-Brempong and Wilson, 2004). On the plausible assumption that private funding cannot fully substitute for public expenditure, government spending on healthcare can be expected to boost potential output, a positive link that seems present in the data for OECD countries (see Barbiero and Cournède, 2013).

\section{Education}

112. Empirical estimates suggest that the distributional effect of government spending is progressive for primary and secondary education and regressive for tertiary education (OECD, 2011). Given that governments spend more on the primary and secondary levels of education, an across-the-board cut in education spending can be considered as regressive. Government spending on education generally tends to increase intergenerational social mobility as well (Causa and Johansson, 2010), meaning that the inequitable consequences of cuts in this area are likely to grow over time.

\section{Other government consumption}

113. Cuts in other government consumption that include reductions in government employment are likely to increase income inequality (Fournier and Koske, 2012). More broadly, reducing the government wage bill can be expected to increase income inequality in most countries (Bova et al, 2012). Cuts in government-provided services will also have the effect of increasing inequality in effective consumption.

\section{Government investment}

114. OECD work on the sources of economic growth found a positive long-term relationship between private and public capital accumulation, suggesting complementarity between the two and a positive effect of government investment on long-term output (see Table 2.7 in OECD, $2003 a$ and Sutherland et al., 2009). On US data, Leduc and Wilson (forthcoming) identify strong, positive long-term GDP effects of road infrastructure grants. Evidence from 583 studies surveyed by Bom and Ligthart (2013) indicates that public capital has positive short- and long-run effects on output. With a depreciation rate of $5 \%$ and a real 
interest rate of $3 \%$, the marginal cost of public capital $(8 \%)$ is lower than the estimated marginal rate of return (10 to $24 \%$ ). This situation suggests underinvestment in public capital, particularly for core public capital where the marginal rate of return may be close to $24 \%$.

115. Evidence on the effect of public investment on inequality in OECD countries is too limited for inclusion in the assessment summarised in Table 2 of the main text. Estimates by Calderon and Serven (2004) show that infrastructure development, a key area of government investment, promotes income equality. This study has however been conducted with a database consisting primarily of developing countries, which raises a question as to whether its finding applies to advanced economies. Furthermore, a model-based study by Chatterjee and Turnovsky (2012) suggests a conceptual channel whereby government investment could increase wealth inequality: because of complementarities between public and private capital, a greater public capital stock raises the value of private capital, the holding of which is concentrated at the top end of the wealth distribution. Finally, the short-term impact of government investment on the income distribution is likely to be positive given the large role of lowskilled labour in construction work, but there is little empirical evidence to document this effect.

\section{Transfers}

116. Transfers equalise income more strongly than taxes (Rawdanowicz et al., 2012; Joumard et al., 2012, Bastagli et al., 2012). On the other hand, aggregate higher social protection expenditure, especially "passive" income support, much of which is achieved through transfers, has been found to be associated with lower economic growth (Arjona et al., 2002). Some categories, such as active labour market programmes (ALMP), are linked with higher growth (Arjona et al., 2002), but most of ALMP spending is recorded as government consumption or subsidies rather than transfers.

\section{Pensions}

117. The distributional impact of reducing public pension spending can change direction depending on the way in which it is implemented. Reducing spending by increasing the average retirement age will have the effect that people who would otherwise have retired and drawn a sometimes low pension will keep drawing a higher salary. The effect is likely to be a more equal distribution of income. On the other hand, as public-pension systems are progressive, although to varying degrees across OECD countries, reducing replacement rates would tend to be regressive on impact. The effect will diminish over time if labour supply increases in response.

\section{Unemployment benefits}

118. Reducing unemployment benefits increases inequality, even in insurance-based systems because less paid workers are more likely to be laid off. In the long term, however, reducing the level of unemployment benefits translates into higher employment rates, implying little if any change in steadystate income distribution (Rawdanowicz et al., 2012).

\section{Sickness and disability benefits}

119. Reducing sickness and disability benefits would mechanically increase inequality as replacement rate tend to be higher for low-income earners (OECD, 2010). However, in the long term, poorly targeted disability benefits can lock up individuals with residual working capacity in poverty traps with negative growth effects and potentially negative effects on equity. In that regard, well targeted reductions in government spending on disability benefits are likely to have regressive effects that diminish over time (Rawdanowicz et al., 2012). Unfocussed budgetary cuts will have lasting regressive effects since part of them fall on people who cannot supply labour to compensate. 


\section{Subsidies}

120. In the present taxonomy of instruments, following the national accounts framework, subsidies are defined as current payments to businesses based on their production levels. Unless they correct market failures, such production subsidies have the potential to distort resource allocation and restrict competition (OECD, 2001) and have been long identified as reducing productive potential (Ford and Suyker, 1990). Agricultural and fossil-fuel subsidies in particular can in addition encourage inefficient use of natural resources (OECD, 2003b), eroding the resource base for long-term growth and harming those most exposed to environmental degradation, which are typically concentrated at the bottom of the income distribution (Serret and Johnstone, 2006).

\section{Taxes}

121. A $1 \%$ of GDP increase in distortionary taxes (labour and capital income taxes, social security contributions, property taxes) is estimated to reduce the level of GDP by $3.2 \%$ after ten years in a recent empirical study (Gemmell, Kneller and Sanz, 2011).

\section{Tax expenditures}

122. The present study does not include tax expenditures in its quantitative analysis of possible consolidation strategies for lack of comparable data across the OECD membership. Tax expenditures have the potential of distorting resource allocation and hurting growth. To give just one example, the combination of mortgage interest relief with no taxation of owner-occupied rental services favours investment in housing over other, typically more productive, forms of capital. With the notable exception of tax relief or credit for low-wage workers, many tax deductions have higher value for high-income earners and are therefore regressive (Rawdanowicz et al., 2012).

\section{Consumption taxes}

123. Consumption taxes are typically regressive because lower-income households spend a higher share of their income (Rawdanowicz et al., 2012). Fiscal authorities often try to limit the regressive effects of indirect taxes by applying reduced rates on bare necessities, but these reductions have large fiscal costs as they are enjoyed not only by low-income households but by all consumers.

\section{Personal income tax and social security contributions}

124. Progressive income taxation reduces growth and equalises after-tax income immediately (Joumard et al., 2012) and permanently (Echevarria, 2012). In many countries, however, a wide array of tax breaks, which have higher value for higher-income households, reduces the redistributive power of personal income taxation. Social security contributions, in contrast, tend to be regressive as they are often concentrated on labour income, which makes a smaller share of the income of higher-income households.

125. The direction of the growth effects of progressive income taxation, compared with flatter tax schedules, are ambiguous in theory. Progressive income taxation reduces the return on work more for more productive workers. Depending on whether they work more to maintain their income (the income effect) or less because of the higher after-tax relative value of leisure (the substitution effect), progressive taxation will boost or reduce output. Another channel is that, in presence of financial constraints, progressive tax schedules leave lower-income workers with more after-tax income from which they can build savings to start their own business. In first instance, this channel means that progressive taxation should be growth-enhancing. However, general-equilibrium effects push up the wages of low-productivity workers under flat tax schedules, which can partly compensate, or more than offset, the previous direct effect depending on the characteristics of the progressive and flat tax schemes being compared (Bohacek and 
Zubricki, 2012). Overall, the question is empirical, and the evidence is largely conclusive that progressive taxation reduces long-term growth (Johansson et al., 2008). Social security contribution schemes are typically far less progressive than income tax (OECD, 2012).

\section{Corporate income tax}

126. Corporate income taxes are one way of taxing capital income, directly and also by limiting the incentive for owners to shelter capital earnings from personal income taxation by keeping them in corporations (Johansson et al., 2008). As capital control is concentrated among higher-income households, corporate income taxation works in the direction of equalising income

127. A large body of empirical evidence indicates that corporate income taxes are highly distortive to long-term output (see for instance Johansson et al., 2008). Because it is calculated on earnings after interest payments, corporate income taxation creates a strong bias in favour of debt over equity financing, contributing to excess leverage and instability (Sutherland et al., 2012; De Mooij, 2012). Higher corporate income taxes have been found to deter FDI (Becker et al., 2012).

\section{Recurring taxes on immovable property}

128. In a number of OECD countries lower-income households pay a larger share of their earnings in recurring real estate taxes than higher-income households, so that recurring property taxes can be seen as regressive in the static income distribution. However, this situation is to some extent (but not fully) related to larger property holdings among pensioners, implying that property taxation is not necessarily regressive in the perspective of lifetime income or wealth distribution (Rawdanowicz et al., 2012). Furthermore, some OECD countries have introduced exemptions or rebates for low-income households to alleviate, or reverse, the regressive effects of recurring real estate taxes (Joumard et al., 2012). Against this background, increases in recurring taxes on immovable property cannot be described as being generally progressive or regressive.

\section{Other property taxes}

129. Inheritance, gift and wealth taxes, which make up much of this category, are highly redistributive because tax schedules are generally strongly progressive and wealth is more concentrated than income (Joumard et al., 2012). The progressive effects of increases, however, are likely to diminish over time due to the mobility of many forms of capital and the greater incentive to put in place tax avoidance strategies for more wealthy households.

\section{Environmental taxes}

130. Environmental taxes can improve welfare by increasing the marginal cost of activities that harm the environment. This welfare benefit is not measured in GDP which for the most part does not record environmental services. One of the effects of environmental taxes, however, is to support long-term output to the extent that they discourage the excessive use of environmental resources that are needed for future production. However, another of their effects, shared with other taxes, is to reduce labour supply and physical capital accumulation. Where applying to internationally mobile activities, environmental taxation will entail smaller gross effects on GDP and bring larger environmental benefits if it is co-ordinated across countries.

131. Lower-income households, who spend more of their income than better-off households on basic resources, therefore tend to pay a greater share of their income in environmental taxes. Prima facie, environmental taxes may therefore be considered as regressive. However, lower-income households are more exposed to environmental degradation than the rest of the population. As a result, when the benefits 
of higher environmental taxation materialise, the net welfare effect of environmental taxation may not necessarily be regressive.

\section{User charges}

132. Charging more for the use public services can boost growth by avoiding their inefficient use. The distributional effects of increases in user charges are likely to be regressive except in cases (such as tertiary education) where public services are used more heavily by higher-income groups.

\section{Methodological information on estimating debt behaviour during consolidation episodes}

133. This section provides detailed information about the methodology used to document the behaviour of debt-GDP ratios during consolidation episodes shown in Figure 6 of the main text. Episode of fiscal consolidation are defined using the IMF Action-Based Dataset (Devries et al., 2011). This definition of fiscal adjustments and discretionary policy choices of fiscal authorities is, in principle, less affected by countries' macroeconomic conditions than measures of the fiscal stance based on cyclical adjustment (Guajardo et al., 2011). A period of fiscal adjustment is defined as a year in which the actionbased budget balance improves by at least $1 \frac{1}{2}$ percent of GDP. As a robustness check, two thresholds of 1.75 and $2 \%$ of GDP were also used, but the results were very similar to the ones reported in Figure 6 . This definition rules out fiscal adjustments which are small annually but prolonged over several years. Furthermore, it selects both one-year consolidation episodes and multi-period adjustments as in Alesina and Ardagna (2010).

134. Figure 6 in the main text presents difference-in-differences estimates of the association between the public debt ratio $d$ and consolidation episodes, from 10 years before to 10 years after the onset of a consolidation. These specifications control for country and year fixed effects according to the following specification:

$$
d_{i c t}=\sum_{k=-10}^{+10} \beta_{k} 1_{t=c+k}+\delta_{i}+\delta_{t}+\varepsilon_{i c t}
$$

135. where $c$ stands for the starting year of a consolidation episode, $i$ the country and $t$ the year under consideration. The period from 15 to 11 years before the onset of a consolidation episode is omitted, meaning that all estimates are relative to these earlier years of data. Each country-year observation has the same weight in the estimation. On the solid lines, each point corresponds to the estimate of $\beta_{\mathrm{k}}$, the difference between the level of public debt in pre- or post-consolidation year k relative to the rest of the sample. Dashed lines represent the $90 \%$ confidence interval adjusted for heteroskedasticity, spatial autocorrelation and within-country autocorrelation as in Driscoll and Kraay (1998) and Auerbach and Gorodnichenko (2012).

\section{Alternative simulations based on simple country groups instead of clustering}

136. A variant has been prepared to test the sensitivity of clustering-based instrument rankings and consolidation packages. In this variant, instead of deriving weights from clustering analysis, countries are divided in three groups of identical sizes based on their current-account positions, and each objective receives the same weight within each group. Current account-positions are evaluated on the basis of cyclically adjusted current account balances as shares of both national and OECD GDP. The country groups and weights are as follows:

1. A first group gathers 10 countries with the largest current-account deficits: Australia, France, Greece, Iceland, New Zealand, Poland, Portugal, Spain, the United Kingdom and the United 
States. Weights of $20 \%$ each are given to each objective (short- and long-term growth and equity, current account).

2. A second group gathers 11 countries with the largest current-account surpluses: Austria, Denmark, Germany, Ireland, Japan, Korea, Luxembourg, Netherlands, the Slovak Republic, Sweden and Switzerland. Weights of $20 \%$ each are given to each objective (short- and long-term growth and equity, current account). The signs of the assessments of current-account effects shown in Table 3 of the main text are reversed to take into account the surplus position of these countries.

3. The third group gathers the remaining 10 countries: Belgium, Canada, the Czech Republic, Estonia, Finland, Hungary, Israel, Italy, Norway and Slovenia. Weights of $25 \%$ each are given to each objective (short- and long-term growth and equity)

137. The rankings that result from this alternative weighting scheme are very highly correlated with the ones obtained with the clustering technique reported in the main text. Rank correlations between clustering-based and alternative rankings are $96 \%$ for Cluster 1, 98\% for Cluster 2, 93\% for Cluster 3, 89\% for Cluster 4 and $95 \%$ for Cluster 5.

138. As a result, the consolidation packages are also very similar as is apparent from comparing Tables A2.4-A2.8 which refer to the alternative simulations to Tables A1.1-A1.5 which refer to the main ones. To facilitate comparison with the main results reported in Tables A1.1-5, the tables A2.4-A2.8 for the variant are shown with the same grouping of countries by cluster although uniform weights for the three above-listed groups have been used. Overall, the simulated consolidation packages in the variant are very close to the clustering-based ones. Noticeable differences appear only in Clusters 3 and 4 where clusteringbased weights differ substantially from $25 \%$. For instance, the instrument mix of the Slovak Republic and Spain changes with greater use of personal income taxes. The variant is similarly robust to shocks to the assessment of effects as the main clustering-based results. The interdecile variations shown between brackes in Tables A2.4-A2.8 remain generally narrow. 
Table A2.4. Instrument use and short- to medium-term consolidation with fixed weights in Cluster No. 1 Percentage of potential GDP except otherwise mentioned

\begin{tabular}{|c|c|c|c|c|c|c|c|c|c|}
\hline Description & AUS & CAN & GBR & ISR & ITA & JPN & NZL & POL & PRT \\
\hline \multirow[t]{2}{*}{ Subsidies } & $0.6^{*}$ & 0.3 & 0 & 0 & 0.3 & 0 & 0 & 0 & 0 \\
\hline & $(0.6-0.6)$ & $(0.3-0.3)$ & $(0.0-0.0)$ & $(0.0-0.0)$ & $(0.0-0.3)$ & $(0.0-0.0)$ & $(0.0-0.0)$ & $(0.0-0.0)$ & $(0.0-0.0)$ \\
\hline \multirow[t]{2}{*}{ Other property taxes } & 0 & $0.5^{*}$ & 0.2 & 0.2 & 0 & $0.4^{*}$ & $0.7^{*}$ & $0.7^{*}$ & $0.3^{*}$ \\
\hline & $(0.0-0.0)$ & $(0.5-0.5)$ & $(0.2-0.2)$ & $(0.2-0.2)$ & $(0.0-0.0)$ & $(0.3-0.3)$ & $(0.7-0.7)$ & $(0.7-0.7)$ & $(0.3-0.3)$ \\
\hline \multirow[t]{2}{*}{ Pensions } & 0 & 0 & 0.3 & 0.2 & 0.3 & 0.8 & 0 & 0.9 & 0.9 \\
\hline & $(0.0-0.0)$ & $(0.0-0.0)$ & $(0.3-0.3)$ & $(0.2-0.2)$ & $(0.3-0.7)$ & $(0.8-0.8)$ & $(0.0-0.0)$ & $(0.9-0.9)$ & $(0.9-0.9)$ \\
\hline \multirow[t]{2}{*}{ Corporate income taxes } & 0 & 0.2 & $0.5^{\star}$ & 0 & 0 & 0 & 0 & $0.9^{*}$ & 0.3 \\
\hline & $(0.0-0.0)$ & $(0.0-0.2)$ & $(0.5-0.5)$ & $(0.0-0.0)$ & $(0.0-0.0)$ & $(0.0-0.0)$ & $(0.0-0.0)$ & $(0.0-0.9)$ & $(0.0-0.3)$ \\
\hline \multirow[t]{2}{*}{ Personal income taxes } & 0 & 0 & 0.5 & 1.3 & 0 & $4.6^{*}$ & 0 & 1.1 & $4.1^{*}$ \\
\hline & $(0.0-0.0)$ & $(0.0-0.0)$ & $(0.5-0.5)$ & $(0.0-1.3)$ & $(0.0-0.0)$ & $(4.6-4.6)$ & $(0.0-0.0)$ & $(0.0-2.0)$ & $(3.2-4.1)$ \\
\hline Recurrent taxes on & 0 & 0 & 0 & 0 & 0 & 0 & 0 & 0.1 & $0.8^{*}$ \\
\hline immovable property & $(0.0-0.0)$ & $(0.0-0.0)$ & $(0.0-0.0)$ & $(0.0-0.0)$ & $(0.0-0.0)$ & $(0.0-0.0)$ & $(0.0-0.0)$ & $(0.0-0.3)$ & $(0.3-0.8)$ \\
\hline \multirow[t]{2}{*}{ Unemployment benefits } & 0 & $0.2^{*}$ & 0 & 0 & 0 & 0.2 & 0 & 0 & 0.3 \\
\hline & $(0.0-0.0)$ & $(0.0-0.2)$ & $(0.0-0.0)$ & $(0.0-0.0)$ & $(0.0-0.0)$ & $(0.2-0.2)$ & $(0.0-0.0)$ & $(0.0-0.0)$ & $(0.0-0.3)$ \\
\hline \multirow[t]{2}{*}{ Environmental taxes } & $0.7^{*}$ & 0.7 & $0.2^{*}$ & 0 & 0 & 0.7 & 0.7 & 0.2 & 0.2 \\
\hline & $(0.0-0.7)$ & $(0.0-0.7)$ & $(0.2-0.2)$ & $(0.0-0.0)$ & $(0.0-0.0)$ & $(0.7-0.7)$ & $(0.0-0.7)$ & $(0.0-0.7)$ & $(0.0-0.2)$ \\
\hline \multirow{2}{*}{$\begin{array}{l}\text { Other gov. in kind } \\
\text { consumption }\end{array}$} & 0.6 & 0.6 & $2.2^{*}$ & 0 & 0 & 0 & 0 & 0 & 0.2 \\
\hline & $(0.0-1.0)$ & $(0.0-1.8)$ & $(2.2-2.2)$ & $(0.0-1.3)$ & $(0.0-0.0)$ & $(0.0-0.0)$ & $(0.0-0.0)$ & $(0.0-1.1)$ & $(0.0-0.6)$ \\
\hline \multirow{2}{*}{$\begin{array}{l}\text { Sales of goods and } \\
\text { services }\end{array}$} & 0 & 0 & $0.7^{*}$ & 0 & 0 & $1.0^{*}$ & 0 & 0 & 0 \\
\hline & $(0.0-0.0)$ & $(0.0-0.0)$ & $(0.6-0.7)$ & $(0.0-0.1)$ & $(0.0-0.0)$ & $(1.0-1.0)$ & $(0.0-0.0)$ & $(0.0-0.4)$ & $(0.0-0.3)$ \\
\hline \multirow{2}{*}{$\begin{array}{l}\text { Consumption taxes } \\
\text { (other } \\
\text { than environmental) }\end{array}$} & 0 & 0 & $1.3^{*}$ & 0 & 0 & 2.5 & 0 & 0 & 0 \\
\hline & $(0.0-1.3)$ & $(0.0-1.0)$ & $(1.3-1.3)$ & $(0.0-0.0)$ & $(0.0-0.0)$ & $(2.5-2.5)$ & $(0.0-0.0)$ & $(0.0-0.5)$ & $(0.0-0.6)$ \\
\hline \multirow[t]{2}{*}{ Public investment } & 0 & 0 & 0.3 & 0 & 0 & 1.1 & 0 & 0 & 0 \\
\hline & $(0.0-0.6)$ & $(0.0-0.1)$ & $(0.2-0.3)$ & $(0.0-0.0)$ & $(0.0-0.0)$ & $(1.1-1.1)$ & $(0.0-0.6)$ & $(0.0-0.1)$ & $(0.0-0.0)$ \\
\hline \multirow{2}{*}{$\begin{array}{l}\text { Sickness and disability } \\
\text { payments }\end{array}$} & 0 & 0 & $0.7^{*}$ & 0 & 0 & 0 & 0.2 & 0 & 0 \\
\hline & $(0.0-0.0)$ & $(0.0-0.0)$ & $(0.7-0.7)$ & $(0.0-0.1)$ & $(0.0-0.0)$ & $(0.0-0.0)$ & $(0.0-0.7)$ & $(0.0-0.4)$ & $(0.0-0.2)$ \\
\hline \multirow{2}{*}{$\begin{array}{l}\text { Health services } \\
\text { provided } \\
\text { in kind }\end{array}$} & 0 & 0 & $1.5^{\star}$ & 0 & 0 & $1.5^{\star}$ & 0 & 0 & 0 \\
\hline & $(0.0-0.0)$ & $(0.0-0.0)$ & $(0.3-1.5)$ & $(0.0-0.0)$ & $(0.0-0.0)$ & $(1.5-1.5)$ & $(0.0-0.1)$ & $(0.0-0.0)$ & $(0.0-0.0)$ \\
\hline \multirow{2}{*}{$\begin{array}{l}\text { Social security } \\
\text { contributions }\end{array}$} & 0 & 0 & 0 & 0 & 0 & $0.9^{*}$ & 0 & 0 & 0 \\
\hline & $(0.0-0.0)$ & $(0.0-0.0)$ & $(0.0-0.7)$ & $(0.0-0.0)$ & $(0.0-0.0)$ & $(0.9-0.9)$ & $(0.0-0.0)$ & $(0.0-0.0)$ & $(0.0-0.0)$ \\
\hline \multirow[t]{2}{*}{ Family } & 0 & 0 & 0 & 0 & 0 & 0 & 0 & 0 & 0 \\
\hline & $(0.0-0.0)$ & $(0.0-0.0)$ & $(0.0-0.8)$ & $(0.0-0.0)$ & $(0.0-0.0)$ & $(0.0-0.0)$ & $(0.0-0.0)$ & $(0.0-0.0)$ & $(0.0-0.0)$ \\
\hline \multirow[t]{2}{*}{ Education } & 0 & 0 & 0 & 0 & 0 & 0.3 & 0 & 0 & 0 \\
\hline & $(0.0-0.0)$ & $(0.0-0.0)$ & $(0.0-0.0)$ & $(0.0-0.0)$ & $(0.0-0.0)$ & $(0.3-0.3)$ & $(0.0-0.0)$ & $(0.0-0.0)$ & $(0.0-0.0)$ \\
\hline \multirow{4}{*}{$\begin{array}{l}\text { Used spending } \\
\text { residual } \\
\text { Used revenue residual } \\
\text { Share spending } \\
\text { efforts }\end{array}$} & 0.1 & 0.1 & 0.8 & 0 & 0 & 0.6 & 0 & 0.1 & 0.1 \\
\hline & 0 & 0 & 0.2 & 0 & 0 & 0.6 & 0.1 & 0.1 & 0.4 \\
\hline & 64 & 45 & 62 & 13 & 100 & 30 & 9 & 25 & 19 \\
\hline & $(35-97)$ & $(23-82)$ & $(62-65)$ & $(13-89)$ & $\begin{array}{c}(100- \\
100)\end{array}$ & $(29-30)$ & $(9-57)$ & $(25-54)$ & $(17-28)$ \\
\hline $\begin{array}{l}\text { Achieved } \\
\text { consolidation }\end{array}$ & 1.9 & 2.7 & 9.2 & 1.7 & 0.7 & 15 & 1.7 & 4 & 7.5 \\
\hline \multirow{3}{*}{$\begin{array}{l}\text { Consolidation } \\
\text { Share top } 9 \\
\text { instruments }\end{array}$} & 1.9 & 2.7 & 9.2 & 1.7 & 0.7 & 18.3 & 1.7 & 4 & 7.5 \\
\hline & 100 & 100 & 46 & 100 & 100 & 48 & 90 & 100 & 100 \\
\hline & $(70-100)$ & $(77-100)$ & $(28-62)$ & $\begin{array}{c}(100- \\
100)\end{array}$ & $\begin{array}{c}(100- \\
100)\end{array}$ & $(43-64)$ & $(89-100)$ & $\begin{array}{c}(100- \\
100)\end{array}$ & $(51-100)$ \\
\hline \multirow{2}{*}{$\begin{array}{l}\text { Instruments } \\
\text { crossing the median }\end{array}$} & 2 & 2 & 7 & 0 & 0 & 5 & 1 & 2 & 3 \\
\hline & $(1-2)$ & $(2-3)$ & $(6-7)$ & $(0-1)$ & $(0-0)$ & $(5-5)$ & $(1-1)$ & $(1-3)$ & $(3-4)$ \\
\hline
\end{tabular}

Note: Simulated interdecile intervals in parentheses computed using 200 random draws. Each dimension of the assessments in Table 2 is increased by 1 or decreased by 1 with equal probability $(1 / 8,1 / 8)$.An asterisk sign $\left({ }^{*}\right)$ denotes an instrument crossing the OECD median. The use of residual items is marginal. Simulated interdecile intervals are not reported for these items. 
ECO/WKP(2013)80

Table A2.5. Instrument use and short- to medium-term consolidation with fixed weights in Cluster No. 2

Percentage of potential GDP except otherwise mentioned

\begin{tabular}{|c|c|}
\hline Description & USA \\
\hline \multirow[t]{2}{*}{ Subsidies } & 0 \\
\hline & $(0.0-0.0)$ \\
\hline \multirow[t]{2}{*}{ Pensions } & 0.5 \\
\hline & $(0.6-0.6)$ \\
\hline \multirow[t]{2}{*}{ Other property taxes } & $0.7^{*}$ \\
\hline & $(0.7-0.7)$ \\
\hline \multirow[t]{2}{*}{ Unemployment benefits } & 0.2 \\
\hline & $(0.2-0.2)$ \\
\hline \multirow[t]{2}{*}{ Corporate income taxes } & 0.2 \\
\hline & $(0.2-0.2)$ \\
\hline \multirow[t]{2}{*}{ Environmental taxes } & 0.7 \\
\hline & $(0.7-0.7)$ \\
\hline \multirow[t]{2}{*}{ Recurrent taxes on immovable property } & 0 \\
\hline & $(0.0-0.0)$ \\
\hline \multirow[t]{2}{*}{ Personal income taxes } & 1 \\
\hline & $(1.0-1.0)$ \\
\hline \multirow[t]{2}{*}{ Other government in kind consumption (excluding family policy) } & 0 \\
\hline & $(0.0-0.0)$ \\
\hline \multirow[t]{2}{*}{ Sales of goods and services } & 0 \\
\hline & $(0.0-0.0)$ \\
\hline \multirow[t]{2}{*}{ Sickness and disability payments } & 0 \\
\hline & $(0.0-0.0)$ \\
\hline \multirow[t]{2}{*}{ Consumption taxes (other than environmental) } & 2.5 \\
\hline & $(2.1-2.5)$ \\
\hline \multirow[t]{2}{*}{ Public investment } & 0.3 \\
\hline & $(0.0-0.3)$ \\
\hline \multirow[t]{2}{*}{ Health services provided in kind } & $1.1^{*}$ \\
\hline & $(1.1-1.5)$ \\
\hline \multirow[t]{2}{*}{ Family } & 0 \\
\hline & $(0.0-0.0)$ \\
\hline \multirow[t]{2}{*}{ Social security contributions } & 0 \\
\hline & $(0.0-0.6)$ \\
\hline \multirow[t]{2}{*}{ Education } & 0 \\
\hline & $(0.0-0.0)$ \\
\hline Used spending residual & 0.3 \\
\hline Used revenue residual & 0.2 \\
\hline \multirow[t]{2}{*}{ Share spending efforts } & 31 \\
\hline & $(31-39)$ \\
\hline Achieved consolidation & 7.7 \\
\hline Consolidation needs & 7.7 \\
\hline \multirow[t]{2}{*}{ Share top 9 instruments } & 46 \\
\hline & $(36-80)$ \\
\hline \multirow[t]{2}{*}{ Instruments crossing the median } & 2 \\
\hline & $(2-2)$ \\
\hline
\end{tabular}

Note: Simulated interdecile intervals in parentheses computed using 200 random draws. Each dimension of the assessments in Table 2 is increased by 1 or decreased by 1 with equal probability $(1 / 8,1 / 8)$. An asterisk sign $\left(^{*}\right.$ denotes an instrument crossing the OECD median. The use of residual items is marginal. Simulated interdecile intervals are not reported for these items. 
Table A2.6. Instrument use and short- to medium-term consolidation with fixed weights in Cluster No. 3

Percentage of potential GDP except otherwise mentioned

\begin{tabular}{|c|c|c|c|}
\hline Description & ESP & GRC & IRL \\
\hline \multirow[t]{2}{*}{ Pensions } & 0 & 0.6 & 0 \\
\hline & $(0.0-0.0)$ & $(0.6-0.6)$ & $(0.0-0.0)$ \\
\hline \multirow[t]{2}{*}{ Subsidies } & 0.2 & 0 & 0 \\
\hline & $(0.2-0.2)$ & $(0.0-0.0)$ & $(0.0-0.0)$ \\
\hline \multirow[t]{2}{*}{ Other property taxes } & 0 & 0 & 0 \\
\hline & $(0.0-0.0)$ & $(0.0-0.0)$ & $(0.0-0.0)$ \\
\hline \multirow[t]{2}{*}{ Unemployment benefits } & 1.6 & 0 & 1.1 \\
\hline & $(0.6-1.6)$ & $(0.0-0.0)$ & $(1.1-1.1)$ \\
\hline \multirow[t]{2}{*}{ Environmental taxes } & 0.5 & 0.2 & $0.3^{*}$ \\
\hline & $(0.0-0.7)$ & $(0.0-0.2)$ & $(0.3-0.3)$ \\
\hline \multirow[t]{2}{*}{ Recurrent taxes on immovable property } & 0.3 & $1.0^{*}$ & $1.0 *$ \\
\hline & $(0.0-0.4)$ & $(0.3-1.0)$ & $(0.9-1.0)$ \\
\hline \multirow[t]{2}{*}{ Corporate income taxes } & $0.9^{*}$ & 0 & $0.3 *$ \\
\hline & $(0.0-0.9)$ & $(0.0-0.0)$ & $(0.3-0.3)$ \\
\hline \multirow[t]{2}{*}{ Sales of goods and services } & 0 & 0 & $0.3^{*}$ \\
\hline & $(0.0-1.0)$ & $(0.0-0.3)$ & $(0.0-0.3)$ \\
\hline \multirow[t]{2}{*}{ Personal income taxes } & $1.7^{*}$ & $3.7^{*}$ & 0.1 \\
\hline & $(0.0-2.5)$ & $(2.8-3.7)$ & $(0.1-0.1)$ \\
\hline \multirow[t]{2}{*}{ Sickness and disability payments } & 0 & 0 & 0.2 \\
\hline & $(0.0-0.7)$ & $(0.0-0.0)$ & $(0.0-0.2)$ \\
\hline Other government in kind consumption & 0 & $2.1^{*}$ & 0 \\
\hline (excluding family policy) & $(0.0-0.6)$ & $(1.1-2.3)$ & $(0.0-0.0)$ \\
\hline \multirow[t]{2}{*}{ Consumption taxes (other than environmental) } & 0 & 0 & $2.2 *$ \\
\hline & $(0.0-1.9)$ & $(0.0-0.7)$ & $(0.6-2.5)$ \\
\hline \multirow[t]{2}{*}{ Public investment } & 0 & 0 & 0 \\
\hline & $(0.0-0.0)$ & $(0.0-0.0)$ & $(0.0-0.3)$ \\
\hline \multirow[t]{2}{*}{ Health services provided in kind } & 0 & 0 & 0 \\
\hline & $(0.0-0.0)$ & $(0.0-0.0)$ & $(0.0-0.0)$ \\
\hline \multirow[t]{2}{*}{ Social security contributions } & 0 & 0 & 0 \\
\hline & $(0.0-0.0)$ & $(0.0-0.0)$ & $(0.0-1.5)$ \\
\hline \multirow[t]{2}{*}{ Family } & 0 & 0 & 0 \\
\hline & $(0.0-0.0)$ & $(0.0-0.0)$ & $(0.0-0.0)$ \\
\hline \multirow[t]{2}{*}{ Education } & 0 & 0 & 0 \\
\hline & $(0.0-0.0)$ & $(0.0-0.0)$ & $(0.0-0.0)$ \\
\hline Used spending residual & 0.1 & 0.1 & 0.1 \\
\hline Used revenue residual & 0.1 & 0.4 & 0.1 \\
\hline \multirow[t]{2}{*}{ Share spending efforts } & 36 & 35 & 26 \\
\hline & $(28-60)$ & $(22-41)$ & $(21-32)$ \\
\hline Achieved consolidation & 5.3 & 8.2 & 5.8 \\
\hline Consolidation needs & 5.3 & 8.2 & 5.8 \\
\hline \multirow[t]{2}{*}{ Share top 9 instruments } & 100 & 100 & 51 \\
\hline & $(93-100)$ & $(51-100)$ & $(38-87)$ \\
\hline \multirow[t]{2}{*}{ Instruments crossing the median } & 2 & 3 & 5 \\
\hline & $(1-2)$ & $(2-3)$ & $(4-5)$ \\
\hline
\end{tabular}

Note: Simulated interdecile intervals in parentheses computed using 200 random draws. Each dimension of the assessments in Table 2 is increased by 1 or decreased by 1 with equal probability $(1 / 8,1 / 8)$. An asterisk mark $\left({ }^{*}\right)$ denotes an instrument crossing the OECD median. The use of residual items is marginal. Simulated interdecile intervals are not reported for these items. 
Table A2.7. Instrument use and short- to medium-term consolidation with fixed weights in Cluster No. 4

Percentage of potential GDP except otherwise mentioned

\begin{tabular}{|c|c|c|c|c|c|}
\hline Description & AUT & BEL & CZE & FIN & FRA \\
\hline \multirow[t]{2}{*}{ Pensions } & 0 & 0 & 0.1 & 0 & 0.6 \\
\hline & $(0.0-0.1)$ & $(0.0-0.0)$ & $(0.0-0.1)$ & $(0.0-0.0)$ & $(0.6-0.6)$ \\
\hline \multirow[t]{2}{*}{ Subsidies } & 0.2 & 0.8 & 0.8 & $0.7^{*}$ & $0.7^{*}$ \\
\hline & $(0.0-0.2)$ & $(0.8-0.8)$ & $(0.8-0.8)$ & $(0.7-0.7)$ & $(0.6-0.6)$ \\
\hline \multirow[t]{2}{*}{ Other property taxes } & 0 & 0 & $0.5^{*}$ & $0.4 *$ & 0 \\
\hline & $(0.0-0.2)$ & $(0.0-0.0)$ & $(0.0-0.6)$ & $(0.4-0.4)$ & $(0.0-0.0)$ \\
\hline \multirow[t]{2}{*}{ Unemployment benefits } & 0 & 0.7 & 0 & 0.9 & $0.9 *$ \\
\hline & $(0.0-0.0)$ & $(0.0-0.7)$ & $(0.0-0.0)$ & $(0.0-0.9)$ & $(0.8-0.9)$ \\
\hline \multirow[t]{2}{*}{ Environmental taxes } & 0 & 0 & 0 & 0 & $0.7 *$ \\
\hline & $(0.0-0.0)$ & $(0.0-0.6)$ & $(0.0-0.0)$ & $(0.0-0.0)$ & $(0.0-0.7)$ \\
\hline \multirow[t]{2}{*}{ Recurrent taxes on immovable property } & 0 & 0 & 0 & $0.8^{*}$ & 0 \\
\hline & $(0.0-0.0)$ & $(0.0-0.3)$ & $(0.0-0.0)$ & $(0.0-0.8)$ & $(0.0-0.0)$ \\
\hline \multirow[t]{2}{*}{ Sales of goods and services } & 0 & 0 & 0 & 0 & 0 \\
\hline & $(0.0-0.0)$ & $(0.0-0.0)$ & $(0.0-0.0)$ & $(0.0-0.0)$ & $(0.0-0.0)$ \\
\hline \multirow[t]{2}{*}{ Sickness and disability payments } & 0 & 0 & 0 & 0 & 0 \\
\hline & $(0.0-0.0)$ & $(0.0-0.0)$ & $(0.0-0.0)$ & $(0.0-0.7)$ & $(0.0-0.0)$ \\
\hline \multirow[t]{2}{*}{ Personal income taxes } & 0 & 0 & 0 & 0 & 0 \\
\hline & $(0.0-0.0)$ & $(0.0-0.0)$ & $(0.0-0.0)$ & $(0.0-0.0)$ & $(0.0-0.0)$ \\
\hline \multirow[t]{2}{*}{ Corporate income taxes } & 0 & 0 & 0 & $0.5^{*}$ & $0.6^{*}$ \\
\hline & $(0.0-0.0)$ & $(0.0-0.2)$ & $(0.0-0.0)$ & $(0.0-0.5)$ & $(0.2-0.6)$ \\
\hline Other government in kind consumption & 0 & 0 & 0 & 0.3 & $1.0 *$ \\
\hline (excluding family policy) & $(0.0-0.0)$ & $(0.0-0.5)$ & $(0.0-0.0)$ & $(0.0-2.1)$ & $(0.0-1.8)$ \\
\hline \multirow[t]{2}{*}{ Consumption taxes (other than environmental) } & 0 & 0 & 0 & 0 & 0 \\
\hline & $(0.0-0.0)$ & $(0.0-0.0)$ & $(0.0-0.0)$ & $(0.0-0.0)$ & $(0.0-0.0)$ \\
\hline \multirow[t]{2}{*}{ Social security contributions } & 0 & 0 & 0 & 0 & 0 \\
\hline & $(0.0-0.0)$ & $(0.0-0.0)$ & $(0.0-0.0)$ & $(0.0-0.0)$ & $(0.0-0.0)$ \\
\hline \multirow[t]{2}{*}{ Family } & 0 & 0 & 0 & 0 & 0 \\
\hline & $(0.0-0.0)$ & $(0.0-0.0)$ & $(0.0-0.0)$ & $(0.0-0.0)$ & $(0.0-0.0)$ \\
\hline \multirow[t]{2}{*}{ Public investment } & 0 & 0 & 0 & 0 & 0 \\
\hline & $(0.0-0.0)$ & $(0.0-0.0)$ & $(0.0-0.0)$ & $(0.0-0.1)$ & $(0.0-1.0)$ \\
\hline \multirow[t]{2}{*}{ Health services provided in kind } & 0 & 0 & 0 & 0 & 0 \\
\hline & $(0.0-0.0)$ & $(0.0-0.0)$ & $(0.0-0.0)$ & $(0.0-0.0)$ & $(0.0-0.5)$ \\
\hline \multirow[t]{2}{*}{ Education } & 0 & 0 & 0 & 0 & 0 \\
\hline & $(0.0-0.0)$ & $(0.0-0.0)$ & $(0.0-0.0)$ & $(0.0-0.0)$ & $(0.0-0.0)$ \\
\hline Used spending residual & 0 & 0.1 & 0.1 & 0.2 & 0.2 \\
\hline Used revenue residual & 0 & 0 & 0 & 0 & 0 \\
\hline \multirow[t]{2}{*}{ Share spending efforts } & 100 & 100 & 66 & 55 & 71 \\
\hline & $(0-100)$ & $(56-100)$ & $(61-66)$ & $(55-89)$ & $(71-86)$ \\
\hline Achieved consolidation & 0.2 & 1.6 & 1.6 & 3.8 & 4.7 \\
\hline Consolidation needs & 0.2 & 1.6 & 1.6 & 3.8 & 4.7 \\
\hline \multirow[t]{2}{*}{ Share top 9 instruments } & 100 & 100 & 100 & 100 & 100 \\
\hline & $(100-100)$ & $(100-100)$ & $(100-100)$ & $(91-100)$ & $(78-100)$ \\
\hline \multirow[t]{2}{*}{ Instruments crossing the median } & 0 & 0 & 1 & 4 & 5 \\
\hline & $(0-0)$ & $(0-1)$ & $(1-1)$ & $(2-4)$ & $(4-5)$ \\
\hline
\end{tabular}

Note: Simulated interdecile intervals in parentheses computed using 200 random draws. Each dimension of the assessments in Table 2 is increased by 1 or decreased by 1 with equal probability $(1 / 8,1 / 8)$. An asterisk $\left(^{*}\right)$ denotes an instrument crossing the OECD median. The use of residual items is marginal. Simulated interdecile intervals are not reported for these items. 
Table A2.7. (cont.) Instrument use and short- to medium-term consolidation with fixed weights in Cluster No. 4 Percentage of potential GDP except otherwise mentioned

\begin{tabular}{|c|c|c|c|c|}
\hline Description & HUN & ISL & SVK & SVN \\
\hline \multirow[t]{2}{*}{ Pensions } & 0.2 & 0 & 0 & 0 \\
\hline & $(0.2-0.2)$ & $(0.0-0.0)$ & $(0.0-0.0)$ & $(0.0-0.0)$ \\
\hline \multirow[t]{2}{*}{ Subsidies } & $0.7 *$ & $0.8^{*}$ & $0.5^{*}$ & $0.5 *$ \\
\hline & $(0.7-0.7)$ & $(0.8-0.8)$ & $(0.5-0.5)$ & $(0.5-0.5)$ \\
\hline \multirow[t]{2}{*}{ Other property taxes } & 0.2 & 0.3 & $0.7 *$ & $0.7^{*}$ \\
\hline & $(0.0-0.2)$ & $(0.3-0.3)$ & $(0.7-0.7)$ & $(0.4-0.7)$ \\
\hline \multirow[t]{2}{*}{ Unemployment benefits } & $0.2 *$ & 0.6 & 0 & 0 \\
\hline & $(0.0-0.2)$ & $(0.3-0.6)$ & $(0.0-0.0)$ & $(0.0-0.0)$ \\
\hline \multirow[t]{2}{*}{ Environmental taxes } & 0 & $0.5^{*}$ & 0.3 & 0 \\
\hline & $(0.0-0.0)$ & $(0.0-0.4)$ & $(0.0-0.7)$ & $(0.0-0.0)$ \\
\hline \multirow[t]{2}{*}{ Recurrent taxes on immovable property } & 0.1 & 0 & $0.4 *$ & 0.2 \\
\hline & $(0.0-0.7)$ & $(0.0-0.0)$ & $(0.0-1.0)$ & $(0.0-0.9)$ \\
\hline \multirow[t]{2}{*}{ Sales of goods and services } & 0 & 0 & 0 & 0 \\
\hline & $(0.0-0.0)$ & $(0.0-0.3)$ & $(0.0-1.0)$ & $(0.0-0.0)$ \\
\hline \multirow[t]{2}{*}{ Sickness and disability payments } & 0 & 0.1 & 0 & 0 \\
\hline & $(0.0-0.0)$ & $(0.0-0.2)$ & $(0.0-0.0)$ & $(0.0-0.0)$ \\
\hline \multirow[t]{2}{*}{ Personal income taxes } & 0.3 & 0 & 2 & 0.5 \\
\hline & $(0.0-0.7)$ & $(0.0-0.0)$ & $(0.0-2.8)$ & $(0.0-0.9)$ \\
\hline \multirow[t]{2}{*}{ Corporate income taxes } & 0.1 & $0.6^{*}$ & 0 & 0.2 \\
\hline & $(0.0-0.7)$ & $(0.0-0.6)$ & $(0.0-0.6)$ & $(0.0-0.9)$ \\
\hline Other government in kind consumption & 0 & 0.5 & 0 & 0 \\
\hline (excluding family policy) & $(0.0-0.6)$ & $(0.1-1.6)$ & $(0.0-0.0)$ & $(0.0-0.9)$ \\
\hline \multirow[t]{2}{*}{ Consumption taxes (other than environmental) } & 0 & 0 & 0 & 0 \\
\hline & $(0.0-0.0)$ & $(0.0-0.0)$ & $(0.0-0.0)$ & $(0.0-0.0)$ \\
\hline \multirow[t]{2}{*}{ Social security contributions } & 0 & 0 & 0 & 0 \\
\hline & $(0.0-0.0)$ & $(0.0-0.0)$ & $(0.0-0.0)$ & $(0.0-0.0)$ \\
\hline \multirow[t]{2}{*}{ Family } & 0 & 0 & 0 & 0 \\
\hline & $(0.0-0.0)$ & $(0.0-0.0)$ & $(0.0-0.0)$ & $(0.0-0.0)$ \\
\hline \multirow[t]{2}{*}{ Public investment } & 0 & 0 & 0 & 0 \\
\hline & $(0.0-0.0)$ & $(0.0-0.0)$ & $(0.0-0.0)$ & $(0.0-0.0)$ \\
\hline \multirow[t]{2}{*}{ Health services provided in kind } & 0 & 0 & 0 & 0 \\
\hline & $(0.0-0.0)$ & $(0.0-0.1)$ & $(0.0-0.0)$ & $(0.0-0.0)$ \\
\hline \multirow[t]{2}{*}{ Education } & 0 & 0 & 0 & 0 \\
\hline & $(0.0-0.0)$ & $(0.0-0.0)$ & $(0.0-0.0)$ & $(0.0-0.0)$ \\
\hline Used spending residual & 0.1 & 0.1 & 0.1 & 0.1 \\
\hline Used revenue residual & 0 & 0 & 0 & 0.1 \\
\hline \multirow[t]{2}{*}{ Share spending efforts } & 68 & 61 & 13 & 23 \\
\hline & $(51-90)$ & $(54-85)$ & $(13-13)$ & $(23-66)$ \\
\hline Achieved consolidation & 1.8 & 3.6 & 4 & 2.2 \\
\hline Consolidation needs & 1.8 & 3.6 & 4 & 2.2 \\
\hline \multirow[t]{2}{*}{ Share top 9 instruments } & 100 & 99 & 100 & 100 \\
\hline & $(100-100)$ & $(83-100)$ & $(96-100)$ & $(100-100)$ \\
\hline \multirow[t]{2}{*}{ Instruments crossing the median } & 2 & 3 & 3 & 2 \\
\hline & $(1-2)$ & $(2-3)$ & $(2-4)$ & $(2-3)$ \\
\hline
\end{tabular}

Note: Simulated interdecile intervals in parentheses computed using 200 random draws. Each dimension of the assessments in Table 2 is increased by 1 or decreased by 1 with equal probability $(1 / 8,1 / 8)$. An asterisk mark $\left({ }^{*}\right)$ denotes an instrument crossing the OECD median. The use of residual items is marginal. Simulated interdecile intervals are not reported for these items. 
Table A2.8. Instrument use and short- to medium-term consolidation with fixed weights in Cluster No. 5

Percentage of potential GDP except otherwise mentioned

\begin{tabular}{|c|c|c|c|}
\hline Description & LUX & NLD & SWE \\
\hline \multirow[t]{2}{*}{ Subsidies } & 0.2 & $0.6^{*}$ & $0.7^{*}$ \\
\hline & $(0.2-0.2)$ & $(0.6-0.6)$ & $(0.2-0.8)$ \\
\hline \multirow[t]{2}{*}{ Other property taxes } & 0 & 0.2 & 0.2 \\
\hline & $(0.0-0.0)$ & $(0.2-0.2)$ & $(0.0-0.7)$ \\
\hline \multirow[t]{2}{*}{ Pensions } & 0 & 0 & 0 \\
\hline & $(0.0-0.0)$ & $(0.0-0.0)$ & $(0.0-0.4)$ \\
\hline \multirow[t]{2}{*}{ Environmental taxes } & 0 & 0 & 0 \\
\hline & $(0.0-0.0)$ & $(0.0-0.0)$ & $(0.0-0.0)$ \\
\hline \multirow[t]{2}{*}{ Recurrent taxes on immovable property } & 0 & $0.8^{*}$ & 0 \\
\hline & $(0.0-0.0)$ & $(0.0-0.8)$ & $(0.0-0.0)$ \\
\hline Other government in kind consumption & 0 & 1 & 0 \\
\hline (excluding family policy) & $(0.0-0.0)$ & $(0.0-1.9)$ & $(0.0-0.0)$ \\
\hline \multirow[t]{2}{*}{ Sales of goods and services } & 0 & 0 & 0 \\
\hline & $(0.0-0.0)$ & $(0.0-0.0)$ & $(0.0-0.0)$ \\
\hline \multirow[t]{2}{*}{ Personal income taxes } & 0 & 0 & 0 \\
\hline & $(0.0-0.0)$ & $(0.0-0.0)$ & $(0.0-0.0)$ \\
\hline \multirow[t]{2}{*}{ Unemployment benefits } & 0 & 0.2 & 0 \\
\hline & $(0.0-0.0)$ & $(0.0-0.4)$ & $(0.0-0.0)$ \\
\hline \multirow[t]{2}{*}{ Social security contributions } & 0 & 0 & 0 \\
\hline & $(0.0-0.0)$ & $(0.0-0.0)$ & $(0.0-0.0)$ \\
\hline \multirow[t]{2}{*}{ Sickness and disability payments } & 0 & 0 & 0 \\
\hline & $(0.0-0.0)$ & $(0.0-0.0)$ & $(0.0-0.0)$ \\
\hline \multirow[t]{2}{*}{ Corporate income taxes } & 0 & 0 & 0 \\
\hline & $(0.0-0.0)$ & $(0.0-0.9)$ & $(0.0-0.0)$ \\
\hline \multirow[t]{2}{*}{ Consumption taxes (other than environmental) } & 0 & 0 & 0 \\
\hline & $(0.0-0.0)$ & $(0.0-0.0)$ & $(0.0-0.0)$ \\
\hline \multirow[t]{2}{*}{ Family } & 0 & 0 & 0 \\
\hline & $(0.0-0.0)$ & $(0.0-0.0)$ & $(0.0-0.0)$ \\
\hline \multirow[t]{2}{*}{ Public investment } & 0 & 0 & 0 \\
\hline & $(0.0-0.0)$ & $(0.0-0.0)$ & $(0.0-0.0)$ \\
\hline \multirow[t]{2}{*}{ Health services provided in kind } & 0 & 0 & 0 \\
\hline & $(0.0-0.0)$ & $(0.0-0.0)$ & $(0.0-0.0)$ \\
\hline \multirow[t]{2}{*}{ Education } & 0 & 0 & 0 \\
\hline & $(0.0-0.0)$ & $(0.0-0.0)$ & $(0.0-0.0)$ \\
\hline Used spending residual & 0 & 0.1 & 0.1 \\
\hline Used revenue residual & 0 & 0 & 0 \\
\hline \multirow[t]{2}{*}{ Share spending efforts } & 100 & 65 & 85 \\
\hline & $(100-100)$ & $(32-92)$ & $(31-100)$ \\
\hline Achieved consolidation & 0.2 & 2.8 & 1 \\
\hline Consolidation needs & 0.2 & 2.8 & 1 \\
\hline \multirow[t]{2}{*}{ Share top 9 instruments } & 100 & 100 & 100 \\
\hline & $(100-100)$ & $(100-100)$ & $(100-100)$ \\
\hline \multirow[t]{2}{*}{ Instruments crossing the median } & 0 & 2 & 1 \\
\hline & $(0-0)$ & $(1-3)$ & $(1-2)$ \\
\hline
\end{tabular}

Note: Simulated interdecile intervals in parentheses computed using 200 random draws. Each dimension of the assessments in Table 2 is increased by 1 or decreased by 1 with equal probability $(1 / 8,1 / 8)$. An asterisk $\left(^{*}\right)$ denotes an instrument crossing the OECD median. The use of residual items is marginal. Simulated interdecile intervals are not reported for these items. 


\section{Alternative simulations allowing additional room for manoeuvre}

139. An important assumption in the simulation design relates to the amount up to which each instrument can be used. As presented in greater detail in Box 5, which also spells out the adjustments made to deal with special cases, two constraints are imposed in the main simulations:

1. A tax can be increased up until proceeds from this tax reach the $66^{\text {th }}$ percentile of the crosscountry distribution of receipts from this kind of tax, as a share of potential GDP. Similarly, spending in one area can be reduced until the country reaches the $33^{\text {rd }}$ percentile of the crosscountry distribution of spending in this area, as a share of potential GDP.

2. Adjustment along one instrument is capped at one standard deviation of the cross-country distribution of tax or spending in the area under consideration as a share of potential GDP.

In the present set of alternative simulations, the first constraint is relaxed by allowing movement until reaching the $80^{\text {th }}$ percentile for taxes and the $20^{\text {th }}$ percentile for spending. The second constraint is retained.

140. Tables A2.9-A2.13 present country details of the short- to medium-term packages simulated under the relaxed first constraint on instrument use. Compared with the main results reported in Tables A2.1-A2.5, these alternative simulations show that allowing more room for manoeuvre makes it possible

Table A2.9. Instrument use and short- to medium-term consolidation with additional room for manoeuvre in Cluster No. 1

Percentage of potential GDP except otherwise mentioned

\begin{tabular}{|c|c|c|c|c|c|c|c|c|c|}
\hline Description & AUS & CAN & GBR & ISR & ITA & JPN & NZL & POL & PRT \\
\hline Subsidies & $0.8^{*}$ & 0.6 & 0.2 & 0.3 & 0.6 & 0.2 & 0 & 0 & 0.2 \\
\hline Other property taxes & 0.2 & $0.7^{*}$ & 0.4 & 0.4 & 0 & $0.6^{*}$ & $0.7^{*}$ & $0.7^{*}$ & $0.6^{*}$ \\
\hline Corporate income taxes & 0 & 0.6 & $0.8^{*}$ & 0 & 0 & 0 & 0 & $0.9^{*}$ & 0.6 \\
\hline Personal income taxes & 0.9 & 0.7 & 2.5 & 0.8 & 0 & $4.6^{*}$ & 0 & 1.3 & $4.6^{*}$ \\
\hline Environmental taxes & 0 & 0 & $0.5^{*}$ & 0 & 0 & 0.7 & 0.7 & 0 & 0 \\
\hline $\begin{array}{l}\text { Other government in kind consumption } \\
\text { (excluding family policy) }\end{array}$ & 0 & 0 & $2.3 *$ & 0 & 0 & 0.6 & 0 & 0 & 0 \\
\hline Sales of goods and services & 0 & 0 & $1.0^{*}$ & 0 & 0 & $1.0^{*}$ & 0 & 0 & 0 \\
\hline $\begin{array}{l}\text { Consumption taxes (other than } \\
\text { environmental) }\end{array}$ & 0 & 0 & $0.4^{*}$ & 0 & 0 & 2.5 & 0 & 0 & 0 \\
\hline Health services provided in kind & 0 & 0 & 0 & 0 & 0 & $1.5^{*}$ & 0 & 0 & 0 \\
\hline Social security contributions & 0 & 0 & 0 & 0 & 0 & $0.9^{*}$ & 0 & 0 & 0 \\
\hline Family & 0 & 0 & 0 & 0 & 0 & 0 & 0 & 0 & 0 \\
\hline Education & 0 & 0 & 0 & 0 & 0 & 0.4 & 0 & 0 & 0 \\
\hline Used spending residual & 0.1 & 0.1 & 0.5 & 0.1 & 0.1 & 0.8 & 0 & 0.1 & 0.1 \\
\hline Used revenue residual & 0 & 0 & 0.3 & 0 & 0 & 0.6 & 0.1 & 0.1 & 0.3 \\
\hline Share spending efforts & 46 & 25 & 35 & 31 & 100 & 35 & 0 & 25 & 16 \\
\hline Achieved consolidation & 1.9 & 2.7 & 9.2 & 1.7 & 0.7 & 16.7 & 1.7 & 4 & 7.5 \\
\hline Consolidation needs & 1.9 & 2.7 & 9.2 & 1.7 & 0.7 & 18.3 & 1.7 & 4 & 7.5 \\
\hline
\end{tabular}

Note: The room for manoeuvre is defined by the $20^{\text {th }}$ percentile of OECD countries for spending items and the $80^{\text {th }}$ percentile of OECD countries for revenue items. An asterisk sign $\left(^{*}\right)$ denotes an instrument crossing the OECD median.

for countries to achieve much more of their adjustment with well ranked instruments. The same finding holds for the simulated long-term packages reported in Table A2.14 for the variant with additional room 
for manoeuvre and Table A2.6 for the main scenario. These findings are obtained even though the relaxation of the constraint is relatively moderate in the sense that the one-standard-deviation constraint is maintained.

Table A2.10. Instrument use and short- to medium-term consolidation with additional room for manoeuvre in Cluster No. 2

Percentage of potential GDP except otherwise mentioned

\begin{tabular}{lc}
\hline Description & USA \\
\hline Subsidies & 0 \\
Pensions & 0.5 \\
Other property taxes & $0.7 *$ \\
Unemployment benefits & 0.2 \\
Corporate income taxes & 0.5 \\
Environmental taxes & 0.7 \\
Recurrent taxes on immovable property & 0 \\
Personal income taxes & 3 \\
Other government in kind consumption (excluding family policy) & 0 \\
Sales of goods and services & 0 \\
Sickness and disability payments & 0 \\
Consumption taxes (other than environmental) & 1.7 \\
Public investment & 0 \\
Health services provided in kind & 0 \\
Family & 0 \\
Social security contributions & 0 \\
Education & 0 \\
\hline Used spending residual & 0 \\
Used revenue residual & 0.1 \\
Share spending efforts & 0.2 \\
Achieved consolidation & 11 \\
Consolidation needs & 7.7 \\
Share top 9 instruments & 7.7 \\
Instruments crossing the median & 77 \\
\hline
\end{tabular}

Note: The room for manoeuvre is defined by the $20^{\text {th }}$ percentile of OECD countries for spending items and the $80^{\text {th }}$ percentile of OECD countries for revenue items. * denotes an instrument crossing the OECD median. 
Table A2.11. Instrument use and short- to medium-term consolidation with additional room for manoeuvre in Cluster No. 3

Percentage of potential GDP except otherwise mentioned

\begin{tabular}{lccc}
\hline Description & ESP & GRC & IRL \\
\hline Pensions & 0 & 0.6 & 0 \\
Subsidies & 0.4 & 0 & 0 \\
Other property taxes & 0.2 & 0.3 & 0.2 \\
Unemployment benefits & 1.9 & 0 & 1.1 \\
Environmental taxes & 0.7 & 0.3 & $0.6^{*}$ \\
Recurrent taxes on immovable property & 1 & $1.0^{*}$ & $1.0^{*}$ \\
Corporate income taxes & $0.9^{*}$ & 0.4 & $0.9^{*}$ \\
Sales of goods and services & 0 & 0.5 & $0.7^{*}$ \\
Personal income taxes & 0 & $4.6^{*}$ & 1 \\
Sickness and disability payments & 0 & 0 & 0 \\
Other government in kind consumption (excluding family policy) & 0 & 0 & 0 \\
Consumption taxes (other than environmental) & 0 & 0 & 0 \\
Public investment & 0 & 0 & 0 \\
Health services provided in kind & 0 & 0 & 0 \\
Social security contributions & 0 & 0 & 0 \\
Family & 0 & 0 & 0 \\
Education & 0 & 0 & 0 \\
\hline Used spending residual & 0.1 & 0.1 & 0.1 \\
Used revenue residual & 0.1 & 0.3 & 0.2 \\
Share spending efforts & 45 & 9 & 22 \\
Achieved consolidation & 5.3 & 8.2 & 5.8 \\
Consolidation needs & 5.3 & 8.2 & 5.8 \\
Share top 9 instruments & 100 & 100 & 100 \\
Instruments crossing the median & 1 & 2 & 4 \\
\hline Note: The room for manouvr is & 0.3 \\
\hline
\end{tabular}

Note: The room for manoeuvre is defined by the $20^{\text {th }}$ percentile of OECD countries for spending items and the $80^{\text {th }}$ percentile of OECD countries for revenue items. A $\left({ }^{*}\right)$ sign denotes an instrument crossing the OECD median. 


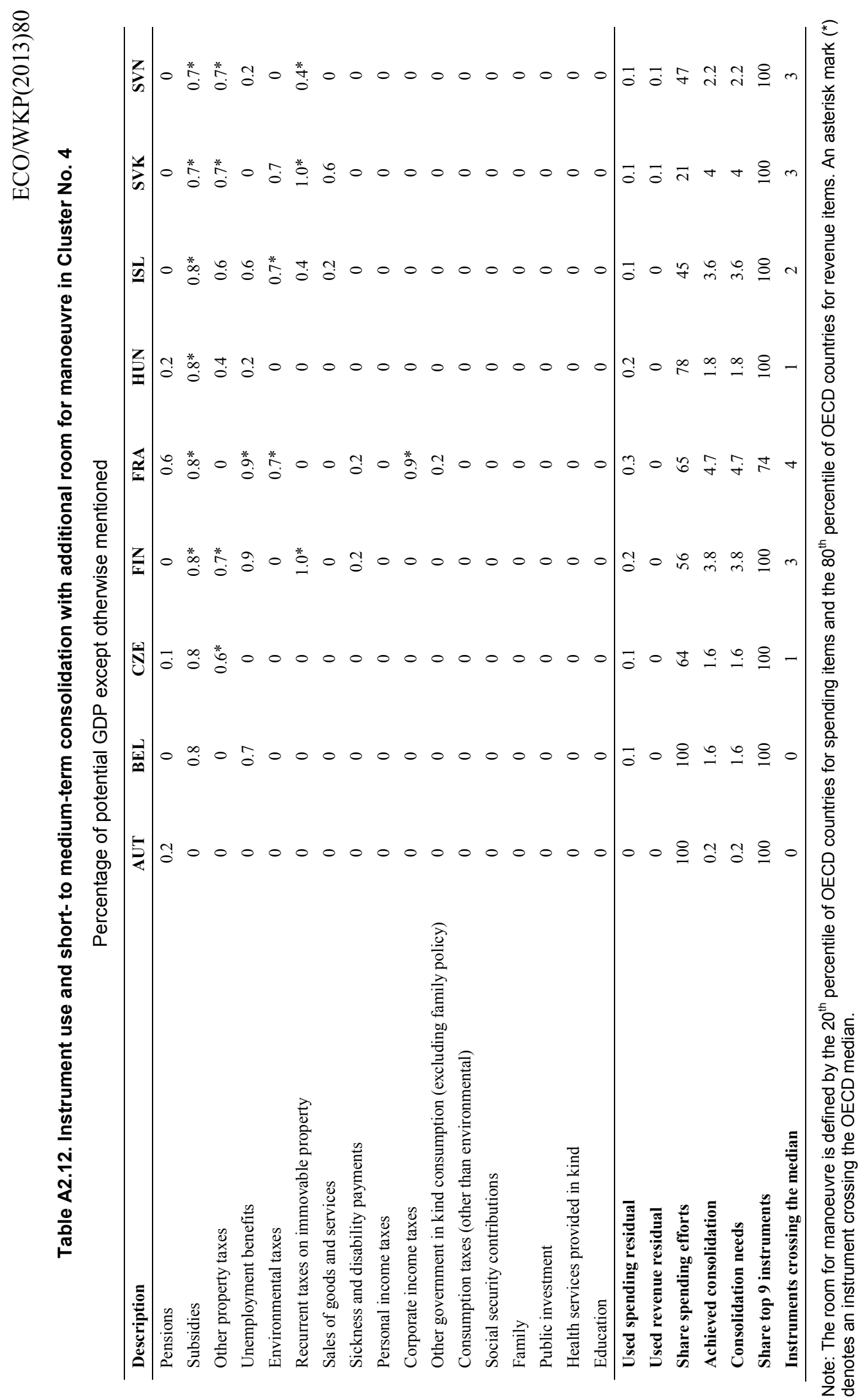


Table A2.13. Instrument use and short- to medium-term consolidation with additional room for manoeuvre in Cluster No. 5

Percentage of potential GDP except otherwise mentioned

\begin{tabular}{|c|c|c|c|}
\hline Description & LUX & NLD & SWE \\
\hline Subsidies & 0.2 & $0.8^{*}$ & $0.8^{*}$ \\
\hline Other property taxes & 0 & 0.5 & 0.1 \\
\hline Pensions & 0 & 0 & 0 \\
\hline Environmental taxes & 0 & 0 & 0 \\
\hline Recurrent taxes on immovable property & 0 & $1.0^{*}$ & 0 \\
\hline Other government in kind consumption (excluding family policy) & 0 & 0.4 & 0 \\
\hline Sales of goods and services & 0 & 0 & 0 \\
\hline Personal income taxes & 0 & 0 & 0 \\
\hline Unemployment benefits & 0 & 0 & 0 \\
\hline Social security contributions & 0 & 0 & 0 \\
\hline Sickness and disability payments & 0 & 0 & 0 \\
\hline Corporate income taxes & 0 & 0 & 0 \\
\hline Consumption taxes (other than environmental) & 0 & 0 & 0 \\
\hline Family & 0 & 0 & 0 \\
\hline Public investment & 0 & 0 & 0 \\
\hline Health services provided in kind & 0 & 0 & 0 \\
\hline Education & 0 & 0 & 0 \\
\hline Used spending residual & 0 & 0.1 & 0.1 \\
\hline Used revenue residual & 0 & 0 & 0 \\
\hline Share spending efforts & 100 & 47 & 95 \\
\hline Achieved consolidation & 0.2 & 2.8 & 1 \\
\hline Consolidation needs & 0.2 & 2.8 & 1 \\
\hline Share top 9 instruments & 100 & 100 & 100 \\
\hline Instruments crossing the median & 0 & 2 & 1 \\
\hline
\end{tabular}

Note: The room for manoeuvre is defined by the $20^{\text {th }}$ percentile of OECD countries for spending items and the $80^{\text {th }}$ percentile of OECD countries for revenue items. A $\left(^{*}\right)$ sign denotes an instrument crossing the OECD median. 


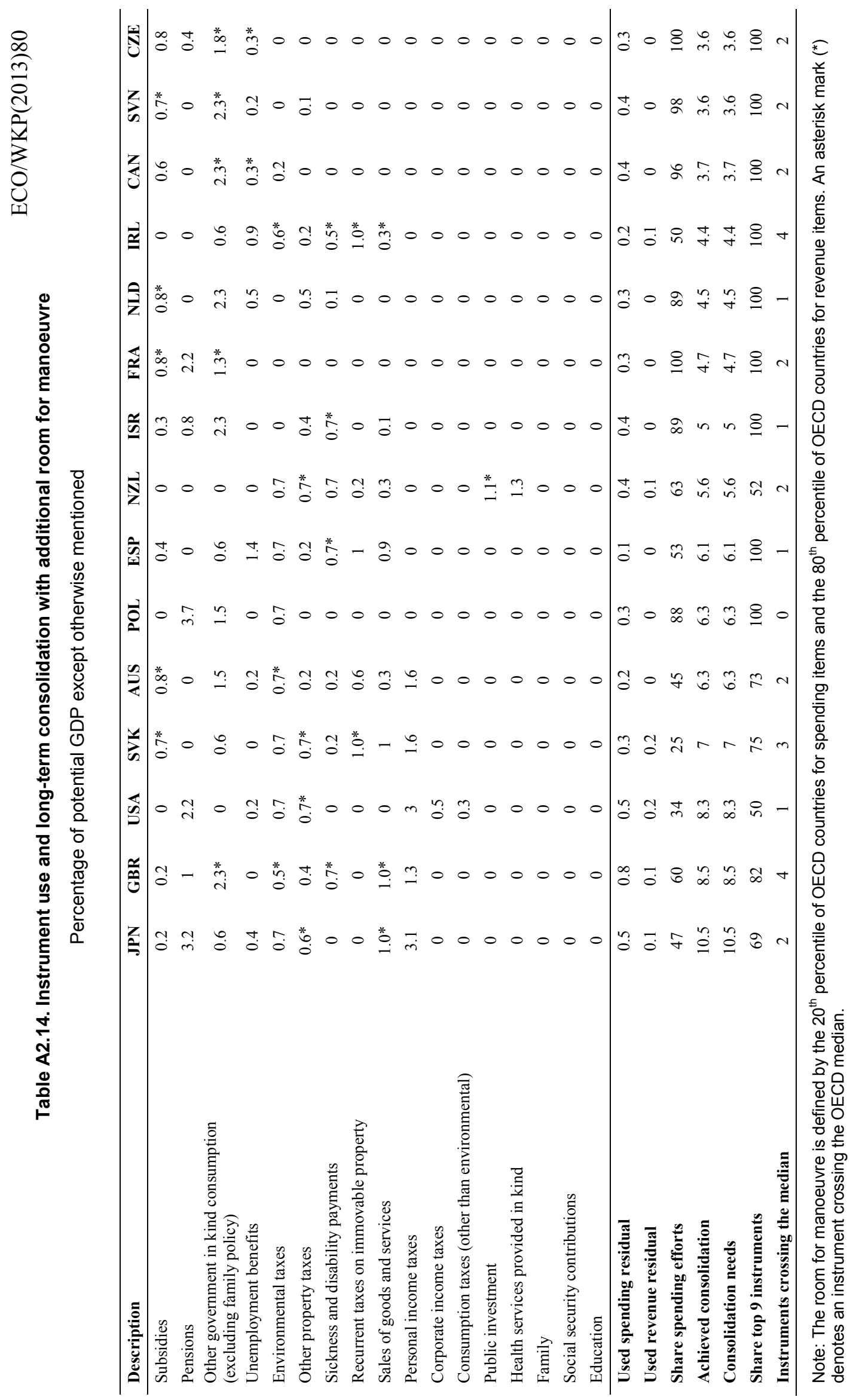




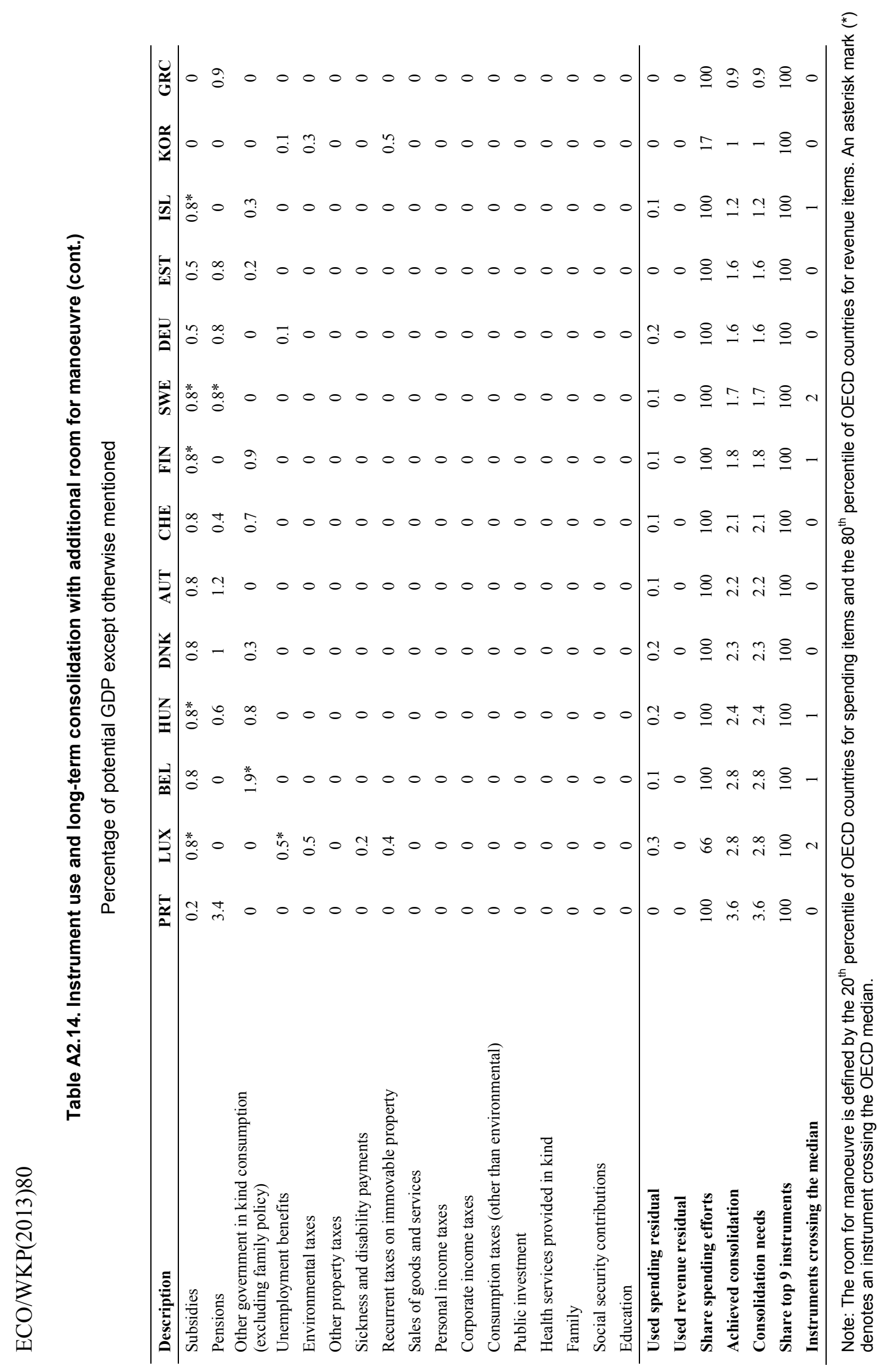




\section{APPENDIX REFERENCES}

\section{Quoted in Section 1:}

de la Maisonneuve, C. and J. Oliveira Martins (2013), "Public Spending on Health and Long-Term Care : A New Set of Projections", OECD Economics Department Working Paper, forthcoming.

Johansson, Å., D. Turner, Y. Guillemette, F. Murtin, C. de la Maisonneuve, P. Bagnoli, G. Bousquet and F. Spinelli (2013), "Long-term Growth Scenarios," OECD Economics Department Working Papers No. 1000, OECD, Paris.

OECD (2012), "Looking to 2060: Long-Term Global Growth Prospects - a Going for Growth report", OECD Economic Policy Papers, No. 3, OECD, Paris.

OECD (2013), OECD Economic Outlook, No. 93, May.

\section{Quoted in Section 2:}

Johansson, Å., D. Turner, Y. Guillemette, F. Murtin, C. de la Maisonneuve, P. Bagnoli, G. Bousquet and F. Spinelli (2013), "Long-term Growth Scenarios," OECD Economics Department Working Papers No. 1000, OECD, Paris.

OECD (2010a), Tax Expenditures in OECD Countries, OECD Publishing.

OECD (2010b), "Health Care Systems: Getting More Value for Money", OECD Economics Department Policy Notes, No. 2.

OECD (2011), OECD Economic Surveys: Switzerland 2011, OECD Publishing.

OECD (2013), OECD Economic Outlook, Vol. 2013/1, No. 93, OECD, Paris, May.

Sutherland, D., R. Price, I. Joumard and C. Nicq (2007), "Performance and Indicators for Public Spending Efficiency in Primary and Secondary Education", OECD Economics Department Working Papers, No. 546, OECD Publishing.

\section{Quoted in Section 3:}

Arjona, R., M. Ladaique and M. Pearson (2002), "Social Protection and Growth", OECD Economic Studies, No. 35.

Bastagli, F., D. Coady and S. Gupta (2012), "Income Inequality and Fiscal Policy", IMF Staff Discussion Note, SDN/12/08 (Revised), 27 September, IMF, Washington DC.

Becker, J., C. Fuest and N. Riedel (2012), "Corporate Tax Effects on the Quality and Quantity of FDI", European Economic Review, No. 56. 
Bom, P. and J. Ligthart (2013) "What Have We Learned from Three Decades Of Research on the Productivity of Public Capital?", Journal of Economic Surveys, forthcoming.

Bova, E, T. Kinda, J. Woo and S. Zhang (2012), "Distributional Consequences of Fiscal Consolidation and the Role of Fiscal Policy: What Do the Data Say?", forthcoming, IMF, Washington DC.

Calderon, Serven (2004), "The Effects of Infrastructure Development on Growth and Income Distribution," World Bank Policy Research Working Paper Series, No. 3400.

Chatterjee, S. and S. Turnovsky (2012), "Infrastructure and inequality", European Economic Review, Vol. 56.

Causa, O. and A. Johansson (2010), "Intergenerational Social Mobility in OECD Countries", OECD Journal: Economic Studies, OECD, Paris.

De Mooij, R. (2012) “Tax Biases to Debt Finance: Assessing the Problem, Finding Solutions”, Fiscal Studies, Vol. 33 No. 4.

Duval, R. (2003), "Retirement Behaviour in OECD Countries: Impact of Old-Age Pension Schemes and Other Social Transfer Programmes," OECD Economic Studies, No. 37, OECD, Paris.

Echevarria, C. (2012), "Income Tax Progressivity, Physical Capital, Aggregate Uncertainty and Long-Run Growth in an Old Economy," Journal of Macroeconomics.

Ford, R. and W. Suyker (1990), "Industrial Subsidies in the OECD Economies," OECD Economic Studies, No. 15.

Fournier Koske (2012), "Less Income Inequality and More Growth - Are they Compatible? Part 7. The Drivers of Labour Earnings Inequality - An Analysis Based on Conditional and Unconditional Quantile Regressions", OECD Economics Department Working Papers, No. 930, OECD, Paris.

Gemmell, N., R. Kneller and Ismael Sanz, (2011), "The Timing and Persistence of Fiscal Policy Impacts on Growth: Evidence from OECD Countries," Economic Journal, Vol. 121(550), pp. 33-58.

Gonand, F. (2010), "Choosing a pension reform : a framework for the social planner," Pension reform, fiscal policy and economic performance : papers presented at the Banca d'Italia workshop held in Perugia, 26 - 28 March 2009, Printing Office of the Banca d'Italia, Rome.

Gyimah-Brempong, K. and M. Wilson (2004), "Health Human Capital And Economic Growth In SubSaharan African and OECD Countries," The Quarterly Review of Economics and Finance, Vol. 44 No. 2.

Hoeller, P., I. Joumard, M. Pisu and D. Bloch (2012), "Less Income Inequality and More Growth: Are They Compatible? Part 1. Mapping Income Inequality Across the OECD", OECD Economics Department Working Papers, No. 924, OECD, Paris.

Johansson, Å, C. Heady, J. Arnold, B. Brys and L. Vartia (2008), "Taxation and Economic Growth", OECD Economics Department Working Papers, No. 620, OECD, Paris.

Joumard, I., P. Hoeller, C. André and C. Nicq (2010), Health Care Systems: Efficiency and Policy Settings, OECD, Paris. 
Joumard, I., M. Pisu and D. Bloch (2012), "Less Income Inequality and More Growth - Are They Compatible? Part 3. Income Redistribution via Taxes and Transfers in OECD Countries", OECD Economics Department Working Papers, OECD, Paris.

Leduc, S. and D. Wilson (forthcoming), "Roads to Prosperity or Bridges to Nowhere? Theory and Evidence on the Impact of Public Infrastructure Investment." NBER Macroeconomics Annual 2012.

OECD (2001), Competition Policy in Subsidies and State Aid, OECD, Paris.

OECD (2003a), Sources of Economic Growth in OECD Countries, OECD, Paris.

OECD (2003b), Environmentally Harmful Subsidies: Policy Issues and Challenges, OECD, Paris.

OECD (2010), Sickness, Disability and Work: Breaking the Barriers, OECD, Paris.

OECD (2011), Divided We Stand, OECD.

OECD (2012), "Special Feature: Trends in Personal Income Tax and Employee Social Security Contribution Schedules", Taxing Wages 2011, OECD, Paris.

Rawdanowicz, L., E. Wurzel and A. K. Christensen (2012), "The Equity Implications of Fiscal Consolidation”, OECD Economics Department Working Papers, No. 1013.

Serret, Y. and N. Johnstone (2006), Ed., The Distributional Effects of Environmental Policy, OECD, Paris.

Sutherland, D., S. Araujo, B. Egert and T. Kozluk (2009), "Infrastructure Investment: Links to Growth and The Role of Public Policies", OECD Economics Department Working Papers, No. 686.

Sutherland, D., P. Hoeller, R. Merola and V. Ziemann (2012), "Debt and Macroeconomic Stability", OECD Economics Department Working Papers, No. 1003.

\section{Quoted in section 4}

Alesina, R. and S. Ardagna (2010), "Large Changes in Fiscal Policy: Taxes versus Spending," in: Tax Policy and the Economy, Volume 24, pp. 35-68, National Bureau of Economic Research.

A. Auerbach and Y. Gorodnichenko (2012), "Fiscal Multipliers in Recession and Expansion," in: Fiscal Policy after the Financial Crisis, National Bureau of Economic Research.

Devries, P., J. Guajardo, D. Leigh and A. Pescatori (2011), “A New Action-Based Dataset on Fiscal Consolidation," IMF Working Paper, No. 11/128, Washington DC.

Driscoll, J. C. and A. C. Kraay (1998), "Consistent Covariance Matrix Estimation with Spatially Dependent Panel Data," The Review of Economics and Statistics, Vol. 80(4), pp. 549-560, MIT Press, November.

Guajardo, J., D. Leigh, and A. Pescatori (2011), "Expansionary Austerity: New International Evidence," IMF Working Papers, WP/11/158. 


\section{APPENDIX 3: SIMULATED FISCAL PATHS PER COUNTRY}

Left axis: Underlying primary balance, per cent of potential GDP

- - Baseline path

Debt-control path

Right axis: Simulated debt-GDP ratio along the debt-control path

- Debt-GDP ratio, per cent

\section{Australia}

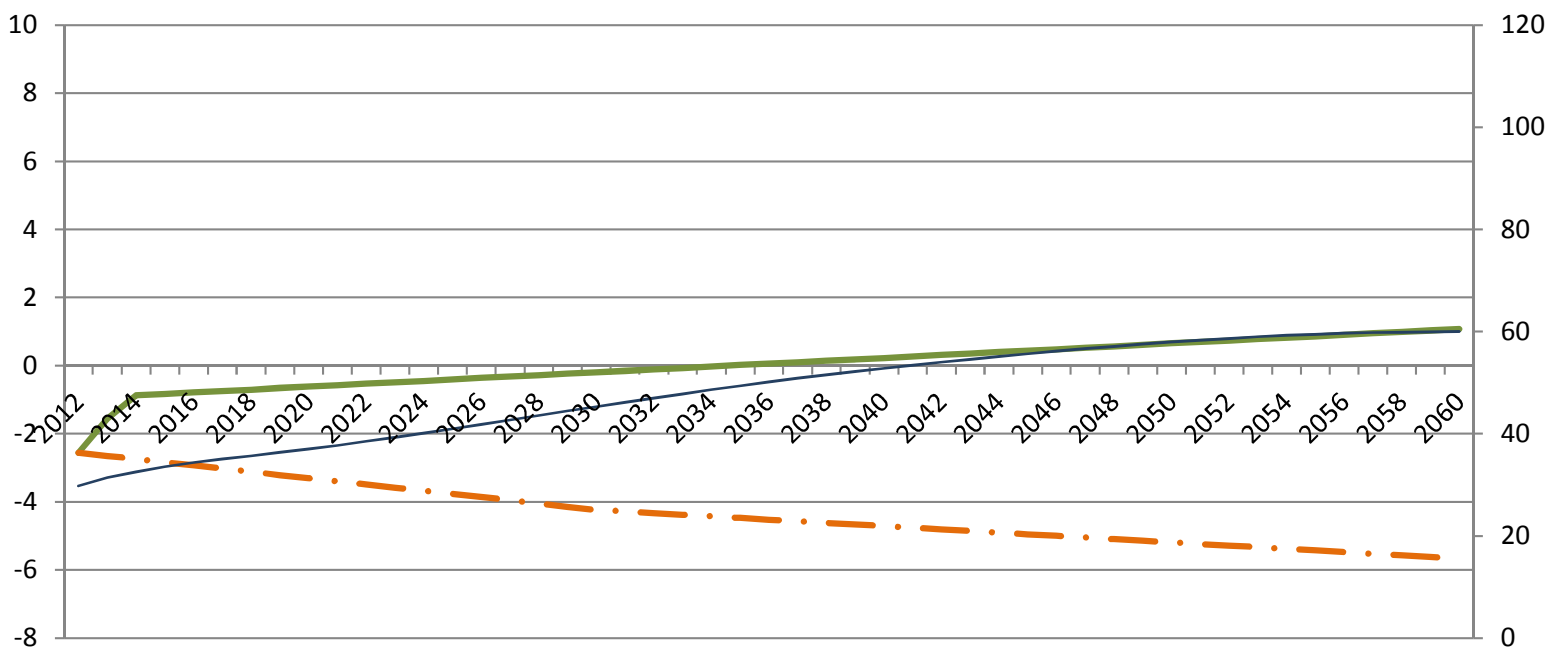

Austria

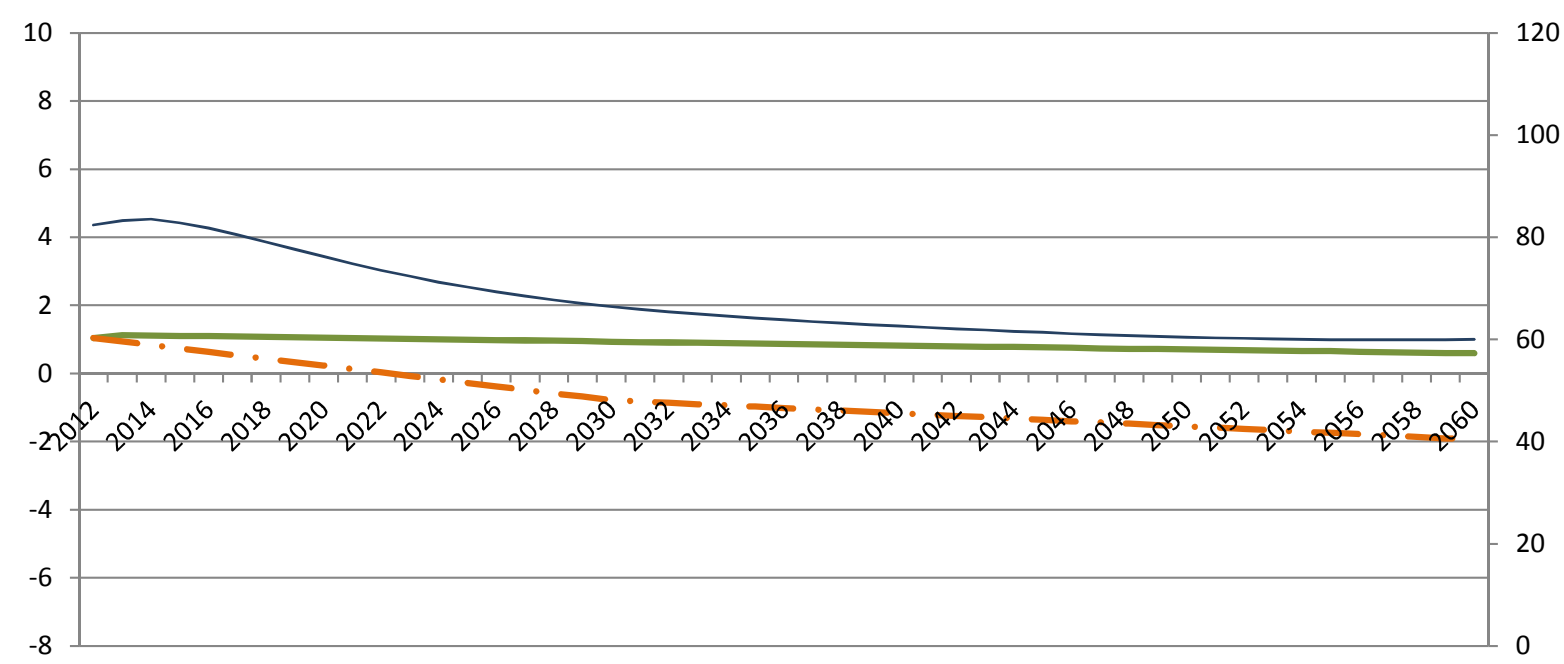


Belgium

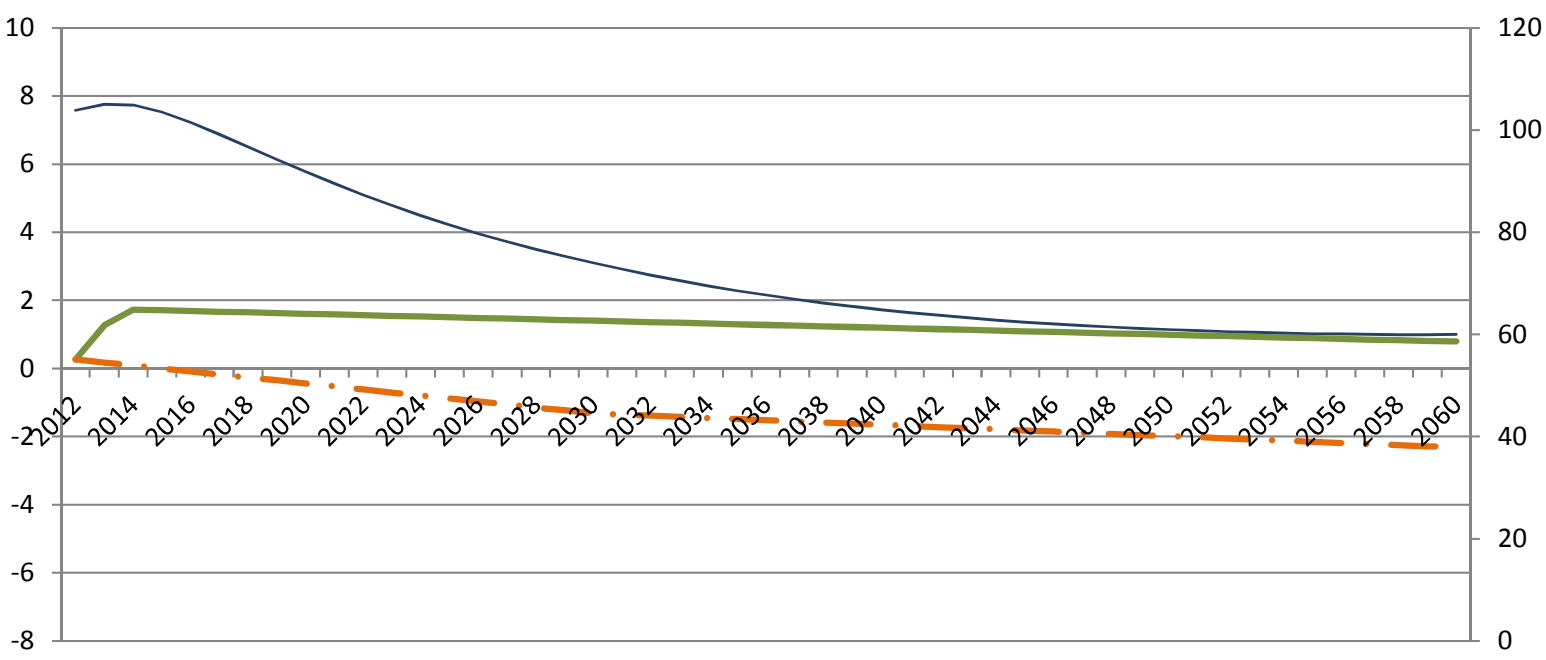

\section{Canada}

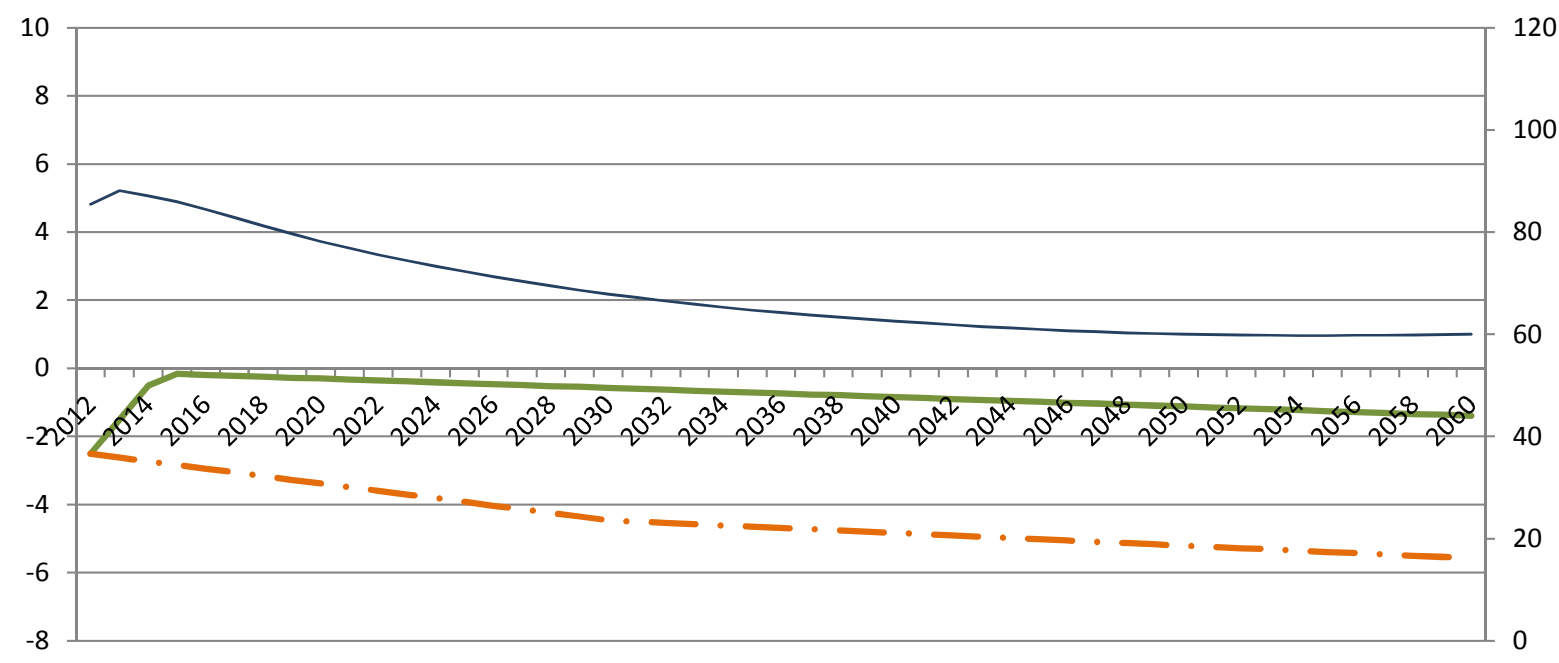

Czech Republic

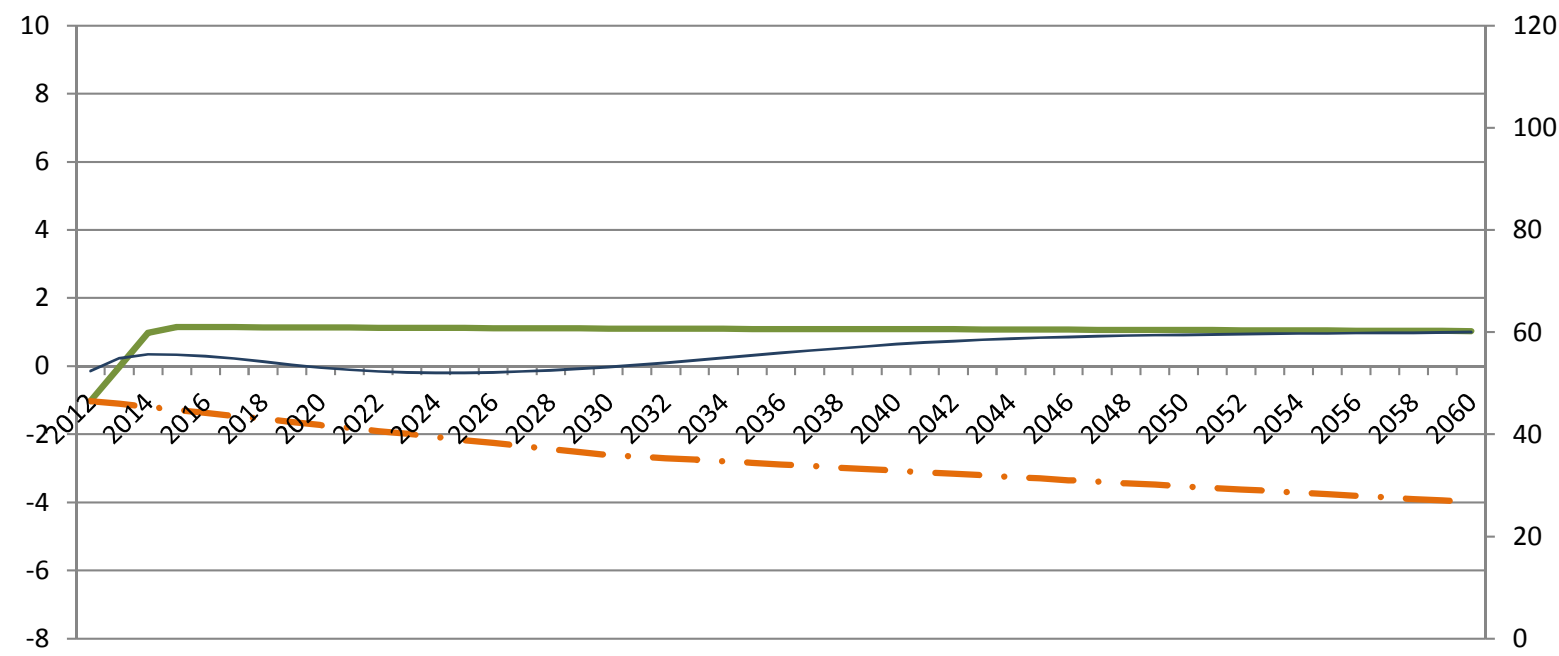


Denmark

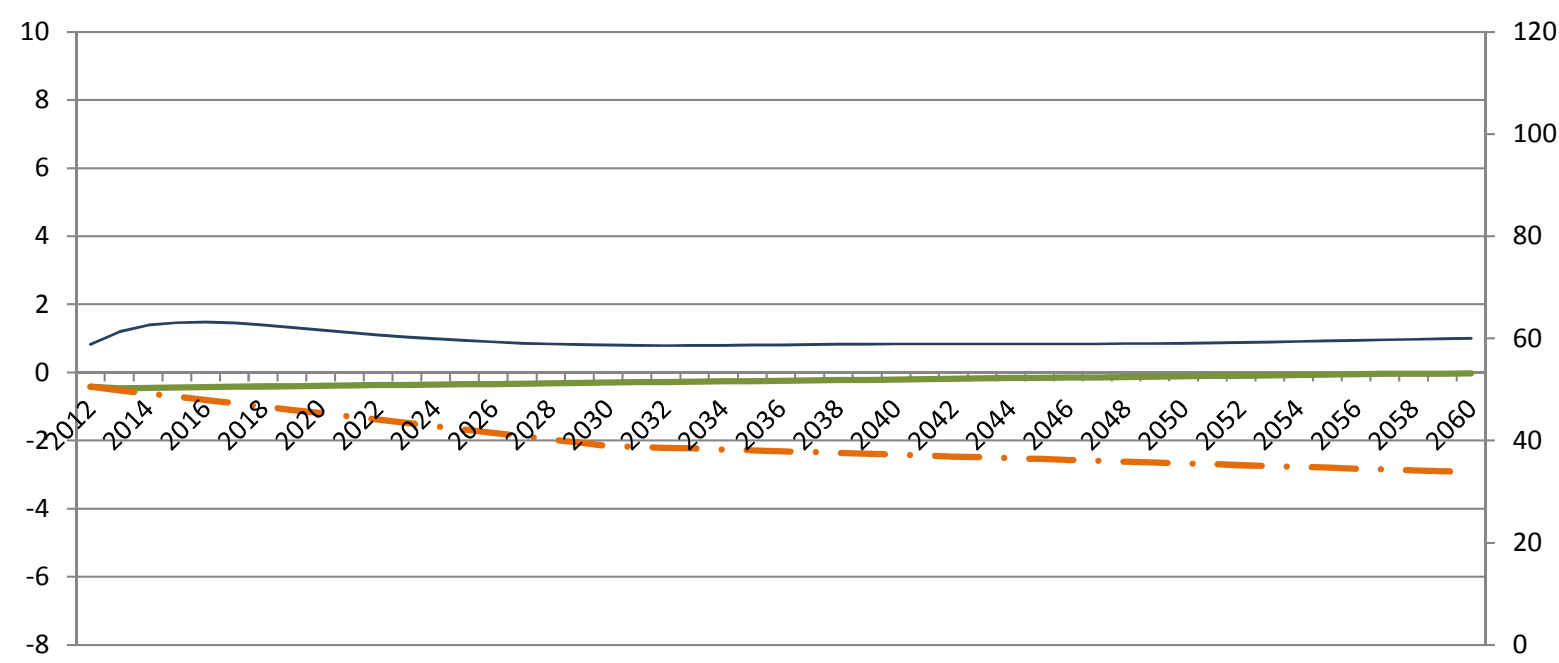

Estonia

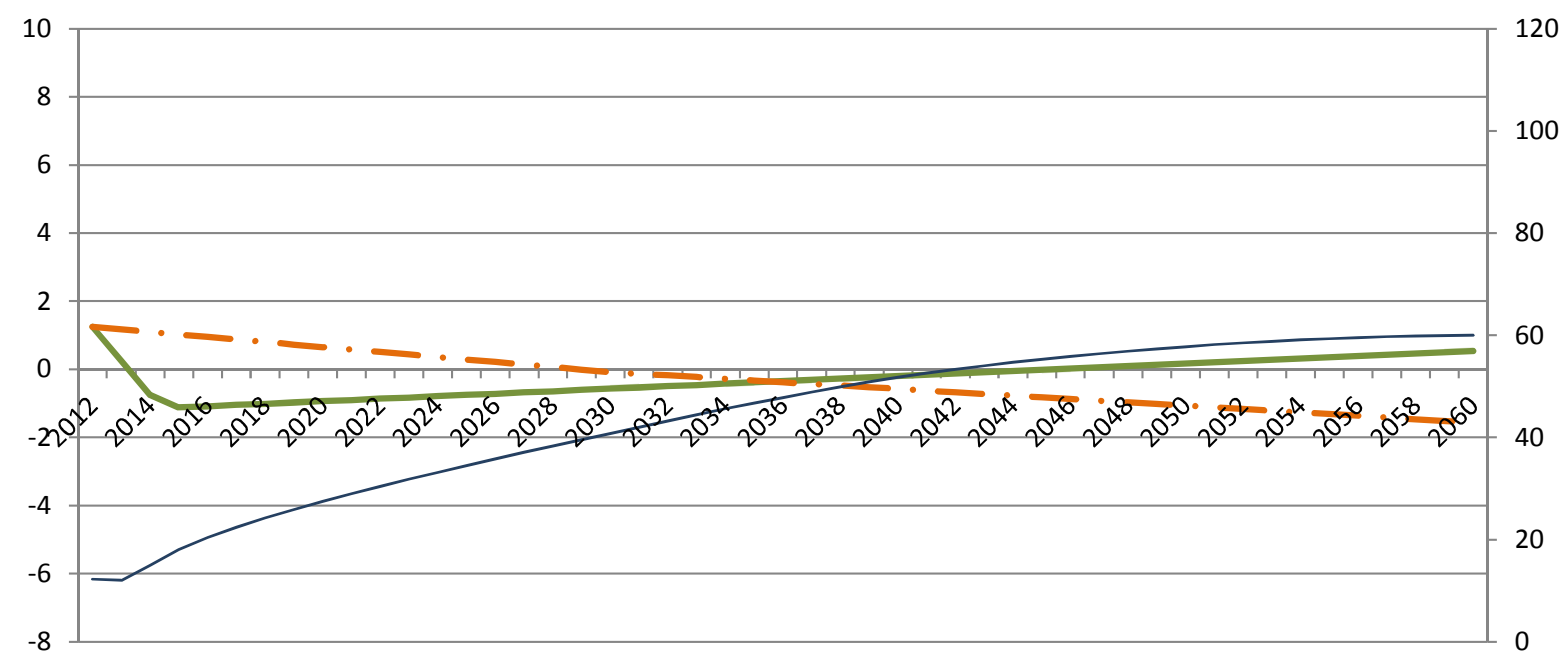

Finland

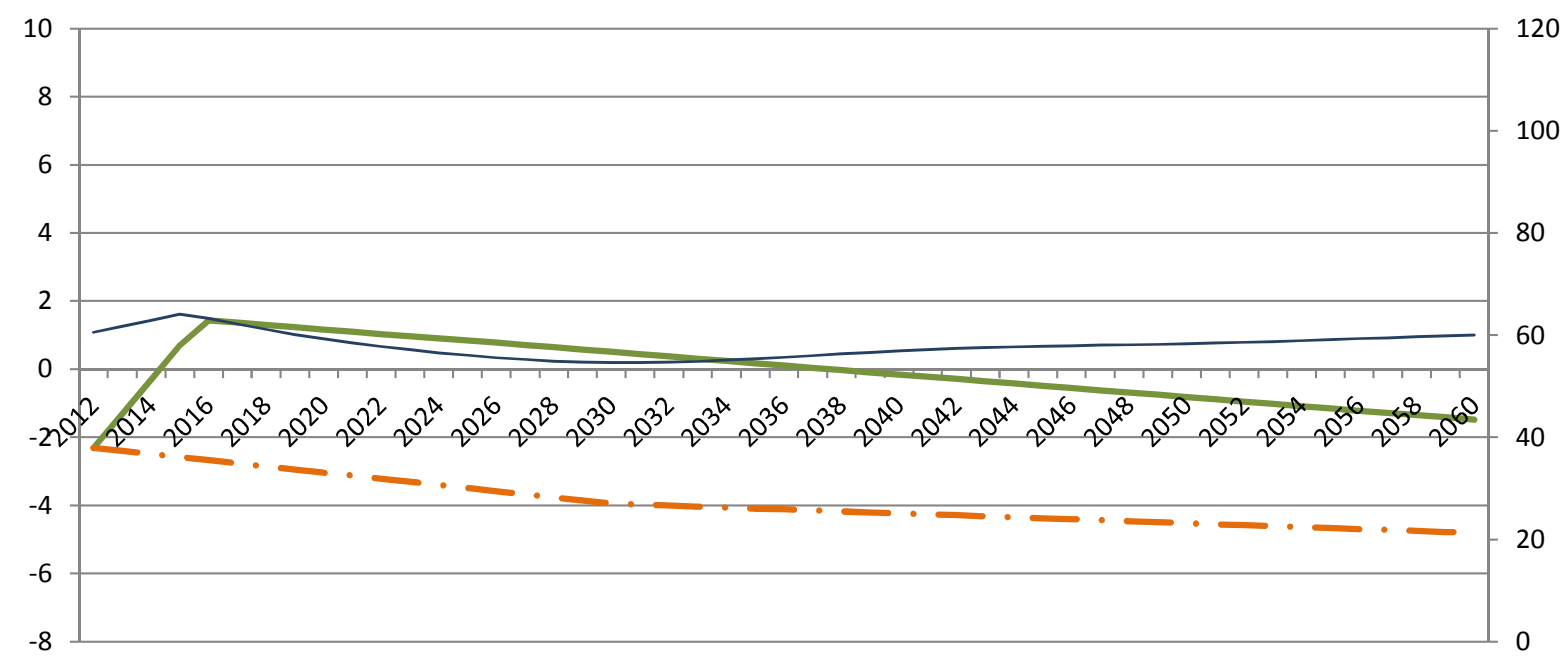




\section{France}

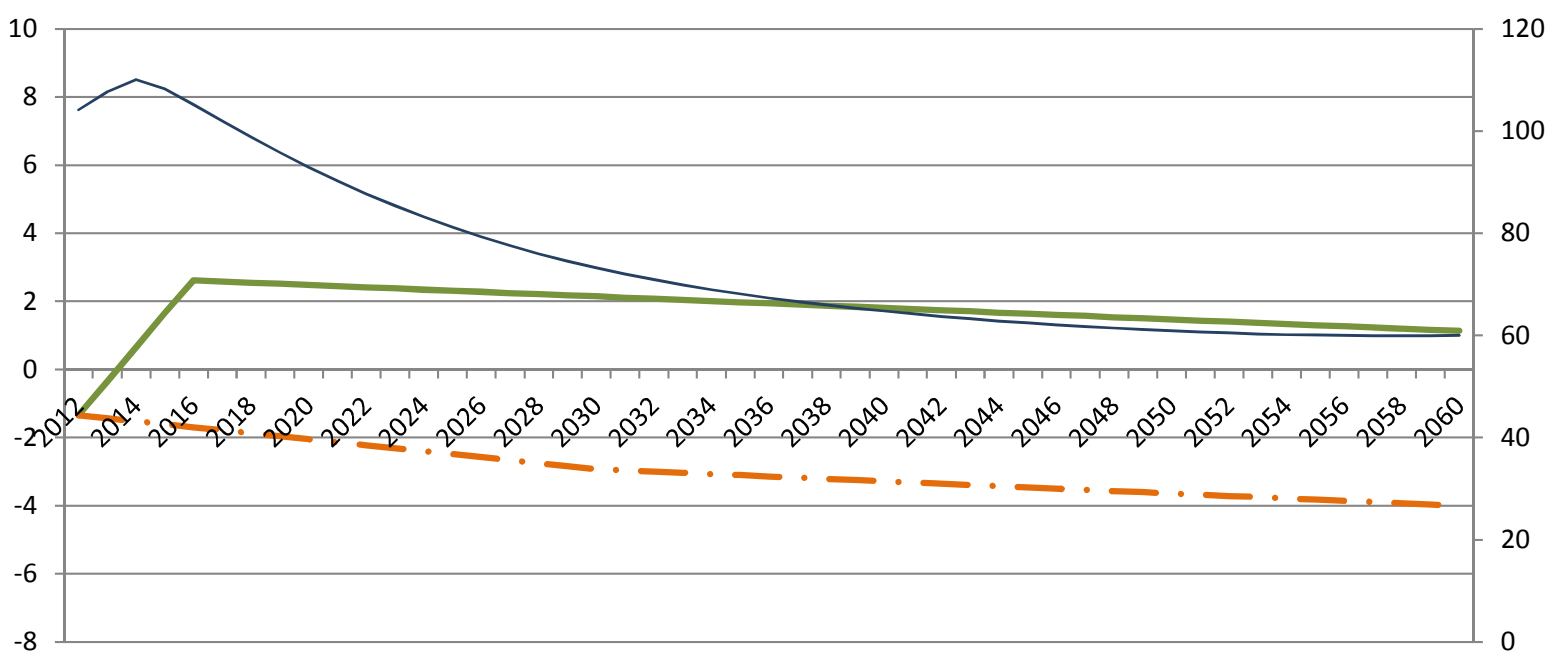

Germany

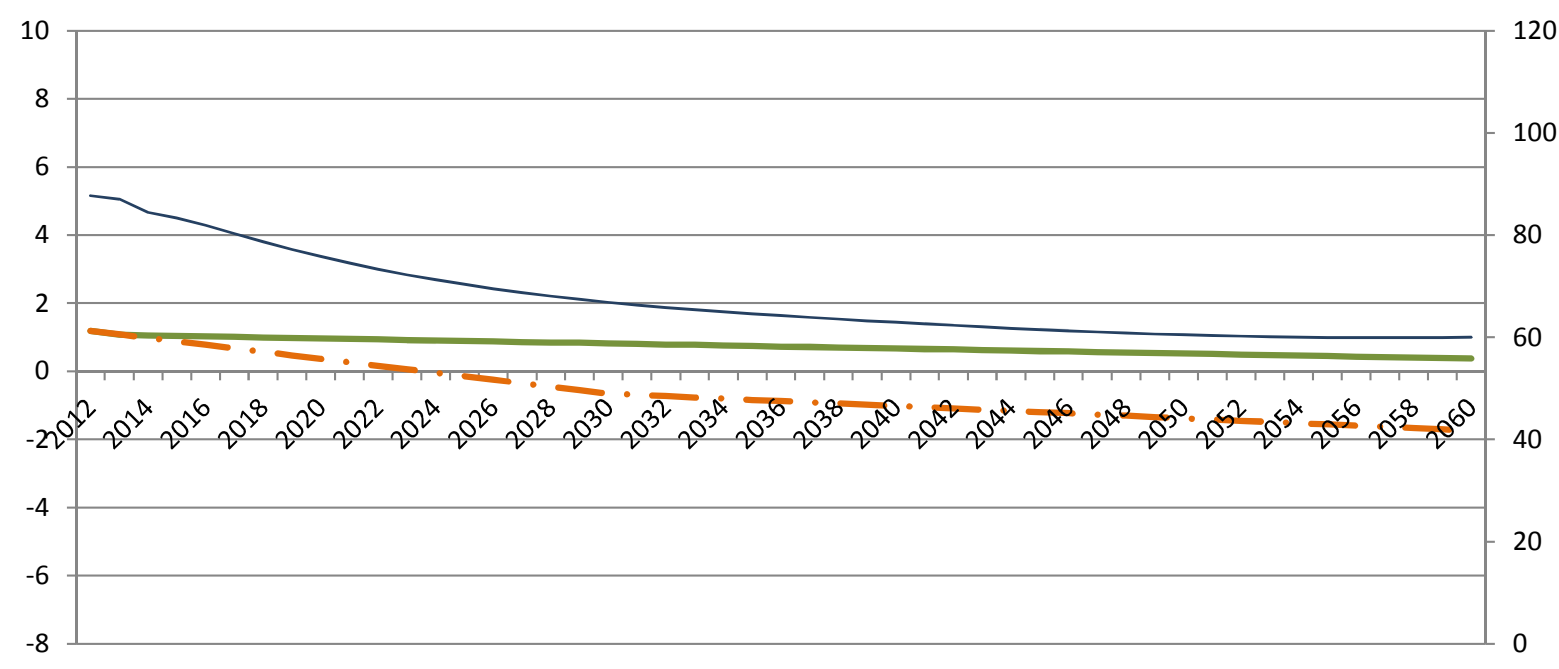

Greece

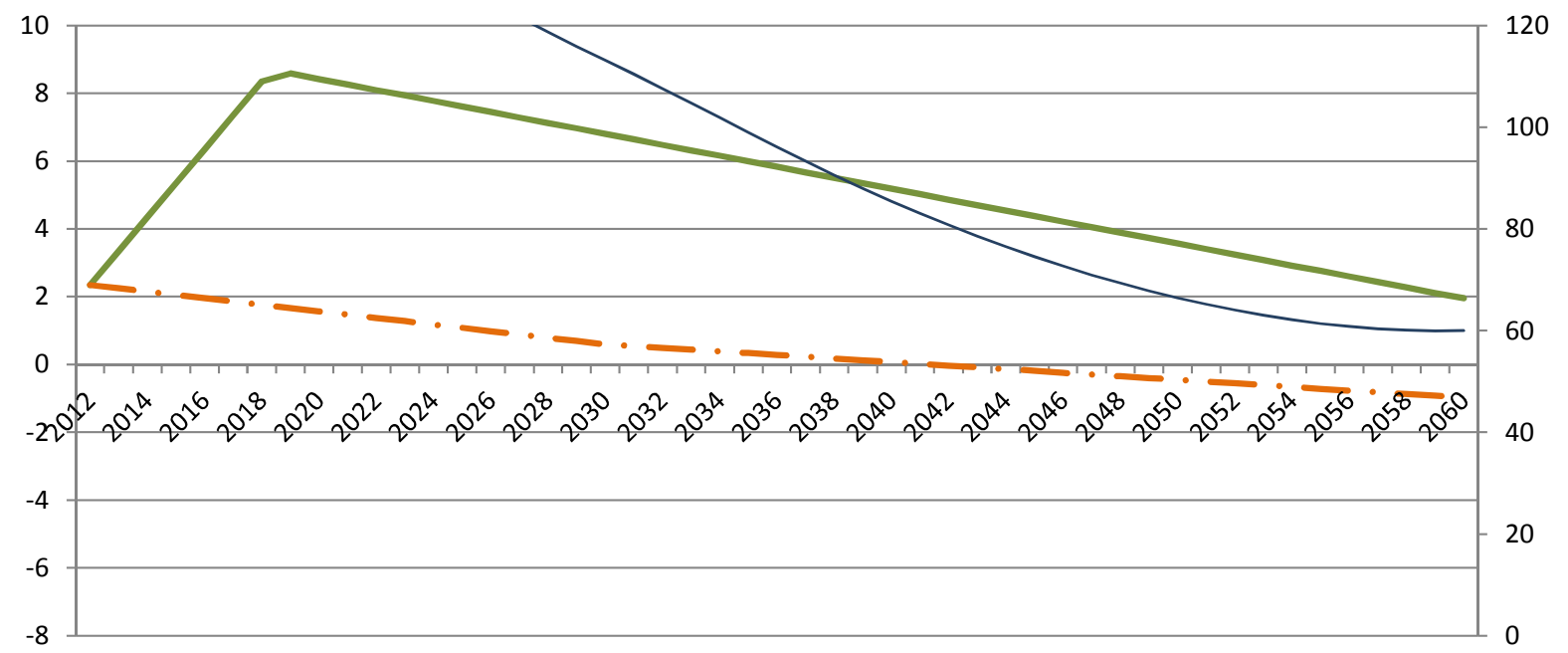


Hungary

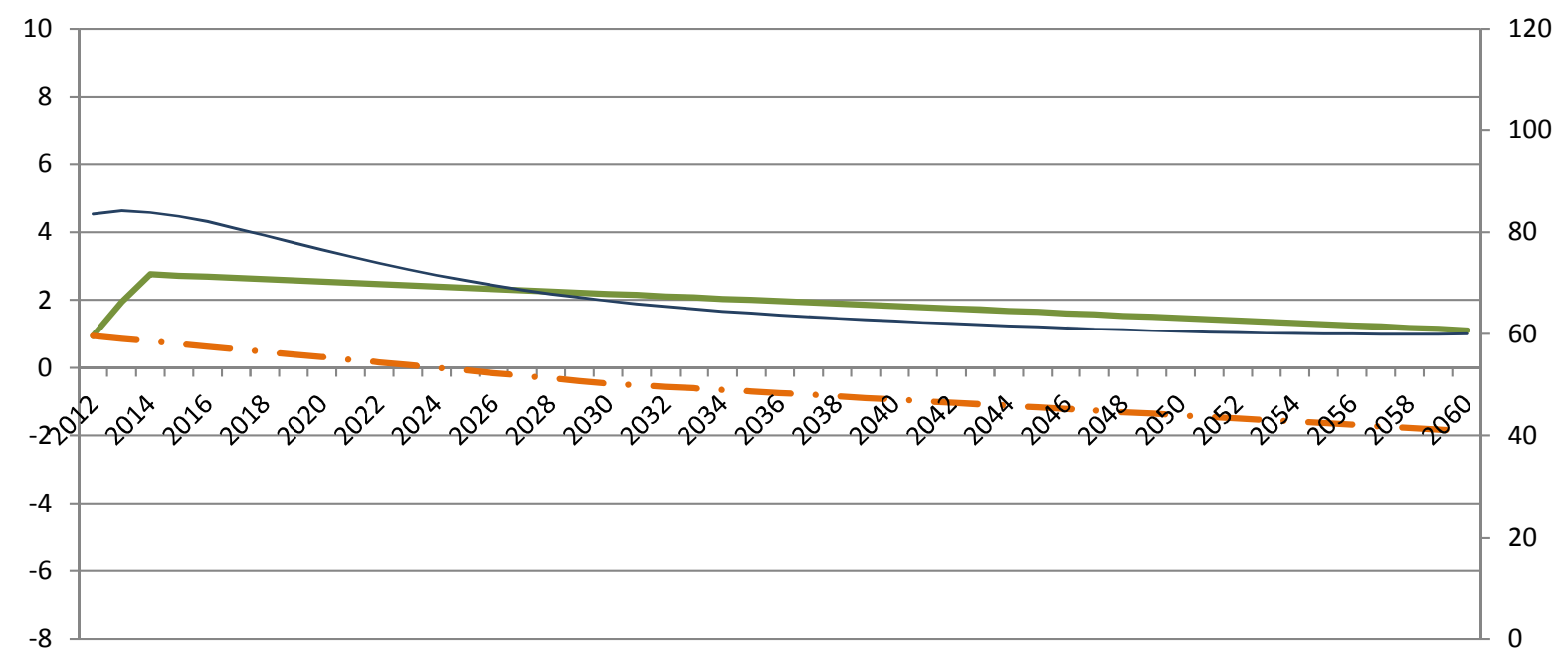

Iceland

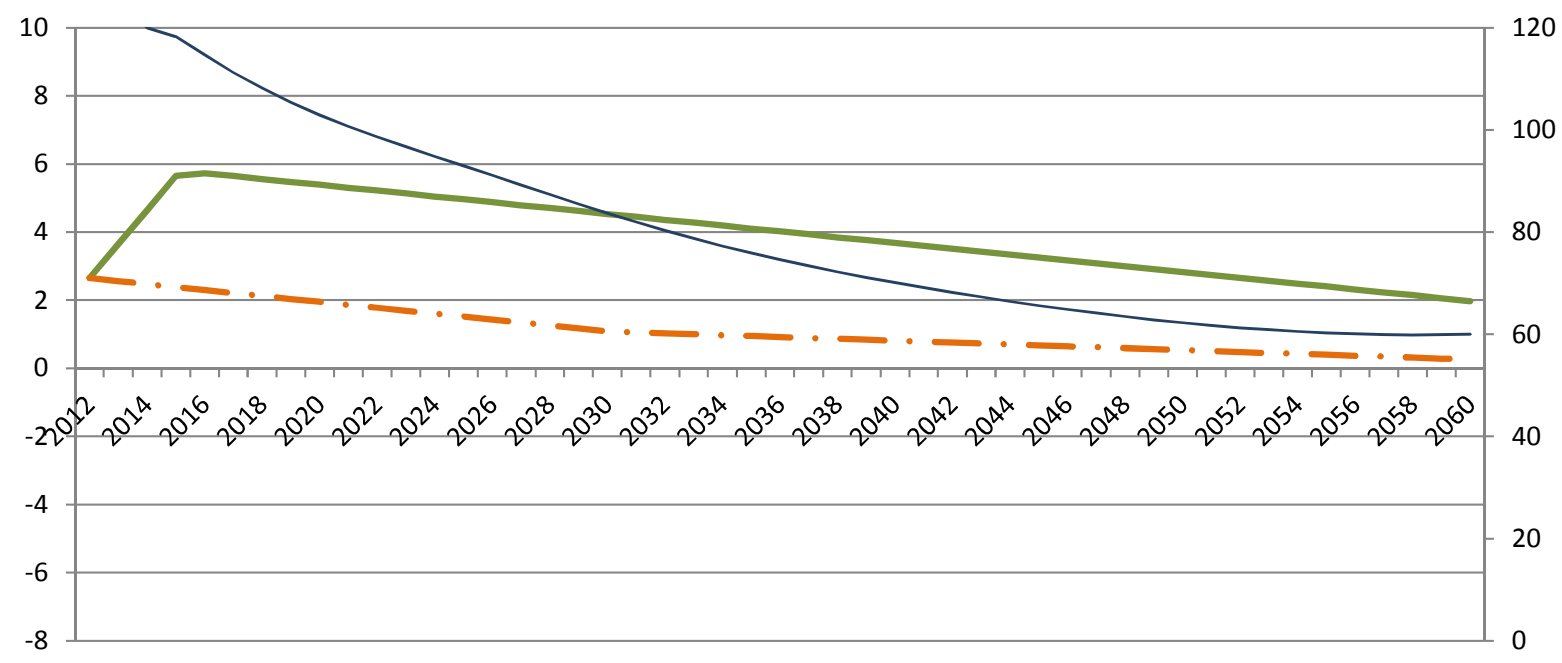

Ireland

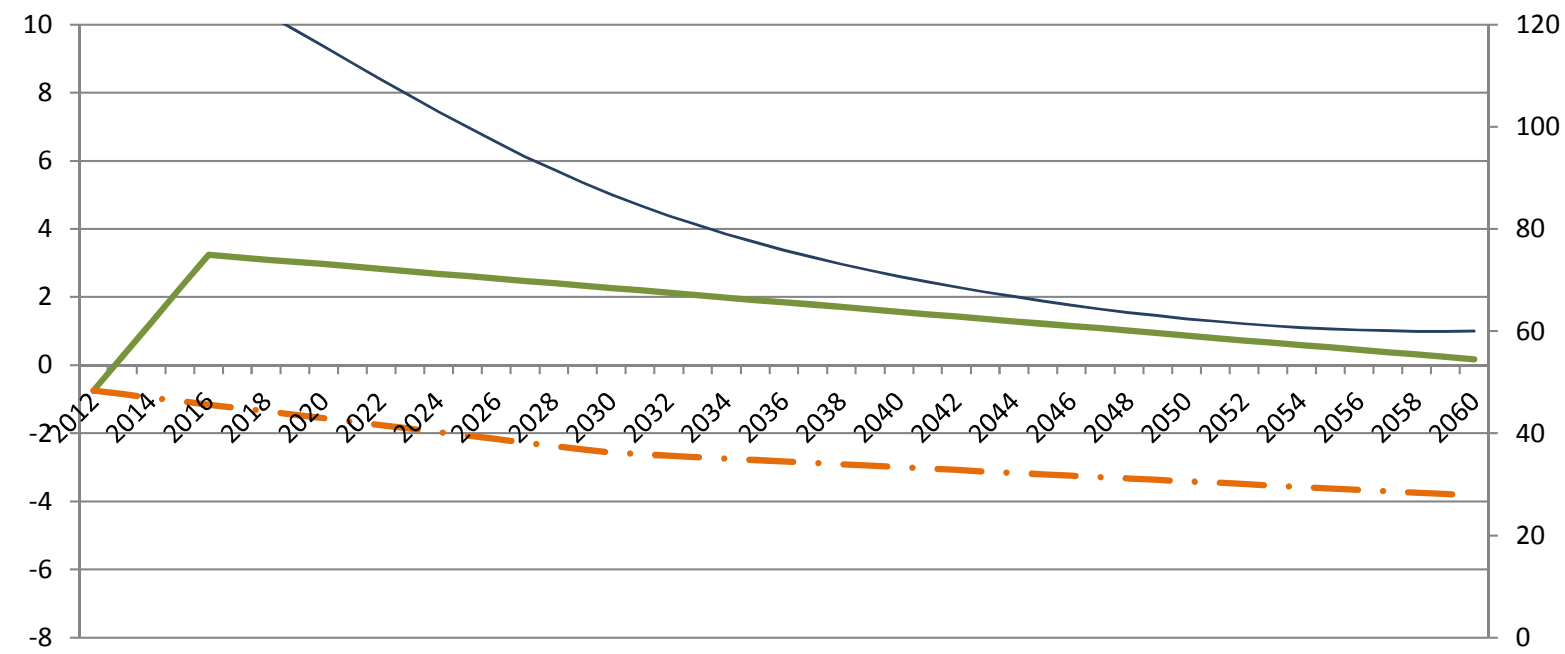


Israel

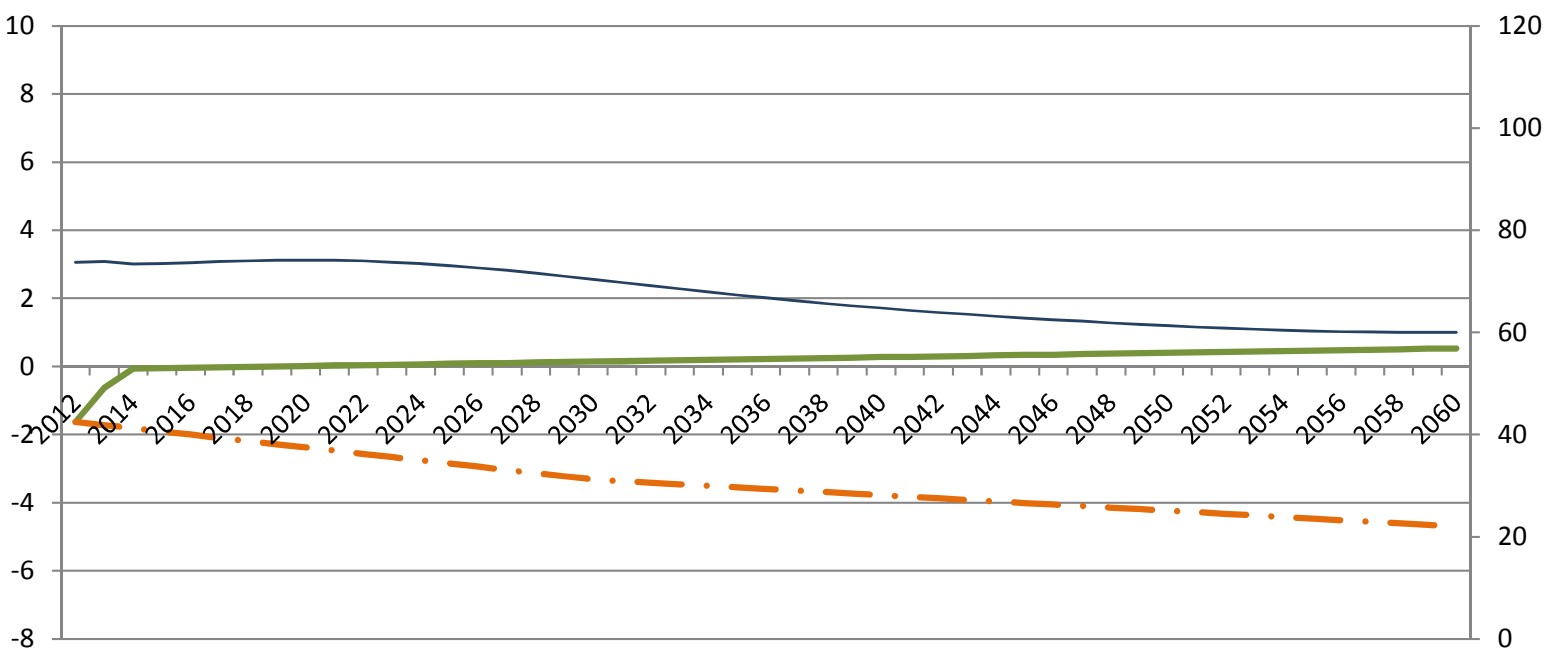

Italy

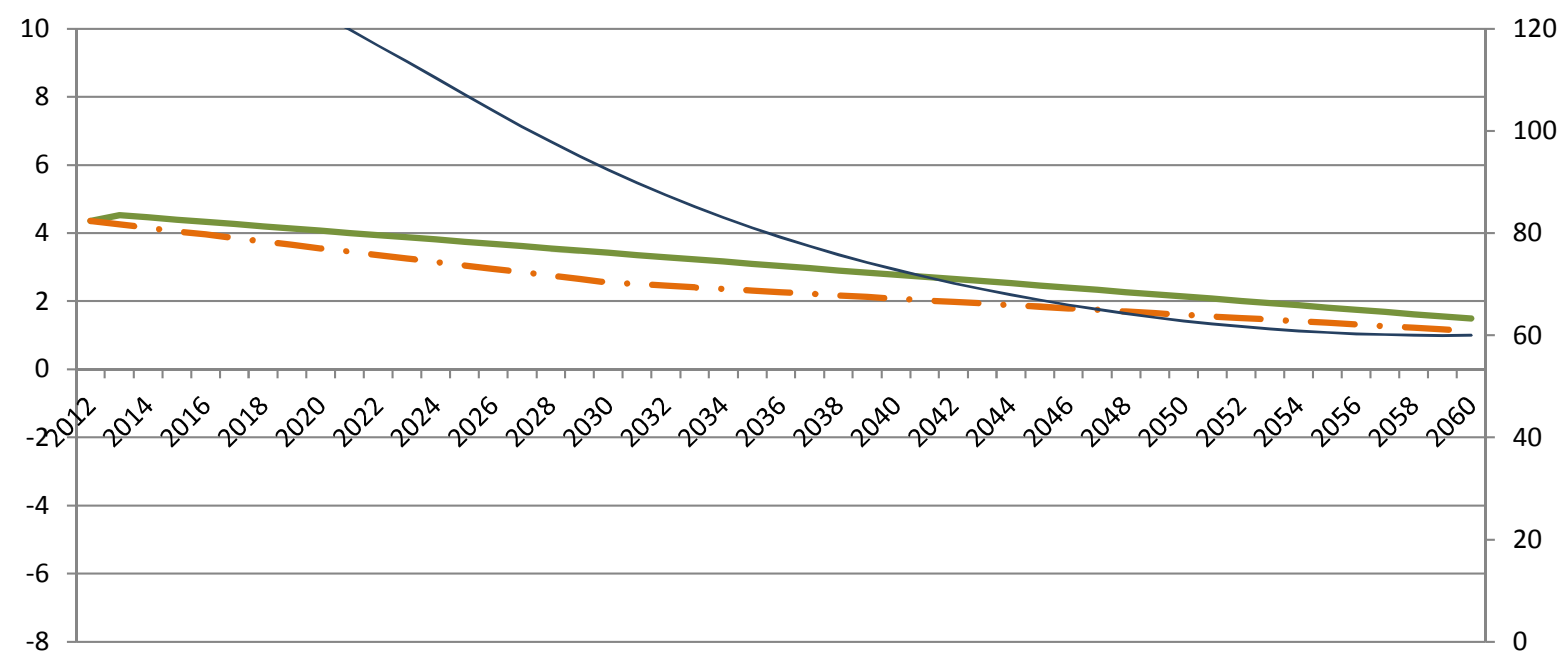

Japan (different scale)

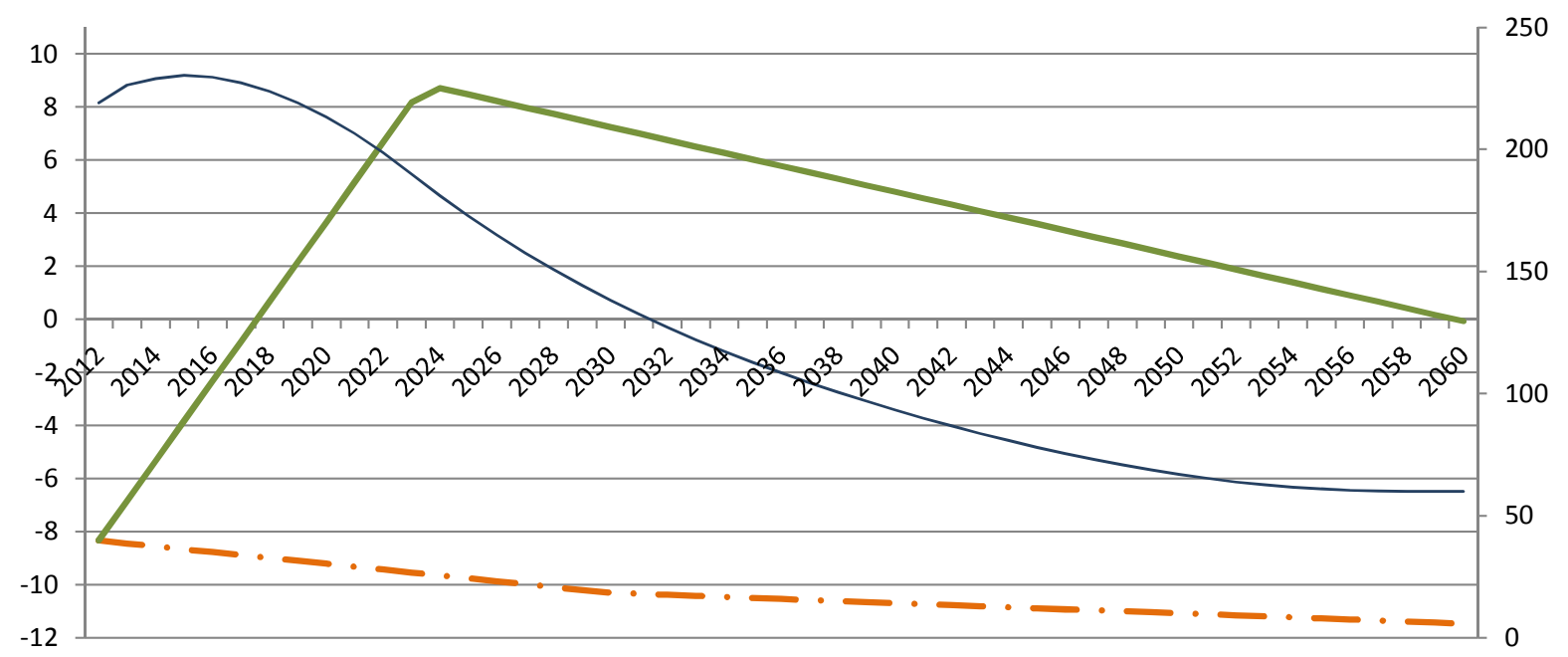


Korea

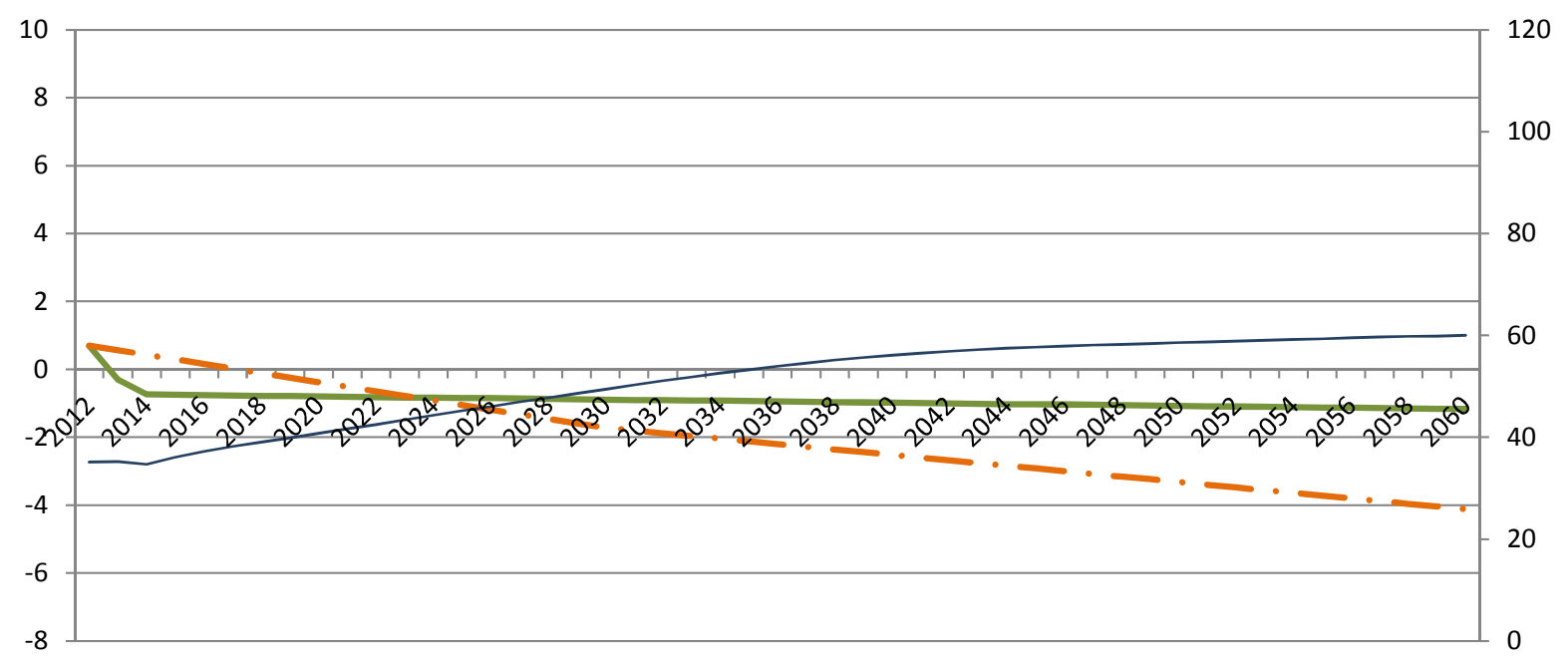

Luxembourg

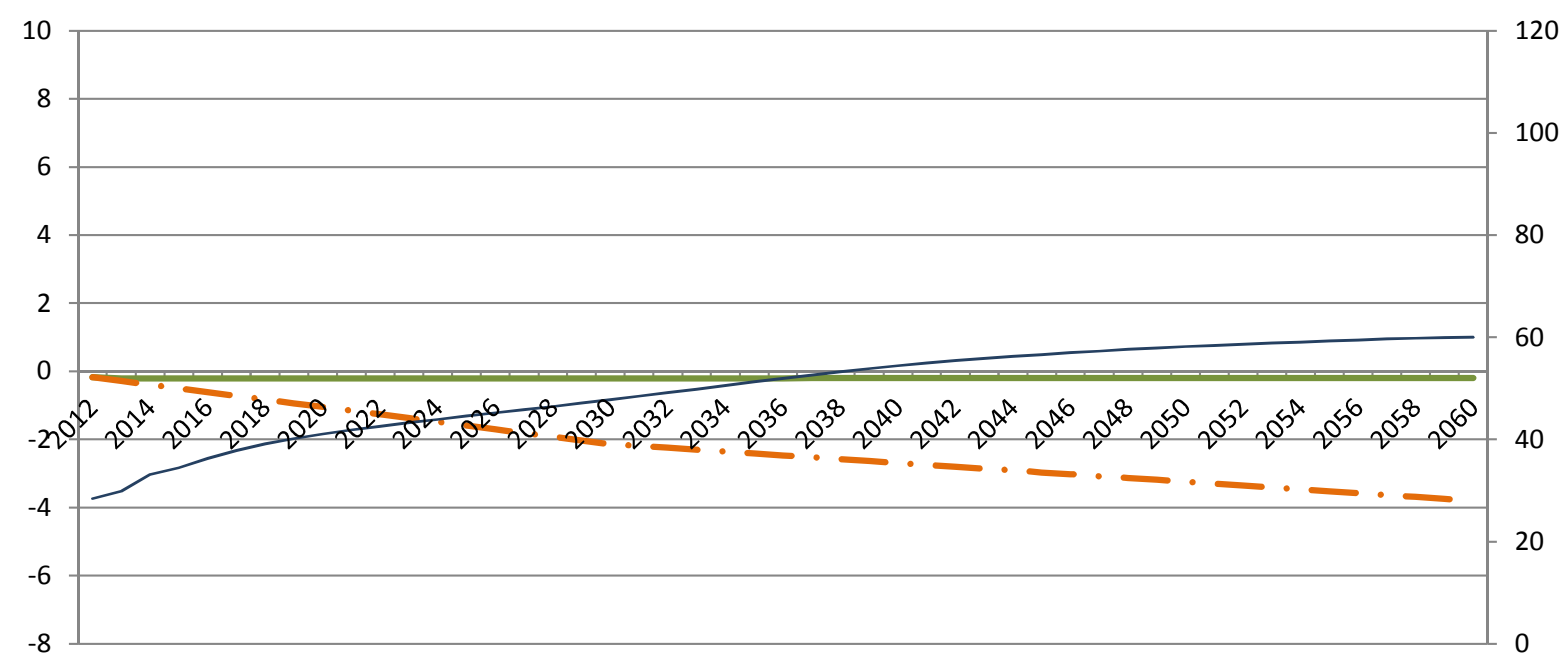

Netherlands

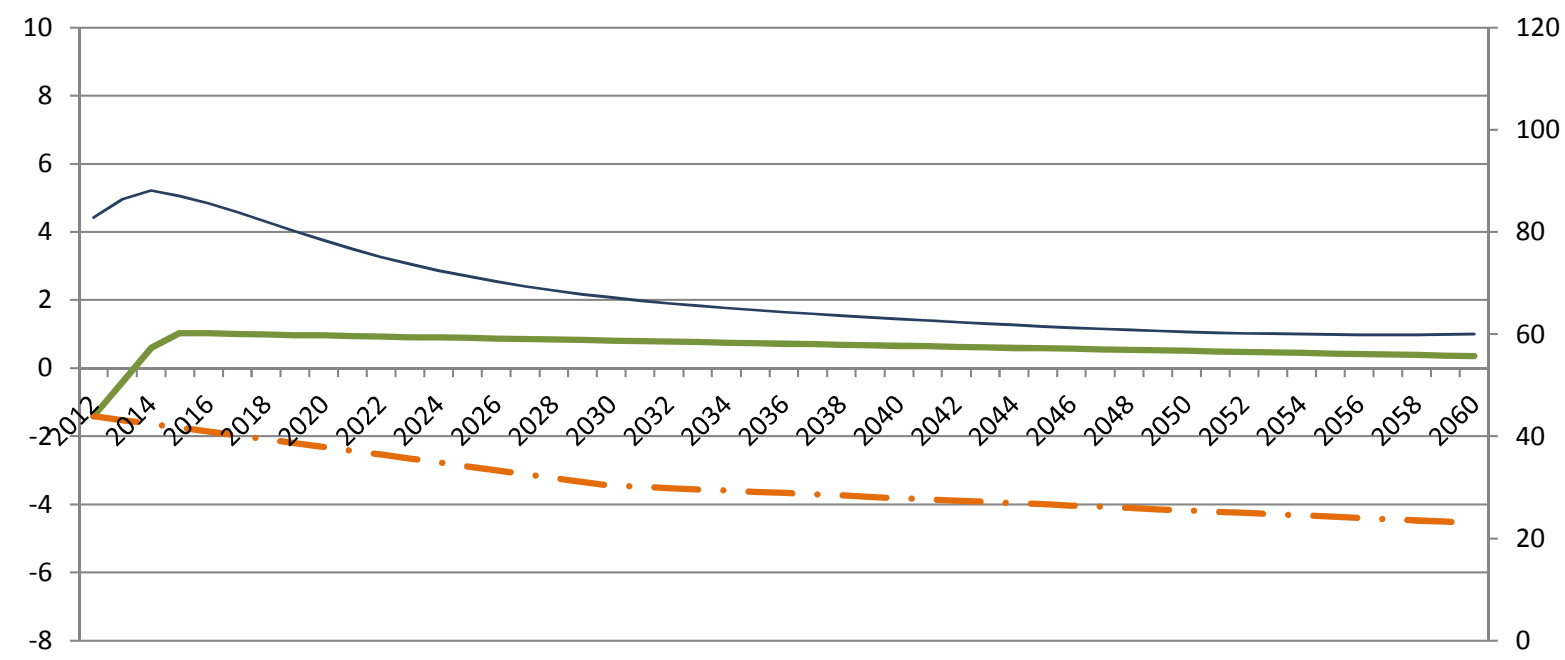


New Zealand

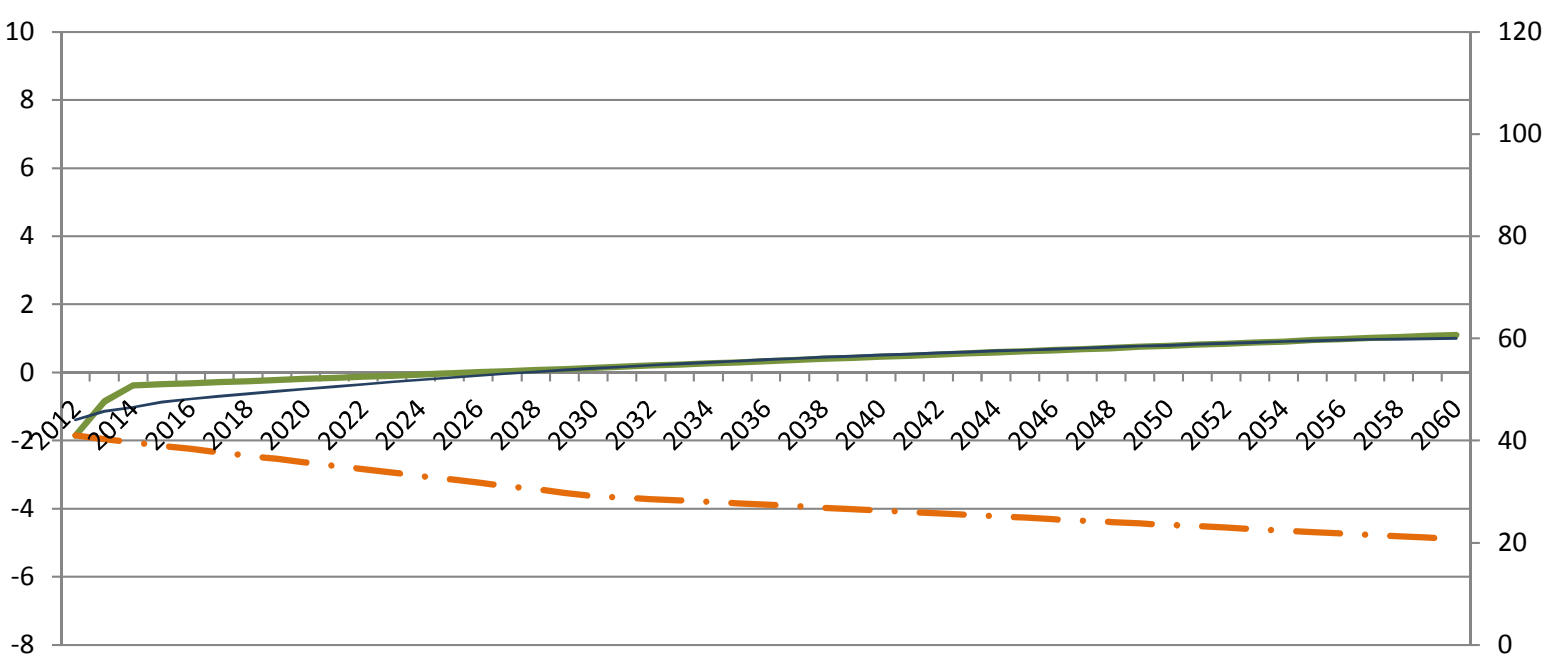

Norway

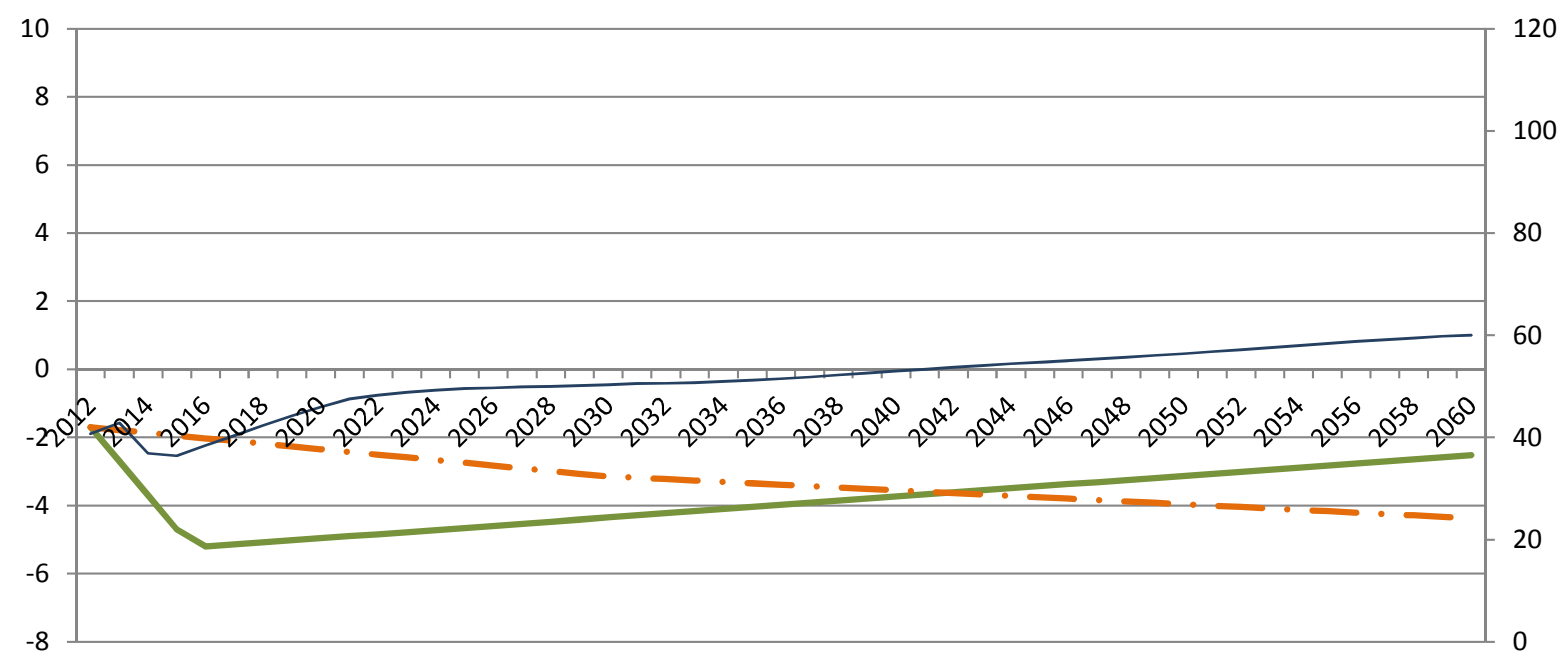

Poland

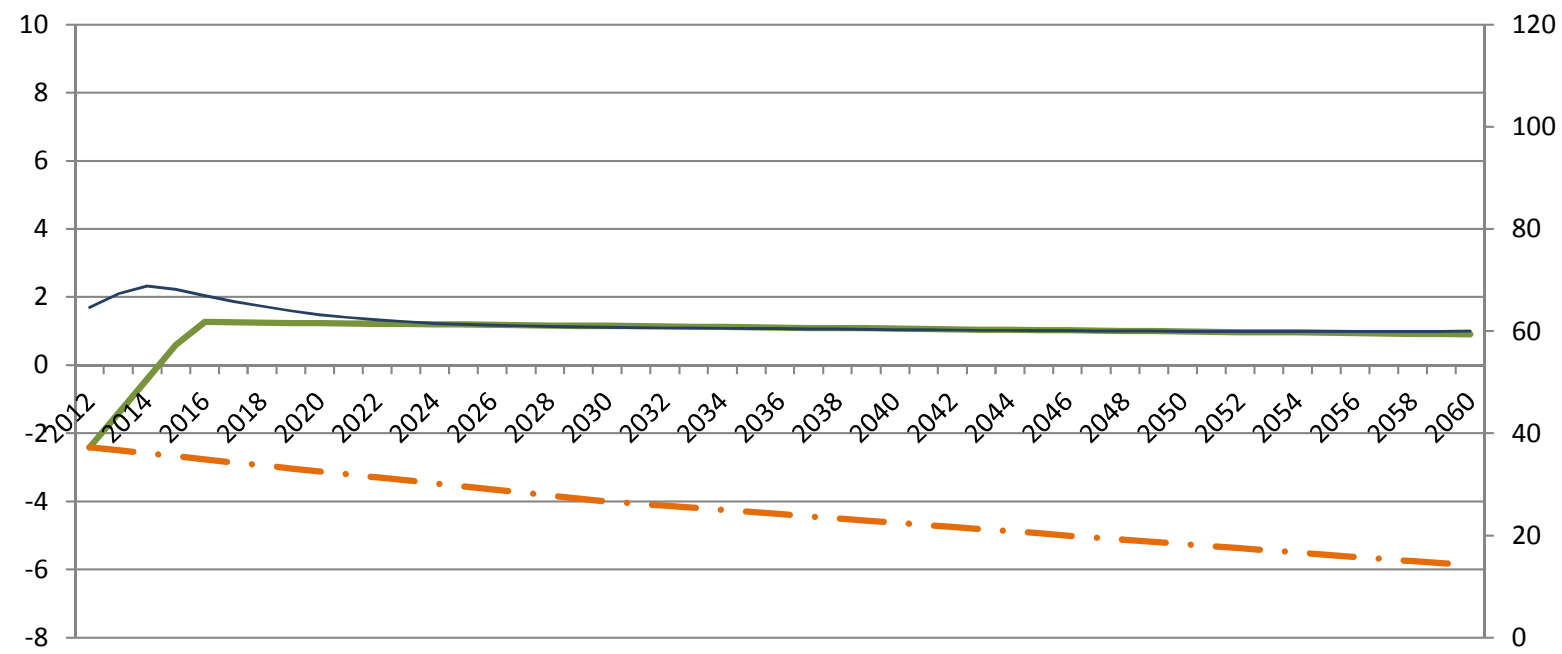


Portugal

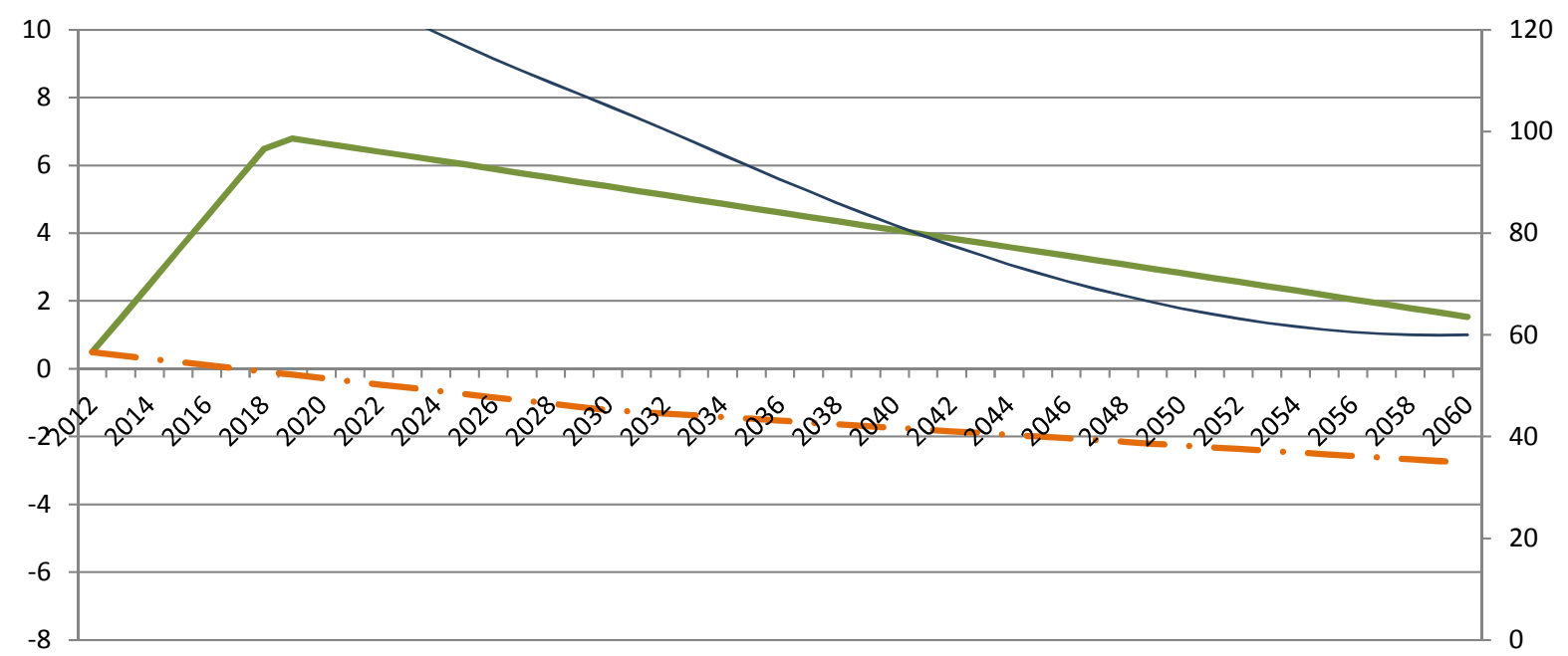

Slovak Republic

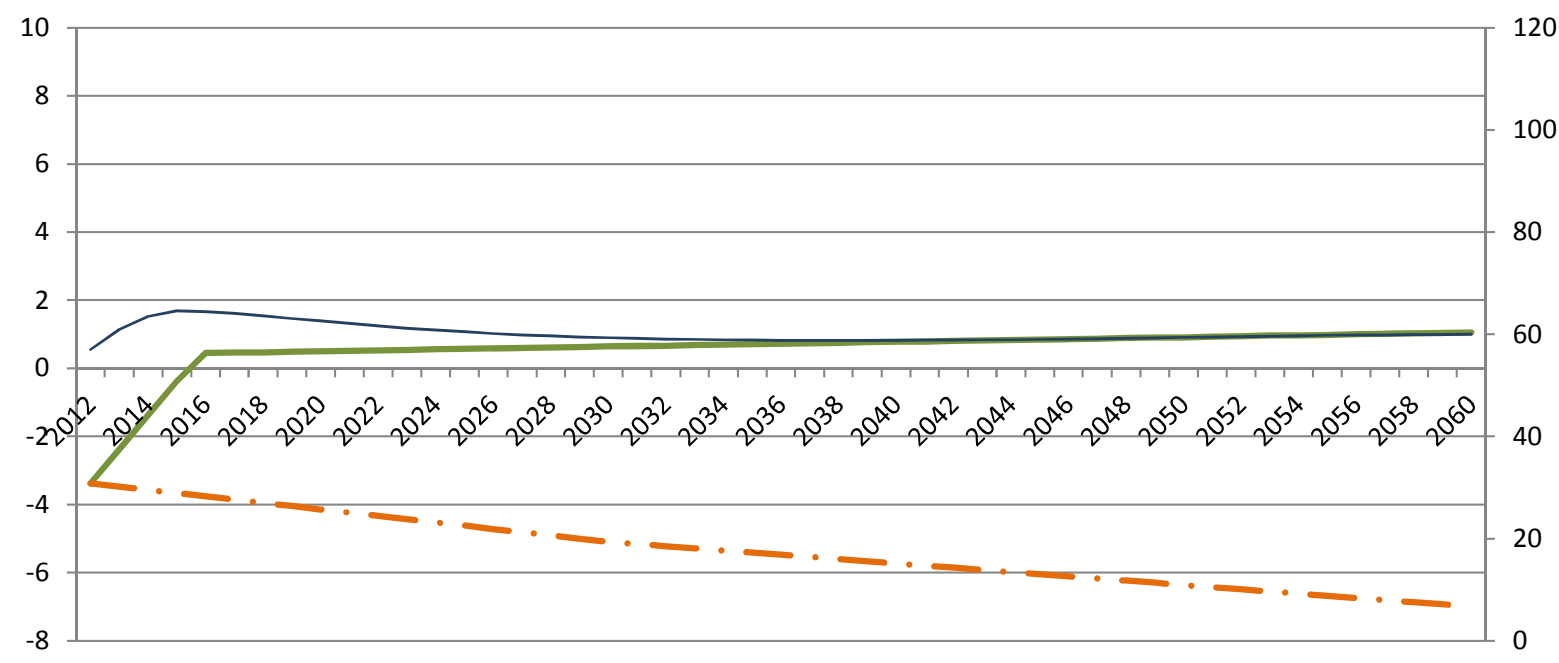

Slovenia

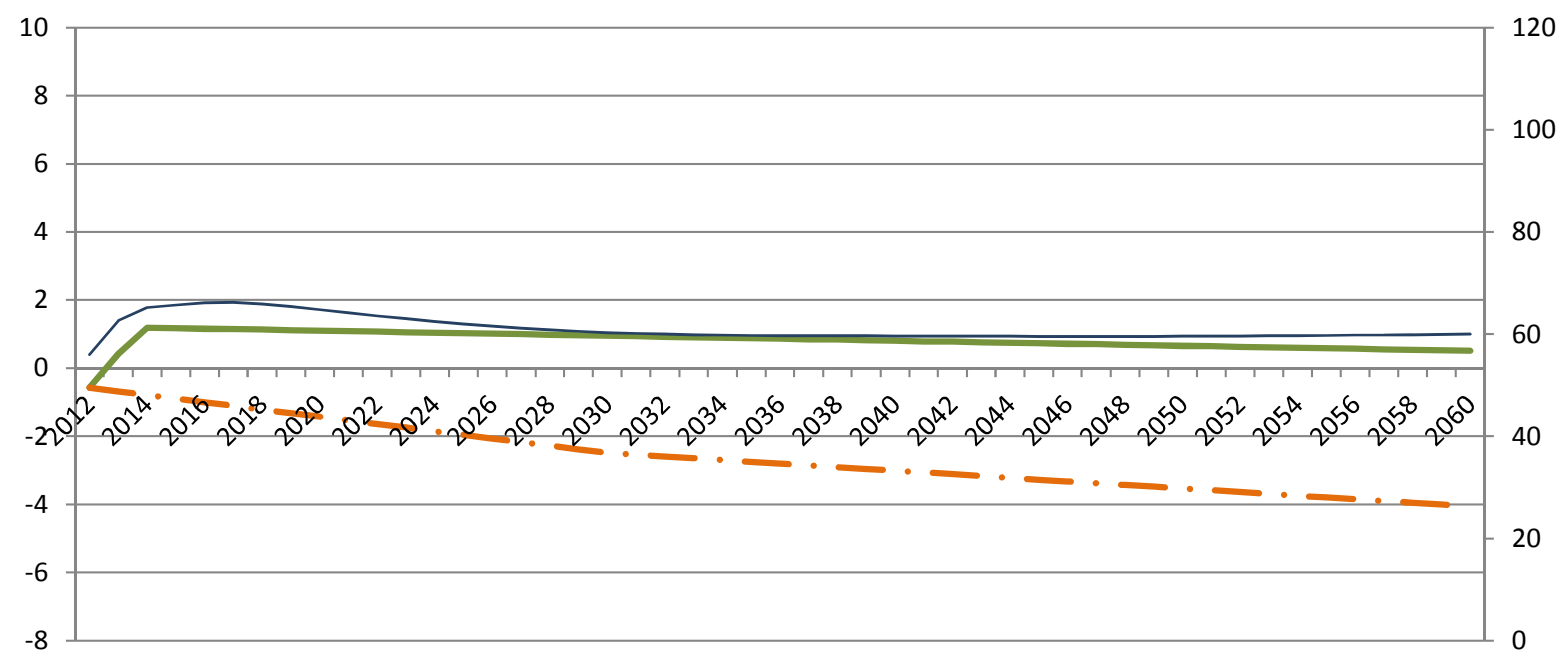




\section{Spain}

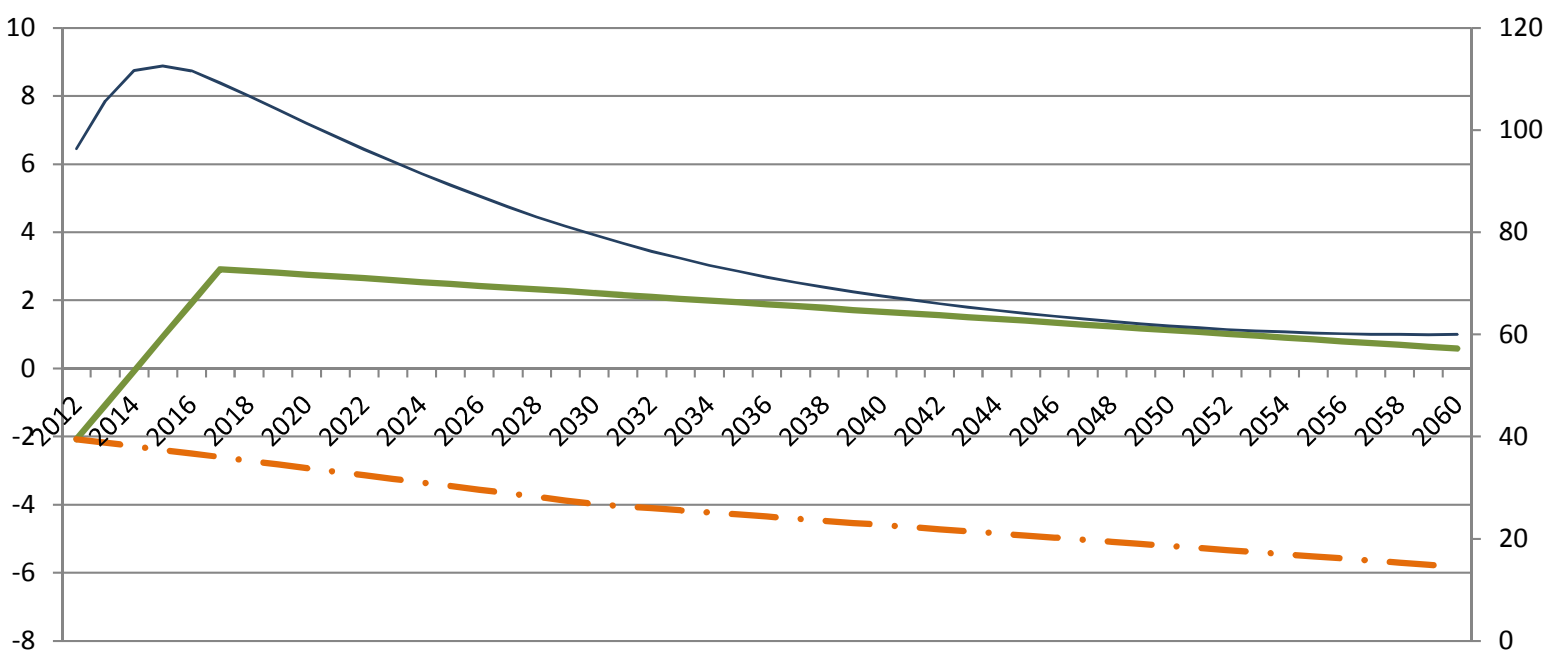

\section{Sweden}

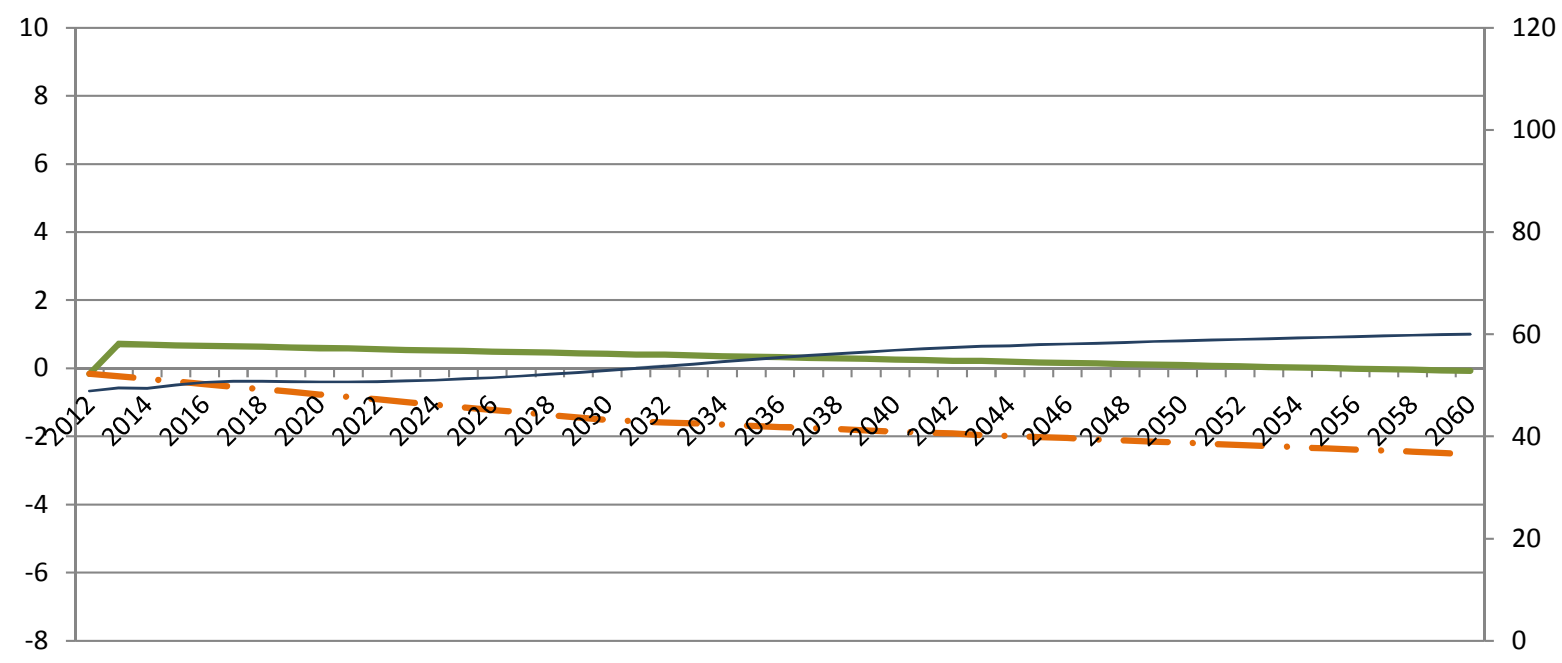

Switzerland

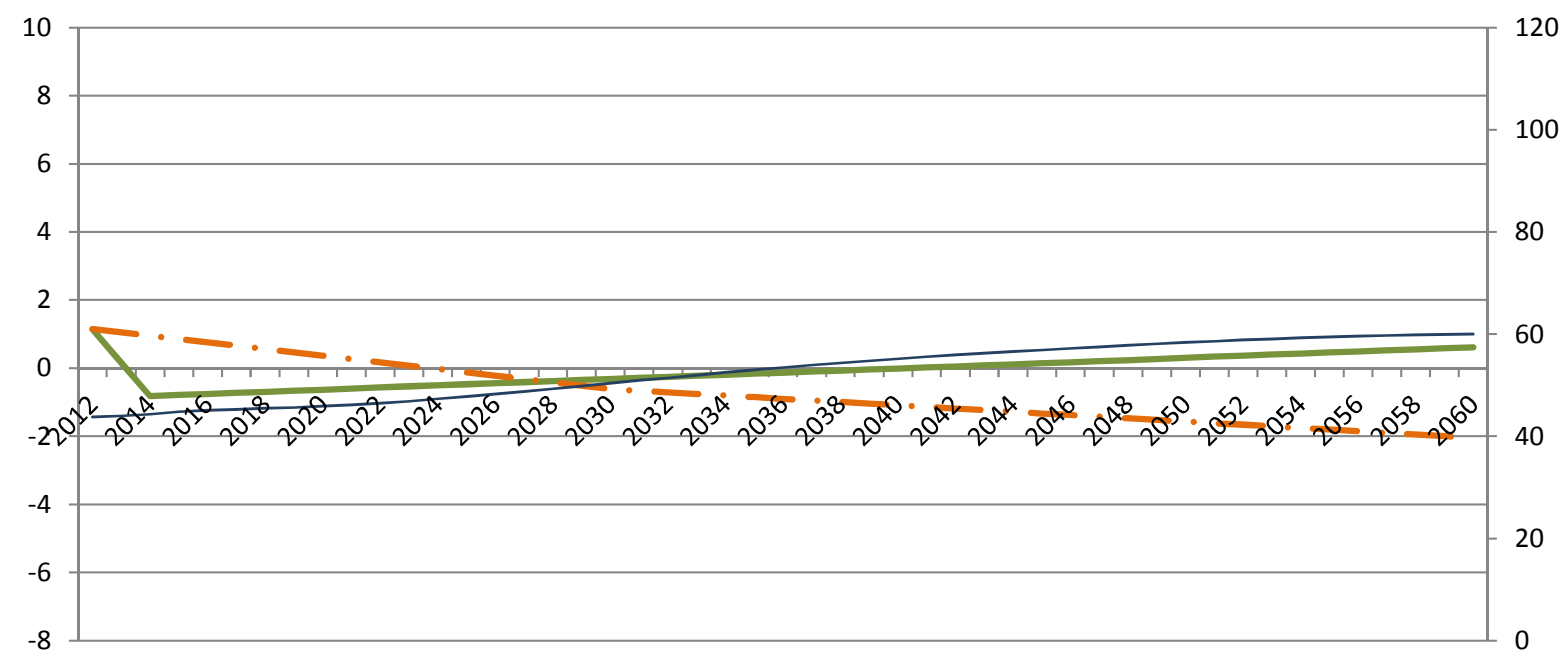


United Kingdom

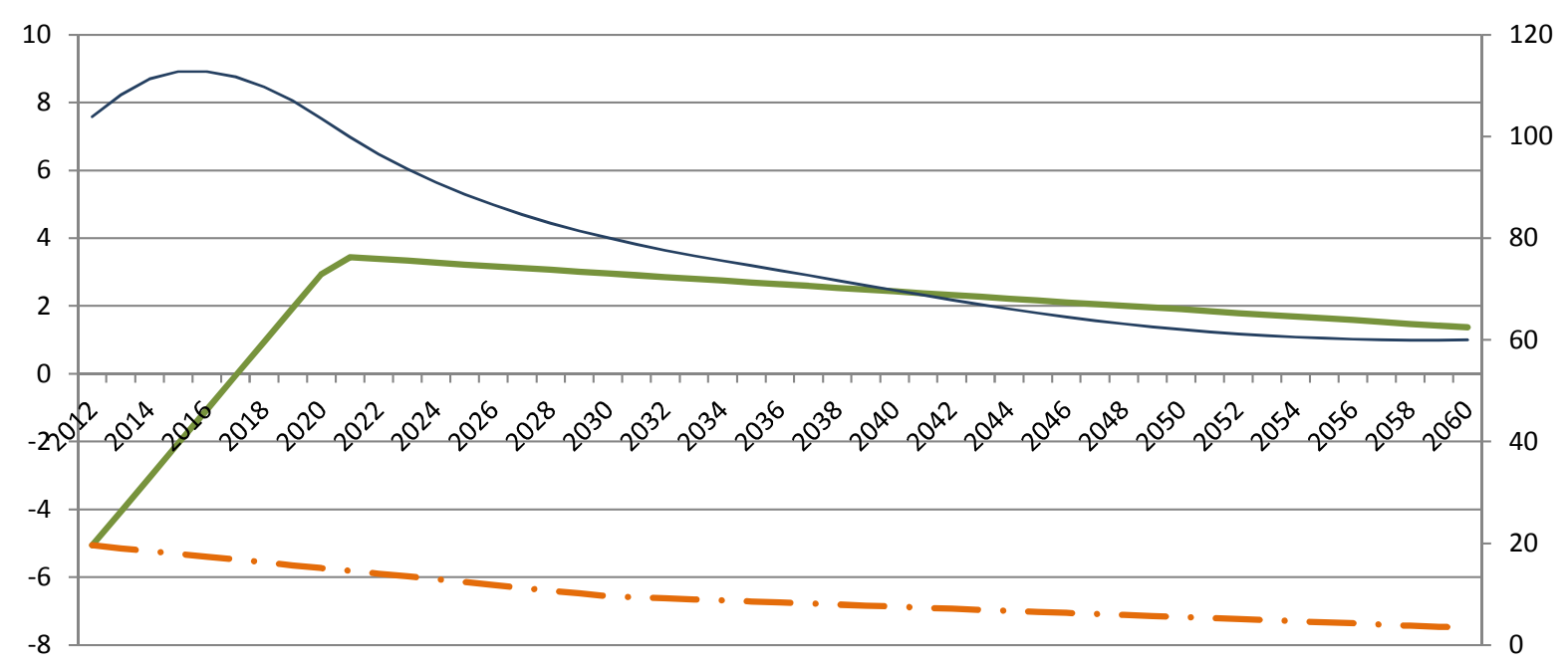

United States

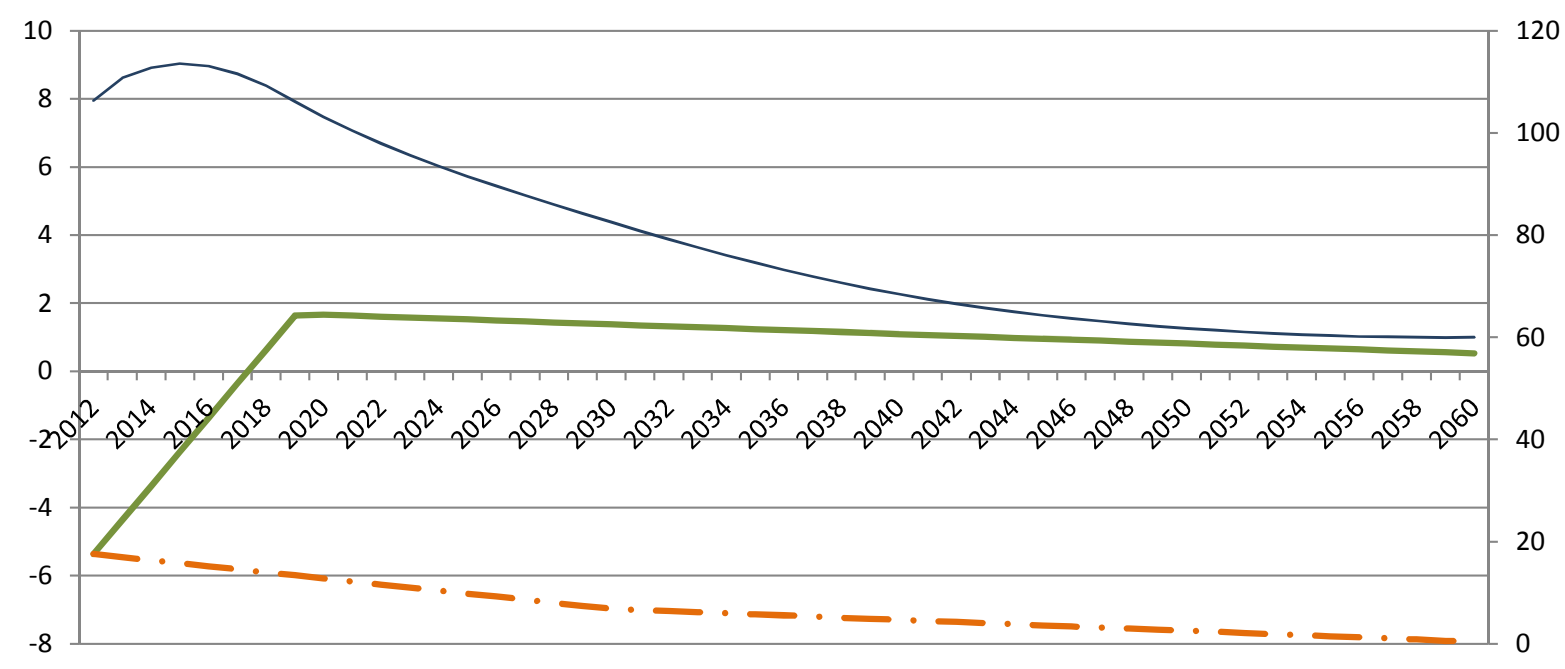




\section{WORKING PAPERS}

The full series of Economics Department Working Papers can be consulted at www.oecd.org/eco/workingpapers/

1087. Improving school-to-work transition in New Zealand (September 2013) by Alexandra Bibbee

1086. The agri-food situation and policies in Switzerland (September 2013) by Peter Jarrett and Charlotte Moeser

1085. Japan's challenging debt dynamics

(August 2013) by Yvan Guillemette and Jan Strasky

1084. Transitions in and out of unemployment among young people in the Irish recession (August 2013) by Elish Kelly, Seamus McGuinness, Philip O'Connell, David Haugh and Alberto González Pandiella

1083. Is there convergence of Russia's regions? Exploring the empirical evidence: 1995-2010 (August 2013) by Hartmut Lehmann and Maria Giulia Silvagni

1082. The benefits and costs of highly expansionary monetary policy

(August 2013) by Łukasz Rawdanowicz, Romain Bouis and Shingo Watanabe

1081. The effectiveness of monetary policy since the onset of the financial crisis

(August 2013) by Romain Bouis, Łukasz Rawdanowicz, Jean-Paul Renne, Shingo Watanabe and Ane Kathrine Christensen

1080. Responding to key well-being challenges in Austria

(August 2013) by Rauf Gönenç, Oliver Röhn, Christian Beer and Andreas Wörgötter

1079. Austria's well-being goes beyond GDP

(August 2013) by Oliver Röhn, Rauf Gönenç, Christian Beer and Romina Boarini

1078. Improving fiscal federal relations for a stronger Mexico

(August 2013) by Aida Caldera Sánchez

1077. Deleveraging: challenges, progress and policies

(August 2013) by Romain Bouis, Ane Kathrine Christensen and Boris Cournède

1076. Policies to support sustainable long-term growth in New Zealand

(July 2013) by Calista Cheung

1075. Do structural policies affect macroeconomic stability?

(July 2013) by Volker Ziemann

1074. A simple fiscal stress testing model - case studies of Austrian, Czech and German economies (July 2013) by Ondra Kamenik, Zdenek Tuma, David Vavra and Zuzana Smidova

1073. Road connectivity and the border effect: evidence from Europe

(July 2013) by Henrik Braconier and Mauro Pisu 
1072. Fiscal consolidation across government levels. Part 3: Intergovernmental grants, pro- or counter-cyclical? (July 2013) by Hansjörg Blöchliger and Balázs Égert

1071. Fiscal consolidation across government levels. Part 2: Fiscal rules for sub-central governments, update of the institutional indicator (July 2013) by Kaja Fredriksen

1070. Fiscal consolidation across government levels. Part 1: How much, what policies? (July 2013) by Hansjörg Blöchliger

1069. Restructuring the electricity sector and promoting green growth in Japan (June 2013) by Randall S. Jones and Myungkyoo Kim

1068. Labour market policies to promote growth and social cohesion in Korea (June 2013) by Randall S. Jones and Satoshi Urasawa

1067. Education reform in Korea (June 2013) by Randall S. Jones

1066. Belgium: enhancing the cost efficiency and flexibility of the health sector to adjust to population ageing (June 2013) by Stéphane Sorbe

1065. Italy and the euro area crisis: securing fiscal sustainability and financial stability (June 2013) by Oliver Denk

1064. Policy implementation in Italy: legislation, public administration and the rule of law (June 2013) by Paul O’Brien

1063. Greening growth in Luxembourg

(June 2013) by Nicola Brandt

Vers une croissance plus verte en Luxembourg (juin 2013) par Nicola Brandt

1062. The post-crisis narrowing of international imbalances-cyclical or durable? (June 2013) by Patrice Ollivaud and Cyrille Schwellnus

1061. Restructuring welfare spending in Slovenia (June 2013) by Rafał Kierzenkowski

1060. The economics of civil justice: new cross-country data and empirics (August 2013) by G. Palumbo; G. Giupponi; L. Nunziata and J. Mora-Sanguinetti

1059. Banks' restructuring and smooth deleveraging of the private sector in Slovenia (June 2013) by Olena Havrylchyk

1058. Assessing the efficiency of welfare spending in Slovenia with data envelopment analysis (June 2013) by Matevz Hribernik and Rafał Kierzenkowski 